\title{
Identification of Potential Waste Processing and Waste Form Options for Molten Salt Reactors
}

Nuclear Technology

Research and Development

\author{
Prepared for \\ U.S. Department of Energy \\ MSR Campaign \\ B.J. Riley, (a) J. McFarlane, ${ }^{(b)}$ \\ G.D. DelCul, (b) J.D. Vienna, ${ }^{(a)}$ \\ C.I. Contescu, ${ }^{(\mathrm{b})}$ L.M. Hay, ${ }^{(\mathrm{a})}$ A.V. Savino, ${ }^{(\mathrm{a})}$ \\ H.E. Adkins, ${ }^{(a)}$ \\ (a) Pacific Northwest National Laboratory \\ (b) Oak Ridge National Laboratory \\ August 15, 2018 \\ NTRD-MSR-2018-000379, PNNL-27723
}





\section{DISCLAIMER}

This information was prepared as an account of work sponsored by an agency of the U.S. Government. Neither the U.S. Government nor any agency thereof, nor any of their employees, makes any warranty, expressed or implied, or assumes any legal liability or responsibility for the accuracy, completeness, or usefulness, of any information, apparatus, product, or process disclosed, or represents that its use would not infringe privately owned rights. References herein to any specific commercial product, process, or service by trade name, trade mark, manufacturer, or otherwise, does not necessarily constitute or imply its endorsement, recommendation, or favoring by the U.S. Government or any agency thereof. The views and opinions of authors expressed herein do not necessarily state or reflect those of the U.S. Government or any agency thereof 


\section{SUMMARY}

The overall summary of the waste management envelope discussed in this report is represented by the diagram shown in Figure S1. The streams that are included in this discussion include the following from reactor systems in which chlorine-based salts with and without processing and fluorine-based salts with and without processing are being considered:

1) Off-gas streams (e.g., particulates, aerosols, reactive gases, ${ }^{3} \mathrm{H}$, water, residual halides, $\mathrm{N}_{2}, \mathrm{O}_{2}$, noble gases)

2) Salt waste streams (e.g., chloride- or fluoride-based)

3) Separated salt streams (e.g., ${ }^{7} \mathrm{Li}$ recycle, ${ }^{37} \mathrm{Cl}$ recycle, eutectic salts, fission products)

4) Metal waste streams (e.g., reactor components, plenums)

5) Carbon waste streams (e.g., graphite, $\mathrm{SiC})$

6) Decommissioning and decontaminating (D\&D) waste streams

7) Operating waste streams

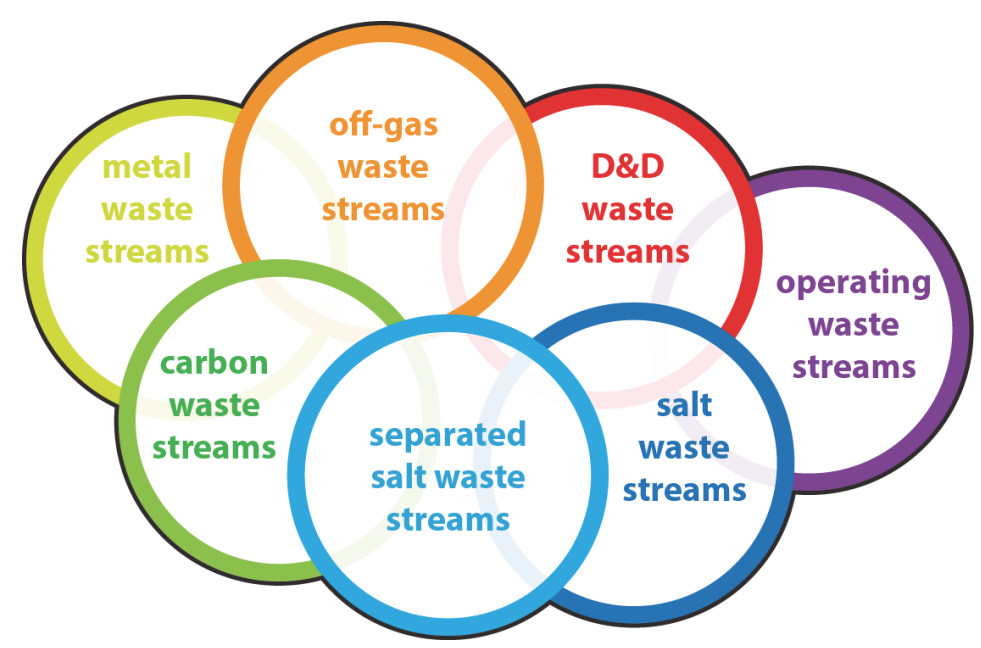

Figure S1. Summary of waste management categories for molten salt reactor program.

The goals of this report are to accomplish the following:

- Assess the potential waste streams that could be generated from molten salt reactor processes

- Determine how these wastes could be treated and/or immobilized in a form that could be disposed of

- Determine the storage, transportation, and disposal requirements for molten salt reactor wastes 


\section{ACKNOWLEDGEMENTS}

The authors would like to thank the Department of Energy Office of Nuclear Energy's, Office of Advanced Reactor Technology for funding this work under the Nuclear Technology Research and Development Program. The authors would also like to thank Lou Qualls (ORNL), Stephen Kung (DOE$\mathrm{NE}$ ), and Brian Robinson (DOE-NE) for project oversight and guidance. Authors would like to thank Steve Frank (INL), Guy Fredrickson (INL), Ken Marsden (INL), David Holcomb (ORNL), Ben Betzler (ORNL), Jim Jerden (ANL), Charles Forsberg (MIT), and Ted Besmann (USC) for helpful discussions related to this work. Gary Sevigny (PNNL) supplied many helpful suggestions during document review. The Pacific Northwest National Laboratory is operated by Battelle under contract DE-AC05-76RL01830. The Oak Ridge National Laboratory is operated by UT-Battelle, LLC, under contract DE-AC05$00 \mathrm{OR} 22725$. 


\section{CONTENTS}

SUMMARY iv

ACKNOWLEDGEMENTS $\mathrm{V}$

ABBREVIATIONS AND ACRONYMS xii

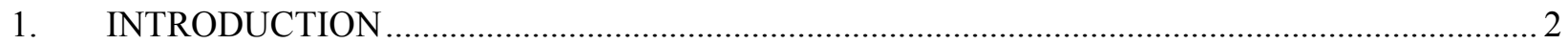

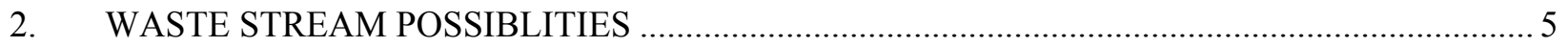

$2.1 \quad$ Volatile Off-Gas Waste Streams ..................................................................................... 5

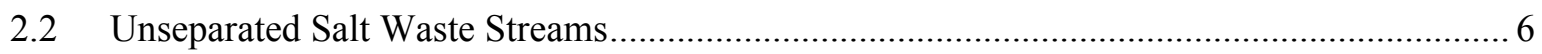

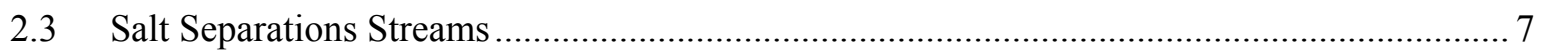

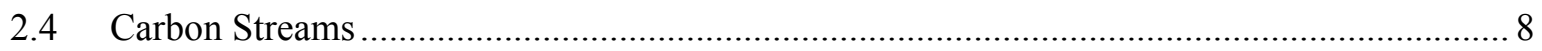

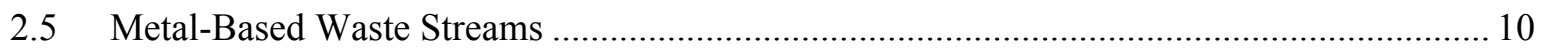

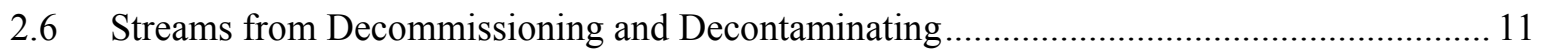

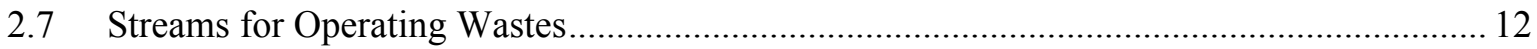

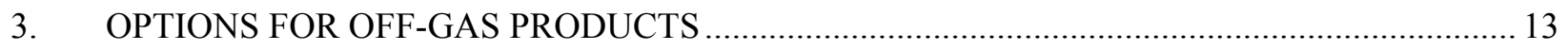

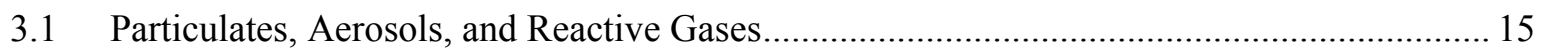

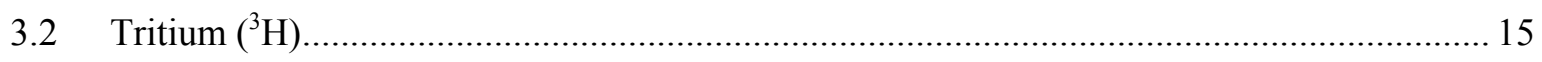

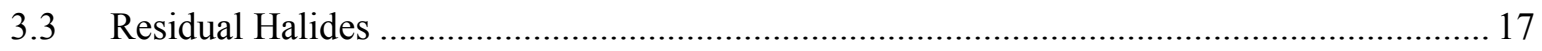

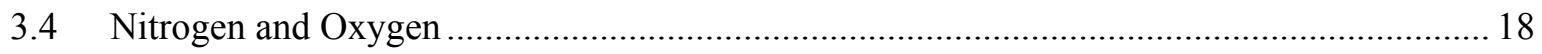

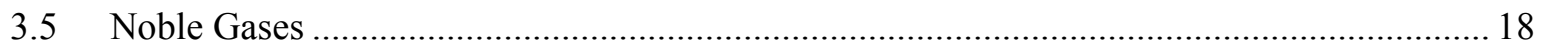

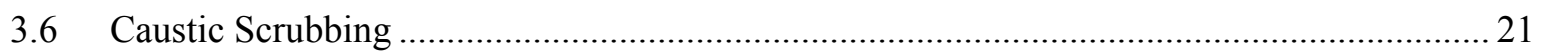

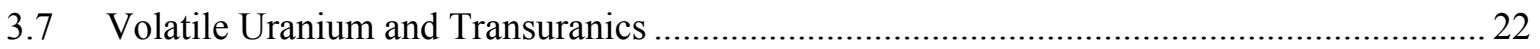

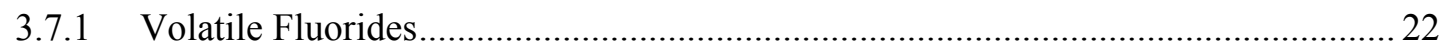

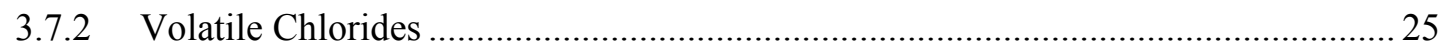

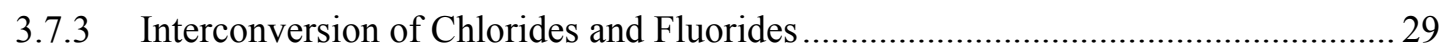

4. OPTIONS FOR UNSEPARATED AND SEPARATED SALTS ...................................................... 30

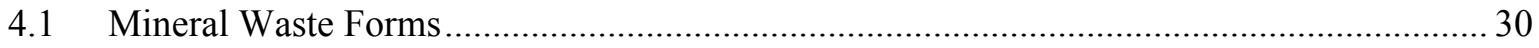

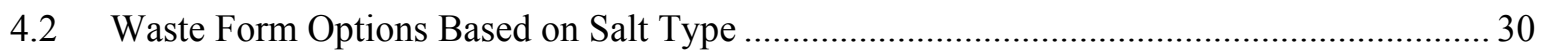

4.2.1 Options for Fluoride-Based Waste Components...................................................... 30

4.2.2 Options for Chloride-Based Waste Components .................................................... 34

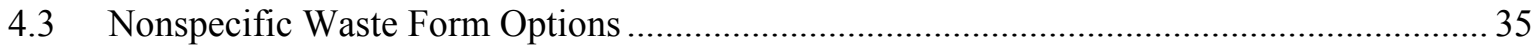

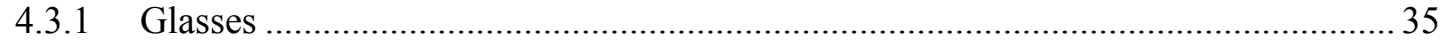

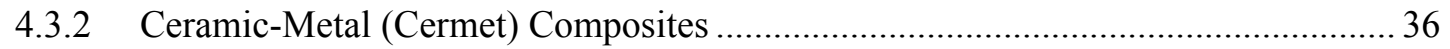

4.3.3 Dehalogenation of Salts Using Phosphate Precursors............................................. 37

4.3.4 Dehalogenation of Salt through Reaction with Ultrastable H-Y Zeolite ................... 42

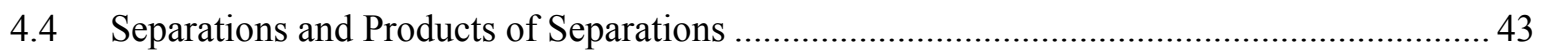

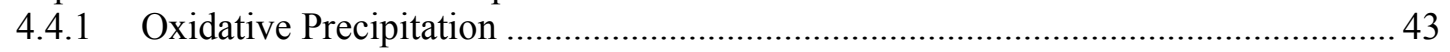

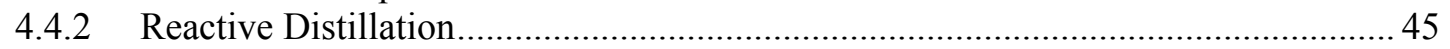

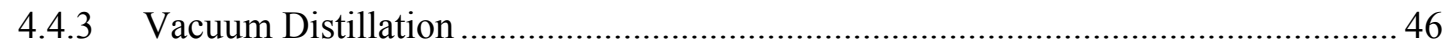

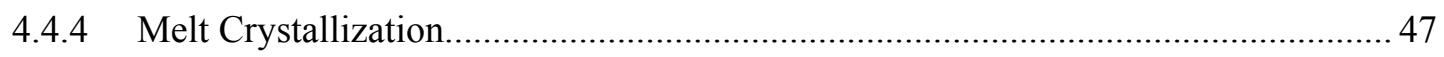




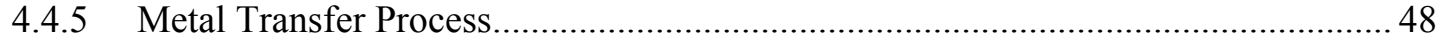

4.5 Lithium-7 ( $\left.{ }^{7} \mathrm{Li}\right)$ Recovery Options for Fluoride Salt Systems ............................................. 51

4.6 Chlorine-37 $\left({ }^{37} \mathrm{Cl}\right)$ Recovery Options for Chloride Salt Systems ..................................... 52

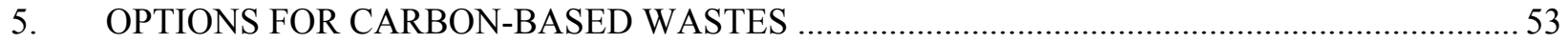

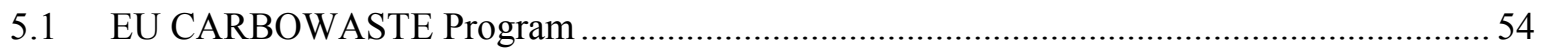

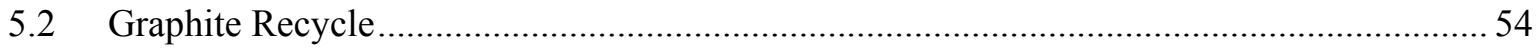

5.3 Spent Nuclear Fuel from FHRs.............................................................................. 55

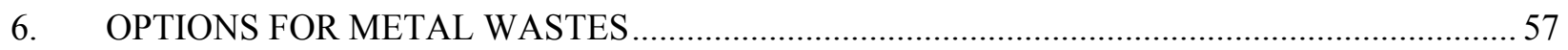

7. OPTIONS FOR DECOMMISSIONING AND DECONTAMINATION WASTES ....................... 59

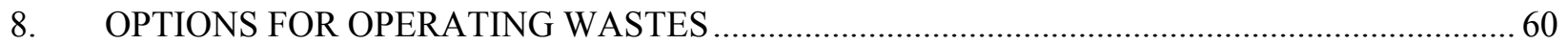

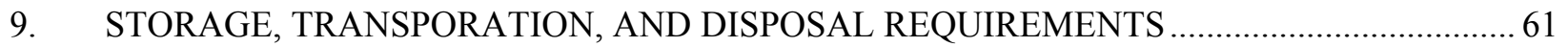

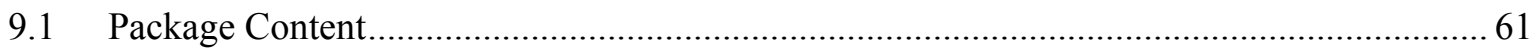

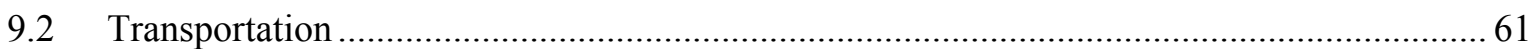

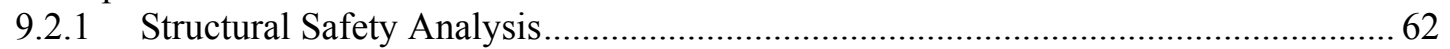

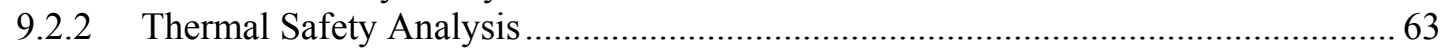

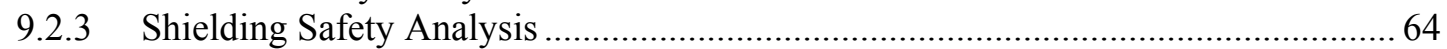

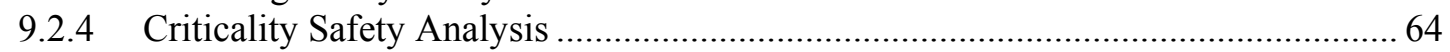

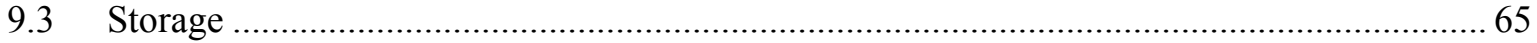

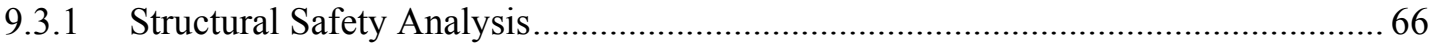

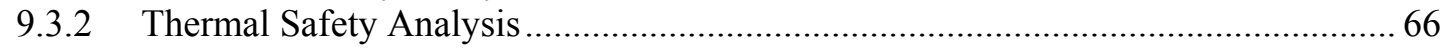

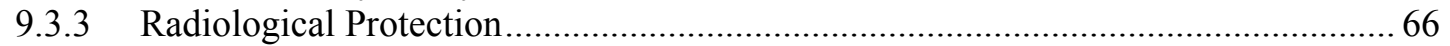

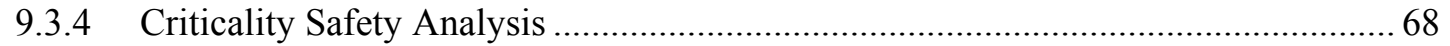

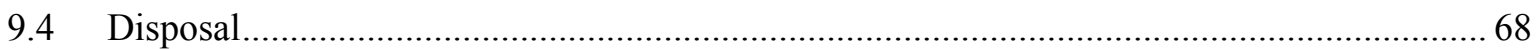

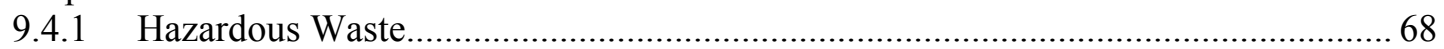

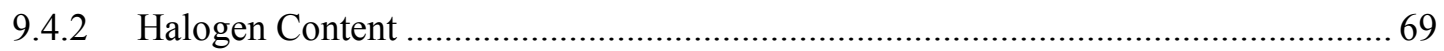

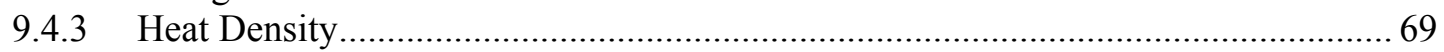

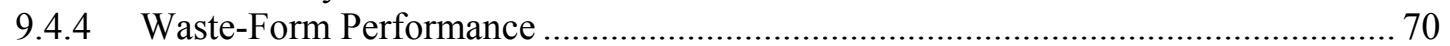

10. EVALUATION OF WHAT WE KNOW HOW TO MANAGE AND WHAT WE DO NOT: RECOMMENDATIONS ON WHAT TO DO NEXT …................................................. 71

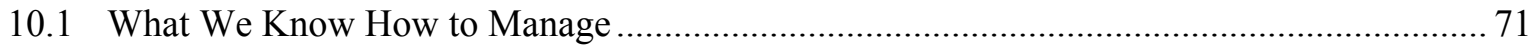

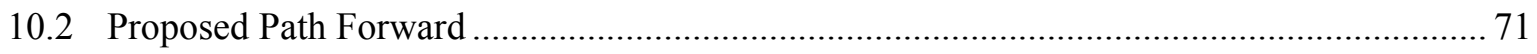

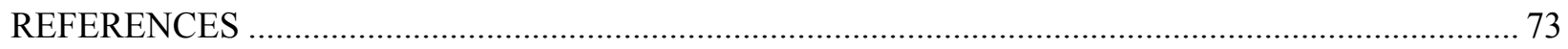

Appendix A Modified Molten Hydroxide Scrubber ...................................................................... A1

Appendix B Radiolysis and Gaseous Product Evolution from Solidified Halide Salts ............................B1 


\section{FIGURES}

Figure 1-1. Waste management hierarchy [modified from Wareing et al. (2013)]. 4

Figure 2-1. Summary of off-gas constituents and planned path forward for capture, immobilization, disposal, and/or release. "WF," "AgZ," and " $\mathrm{Ag}^{0}$-aerogel" denote waste form, silver mordenite, and silver-functionalized silica aerogel, respectively. 6

Figure 2-2. Summary of unseparated salt waste streams along with disposal pathways. "WF" and "cermet" denote waste form and ceramic-metal composite, respectively.

Figure 2-3. Summary of separated salt streams along with suggested processing routes and action and/or disposal pathways for different options...

Figure 2-4. Comparison of dimensional changes under irradiation of several nuclear graphite grades and of POCO AXF-8Q1 grade (highlighted for $400-700^{\circ} \mathrm{C}$ ). The $1 \mathrm{dpa}$ (displacements per atoms) shows the exposure at which each carbon atoms have suffered statistically one single displacement. This figure was modified from Pitner (1971).

Figure 2-5. Summary of carbon-based waste streams as well as action and disposal pathways.

Figure 2-6. Summary of metal-based waste streams as well as action and disposal pathways for these streams

Figure 2-7. Summary of decommissioning and decontamination streams as well as actions and disposal pathways.

Figure 2-8. Summary of streams for operating wastes as well as actions and disposal pathways.

Figure 3-1. Compilation of $\mathrm{H}_{2(\mathrm{~g})}$ permeability through different metals. These data were compiled by Steward (1983). Refer to Table 3-2 for specific data and temperature ranges recommended by the authors for data validity.

Figure 3-2. Summary of Xe and $\mathrm{Kr}$ adsorption with SBMOF-1, a metal-organic framework (Banerjee et al., 2016). (a) Xe and $\mathrm{Kr}$ adsorption isotherms. (b) $\mathrm{Xe} / \mathrm{Kr}$ separation performance in top-performing MOF adsorbents $\left({ }^{\dagger}\right.$ denotes $297 \mathrm{~K}$ and ${ }^{\star}$ denotes $292 \mathrm{~K}$ for data collection temperatures).

Figure 3-3. Xe/Kr selectivity for a variety of sorbents evaluated for a $\mathrm{Xe} / \mathrm{Kr}$ (20/80 mixture, by volume) at 1 bar and $T=273-303 \mathrm{~K}$. Data in blue and yellow represent measured (i.e., breakthrough) and calculated (i.e., IAST) data, respectively. The plot was modified from Deliere et al. (2016).

Figure 3-4. Ideal Adsorbed Solution Theory (IAST) Xe/Kr selectivity of $\mathrm{MoS}_{x}$, SbS-I, SbS-II, and SbS-III chalcogels at $273 \mathrm{~K}$ calculated from pure adsorption isotherms. This plot was taken from Subrahmanyam et al. (2017).

Figure 3-5. Schematic of the overall off-gas system for a commercial MSR based on the MSRE experience. All of the components shown, except the molten hydroxide packed-bed scrubber, are commercially available.

Figure 3-6. Vapor pressures as a function of temperature for $\mathrm{MoF}_{6}, \mathrm{HF}$, and $\mathrm{UF}_{6}(\mathrm{HSC}$ Chemistry).

Figure 3-7. Predominance diagram for U-Cl-O system at $\mathrm{pO}_{2(\mathrm{~g})}=1 \times 10^{-20}$ bar (HSC Chemistry)...........28

Figure 3-8. Predominance diagram for U-Cl-O system at $\mathrm{pO}_{2(\mathrm{~g})}=1 \times 10^{-10}$ bar (HSC Chemistry)...........28 
Figure 4-1. Pictures of ZBLAN glass fibers showing visible fluorescence from rare-earth-doped ZBLAN fibers, including (from left to right): Tm-doped, Er-doped, and Nd-doped (courtesy of FiberLabs Inc.).

Figure 4-2. Glass formation region phase diagrams for (a) $\mathrm{TeO}_{2}-\mathrm{Li}_{2} \mathrm{O}-\mathrm{LiX}(\mathrm{X}=\mathrm{F}, \mathrm{Cl}, \mathrm{Br}$ ) and (b) $\mathrm{TeO}_{2}-\mathrm{Li}_{2} \mathrm{O}-\mathrm{LiF}$. This figure was taken from Yoko et al. (1989). .33

Figure 4-3. Crystal structure for $\mathrm{Ca}_{5}\left(\mathrm{PO}_{4}\right)_{3} \mathrm{~F}$ fluorapatite. This image was created by viewing Inorganic Crystal Structure Database file 302261 with CrystalMaker (v9.2.9f1). .34

Figure 4-4. Summary of $\mathrm{TeO}_{2}-\mathrm{PbO}$ glasses fabricated with different chloride salt simulants from electrochemical reprocessing of UNF, including (a) $\mathrm{SrCl}_{2}$, OR salt simulant (LiCl-rich), $\mathrm{ER}(\mathrm{SF})$ salt simulant (LiCl-KCl-rich) (Riley et al., 2017c), and (b) the rare-earth chloride fission products simulant (Riley et al., 2018b). The percentages listed in the figure denote mass $\%$ loadings of each salt. .34

Figure 4-5. Summary of (a) generic alkali-halide sodalite unit cell and (b) sodalite $\beta$-cage arrangement. (c) Scanning electron micrograph of a glass-bonded sodalite waste form (Riley et al., 2018a; Riley et al., 2017d). .35

Figure 4-6. Picture of copper exterior canister liner (left) and canister (right) for the Onkalo geological repository in Finland (Bohner, 2018).

Figure 4-7. Copper cermet made with HLW at a 40 vol\% loading. (a) Picture of the product (diameter is $41 \mathrm{~mm}$ ) and (b) scanning electron micrograph of the material at $100 \times$ magnification (DelCul et al., 2018).

Figure 4-8. Data plotted from Donze et al. (2000) including (a) Cl retention as a function of salt $\left(\mathrm{PbCl}_{2}+\mathrm{CdCl}_{2}+\mathrm{NaCl}+\mathrm{KCl}\right)$ loading, (b) ratio of targeted:measured values (by element) in glasses heated at $700 \mathrm{C}$ for $30 \mathrm{~min}$, and (c) ratio of targeted:measured values (by element) in glasses heated at $900^{\circ} \mathrm{C}$ for $2 \mathrm{~h}$. 38

Figure 4-9. Gibbs free energy of formation of ammonium halide salts (halide $=\mathrm{F}, \mathrm{Cl}, \mathrm{Br}, \mathrm{I}$ ) as a function of temperature. These data were collected with HSC.

Figure 4-10. Summary of measured compositions as a function of target composition for iron phosphate glasses batched with (a) $\mathrm{CsCl}$ or (b) $\mathrm{CsCl}+\mathrm{SrF}_{2}$ (Mesko et al., 2000). The gray boxes in the bottom left corner of each plot show the encompassing regions for which magnified insets are provided in the bottom right corners of each plot. Note that fluoride retention was not measured and is not included here.

Figure 4-11. Variation in the iron phosphate glass dissolution rate as a function of the O/P molar ratio for (a) Hanford Tank Farm B waste (Day et al., 1998) and (b) Idaho National Laboratory Na-bearing waste compared with other waste forms (Day and Ray, 2013).

Figure 4-12. Process flow diagram for using ultrastable $\mathrm{H}-\mathrm{Y}$ zeolite to dechlorinate used pyroprocessing salt wastes before immobilization (Bagri and Simpson, 2015). "GBZ" denotes glass-bonded zeolite. 42

Figure 4-13. Reactive distillation process demonstrated by demonstrated by Eun et al. (2016). 45

Figure 4-14. Vacuum-distillation equipment for $\mathrm{LiF}_{-} \mathrm{BeF}_{2}-\mathrm{ZrF}_{4}$ recovery (McNeese et al., 1972). This drawing was modified from the original version to call attention to specific portions of the apparatus.

Figure 4-15. Vacuum distillation rate (i.e., $\mathrm{ft}^{3}$ of salt distilled per day per $\mathrm{ft}^{2}$ of vaporization surface area) as a function of temperature when the condenser pressure was $<13.3 \mathrm{~Pa}$ $(<0.1$ Torr) (McNeese et al., 1972). This figure was modified from the original. 
Figure 4-16. Mass transfer process for removal of rare earths from a single-fluid MSBR (Robertson, 1971). 50

Figure 4-17. Drawing of Glass Material Oxidation and Dissolution System (GMODS; modified from original) (Forsberg et al., 1994).

Figure 4-18. Flow diagram of the Glass Material Oxidation and Dissolution System (GMODS; modified from original) (Forsberg et al., 1997).

Figure 5-1. Proposed process for producing nuclear-grade graphite using ground recycled graphite as a feed stock. The impregnation step is carried out by adding new pitch to improve strength and density; this process is typically performed three times for nuclear graphite. This image was modified from the original by Burchell and Pappano (2010).

Figure 5-2. Schematic (left) and pseudocolored micrograph (right) of TRISO fuel Courtesy of Idaho National Laboratory (De Guire, 2013) (Copyright American Ceramic Society). .56

Figure 6-1. Backscattered scanning electron micrographs of Mo-Ru-Rh-Pd-Re $\varepsilon$-metal sample $\left(35 \% \mathrm{ZrO}_{2}-\mathrm{HIP}-1-\mathrm{Ta}-2012\right)$ consolidated with hot isostatic pressing at $1500^{\circ} \mathrm{C}$ for $1 \mathrm{~h}$ at $207 \mathrm{MPa}$ in a tantalum-foil package from Crum et al. (2013). The dark phase within the sample is $\mathrm{ZrO}_{2}$. The $\varepsilon$-metal yield in this sample after heat-treatment was 54.8 mass\% (49.7 mass\% hexagonal and 5.1 mass \% cubic). .58

Figure A1. Modified schematic (from Figure 3-5 in Section 3.6) of the overall off-gas system for a commercial MSR based on the MSRE experience. All of the components shown here except the molten hydroxide packed-bed scrubber are commercially available.

\section{TABLES}

Table 1-1. Summary of different types of MSRs designs. The salt-cooled, solid-fuel option using TRISO (tristructural isotopic) fuel was provided by Brown et al. (2017).

Table 1-2. Summary of salt-processing scenarios to be covered within the scope of this document. "High processing" and "low processing" denote the frequency by which fission products are removed from the reactor.

Table 1-3. Materials used in an MSDR-type thermal reactor (Greenwood et al., 2018)......................... 4

Table 2-1. Summary of metal compositions (mass \%) for MSR reactor components............................... 10

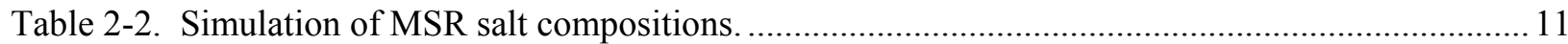

Table 3-1. Summary of volatile off-gas waste components that will or could require capture and/or immobilization.

Table 3-2. List of Arrhenius fitting parameters and recommended temperature ranges for $\mathrm{H}_{2(\mathrm{~g})}$ permeabilities through different metals using Equation (3-10).

Table 3-3. Permeability of tritium through selected materials Christensen et al. (2016).

Table 3-4. Summary of volatile fluorides that can be found in LWR used nuclear fuel (UNF), along with boiling temperature $\left(T_{\mathrm{b}}\right)$ and the typical amount found in LWR UNF. (In the references, HSC Chemistry refers to the chemistry software package.).

Table 3-5. Summary of vapor pressures and boiling temperatures $\left(T_{\mathrm{b}}\right)$ for various chloride species. 
Table 4-1. Summary of mineral compositions for various salts. ${ }^{a}$

Table 4-2. Important data and parameters for mixing $\mathrm{NH}_{4} \mathrm{H}_{2} \mathrm{PO}_{4}$ with $\mathrm{Cl}$-salts based on work by Donze et al. (2000) as well as melting temperatures $\left(T_{\mathrm{m}}\right)$ and boiling temperatures $\left(T_{\mathrm{b}}\right)$ for applicable compounds ("Physical Constants of Inorganic Compounds", 2007-2008)

Table 4-3. Batch and analyzed inductively-coupled plasma emission spectroscopy (ICP-ES) compositions (mass $\%$ ) of iron phosphate glasses containing 30 mass $\%$ simulated LAW waste (i.e., IP30LAW, IP30- LAW-A and IP30LAW-C) according to Kim and Day (2003) $(\mathrm{NM}=$ not measured)

Table 4-4. Equilibrium constants calculated using HSC for Reactions (4-14) - (4-19). Values are in $\mathrm{kmol} / \mathrm{kmol}$ (unitless). 44

Table 4-5. Equilibrium constants calculated using HSC for Reactions (4-20) - (4-27). Values are in $\mathrm{kmol} / \mathrm{kmol}$ (unitless). 


\section{ABBREVIATIONS AND ACRONYMS}

\begin{tabular}{|c|c|}
\hline$\eta$ & viscosity (in centipoise or $\mathrm{cP}$ ) \\
\hline$\rho$ & density (in $\mathrm{g} / \mathrm{cm}^{3}$ ) \\
\hline $\mathrm{ACl}$ & alkali chloride \\
\hline $\mathrm{AE}$ & alkaline earth \\
\hline $\mathrm{AECl}_{2}$ & alkaline earth chloride \\
\hline $\mathrm{AEF}_{2}$ & alkaline earth fluoride \\
\hline $\mathrm{AF}$ & alkali fluoride \\
\hline $\mathrm{Ag}^{0}$-aerogel & silver-functionalized silica aerogel \\
\hline $\mathrm{AgZ}$ & silver mordenite \\
\hline An & actinoids (or actinides) (i.e., ${ }_{89} \mathrm{Ac} \rightarrow{ }_{103} \mathrm{Lr}$ ) \\
\hline Cermet & ceramic-metal composite \\
\hline CSI & Criticality Safety Index \\
\hline D\&D & decontamination (or decontaminating) and decommissioning \\
\hline DOE & Department of Energy \\
\hline dpa & displacements per atom \\
\hline EFPD & effective full power day \\
\hline FHR & fluoride salt-cooled high-temperature reactor \\
\hline FLiBe & $\mathrm{LiF}-\mathrm{BeF}_{2}$ salt (i.e., typically $2{ }^{7} \mathrm{LiF} \cdot \mathrm{BeF}_{2}$ ) \\
\hline FOR & functional and operational requirements \\
\hline FS-MSR & fast-spectrum molten salt reactor \\
\hline GBS & glass-bonded sodalite \\
\hline GMODS & Glass Material Oxidization and Dissolution System \\
\hline GTCC & greater-than-Class-C (waste) \\
\hline HAC & hypothetical accident conditions \\
\hline HEPA & high-efficiency particulate air (filter) \\
\hline HIP & hot isostatic press \\
\hline HLW & high-level waste \\
\hline HMF & heavy-metal fluoride \\
\hline HTGR & high-temperature gas-cooled reactor \\
\hline $\mathrm{HZ}$ & hydrogen mordenite \\
\hline
\end{tabular}


IAEA International Atomic Energy Agency

IAST Ideal Adsorbed Solution Theory

ICP inductively-coupled plasma

ICP-ES inductively-coupled plasma emission spectroscopy

$\mathrm{lbf} / \mathrm{in}^{2} \quad$ pounds per square inch (PSI)

LLW low-level waste

Ln lanthanoids (or lanthanides) (i.e., ${ }_{57} \mathrm{La} \rightarrow{ }_{71} \mathrm{Lu}$ )

LWR light-water reactor

MOF metal-organic framework

MOX mixed-oxide (fuel)

MSBR molten salt breeder reactor

MSDR molten salt demonstration reactor

MSR molten salt reactor

MSRE molten salt reactor experiment

MWt megawatt thermal

NCT normal conditions of transport

NMR nuclear magnetic resonance

NRC Nuclear Regulatory Commission

PPE personal protective equipment

RCRA Resource Conservation and Recovery Act

RE or REs rare earth (element); lanthanoids (or lanthanides) $+\mathrm{Sc}+\mathrm{Y}$

RF $\quad$ radio frequency

$\mathrm{SiC} \quad$ silicon carbide

SLM standard liters per minute $\left(\mathrm{L} \mathrm{min}^{-1}\right)$

SOZ salt-occluded zeolite

SS $\quad$ stainless steel

$t_{1 / 2} \quad$ half-life (time required for a quantity to reduce to half its initial value)

$T_{\mathrm{b}} \quad$ boiling temperature

$T_{\mathrm{m}} \quad$ melting temperature

TCLP Toxicity Characteristic Leaching Procedure

TF tritium fluoride 


$\begin{array}{ll}\text { TRISO } & \text { tristructural isotopic (fuel) } \\ \text { TRU } & \text { transuranics } \\ \text { UNF } & \text { used nuclear fuel } \\ \text { USH-Y } & \text { ultrastable } \mathrm{H}-\mathrm{Y} \text { zeolite; hydrogen-based faujasite-type zeolite with } \mathrm{Si} / \mathrm{Al} \geq 3 \text { (by mole) } \\ \text { WF } & \text { waste form } \\ \text { WIPP } & \text { Waste Isolation Pilot Plant (New Mexico) } \\ \text { ZBLAN } & \mathrm{ZrF}_{4}-\mathrm{BaF}_{2}-\mathrm{LaF}_{3}-\mathrm{AlF}_{3}-\mathrm{NaF} \text { glass }\end{array}$




\section{INTRODUCTION}

Molten salt reactors (MSRs) are one of the Generation IV reactor types being investigated as alternatives to the nuclear reactor technologies currently deployed. The MSR-type reactors fit into a few different classifications summarized in Table 1-1 in which the salt component can be used as just the coolant or both the fuel and the coolant. Additionally, the fuel can be split into separate salt streams containing either fissile or fertile components (i.e., two-fluid), or these can be combined into a single salt (i.e., single-fluid). These systems can be run in either continuous or batch-style processing routes in which fission products can be removed during operation or at end-of-life (or end-of-batch) of the reactor. MSRs can be breeder-type or burner-type reactors. For MSR applications, the fluid should be nonaqueous; economical; compatible with standard materials of construction; stable against radiation and hightemperature gases, with no emissions on its own (no vapor pressure at the operating temperature); and chemically resistant to residual salt, halides and halogens, volatile species, and their nonvolatile daughters. It should remain a liquid for a wide operating range of temperatures and display a low viscosity $(\eta)$ for easy pumping using high-temperature pumps or thermo-syphoning.

Table 1-1. Summary of different types of MSRs designs. The salt-cooled, solid-fuel option using TRISO (tristructural isotopic) fuel was provided by Brown et al. (2017).

\begin{tabular}{|c|c|c|}
\hline Type & Fuel & Coolant \\
\hline Salt-cooled & $\begin{array}{l}\text { Solid TRISO fuel } \\
\left.\text { (e.g., } 15.5 \% \mathrm{UCO}_{0.5} \mathrm{O}_{1.5}\right)\end{array}$ & $\begin{array}{l}\text { Molten salt coolant } \\
\left.\text { (e.g., } 2^{7} \mathrm{LiF}_{-} \mathrm{BeF}_{2}\right)\end{array}$ \\
\hline $\begin{array}{l}\text { Salt-fueled/cooled } \\
\text { (single-fluid) }\end{array}$ & $\begin{array}{l}\text { Molten salt fuel } \\
\text { (e.g., } \mathrm{UF}_{4}, \mathrm{PuF}_{3} \text {, and/or } \mathrm{ThF}_{4} \text { in } \\
\text { contact with } \mathrm{Li}-\mathrm{Be}-\mathrm{Zr}, \mathrm{Na}-\mathrm{Zr}-\mathrm{U} \text { ) }\end{array}$ & $\begin{array}{l}\text { Molten salt coolant } \\
\left.\text { (e.g., } \mathrm{NaBF}_{4}-\mathrm{NaF}, 2^{7} \mathrm{LiF}_{-} \mathrm{BeF}_{2}\right)\end{array}$ \\
\hline $\begin{array}{l}\text { Salt-fueled/cooled } \\
\text { (two-fluid) }\end{array}$ & $\begin{array}{l}\text { Molten salt with fissile material } \\
\left.\text { (e.g., }{ }^{233} \mathrm{UF}_{4}\right) \\
\text { Molten salt with fertile material } \\
\left.\text { (e.g., } \mathrm{ThF}_{4}\right)\end{array}$ & $\begin{array}{l}\text { Molten salt coolant } \\
\left.\text { (e.g., } \mathrm{NaBF}_{4}-\mathrm{NaF}, 2^{7} \mathrm{LiF}_{-} \mathrm{BeF}_{2}\right)\end{array}$ \\
\hline
\end{tabular}

The salts used in MSRs are likely to be halide-based salts in the form of either fluorides or chlorides; and each loop system will be exclusively one halide or the other, not a mixture of the two. Fluoride-based designs are typically used for thermal or fast reactors, whereas the chlorides are typically used for fast reactor designs. For all cases using lithium-based salts, ${ }^{7} \mathrm{Li}$-enrichment will be necessary to minimize tritium generation (a topic discussed later in this report). For chloride fast-spectrum reactors, isotopically pure ${ }^{37} \mathrm{Cl}$ is required for high breeding ratios. The different systems being investigated within the context of this document include both high-processing and low-processing routes for chloride-based salts and fluoride-based salts (shown in Table 1-2). However, the solid tristructural isotopic (TRISO) fuel used in fluoride salt-cooled high-temperature reactors (FHRs) is not covered in this report, as disposal of this fuel has been extensively investigated elsewhere (Bari et al., 2013; Heath et al., 2013; Heuer et al., 2014).

Table 1-2. Summary of salt-processing scenarios to be covered within the scope of this document. "High processing" and "low processing" denote the frequency by which fission products are removed from the reactor.

\begin{tabular}{|l|c|c|}
\cline { 2 - 3 } \multicolumn{1}{c|}{} & High processing & Low processing \\
\hline Cl-based salt & $\checkmark$ & $\checkmark$ \\
\hline F-based salt & $\checkmark$ & $\checkmark$ \\
\hline
\end{tabular}


Starting in the late 1950s with the molten salt reactor experiment (MSRE), fluoride fuel-salt reactors have been a topic of scientific investigation (Molten Salt Reactors, World Nuclear Association, 2017). Some fluoride salt compositions are given in Table 1-1. The program at Oak Ridge investigating FHRs ran until 1976. In some configurations, fertile materials were used in the core, i.e., ${ }^{238} \mathrm{U}$ and ${ }^{232} \mathrm{Th}$. Handling of fertile materials is not discussed in this report. The dispositioning of these materials comes with additional concerns, such as the high activity of ${ }^{233} \mathrm{~Pa}$.

Recently, chloride-fueled salts have generated interest because the actinide-chlorides have lower melting points than the fluorides and higher solubility in the chloride salt itself. Although several designs have been produced, these reactors have never been made operational or taken to criticality; assumptions about the chemistry and handling of chloride melts comes from chloride pyroprocessing. Chlorides have been targeted for use in fast spectrum reactors, with different burner-to-breeder ratios depending on the design. The advantage of using a fast spectrum is that online fuel processing is not necessary, as fission product compounds have lower neutron capture cross sections at higher neutron energies. The fuels can include plutonium and uranium chlorides, in mixtures that may or may not include $\mathrm{NaCl}, \mathrm{MgCl}_{2}$, and $\mathrm{CaCl}_{2}$. The Janz compilation (1975) provides much data on single and binary chloride salts, but there is concern that simple mixing rules may not apply for minor elements and fission products within the salts. The stabilities of the salts themselves need to be examined, particularly at temperatures a couple of hundred degrees above the liquidus temperature where incongruent volatilization can occur. However, the main considerations regarding waste handling (e.g., fission product speciation, actinide distributions, uptake onto structural materials, off-gas performance) and waste form stability (e.g., chemical durability) have commonalities between the fluoride and chloride-based salts.

The Fuel Cycle Operations Campaign evaluated 4400 distinct options for fast and thermal nuclear reactors and rated 40 groups (Wigeland et al., 2014). The most promising evaluation groups all involved a continuous recycle of uranium and plutonium (or transuranic elements) with new natural-grade uranium. However, the current US Department of Energy (DOE) program is focusing on near-term deployment. Fuel cycles involving online recycling have yet to be developed. Assessment of process options will be a longer-term activity. Hence, off-gas and waste-streams from continuous fuel processing are discussed only in a generic sense within the context of this report.

Thus, at this point, it is uncertain whether waste management will be conducted at the reactor facility or at some off-site facility, as this will depend on the extent of processing required. Having one or a few waste and effluent management facilities close to a few different reactor facilities that are co-located within a particular region may improve the flow of the process and reduce transportation burdens. Within this context, the fissile material that is removed from the reactor, particularly breeder reactors, must be tracked closely as a global safeguards approach. The tracking would include materials from the reactor facility, materials at the post-processing facility, and those en route between facilities.

Waste materials will comprise much more than the fuel itself. Reactor concepts have been reviewed by Greenwood and colleagues (2018) and include the following: the MSRE, the molten salt breeder reactor (MSBR), the molten salt demonstration reactor (MSDR), the aircraft reactor experiment (ARE), and the REBUS-3700 chloride salt-fueled reactor. Inventories of materials in the MSDR reactor come from this review and are summarized in Table 1-3. Similar details are not readily available for other reactor designs. Materials that will not come into contact directly with radiological material, such as secondary side steam generators or coolant salt loops (e.g., fluorides, nitrates), are not discussed in this report. 
Table 1-3. Materials used in an MSDR-type thermal reactor (Greenwood et al., 2018).

\begin{tabular}{|l|l|l|}
\hline Component & Materials of Construction & Amount \\
\hline Heat exchanger & Alloy-N & 1368 tubes, $0.30 \mathrm{~m}^{3}$ \\
\hline $\begin{array}{l}\text { Primary loop core and } \\
\text { reflectors }\end{array}$ & graphite & $66,000 \mathrm{~kg}, 373 \mathrm{~m}^{3}$ \\
\hline Primary flow loop & $\begin{array}{l}\text { Fluoride fuel salt } \\
\mathrm{LiF}^{-} \mathrm{BeF}_{2}-\mathrm{ThF}_{4}-\mathrm{UF}_{4} \\
71.5 \%-16 \%-12 \%-0.5 \%\end{array}$ & $14,000 \mathrm{~kg}, 41 \mathrm{~m}^{3}$ \\
\hline Primary coolant loop & Coolant salt, FLiBe & $88,000 \mathrm{~kg}, 34 \mathrm{~m}^{3}$ \\
\hline Decay heat removal & $\mathrm{NaK}, 22 \%-78 \%$ & \\
\hline
\end{tabular}

The goals of this report are to accomplish the following:

- Assess the potential waste streams that could be generated from MSR processes

- Determine how these wastes could be treated and/or immobilized in a form that could be disposed of

- Determine the storage, transportation, and disposal requirements for MSR-type wastes

From an environmental impact perspective, the goal would be to find ways to prevent and minimize waste generation as well as reuse/recycle reactor components wherever possible but some wastes will require disposal no matter what reactor designs are implemented (see Figure 1-1).

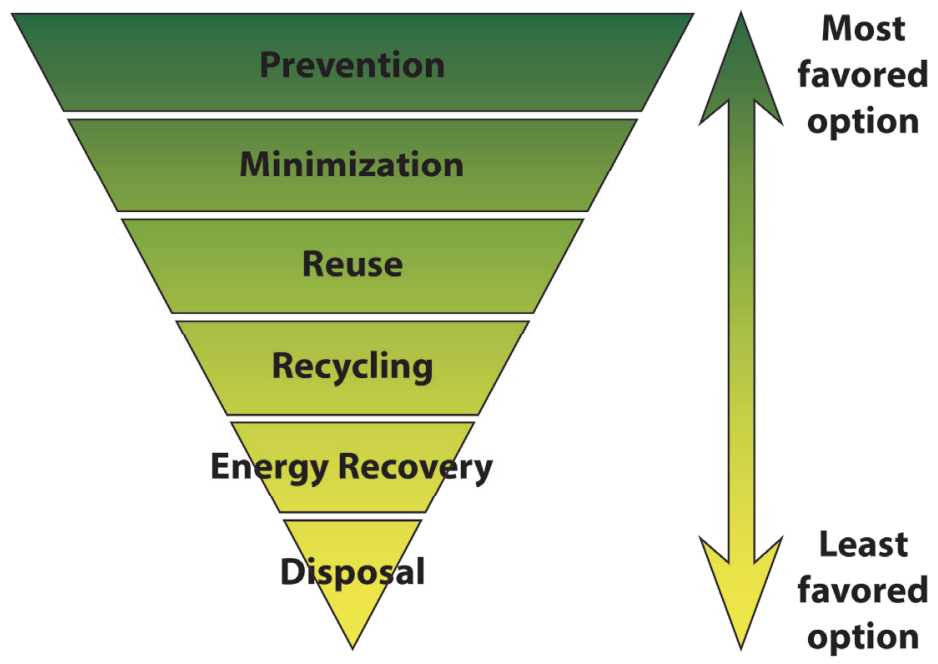

Figure 1-1. Waste management hierarchy [modified from Wareing et al. (2013)]. 


\section{WASTE STREAM POSSIBLITIES}

The different waste streams that are expected from a generic MSR concept include the following:

1) Volatile off-gas byproducts

2) Unseparated salt-based waste streams

3) Separated salt-based waste streams

4) Carbon-based waste streams

5) Metal-based waste streams

6) Streams from decommissioning and decontamination (D\&D)

7) Streams for operating wastes

Each of these streams is discussed in more detail within separate sections (Sections 2.1-2.7). Even more detail is given in subsequent sections following this section. In the structure of this report, certain topics are touched upon in different ways and in different contexts. While some of the chemistry between these different waste streams might be similar, the way in which different streams are handled or postprocessed may vary. For instance, unseparated and separated salt waste streams may have several salt components in common, depending on what separations are conducted. Alternatively, the separated streams might have lower fission products loadings and could have different associated regulations. Another example is cases in which particular waste form options could be used for different streams. In such cases, those options are summarized throughout the document where appropriate.

\subsection{Volatile Off-Gas Waste Streams}

Following fission of the different fuel types, a variety of radioactive gaseous fission products or nonradioactive gases/vapors mixed in with radionuclides could be released, including particulates, aerosols, reactive gases (e.g., halides), hydrogen (e.g., ${ }^{3} \mathrm{H}$ ), water, $\mathrm{N}_{2(\mathrm{~g})}, \mathrm{O}_{2(\mathrm{~g})}$, and noble gases (e.g., $\mathrm{Xe}, \mathrm{Kr}$ ). These radionuclides will be generated continuously during reactor operation, and releases must be managed to be below regulatory limits. A baseline process is provided in Figure 2-1 to show how these main off-gas effluents could be managed after being removed from the headspace of an MSR. It lays out various parallel pathways targeting specific species. 


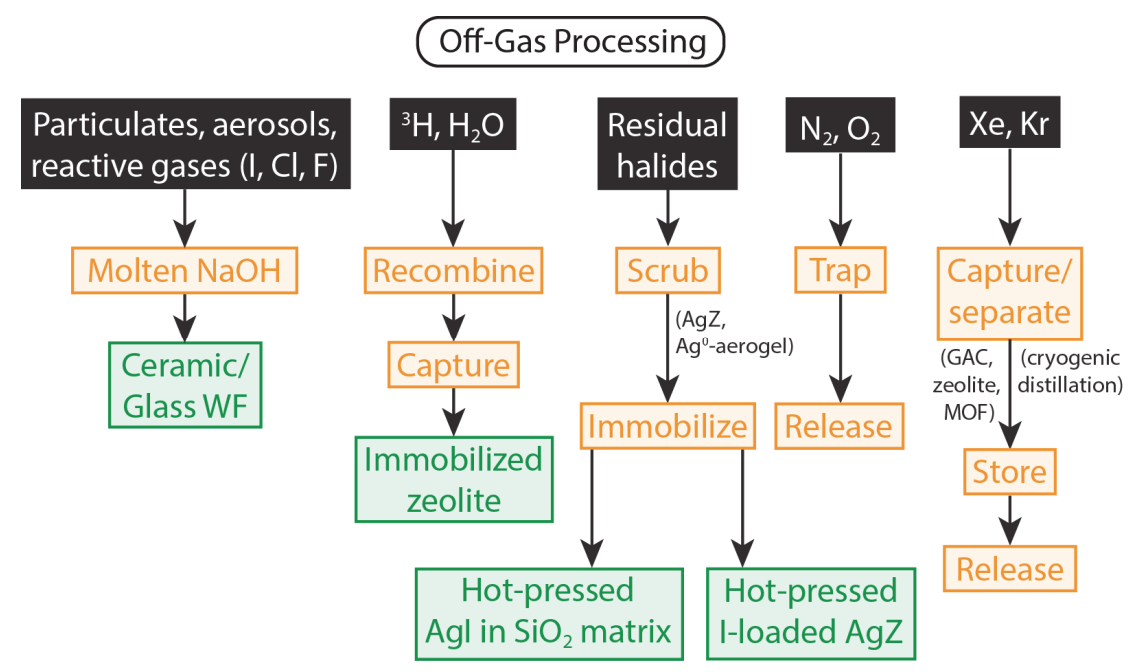

Figure 2-1. Summary of off-gas constituents and planned path forward for capture, immobilization, disposal, and/or release. "WF," "AgZ," and " $\mathrm{Ag}^{0}$-aerogel" denote waste form, silver mordenite, and silverfunctionalized silica aerogel, respectively.

\subsection{Unseparated Salt Waste Streams}

Since different system designs use either fluoride-based salts or chloride-based salts (not both), the overall chemistry of the reactor will depend on the fuel, coolant, and fission product distributions. A variety of options for immobilizing the salt are available depending, on the salt type, and are summarized in Figure 2-2. Most of the options available for immobilizing chloride-based salts can be similar for fluoride-based salts albeit with some slight differences in the required processes.

For instance, while a glass-bonded sodalite is ideal for immobilizing mixed chloride-based salt wastes, glass-bonded apatite is a better option for fluoride-based salt wastes. This is because the sodalite and apatite structures have key differences, e.g., the sodalite structure can readily incorporate alkalis and halides, whereas the apatite structure can incorporate alkalis, alkaline earths, and halides.

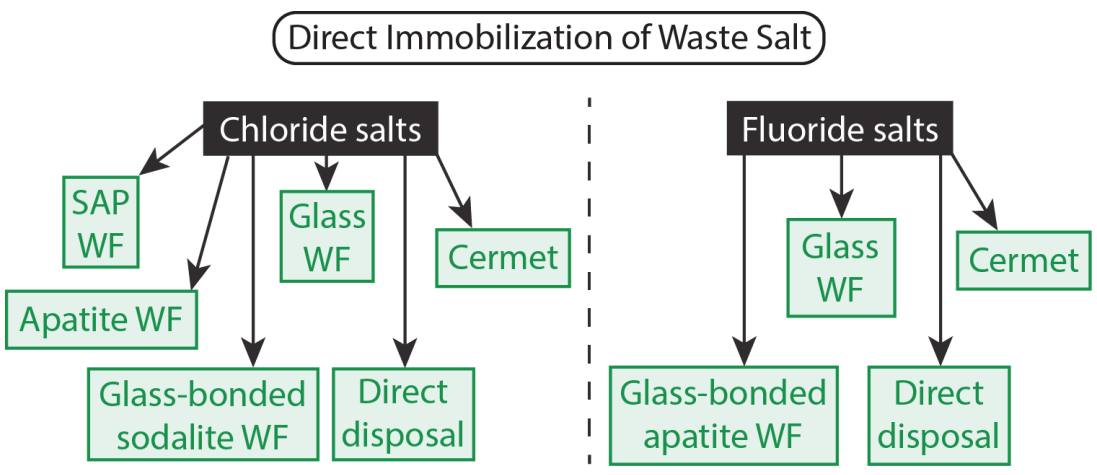

Figure 2-2. Summary of unseparated salt waste streams along with disposal pathways. "WF" and "cermet" denote waste form and ceramic-metal composite, respectively. 
Here are some possible salt chemistries based on the literature for fluoride-based salts:

- Salts based on the MSRE

○ Fuel salt: ${ }^{7} \mathrm{LiF}_{-} \mathrm{BeF}_{2}-\mathrm{ZrF}_{4}-\mathrm{UF}_{4}$ (65-29-5-1 mol\%, respectively) (Serp et al., 2014), $\mathrm{PuF}_{3}$ $\mathrm{NaF}-\mathrm{ZrF}_{4}$ (Holcomb et al., 2011)

○ Coolant salt: $2\left({ }^{7} \mathrm{LiF}\right)-\mathrm{BeF}_{2}$ (Serp et al., 2014)

- Salts based off the MSBR

○ Fuel salt: ${ }^{7} \mathrm{LiF}_{-} \mathrm{BeF}_{2}-\mathrm{ThF}_{4}-\mathrm{UF}_{4}$ (fuel, 71.7-16-12-0.3 mol\%, respectively) (Grimes, 1970),

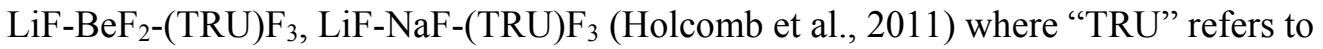
transuranics

- Coolant salt: $\mathrm{NaBF}_{4}-\mathrm{NaF}$ (Rosenthal et al., 1972)

- Carrier salts based on advanced designs, diluents for (TRU)F 3 (Holcomb et al., 2011)

- $\mathrm{NaF}^{7}{ }^{7} \mathrm{LiF}_{-\mathrm{BeF}}$ (European MOSART reactor) (IAEA, 2009)

$\circ \quad \mathrm{NaF}-\mathrm{PbF}_{2}-\mathrm{ZrF}_{4}-\mathrm{LaF}_{3}$

Here are some possible salt chemistries for chloride-based salts for fast spectrum-molten salt reactors (FSMSRs) as reviewed by (Holcomb et al., 2011):

- FS-MSR breeder fuel salts, $\mathrm{NaCl}-\mathrm{KCl}-\mathrm{PuCl}_{3}, \mathrm{PuCl}_{3}-\mathrm{NaCl}\left(40 \% \mathrm{PuCl}_{3}\right)$

- Coolant salts: $\mathrm{NaCl}-\mathrm{MgCl}_{2}, \mathrm{KCl}-\mathrm{MgCl}_{2}, \mathrm{LiCl}-\mathrm{KCl}-\mathrm{MgCl}_{2}, \mathrm{LiCl}-\mathrm{RbCl}, \mathrm{LiCl}-\mathrm{KCl}$

- Other diluents: $\mathrm{MgCl}_{2}, \mathrm{CaCl}_{2}, \mathrm{KCl}-\mathrm{SrCl}_{2}-\mathrm{RbCl}$

Unlike the fluoride-based MSRs, chloride salt reactors have not been brought to criticality and are at the conceptual stage of development. A breeder-to-burner configuration can be controlled by the ratio of ${ }^{238} \mathrm{U}$ to TRU. As an aside, chloride-based coolant salts are being evaluated for concentrating solar power thermal energy storage, and that application shares many of the issues related to salt purity (Holcomb et al., 2011). To minimize the radiotoxicity of chlorine, isotopic enrichment of the ${ }^{37} \mathrm{Cl}$ isotope would need to be done as ${ }^{35} \mathrm{Cl}$ activates to ${ }^{36} \mathrm{Cl}$ (a $709 \mathrm{keV} \beta$-emitter, with a $t_{1 / 2}=3.01 \times 10^{5} \mathrm{y}$ that is soluble in water).

\subsection{Salt Separations Streams}

Salt processing encompasses two areas: the initial salt cleanup for fueling the reactor and online processing during reactor operation. Front-end processing can include preparation of high-purity feedstock and conversion of an available source of actinides (e.g., the stockpile of $\mathrm{UF}_{6}$ or conversion of used light-water reactor, or LWR, fuel) to MSR fuel. Front-end processes are not discussed in detail in this report. Online fuel cycling that will be needed for thermal spectrum MSRs will generate radioactive waste and hence is relevant to this report. The simplest processing involves removal of volatile fission products through an off-gas system, which is discussed in detail in Section 3. The other goal of online salt processing is to remove fission products that interfere with reactor operation.

Besides reactor operation, processes for separating salt streams are also driven by criteria that do not directly influence reactor operation. Separation of salt streams has a diverse set of options that are briefly summarized in Figure 2-3. The approaches and benefits of separating the salts from the reactor involve multiple aspects, but these can be divided into two goals, which are not necessarily in competition with each other:

- Allowing for more efficient waste form production (e.g., higher waste loadings, more chemically durable waste forms)

- Allowing for recycling of salt components that are directly reusable, expensive to procure/produce/purify (e.g., ${ }^{37} \mathrm{Cl},{ }^{7} \mathrm{Li}$ ), non-radioactive (i.e., they dilute waste loading in a final waste form), and/or difficult to process from a health hazard perspective (e.g., $\mathrm{BeF}_{2}$ ) 


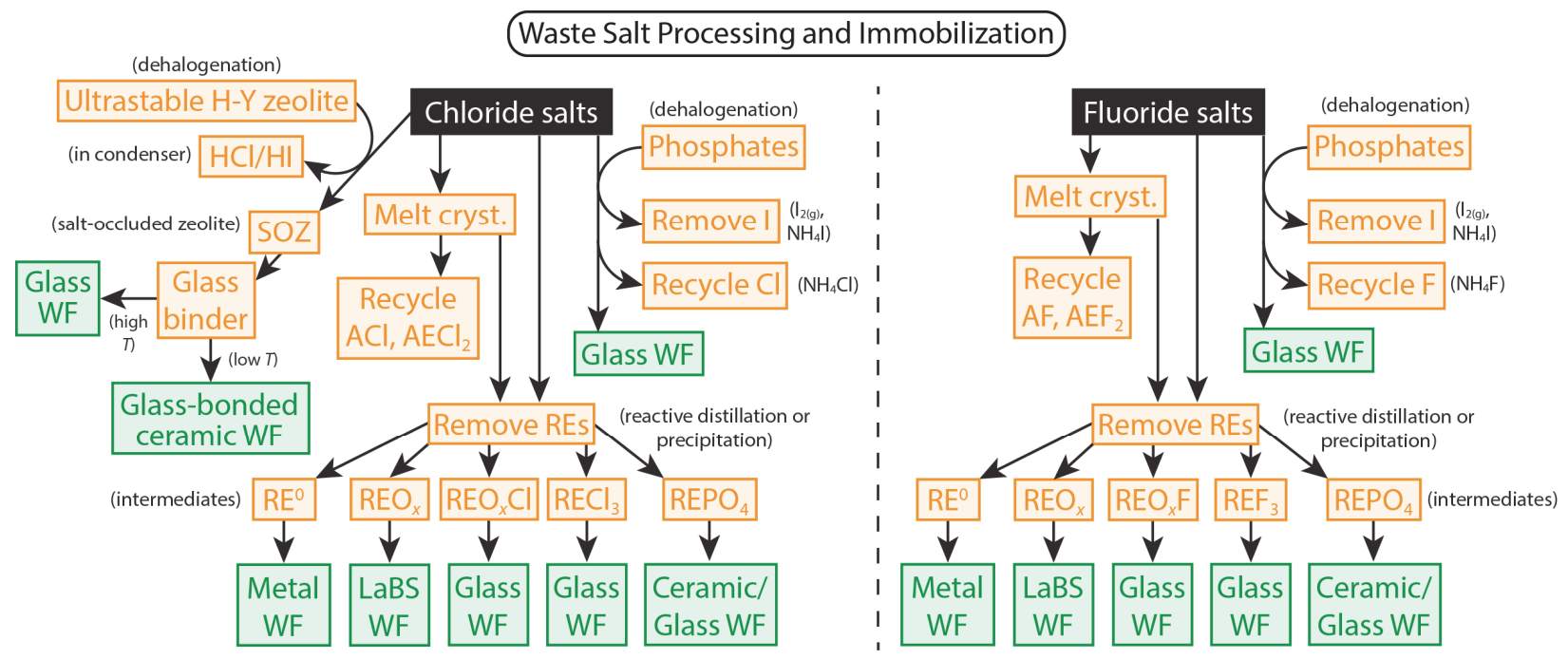

Figure 2-3. Summary of separated salt streams along with suggested processing routes and action and/or disposal pathways for different options.

Processing options for the salts include electrorefining, separations through volatility differences or distillation, melt crystallization and precipitation, filtration, and redox chemistry. These processes have been briefly discussed by Holcomb et al. (2011) and Forsberg (2018a). Details on the chemistry of chloride and fluoride salts and the impact on waste stability are provided in Section 4.

\subsection{Carbon Streams}

One of the limiting factors for the potential reactor lifetime is damage introduced by neutron irradiation in the structure of graphite core components. Different types of carbon-based reactor components will be used for reactor operation; these include (but are not limited to) graphite structural components and silicon carbide $(\mathrm{SiC})$ within the fuel kernels. High-energy neutrons can displace carbon atoms from their equilibrium positions in the graphite crystal lattice. The primary knock-out carbon atoms initiate a series of secondary knock-out carbons that develop in a cascade manner through graphite crystallites. Some of the displaced atoms may recoil through the carbon lattice, producing other displacements and leaving behind vacancy positions. Other displaced atoms tend to migrate between parallel graphite layers and eventually to coalesce in clusters, forming essentially a new interstitial graphite plane. Yet, other displaced atoms may recombine with the vacancies and return to normal lattice positions. The dose received by graphite materials is measured in terms of average displacements per atom (dpa); the conversion factor is $1 \mathrm{dpa}=7.3 \times 10^{26} \mathrm{n} / \mathrm{m}^{2}(E>0.1 \mathrm{MeV})$.

The formation and growth of new interstitial planes causes dimensional changes in graphite crystallites: growth in the direction perpendicular to the layer planes ( $c$-axis) and shrinkage parallel to layer planes $(a$ axis). Since nuclear graphite has about $18-20 \%$ porosity by volume, the initial growth of crystallite along the $c$-axis can be accommodated by pores lying parallel with the graphite planes. At the early stages of irradiation, only the shrinkage along the $a$-axis has a net effect on graphite dimensions. The initial volume shrinkage of graphite specimens may reach up to $10 \%$, depending on graphite properties. When all accommodation pores have been filled, and a minimum volume attained, the shrinkage can no longer be accommodated. At higher levels of irradiation, the dimensional changes are dominated by expansion along the $c$-axis and the generation of new porosity. After a "turn-around" point, graphite starts to swell back to the initial dimensions and even further. This swelling is accompanied by the development of internal stresses among randomly oriented crystallites, which eventually results in complete graphite disintegration. This behavior is general to all graphite grades, but the behavior of each grade depends on manufacturing details, the nature of the precursor, and microstructural properties. Notable exceptions are several binder-less graphite grades manufactured by POCO Graphite Inc., which have very small volume 
variations. That might be significant because ultrafine-grade graphite, such as binder-less POCO grades, may be viable candidates for use in MSRs. Figure 2-4 shows volume changes of several nuclear graphite grades and one POCO graphite, which show practically no volume changes with irradiation (Pitner, 1971).

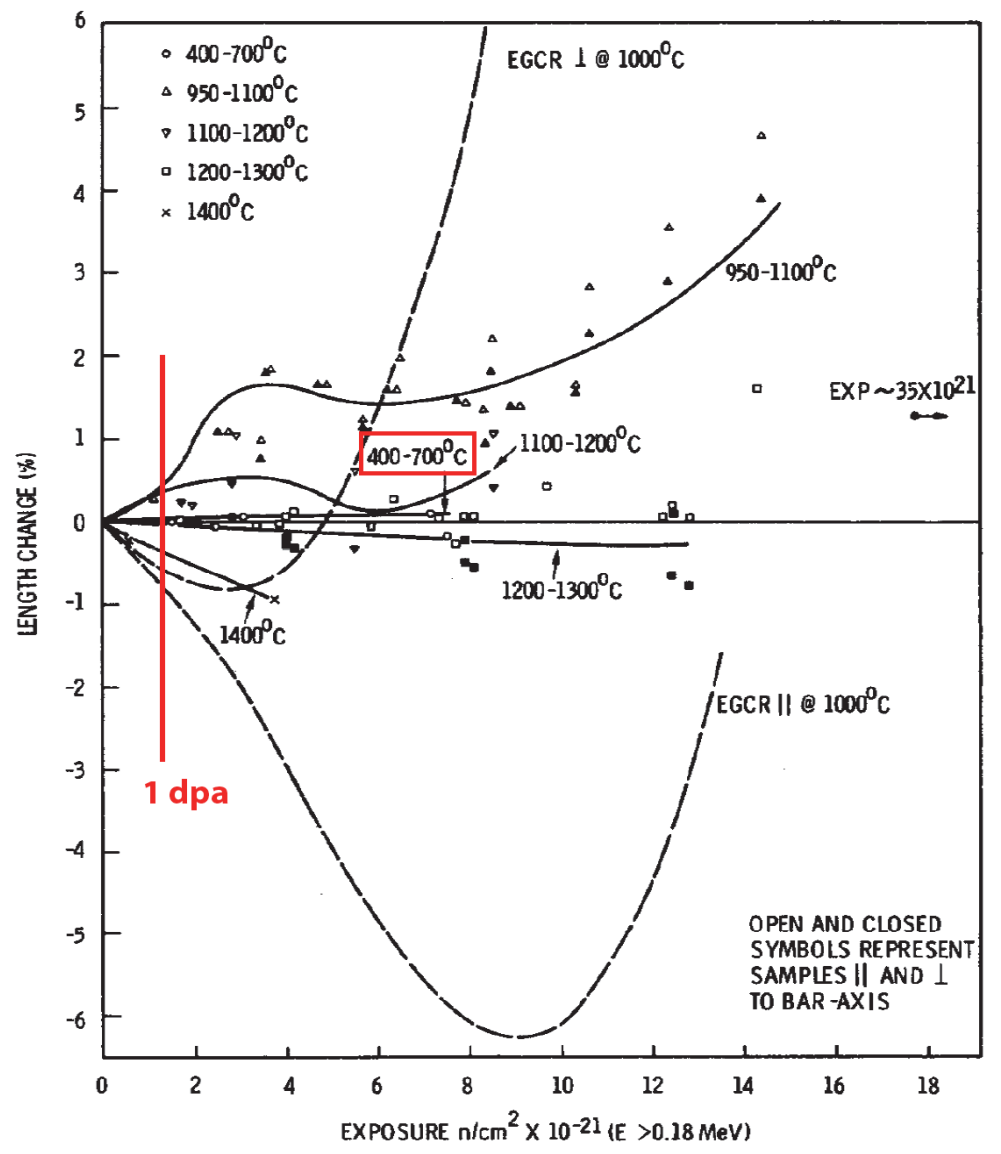

Figure 2-4. Comparison of dimensional changes under irradiation of several nuclear graphite grades and of POCO AXF-8Q1 grade (highlighted for $400-700^{\circ} \mathrm{C}$ ). The $1 \mathrm{dpa}$ (displacements per atoms) shows the exposure at which each carbon atoms have suffered statistically one single displacement. This figure was modified from Pitner (1971).

The carbon-based wastes can be either hot pressed into a carbon waste form, processed by some other route not yet determined, or potentially recycled to form new reactor components. These options are shown schematically in Figure 2-5. Options that might fit into the "?" boxes in Figure 2-5 are methods to decontaminate the carbon-based reactor components to broaden the disposal pathways via a technique such as mechanical treatment (e.g., sand blasting) or chemical treatment (e.g., acid etching). 


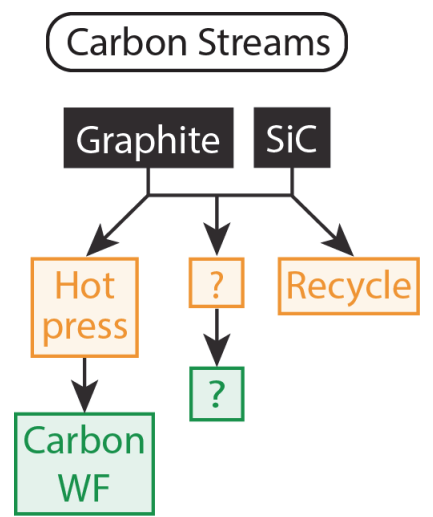

Figure 2-5. Summary of carbon-based waste streams as well as action and disposal pathways.

\subsection{Metal-Based Waste Streams}

Depending on the types of metals used for the reactor, the overall metallic waste form options will vary. The more common metals that have been used to date include Hastelloy-N (Bettis and Robertson, 1970) and Alloy $800 \mathrm{H}$ (LeBlanc, 2010) (see Table 2-1). Other metals that could be used include various types of stainless steel (SS), Inconel, and international alloys such as MONICR.

Table 2-1. Summary of metal compositions (mass\%) for MSR reactor components.

\begin{tabular}{|c|c|c|c|c|c|}
\hline Element & Hastelloy-N & Alloy 800H & MONICR & Inconel 600 & 316L SS \\
\hline Reference & $\begin{array}{c}\text { (Bettis and } \\
\text { Robertson, 1970) }\end{array}$ & (Alloy $800 \mathrm{H} / \mathrm{HT}^{\circledR}$ ) & $\begin{array}{c}\text { (Slama and } \\
\text { Marecek, 2015) }\end{array}$ & $\left(\right.$ Inconel $\left.{ }^{\circledR} 600\right)$ & (316L SS) \\
\hline $\mathrm{Ni}$ & $75 \%$ & $30-35 \%$ & 74.65 & $\geq 72$ & $10-14$ \\
\hline Mo & $12 \%$ & - & 15.81 & & $2-3$ \\
\hline $\mathrm{Cr}$ & $7 \%$ & $19-23 \%$ & 6.82 & $14-17$ & $16-18$ \\
\hline $\mathrm{Fe}$ & $4 \%$ & $\geq 39.5 \%$ & 2.32 & $6-10$ & Remainder \\
\hline $\mathrm{Ti}$ & $1 \%$ & $0.15-0.60 \%$ & 0.03 & - & - \\
\hline $\mathrm{Al}+\mathrm{Ti}$ & - & $0.30-1.20 \%$ & - & - & - \\
\hline $\bar{C}$ & - & $0.05-0.10 \%$ & - & $\leq 0.10$ & 0.08 \\
\hline $\mathrm{Al}$ & - & $0.15-0.60 \%$ & 0.26 & - & - \\
\hline $\mathrm{Mn}$ & - & $\leq 1.5 \%$ & 0.04 & $\leq 1.00$ & 2.00 \\
\hline $\mathrm{S}$ & - & $\leq 0.015 \%$ & - & $\leq 0.015$ & 0.03 \\
\hline $\mathrm{Si}$ & - & $\leq 1 \%$ & - & $\leq 0.50$ & 0.75 \\
\hline $\mathrm{Cu}$ & - & $\leq 0.75 \%$ & - & $\leq 0.50$ & - \\
\hline $\mathrm{P}$ & - & $\leq 0.045$ & - & - & 0.045 \\
\hline $\mathrm{W}$ & - & - & 0.06 & - & - \\
\hline $\mathrm{Nb}$ & - & - & 0.01 & - & - \\
\hline $\mathrm{N}_{2}$ & - & - & - & - & 0.10 \\
\hline Other & $1 \%$ & - & - & - & - \\
\hline
\end{tabular}

The metal wastes can be size reduced and/or decontaminated and then either melted or compacted into a metal waste form. This is shown schematically in Figure 2-6. The metal options include a size reduction and decontamination step, along with melting or compaction into a metal waste form. Another potential option is to recycle the metal components. 


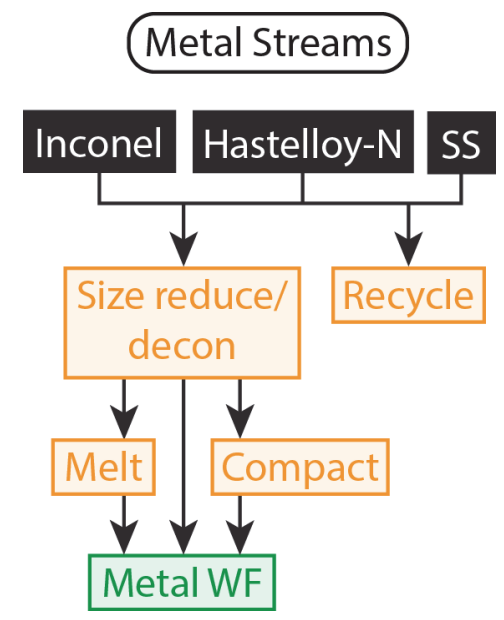

Figure 2-6. Summary of metal-based waste streams as well as action and disposal pathways for these streams.

\subsection{Streams from Decommissioning and Decontaminating}

For every reactor concept, wastes will be generated by D\&D of the facilities. These wastes will include metals, cements, and carbon-based streams (e.g., graphite, $\mathrm{SiC}$ ). The elements from fission and activation are shown in Table 2-2 for a simulation of three different MSR types. Breeder and burner reactors were considered, including thorium as well as uranium-based fuels. The simulation assumed that any isotopes would be removed through salt processing and did not include online removal of fission gases through an off-gas system.

Table 2-2. Simulation of MSR salt compositions.

\begin{tabular}{|c|c|c|c|}
\hline Parameter & $\begin{array}{l}\text { Molten salt breeder } \\
\text { reactor }\end{array}$ & $\begin{array}{l}\text { Thermal spectrum } \\
\text { MSR }\end{array}$ & Fast spectrum MSR \\
\hline Reference & Betzler et al. (2017b) & Betzler et al. (2018) & Betzler et al. (2017a) \\
\hline Fuel type & $\mathrm{Th} /{ }^{233} \mathrm{U}$ & Low-enrichment U & $\mathrm{U} / \mathrm{Pu}$ \\
\hline Carrier salt & FLiBe & $\mathrm{LiF}$ & $\mathrm{NaCl}$ \\
\hline Fuel salt & $\mathrm{ThF}_{4}, \mathrm{UF}_{4}$ & $\mathrm{UF}_{4}$ & $\mathrm{UCl}_{3}, \mathrm{PuCl}_{3}$ \\
\hline $\begin{array}{l}\text { Operating } \\
\text { temperature }\left({ }^{\circ} \mathrm{C}\right)\end{array}$ & 636 & 613 & 750 \\
\hline Salt volume $\left(\mathrm{m}^{3}\right)$ & 48.7 & 46.8 & 12.3 \\
\hline Fueling condition & $\begin{array}{l}\text { Maintain constant }{ }^{232} \mathrm{Th} \\
\text { loading }\end{array}$ & $\begin{array}{l}\text { Add } 500 \mathrm{~kg} / \text { year low- } \\
\text { enrichment U }(5 \%)\end{array}$ & $\begin{array}{l}\text { Maintain constant }{ }^{238} \mathrm{U} \\
\text { loading }\end{array}$ \\
\hline $\begin{array}{l}\text { Low-level } \\
\text { processing }\end{array}$ & No isotopes removed & $\begin{array}{l}\mathrm{Ag}, \mathrm{H}, \mathrm{Kr}, \mathrm{Mo}, \mathrm{Nb}, \mathrm{Pd}, \\
\mathrm{Rh}, \mathrm{Ru}, \mathrm{Sb}, \mathrm{Se}, \mathrm{Tc}, \mathrm{Te}, \\
\text { Xe removed. }\end{array}$ & $\begin{array}{l}\mathrm{Ag}, \mathrm{Kr}, \mathrm{Mo}, \mathrm{Nb}, \mathrm{Pd} \\
\mathrm{Pu}, \mathrm{Rh}, \mathrm{Ru}, \mathrm{Sb}, \mathrm{Se}, \mathrm{Tc}, \\
\mathrm{Te}, \mathrm{Xe} \text { removed }\end{array}$ \\
\hline $\begin{array}{l}\text { High-level } \\
\text { processing }\end{array}$ & $\begin{array}{l}\mathrm{Ag}, \mathrm{Ba}, \mathrm{Br}, \mathrm{Cd}, \mathrm{Ce}, \mathrm{Cs}, \\
\mathrm{Eu}, \mathrm{Gd}, \mathrm{I}, \mathrm{In}, \mathrm{Kr}, \mathrm{La}, \\
\mathrm{Mo}, \mathrm{Nb}, \mathrm{Nd}, \mathrm{Pa}, \mathrm{Pd}, \\
\mathrm{Pm}, \mathrm{Pr}, \mathrm{Rb}, \mathrm{Rh}, \mathrm{Ru}, \mathrm{Sb}, \\
\mathrm{Se}, \mathrm{Sm}, \mathrm{Sn}, \mathrm{SR}, \mathrm{Tc}, \mathrm{Te} \\
\mathrm{Xe}, \mathrm{Y}, \mathrm{Zr}\end{array}$ & $\begin{array}{l}\mathrm{Ag}, \mathrm{As}, \mathrm{Ba}, \mathrm{Br}, \mathrm{Ca}, \mathrm{Cd}, \\
\mathrm{Ce}, \mathrm{Co}, \mathrm{Cr}, \mathrm{Cs}, \mathrm{Cu}, \mathrm{Eu}, \\
\mathrm{Fe}, \mathrm{Ga}, \mathrm{Gd}, \mathrm{Ge}, \mathrm{H}, \mathrm{I}, \\
\mathrm{In}, \mathrm{Kr}, \mathrm{La}, \mathrm{Mn}, \mathrm{Mo}, \\
\mathrm{Nb}, \mathrm{Nd}, \mathrm{Ni}, \mathrm{Pd}, \mathrm{Pm}, \mathrm{Pr} \\
\mathrm{Rb}, \mathrm{Rh}, \mathrm{Ru}, \mathrm{Sb}, \mathrm{Sc}, \mathrm{Se}, \\
\mathrm{Sm}, \mathrm{Sn}, \mathrm{Sr}, \mathrm{Tc}, \mathrm{Te}, \mathrm{Ti} \\
\mathrm{V}, \mathrm{Xe}, \mathrm{Y}, \mathrm{Zn}, \mathrm{Zr}\end{array}$ & $\begin{array}{l}\mathrm{Ag}, \mathrm{As}, \mathrm{Ba}, \mathrm{Br}, \mathrm{Cd}, \mathrm{Ce} \text {, } \\
\mathrm{Cs}, \mathrm{Dy}, \mathrm{Er}, \mathrm{Eu}, \mathrm{Gd}, \mathrm{Ge}, \\
\mathrm{Ho}, \mathrm{I}, \mathrm{In}, \mathrm{Kr}, \mathrm{La}, \mathrm{Mo}, \\
\mathrm{Nb}, \mathrm{Nd}, \mathrm{O}, \mathrm{Pd}, \mathrm{Pm}, \mathrm{Pr}, \\
\mathrm{Pu}, \mathrm{Rb}, \mathrm{Rh}, \mathrm{Ru}, \mathrm{Sb}, \mathrm{Se}, \\
\mathrm{Sm}, \mathrm{Sn}, \mathrm{Sr}, \mathrm{Tb}, \mathrm{Tc}, \mathrm{Te}, \\
\mathrm{Y}, \mathrm{Zr}\end{array}$ \\
\hline
\end{tabular}


Following size reduction, removal of radionuclides through decontamination, and appropriate packaging, these wastes can likely be disposed of as low-level waste (LLW) or greater-than-Class C (GTCC) waste. This is shown schematically in Figure 2-7. Greenwood et al. (2018) assessed the overall amounts of construction materials used in an MSDR; these are presented in Table 1-3. The salt itself and graphite are the largest-volume waste materials.

\section{D\&D Streams}

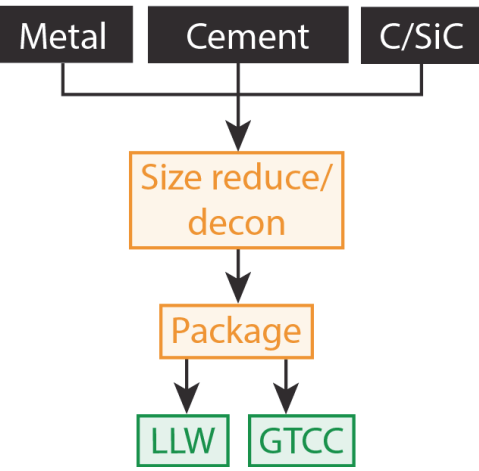

Figure 2-7. Summary of decommissioning and decontamination streams as well as actions and disposal pathways.

\subsection{Streams for Operating Wastes}

For every reactor concept, operating wastes will be generated and handled. Figure 2-8 provides a summary of expected types of operating wastes. These include failed equipment, materials cans, job control wastes (e.g., personal protective equipment), facility filters (e.g., high-efficiency particulate air, or HEPA; these are typically fabric-based), water cleanup wastes (e.g., ion-exchange resins), glovebox gloves and manipulator boots, process HEPA filters (e.g., metal filters), and laboratory samples. It is expected that these wastes can be reduced in size, decontaminated, packaged, and disposed of as LLW or GTCC wastes.

\section{Operating Wastes}

\section{Failed equipment Materials cans}

\begin{tabular}{c|c|c|}
$\begin{array}{c}\text { Job control } \\
\text { waste (PPE) }\end{array}$ & $\begin{array}{c}\text { Facility HEPA } \\
\text { (fabric) }\end{array}$ & $\begin{array}{c}\text { Water cleanup } \\
\text { wastes (resins) }\end{array}$ \\
\hline
\end{tabular}

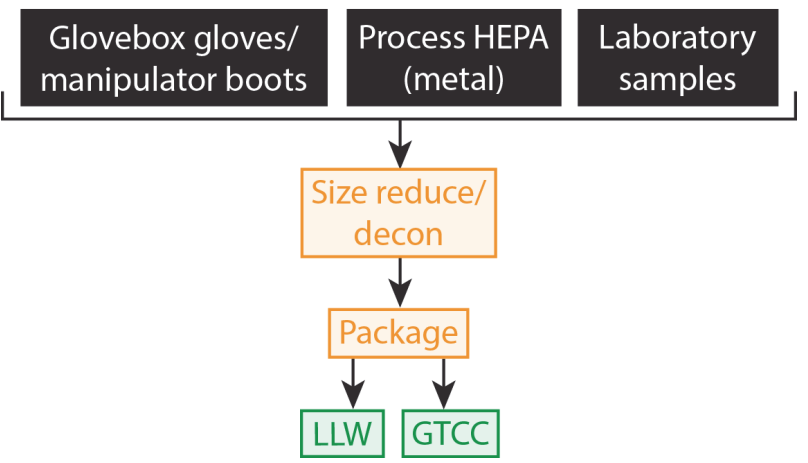

Figure 2-8. Summary of streams for operating wastes as well as actions and disposal pathways. 


\section{OPTIONS FOR OFF-GAS PRODUCTS}

The purpose of this section is to elaborate on Subsection 2.1, Volatile Off-Gas Waste Streams. Based on the MSRE experience, we should expect the following contaminants to be treated by the off-gas system of a commercial MSR (fluoride or chloride systems alike):

1) Mists, aerosols, and particles (e.g., pyrolysis products, salt residues, graphite debris for graphite moderated fluoride systems, noble metals)

2) Volatile species (e.g., $\mathrm{Kr}, \mathrm{Xe},{ }^{3} \mathrm{HF}, \mathrm{HF}, \mathrm{H}_{2} \mathrm{O}, \mathrm{O}_{2}, \mathrm{~F}_{2}, \mathrm{Cl}_{2}, \mathrm{Br}_{2}, \mathrm{I}_{2}$, Ar, interhalogens, volatile halides) and the decay products (e.g., Cs, Ba, Rb, Sr, La, Br, I, Se, Te)

3) Tritium (e.g., ${ }^{3} \mathrm{H}_{2(\mathrm{~g})},{ }^{3} \mathrm{HH}_{(\mathrm{g})},{ }^{3} \mathrm{HF}_{(\mathrm{g})},{ }^{3} \mathrm{HF}_{(\mathrm{l})}$, and possibly ${ }^{3} \mathrm{HHO}_{(\mathrm{g})}$ and ${ }^{3} \mathrm{H}_{2} \mathrm{O}_{(\mathrm{g})}$ )

4) Short-lived volatile radionuclides and their daughters (e.g., ${ }^{139} \mathrm{Xe} t_{1 / 2}=39.5 \mathrm{~s},{ }^{90} \mathrm{Kr} t_{1 / 2}=32.3 \mathrm{~s}$, ${ }^{137} \mathrm{Xe} t_{1 / 2}=3.83 \mathrm{~min},{ }^{135 \mathrm{~m}} \mathrm{Xe} t_{1 / 2}=15.3 \mathrm{~min},{ }^{89} \mathrm{Kr} t_{1 / 2}=3.18 \mathrm{~min},{ }^{135} \mathrm{Xe} t_{1 / 2}=9.1 \mathrm{~h},{ }^{88} \mathrm{Kr} t_{1 / 2}=2.84 \mathrm{~h}$, $\left.{ }^{133 \mathrm{~m}} \mathrm{Xe} t_{1 / 2}=2.19 \mathrm{~d},{ }^{133} \mathrm{Xe} t_{1 / 2}=5.25 \mathrm{~d}\right)$

5) Longer-lived radionuclides (e.g., ${ }^{85} \mathrm{Kr} t_{1 / 2}=10.7 \mathrm{y},{ }^{36} \mathrm{Cl} t_{1 / 2}=3 \times 10^{5} \mathrm{y},{ }^{79} \mathrm{Se} t_{1 / 2}=6.5 \times 10^{4} \mathrm{y}$, $\left.{ }^{129} \mathrm{I} t_{1 / 2}=1.57 \times 10^{7} \mathrm{y}\right)$

A summary of potential options for processing various streams is presented in Table 3-1.

Table 3-1. Summary of volatile off-gas waste components that will or could require capture and/or immobilization.

\begin{tabular}{|c|c|c|c|}
\hline Waste type & Capture method & Immobilization method & Reference \\
\hline \multirow{2}{*}{ Particulates } & Molten $\mathrm{NaOH}$ & $\begin{array}{l}\text { Ceramic or glass waste } \\
\text { form (WF) }\end{array}$ & Smith (1956) \\
\hline & $\begin{array}{l}\text { HEPA filters }(\geq 300 \mathrm{~nm} \\
\text { diameter) }\end{array}$ & $\begin{array}{l}\text { Size reduction and } \\
\text { decontamination }\end{array}$ & (IAEA, 1987) \\
\hline \multirow{3}{*}{ Aerosols* } & Molten $\mathrm{NaOH}$ & Ceramic or glass WF & Smith (1956) \\
\hline & Particle traps, charcoal beds & Solids & $\begin{array}{l}\text { Greenwood et al. (2018) } \\
\text { Zagnit'ko and Chuvilin } \\
\text { (2009) }\end{array}$ \\
\hline & HEPA filters & $\begin{array}{l}\text { Size reduction and } \\
\text { decontamination }\end{array}$ & (IAEA, 1987) \\
\hline Reactive gases & Molten $\mathrm{NaOH}$ & Ceramic or glass WF & Smith (1956) \\
\hline $\begin{array}{l}\text { Tritium } \\
\left(\text { i.e., }{ }^{3} \mathrm{H}_{(\mathrm{g})}\right. \\
\left.{ }^{3} \mathrm{H}_{2} \mathrm{O}\right)\end{array}$ & $\begin{array}{l}\text { Separated from low-volume } \\
\text { gas or high-volume water } \\
\text { streams (e.g., desiccant, } \\
\text { molecular sieve, carbon) }\end{array}$ & $\begin{array}{l}\text { Low-water cement in } \\
\text { high-integrity containers }\end{array}$ & Vienna et al. (2015a) \\
\hline \multirow{5}{*}{$\begin{array}{l}\text { Residual } \\
\text { halides (e.g., } \\
\mathrm{F}, \mathrm{Cl}, \mathrm{I})\end{array}$} & Silver mordenite (AgZ) & As AgI in composite WF & Bruffey et al. (2016) \\
\hline & $\begin{array}{l}\mathrm{Ag}^{0} \text {-functionalized silica } \\
\text { aerogel }\end{array}$ & As AgI in composite WF & Matyáš et al. (2011) \\
\hline & $\begin{array}{l}\mathrm{Ag}^{+/ 0} \text {-loaded aluminosilicate } \\
\text { aerogels }\end{array}$ & As AgI in composite WF & Riley et al. (2017a) \\
\hline & Sulfide aerogel (chalcogel) & In chalcogenide glass & $\begin{array}{l}\text { Riley et al. (2013a); } \\
\text { Riley et al. (2015) }\end{array}$ \\
\hline & Molten $\mathrm{NaOH}$ & Ceramic or glass WF & Smith (1956) \\
\hline $\mathrm{N}_{2}, \mathrm{O}_{2}^{\dagger}$ & $\begin{array}{l}\text { Activated carbon, magnetic } \\
\text { separation, cryogenic }\end{array}$ & Released & Baker et al. (2007) \\
\hline
\end{tabular}




\begin{tabular}{|l|l|l|l|}
\hline Waste type & Capture method & Immobilization method & Reference \\
\hline \multirow{4}{*}{$\begin{array}{l}\text { Noble gases } \\
\text { (e.g., Kr, Xe) }\end{array}$} & Cryogenic distillation & $\begin{array}{l}\text { Storage as compressed } \\
\text { gas }\end{array}$ & Liu et al. (2014a) \\
\cline { 2 - 4 } & \begin{tabular}{l} 
actid sorbents (AgZ, HZ, \\
\cline { 2 - 4 }
\end{tabular} & $\begin{array}{l}\text { Storage as compressed } \\
\text { gas }\end{array}$ & Vienna et al. (2015a) \\
\cline { 2 - 4 } & Metal-organic frameworks & $\begin{array}{l}\text { Storage as compressed } \\
\text { gas }\end{array}$ & Liu et al. (2014a) \\
\cline { 2 - 4 } & Sulfide aerogel (chalcogel) & $\begin{array}{l}\text { Storage as compressed } \\
\text { gas }\end{array}$ & $\begin{array}{l}\text { Subrahmanyam et al. } \\
(2017)\end{array}$ \\
\hline
\end{tabular}

*Full salt composition from splashes, or condensation of volatile daughters

TNote that the isotopes generated from a fluoride salt are ${ }^{16} \mathrm{O},{ }^{17} \mathrm{O}$, and ${ }^{18} \mathrm{O}$ for oxygen and ${ }^{15} \mathrm{~N}$ for nitrogen, which are all stable; thus these could be released.

A commercial MSR will probably include a much larger helium cover gas system, including an active system for the removal of noble gases, particularly ${ }^{135} \mathrm{Xe}$, given its extremely high neutron poisoning effect. The production of mists, aerosols, and particles is also expected. Mechanical means such as screen and filters may be susceptible to the same plugging problems encountered at the MSRE. Routine maintenance and exchange of particle filters with the reactor in operation may be particularly problematic. A different approach includes the use of a gravitational wet scrubber, which can be particularly efficient for the removal of mists, aerosols, and particles (Kim et al., 2001). Scrubbers provide a very large surface area and display a very low pressure drop across the bed.

The MSRE off-gas system has been described in publications by Compere and colleagues (Compere et al., 1975; Thoma, 1971). In MSRE, 5.6 standard liters per minute (SLM) of helium was injected as a cover gas for both the fuel salt and cooling salt loops. Of the 3.3 SLM for the fuel salt, 2.4 SLM was introduced at the annulus of the rotating impeller shaft, 0.37 SLM at each of two bubbler tubes, and 0.15 SLM to a bubbler reference line. The off-gas system was dependent on using the pressurized helium ( 5 psig) to drive fission gases towards a train of metal filters and charcoal beds that were vented to the atmosphere. The main goal of the off-gas system was to capture fission gases. Details are given in the MSRE reports about the issues with the off-gas system, which was likely the least reliable component of the reactor system during operation. The off-gas system experienced multiple problems with plugging of several components including the metal filters, the lines, and upstream valves; additionally, there were several problems with controlling and maintaining the gas flow. In post-test analysis, MSRE staff determined that most of the problems were caused by carbonaceous deposits, generated by the pyrolysis of pump oil leaking into the fuel salt circuit. They did not discount the production of graphite particles eroded from the graphite moderator.

Details have been provided by Greenwood and colleagues (2018) for the MSDR, which was based on the design of the MSBR. The MSDR ties the off-gas system to three fuel pumps mounted symmetrically on top of the reactor vessel. The cover gas for the primary fuel and coolant salt is helium. Fission gases are purged from bypass lines that direct $10 \%$ of the pump flow from the outlet, through a bubble generator and stripper, back to the pump inlet. The stripper removes salt and helium at a 2:1 ratio and sends this mixture to the drain tank. Helium and fission gases separate from the salt, which is pumped back to the reactor. The drain tank holds the fission gases for about 6 hours, while being cooled by recirculating NaK coolant. The fission gases are then passed through particle traps that remove the condensed daughters of the noble gas fission products. The helium gas lines separate after the particle traps. One of the lines is split and returns to the three bubble generators, one on each of the pump bypass loops. The other line flows to one of two redundant charcoal beds, which provide a 90 day hold-up. The charcoal beds are cooled with $\mathrm{NaK}$ and air. The gas is then compressed and stored, until it is returned to the primary fuel salt. In this system, the consumables are the particle traps and the charcoal beds, which become contaminated with fission products; the He is recycled. 


\subsection{Particulates, Aerosols, and Reactive Gases}

Particulates and aerosols could be generated in several ways during reactor operation. The MSRE had evidence of corrosion from the graphite moderator. As the carbon was less dense than the salt, it floated and could become entrained in a purge gas passing over the salt. Pyrolysis of the carbon would also produce particulates and soot. The fuel salt itself could become airborne through splashing or volatilization. Reports documenting MSRE activities [i.e., Compere et al. (1975) and references within] suggest that less than $1 \%$ of the salt became airborne, but it was not quantified. Noble metals were also observed in small amounts. The main constituents of the salts aside from carbon included the decay daughters of $\mathrm{Kr}$ and $\mathrm{Xe}$ (i.e., I, $\mathrm{Cs}, \mathrm{Ce}, \mathrm{Ba}, \mathrm{Br}, \mathrm{Rb}, \mathrm{Sr}, \mathrm{Y}$ ) and $\mathrm{Br}$ and I from $\mathrm{Se}$ and $\mathrm{Te}$, respectively. As discussed earlier in the section, the off-gas was designed to remove and hold up $\mathrm{Kr}$ and $\mathrm{Xe}$.

As shown in Section 3.6, particulates, aerosols, and reactive gases could be captured using a molten hydroxide scrub [i.e., $T_{\mathrm{m}} \geq 318^{\circ} \mathrm{C}$ (melting temperature) for $\mathrm{NaOH}$ ]. Alternatively, these could be run through a submerged-bed aqueous hydroxide scrubber. Both systems will remove the particulates and aerosols while they neutralize the reactive halide gases into salts + water through the following equations (while the actual products of the dissolution will be determined by the phase diagrams of $\mathrm{NaF}-\mathrm{NaOH}$, $\mathrm{NaCl}-\mathrm{NaOH}$, and $\mathrm{NaI}-\mathrm{NaOH})$ :

Molten hydroxide scrubber:

$$
\begin{aligned}
\mathrm{HF}_{(\mathrm{g})}+\mathrm{NaOH}_{(\text {liq })} & \rightleftharpoons \mathrm{Na}_{(\text {soln })}^{+}+\mathrm{F}_{(\text {soln })}^{-}+\mathrm{H}_{2} \mathrm{O}_{(\mathrm{g})} \\
\mathrm{HCl}_{(\mathrm{g})}+\mathrm{NaOH}_{(\text {liq })} & \rightleftharpoons \mathrm{Na}_{(\text {soln })}^{+}+\mathrm{Cl}_{(\text {soln })}^{-}+\mathrm{H}_{2} \mathrm{O}_{(\mathrm{g})} \\
\mathrm{HI}_{(\mathrm{g})}+\mathrm{NaOH}_{(\text {liq })} & \rightleftharpoons \mathrm{Na}_{(\text {soln })}^{+}+\mathrm{I}_{(\text {soln })}^{-}+\mathrm{H}_{2} \mathrm{O}_{(\mathrm{g})}
\end{aligned}
$$

$\underline{\text { Submerged-bed aqueous scrubber: }}$

$$
\begin{aligned}
\mathrm{HF}_{(\mathrm{aq})}+\mathrm{NaOH}_{(\mathrm{aq})} & \rightleftharpoons \mathrm{Na}_{(\text {soln })}^{+}+\mathrm{F}_{(\text {soln })}^{-}+\mathrm{H}_{2} \mathrm{O}_{(\text {liq })} \\
\mathrm{HCl}_{(\mathrm{aq})}+\mathrm{NaOH}_{(\mathrm{aq})} & \rightleftharpoons \mathrm{Na}_{(\text {soln })}^{+}+\mathrm{Cl}_{(\text {soln })}^{-}+\mathrm{H}_{2} \mathrm{O}_{(\text {liq })} \\
\mathrm{HI}_{(\mathrm{aq})}+\mathrm{NaOH}_{(\mathrm{aq})} & \rightleftharpoons \mathrm{Na}_{(\text {soln })}^{+}+\mathrm{I}_{(\text {soln })}^{-}+\mathrm{H}_{2} \mathrm{O}_{(\text {(liq })}
\end{aligned}
$$

A drier would need to be applied to streams involving aqueous-based processes to maintain downstream performance.

\subsection{Tritium $\left({ }^{3} \mathrm{H}\right)$}

Tritium $\left({ }^{3} \mathrm{H}\right)$ can be present within an FHR or MSR in the form of acid (i.e., tritium fluoride; TF or ${ }^{3} \mathrm{HF}$ ) or gas (i.e., ${ }^{3} \mathrm{H}_{2(\mathrm{~g})}$ or ${ }^{3} \mathrm{HH}_{(\mathrm{g})}$, also HT). Tritium arises from the neutron activation of FLiBe salt through several pathways, as discussed below (Forsberg et al., 2017; Stempien et al., 2016) and it is mostly dissolved in the form of TF. However, headspace concentrations of $\mathrm{H}_{2} / \mathrm{HF}$ will build up until an equilibrium is reached. The ratio of ${ }^{3} \mathrm{HF}$ to $\mathrm{T}_{2}$ can vary based on the redox potential of the salt (Forsberg et al., 2017). (Note that additional discussion of tritium is provided in Section 5.)

$$
\begin{gathered}
{ }^{6} \mathrm{LiF}+n \rightarrow{ }_{2}^{4} \mathrm{He}+{ }_{1}^{3} \mathrm{HF} \\
{ }^{7} \mathrm{LiF}+n \rightarrow{ }_{2}^{4} \mathrm{He}+{ }_{1}^{3} \mathrm{HF}+n^{\prime} \\
{ }_{9}^{19} \mathrm{~F}+n \rightarrow{ }_{8}^{17} \mathrm{O}+{ }_{1}^{3} \mathrm{H}
\end{gathered}
$$

For fluoride-based MSRs, ${ }^{3} \mathrm{H}$ has been identified as giving the highest contribution to the source term during normal operation A $236 \mathrm{MWt}$ (megawatt thermal) FHR is expected to have a peak tritium release rate of $2410 \mathrm{Ci} / \mathrm{EFPD}$ (i.e., EFPD = effective full power day) (Stempien et al., 2015). This is roughly two to three orders of magnitude more than tritium production rates in other fission reactors. The source term can be reduced, but not eliminated, by the enrichment of natural Li to ${ }^{7} \mathrm{Li}$. Production rates vary 
with Li enrichment, salt properties, reactor flux, and salt inventory. In this report, tritium removal is considered in two sections, this one, focused on off-gas treatment, and Section 5 where tritium is associated with the graphite waste form.

Tritium is released throughout the primary circuit, but there is a high risk that ${ }^{3} \mathrm{H}_{2}$ will diffuse through hot metal parts of heat exchangers and escape out of the core. Thus, problems of tritium generation, migration, and capture require special attention. Therefore, ${ }^{3} \mathrm{H}$ must be removed from the salt and barrier materials to avoid surpassing allowable releases to the environment (Forsberg et al., 2017). Methods to selectively remove tritium from the primary circuit have been considered including capture on a carbon bed or a getter material, capture on a molecular sieve after conversion to $\mathrm{T}_{2} \mathrm{O}$, controlled removal by stripping with an inert gas, hydrogen back-diffusion from a secondary loop, use of a barrier material in critical locations (Harrison et al., 2016), or removal using a metallic permeator on a scaffold (e.g., Pd on $\mathrm{Al}_{2} \mathrm{O}_{3}$, Pd on Ta foil) (Peachey et al., 1996; Snelling, 1916). A great fraction of tritium can be removed by a sparging gas such as helium and captured outside the reactor on a carbon bed or in a solvent. This was the procedure used in the MRSE project and similar other systems are being now investigated. However, for the most part, the effectiveness of these methods in an FHR or MSR have not been demonstrated to a high level of confidence because of the difficulty in quantifying tritium release.

Hydrogen naturally permeates through barriers. Steward (1983) provided a summary of $\mathrm{H}_{2(\mathrm{~g})}{ }^{-}$ permeabilities $(\phi)$ through a variety of metals according to the literature and these are summarized in Figure 3-1 and Table 3-2. They were calculated using Equation (3-10) where $\phi_{0}$ is the pre-exponential factor, $E_{\phi}$ is the activation energy for the permeability $\left(E_{\phi}=E_{\mathrm{D}}+E_{\mathrm{S}}\right.$; subscripts "D" and "S" denote diffusion and solubility, respectively), $R$ is the gas constant, and $T$ is temperature. For comparison purposes, the $E_{\phi}$ values for each system provided in Table 3-2 are shown after calculations with $R$ in the appropriate units as $E_{\phi} / R$.

$$
\phi=\phi_{0} \exp \left(-E_{\phi} / R T\right)
$$

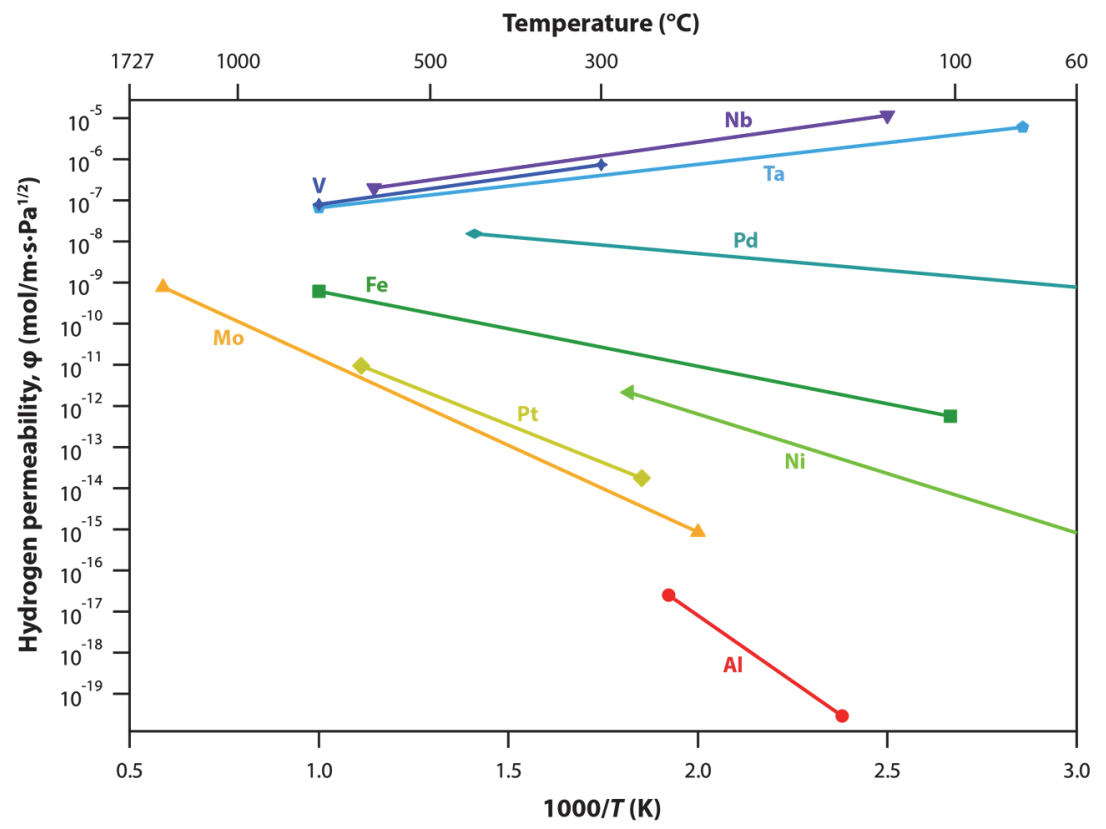

Figure 3-1. Compilation of $\mathrm{H}_{2}(\mathrm{~g})$ permeability through different metals. These data were compiled by Steward (1983). Refer to Table 3-2 for specific data and temperature ranges recommended by the authors for data validity. 
Table 3-2. List of Arrhenius fitting parameters and recommended temperature ranges for $\mathrm{H}_{2}(\mathrm{~g})$ permeabilities through different metals using Equation (3-10).

\begin{tabular}{|l|c|c|c|c|l|}
\hline \multirow{2}{*}{ Metal } & $\boldsymbol{E}_{\boldsymbol{\phi}} / \boldsymbol{R}$ & $\boldsymbol{\phi}_{\mathbf{0}}$ & \multicolumn{2}{|c|}{ Temperatures } & \multirow{2}{*}{ Reference } \\
\cline { 2 - 5 } & $\mathbf{( K )}$ & $\mathbf{( \mathbf { m o l } / \mathbf { m } \cdot \mathbf { s } \cdot \mathbf { P a } ^ { \mathbf { 0 . 5 } } \mathbf { ) }}$ & $\mathbf{( K )}$ & $\left.\boldsymbol{(}^{\circ} \mathbf{C}\right)$ & \\
\hline $\mathrm{Nb}$ & -3010 & $6.30 \mathrm{E}-09$ & $400-873$ & $127-600$ & Völkl and Alefeld (1975) \\
\hline $\mathrm{Pd}$ & 1885 & $2.20 \mathrm{E}-07$ & $300-709$ & $27-436$ & Koffler et al. (1969) \\
\hline $\mathrm{Ta}$ & -2430 & $5.80 \mathrm{E}-09$ & $>350$ & $>77$ & Völkl and Alefeld (1975) \\
\hline $\mathrm{V}$ & -2990 & $4.00 \mathrm{E}-09$ & $>573$ & $>300$ & Veleckis and Edwards (1969) \\
\hline $\mathrm{Fe}$ & 4200 & $4.10 \mathrm{E}-08$ & $>375$ & $>102$ & Gonzalez (1967) \\
\hline $\mathrm{Mo}$ & 9710 & $2.33 \mathrm{E}-07$ & $500-1700$ & $227-1427$ & Chandler and Walter (1968) \\
\hline $\mathrm{Pt}$ & 8500 & $1.20 \mathrm{E}-07$ & $540-900$ & $267-627$ & Ebisuzaki et al. (1968) \\
\hline $\mathrm{Ni}$ & 6660 & $3.90 \mathrm{E}-07$ & $300-550$ & $27-277$ & Louthan et al. (1975) \\
\hline $\mathrm{Al}$ & 14800 & $5.80 \mathrm{E}-05$ & $420-520$ & $147-247$ & Ihle et al. (1976) \\
\hline
\end{tabular}

The values above can be compared with the permeability of tritium through other materials, including the salt itself. Additional permeabilities are presented in Table 3-3 according to Christensen et al. (2016).

Table 3-3. Permeability of tritium through selected materials Christensen et al. (2016).

\begin{tabular}{|c|c|c|c|c|}
\hline Material & $\begin{array}{c}\text { Solubility } \\
\left(\mathrm{mol} / \mathrm{m}^{3}-\mathrm{Pa}\right. \\
\left.\text { or } \mathrm{mol} / \mathrm{m}^{3}-\mathrm{Pa}^{0.5}\right)\end{array}$ & $\begin{array}{c}\text { Diffusivity } \\
\left(\mathrm{m}^{2} / \mathrm{s}\right)\end{array}$ & $\begin{array}{c}\text { Permeability } \\
(\mathrm{mol} / \mathrm{m}-\mathrm{s}-\mathrm{Pa} \\
\left.\text { or } \mathrm{mol} / \mathrm{m}-\mathrm{s}-\mathbf{P a}^{0.5}\right)\end{array}$ & Reference \\
\hline FLiNaK & $5.66 \mathrm{E}-09$ & $8.64 \mathrm{E}-10$ & $4.89 \mathrm{E}-18$ & Fukada (2007) \\
\hline FLiBe & $1.04 \mathrm{E}-03$ & $5.177 \mathrm{E}-09$ & $5.38 \mathrm{E}-12$ & Simpson et al. (2006) \\
\hline $\mathrm{Pd}$ & $5.30 \mathrm{E}-02$ & $1.75 \mathrm{E}-08$ & $9.27 \mathrm{E}-10$ & \multirow{3}{*}{ Calderoni et al. (2008) } \\
\hline $\mathrm{Ni}$ & $2.47 \mathrm{E}-01$ & $3.76 \mathrm{E}-09$ & $9.3 \mathrm{E}-10$ & \\
\hline Stainless steel & $9.82 \mathrm{E}-02$ & $1.66 \mathrm{E}-09$ & $4.14 \mathrm{E}-12$ & \\
\hline Graphite & $4.56 \mathrm{E}-04$ & $3.3 \mathrm{E}-10$ & $1.5 \mathrm{E}-13$ & Atsumi (2002) \\
\hline Air & - & $6.10 \mathrm{E}-05$ & - & Fukada and Morisaki (2006) \\
\hline
\end{tabular}

It has also been proposed that tritium be captured and removed using carbon components (graphite in moderator or reflector, fuel matrix carbon in pebbles, and even packed beds of carbon) in the core or outside the core. As can be seen from Table 3-3, the permeability of tritium through graphite is quite low. However, both nuclear graphite and fuel matrix carbon have dramatically lower adsorption capacities for hydrogen isotopes at the temperature (i.e., $700^{\circ} \mathrm{C}$ ) and pressure (i.e., $1 \mathrm{~Pa}$ ) of tritium under FHR conditions. The capture of tritium in graphite is discussed in some detail in Section 5, in consideration of graphitic waste forms.

Another approach that has been considered to mitigate ${ }^{3} \mathrm{H}_{2(\mathrm{~g})}$ release is to maintain a partial pressure of ${ }^{1} \mathrm{H}_{2(\mathrm{~g})}$ in the cover gas to reduce ${ }^{3} \mathrm{H}$ transport rates as well as shift the redox potential of the salt to help limit corrosion in the system (Forsberg et al., 2017; Stempien et al., 2016). Options for collecting water in the off-gas system include anhydrous desiccants such as silica gel or calcium sulfate.

\subsection{Residual Halides}

Residual halides will include those derived from contaminants in the salt (e.g., $\mathrm{Br}_{2}$ ), fission products (e.g., $\mathrm{I}_{2}$ ), and products of salt breakdown (e.g., $\mathrm{Cl}_{2}$ or $\mathrm{F}_{2}$ ). Several sorbents have been identified in the literature that show promise for capturing residual halides. An overview of sorbents and other methods for the capture and/or immobilization of iodine are presented in a previous review by Riley et al. (2016). Many 
of the sorbents identified in that study could be used for capturing chlorine and some could be relevant for fluorine as well.

Several metal-impregnated/functionalized sorbents have been investigated for halide capture. One of the most frequently studied types of solid sorbents for halides is the zeolite family of minerals. These include $\mathrm{Pb}^{0}$ faujasite (i.e., $\mathrm{PbX}$ ) (Thomas et al., 1978), $\mathrm{Ag}^{0}$ faujasite (i.e., $\mathrm{AgX}$ ) (Wilhelm and Puppe, 1989), and $\mathrm{Ag}^{0}$ mordenite (i.e., $\mathrm{AgZ}$ ) (Jubin, 1981). Other metal-impregnated sorbents include $\mathrm{Ag}^{0}$-functionalized silica aerogels (Matyáš et al., 2011), $\mathrm{Ag}^{0}$-functionalized aluminosilicate aerogels (Riley et al., 2017b), $\mathrm{Ag}^{+}$-impregnated aluminosilicate aerogels (Riley et al., 2017b), $\mathrm{AgNO}_{3}$-impregnated silica (Mineo et al., 2003; Mineo et al., 2002), and $\mathrm{AgNO}_{3}$-impregnated alumina (Tanabe et al., 2010).

Sorbents without metal getter additives include sulfide-based aerogels (chalcogels) (Riley et al., 2011; Riley et al., 2013b; Riley et al., 2014), graphene aerogels (Scott et al., 2015), graphene powders (Scott et al., 2015), granular activated carbon (Jubin, 1988), and metal-organic frameworks (MOFs) (Sava et al., 2013; Sava et al., 2012; Sava et al., 2011).

In addition to these options, an aqueous-based caustic scrub or a nonaqueous molten hydroxide scrub could be used to pull these species out of a gas stream. Upon contact with the hydroxide, they would undergo neutralization with the $\mathrm{OH}^{-}$.

\subsection{Nitrogen and Oxygen}

Oxygen and nitrogen may be present as contaminants in the salts or in the He purge and they can be produced by activation of the salts during burn-up. In the MSRE, oxygen was removed from injected He to below $1 \mathrm{ppm}$. Neutron irradiation of the fuel salt in the MSRE was estimated to produce $10 \mathrm{~cm}^{3}$ per day at $10 \mathrm{MW}$, resulting in $2 \mathrm{ppm}$ of $\mathrm{O}_{2}$ in the He purge.

Nitrogen ingress into structural materials can change the properties of the material. Oxygen can change the redox chemistry in the salt. It has been estimated that $1 \mathrm{ppm}$ of $\mathrm{O}_{2}$ in the He purge stream would precipitate $5.5 \mathrm{~g}$ of $\mathrm{ZrO}_{2}$ per year in the fuel salt (equivalent to $18 \mathrm{~g}$ of $\mathrm{U}$ per year) (Robertson, 1965). Thus, ongoing removal of oxygen is necessary to keep concentrations at $<1 \mathrm{ppm}$. In the MSRE, the He purge into the reactor was dried by passing it through a molecular sieve and oxygen was removed with a heated titanium sponge, with the goal of reducing oxygen in either form to $\leq 1 \mathrm{ppm}$.

\subsection{Noble Gases}

Krypton and Xe will be present as a multitude of radionuclides with half-lives ranging from seconds (e.g. ${ }^{139} \mathrm{Xe} t_{1 / 2}=39.5 \mathrm{~s},{ }^{90} \mathrm{Kr} t_{1 / 2}=32.3 \mathrm{~s}$ ), to minutes (e.g. ${ }^{137} \mathrm{Xe} t_{1 / 2}=3.83 \mathrm{~min},{ }^{135 \mathrm{~m}} \mathrm{Xe} t_{1 / 2}=15.3 \mathrm{~min},{ }^{89} \mathrm{Kr} t_{1 / 2}=3.18$ $\mathrm{min}$ ), hours (e.g. ${ }^{135} \mathrm{Xe} t_{1 / 2}=9.1 \mathrm{~h},{ }^{88} \mathrm{Kr} t_{1 / 2}=2.84 \mathrm{~h}$ ), or days (e.g. $\left.{ }^{133 \mathrm{~m}} \mathrm{Xe} t_{1 / 2}=2.19 \mathrm{~d},{ }^{133} \mathrm{Xe} t_{1 / 2}=5.25 \mathrm{~d}\right)$. Noble gas removal methods in historic MSRs are presented earlier in the section. The introduction of helium was thought to remove about a quarter or a third of the inventory, with the remainder decaying in situ in the salt or penetrating the graphite moderator. However, there has been a broad study of the removal of noble gases relevant to reactor safety and fuel storage. Cryogenic distillation is a commercially available technique used to capture rare gases (e.g., noble gases) at cryogenic temperatures using liquid nitrogen as the typical medium (Baetsle and Broothaerts, 1977; Chesne et al., 1977; Henrich and von Ammon, 1985; Laser et al., 1973; Yarbro et al., 1977). Some issues arise with this technology when gases that condense at or above liquid nitrogen temperatures $(77 \mathrm{~K})$ must be removed from the stream before capture to prevent build-up within the equipment. Condensed gases can also produce reactive gases through radiolysis (e.g., $\mathrm{O}_{3}$ production from $\mathrm{O}_{2}$ and ${ }^{85} \mathrm{Kr}$ ). Once these other species are removed, $\mathrm{Kr}$ and $\mathrm{Xe}$ can be removed from the stream in a stripping column as they are dissolved in liquid nitrogen, and then they can be separated in purification columns. Pressure swing adsorption is also a commercially available method for gas separations.

Zeolites have been demonstrated as viable options for recovering noble gases from dissolver off-gas streams. For instance, work by Trevorrow et al. (1983) showed that silver mordenite (AgZ) could be used 
at ambient temperatures to recover Xe. The resulting stream was then chilled and run through a hydrogen mordenite (HZ) column at approximately $80^{\circ} \mathrm{C}$ where the $\mathrm{Kr}$ was then removed. The $\mathrm{Kr}$ was then recovered and concentrated on a separate $\mathrm{HZ}$ column at approximately $60^{\circ} \mathrm{C}$, and then removed to a cold trap. The $\mathrm{Kr}$ was then removed to a cold trap. The Xe bed could be regenerated at heat-treatments of $200-250^{\circ} \mathrm{C}$.

Activated carbon (or charcoal) has been used for capturing noble gases from process off-gases with success. For instance, $\mathrm{Kr}$ was captured using adsorptive chromatographic separation at Julich in Germany (Ringel, 1990). For these demonstrations, $\mathrm{Kr}$ purities were $>99 \%$ in the final collected product. In a separate study by Bazan et al. (2011), activated carbon (SorboNorit B3; Norit, The Netherlands) and two zeolites (Koestrolith 13X-K2 and Koestrolith 4AK; CWK Chemiewerk Bad Köstritz GmbH, Germany) were evaluated in parallel for efficiency as sorbents for $\mathrm{O}_{2}, \mathrm{Ar}, \mathrm{Kr}$, and $\mathrm{Xe}$. The results showed that all sorbents had the same order of capacities for the gases evaluated: $\mathrm{Xe}>\mathrm{Kr}>\mathrm{O}_{2}>$ Ar. The activated carbon showed higher $\mathrm{Kr}$ capacities at pressures up to approximately $12 \mathrm{bar}$ and, at higher pressures, the $13 \mathrm{X}-\mathrm{K} 2$ zeolite showed higher $\mathrm{Kr}$ capacities. Also, the 13X-K2 zeolite was also the most effective Xe sorbent evaluated. An activated charcoal delay bed system similar to the ones presently used at commercial boiling water reactor power stations can be used to delay the movement of short lived species so that they will decay and be trapped. The ${ }^{85} \mathrm{Kr}$ and stable species of $\mathrm{Xe}, \mathrm{Kr}, \mathrm{Ar}$, and $\mathrm{H}_{2} \mathrm{O}\left({ }^{3} \mathrm{H}_{2} \mathrm{O}\right)$ will eventually emerge from these delay-beds along with the He carrier.

MOFs are compounds structured by organic ligands bound by metal ions or clusters into multidimensional networks. The compositional flexibility of these compounds grows every year as researchers push the boundaries of MOF chemistries using modeling efforts and various design approaches (Lu et al., 2014; Nouar et al., 2008; Wang et al., 2013). Some more recent work by Thallapally et al. has shown that MOFs can be used for selective capture of Xe and $\operatorname{Kr}$ (Banerjee et al., 2016) (see Figure 3-2).

Additionally, a two-column experiment run with two separate MOFs, each optimized for Xe or $\mathrm{Kr}$, was used to demonstrate even higher noble gas removal efficiencies from a simulated process off-gas stream from a reprocessing facility (Liu et al., 2014b). These materials show great promise for $\mathrm{Xe} / \mathrm{Kr}$ capture; however, MOFs are expensive to synthesize on industrial scales.
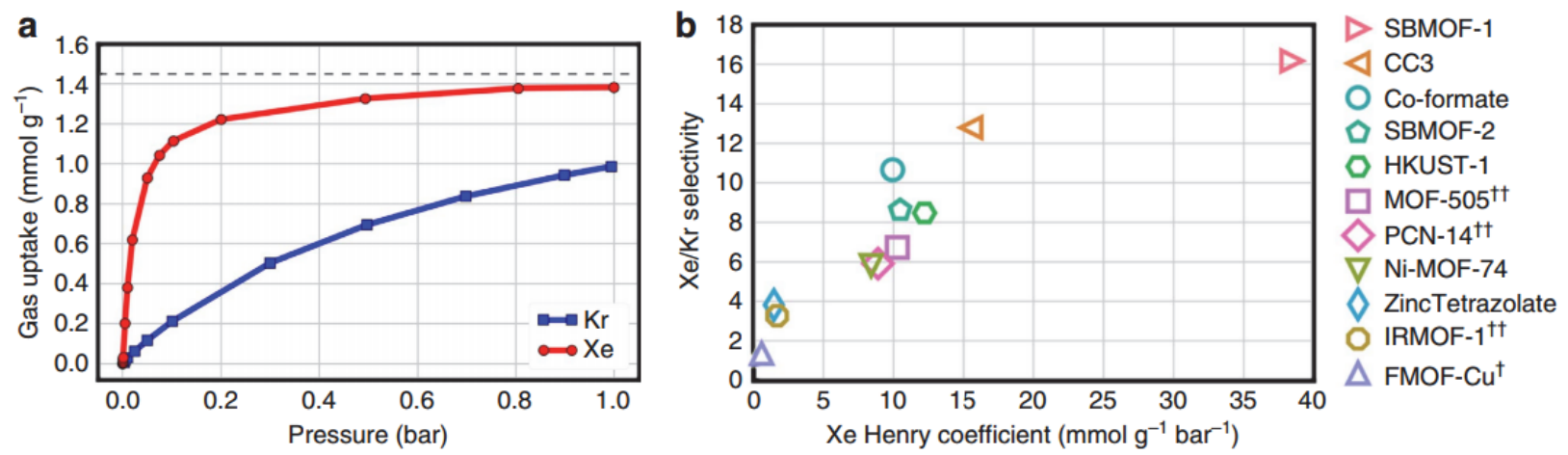

Figure 3-2. Summary of Xe and Kr adsorption with SBMOF-1, a metal-organic framework (Banerjee et al., 2016). (a) Xe and Kr adsorption isotherms. (b) Xe/Kr separation performance in top-performing MOF adsorbents ( ${ }^{\dagger}$ denotes $297 \mathrm{~K}$ and ${ }^{\star}$ denotes $292 \mathrm{~K}$ for data collection temperatures).

In more recent studies by Farrusseng et al. (Daniel et al., 2013; Deliere et al., 2016), Ag-loaded zeolites were evaluated for $\mathrm{Xe}$ and $\mathrm{Kr}$ capture and show promise. One of the most promising of these candidate materials was Ag-loaded ZSM-5 (Ag@ZSM-5; Na-ZSM-5 exchanged with $\mathrm{Ag}^{+}$using a $\mathrm{AgNO}_{3}$ process followed by reduction to $\mathrm{Ag}^{0}$ ) that showed $\mathrm{Xe}$ and $\mathrm{Kr}$ capacities of $35 \pm 3 \times 10^{-5}$ and $<50 \times 10^{-8} \mathrm{~mol} \mathrm{~g}^{-1}$, respectively, and a $\mathrm{Xe} / \mathrm{Kr}$ selectivity of $>100$ (Deliere et al., 2016). The paper by Deliere et al. (2016) compares the Xe/Kr selectivities of Ag@ZSM-5 (Deliere et al., 2016) with those of several MOFs [i.e., Pd-MOF (Ryan et al., 2011), $\mathrm{CO}_{3}$ (HCOO) 6 (Wang et al., 2014), Ag@NiMOF-74 (Krishna, 2017), MOF- 
505 (Ryan et al., 2011), HKUST-1 (Betzendahl, 2014; Ryan et al., 2011), and Ni/DOBDC (Betzendahl, 2014)] with activated carbon (Betzendahl, 2014) and showed that the Ag@ZSM-5 was far superior in this regard (see Figure 3-3).

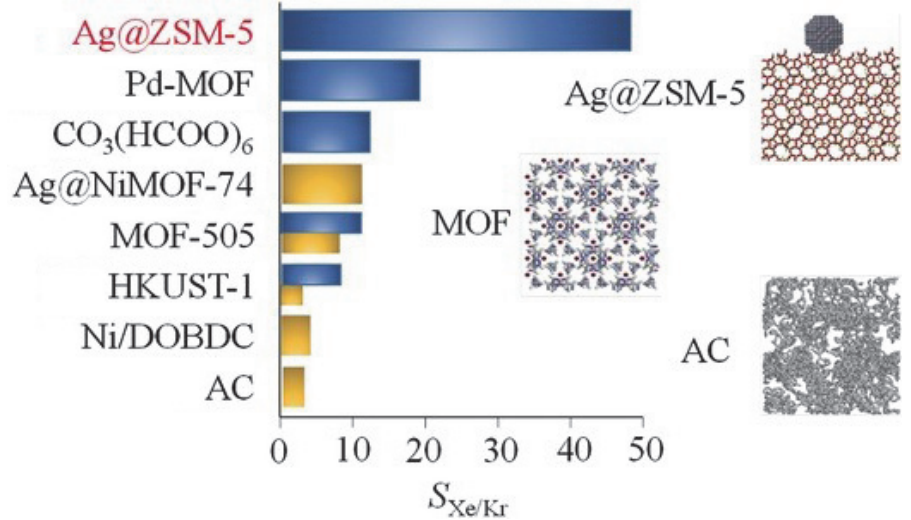

Figure 3-3. $\mathrm{Xe} / \mathrm{Kr}$ selectivity for a variety of sorbents evaluated for a $\mathrm{Xe} / \mathrm{Kr}(20 / 80 \mathrm{mixture}$, by volume) at 1 bar and $T=273-303 \mathrm{~K}$. Data in blue and yellow represent measured (i.e., breakthrough) and calculated (i.e., IAST) data, respectively. The plot was modified from Deliere et al. (2016).

A relatively new class of $\mathrm{Xe} / \mathrm{Kr}$ sorbents includes sulfide-based aerogels, also referred to as chalcogels. Subrahmanyam et al. (2017) evaluated the Xe/Kr selectivity of $\left(\mathrm{NH}_{4}\right)_{0.03} \mathrm{MoS}_{4}$ (i.e., $\left.\mathrm{MoS}_{x}\right), \mathrm{Na}_{0.3} \mathrm{Sb}_{2} \mathrm{~S}_{3}$ (SbS-I), $\mathrm{K}_{0.15} \mathrm{Na}_{0.3} \mathrm{Sb}_{2} \mathrm{~S}_{2.5}$ (SbS-II), and $\mathrm{Na}_{0.1} \mathrm{Sb}_{2} \mathrm{~S}_{3}$ (SbS-III) chalcogels and found 0.69, 0.42, 0.37, and $0.29 \mathrm{mmol} \mathrm{g}^{-1}$ of Xe uptake, respectively, and $0.28,0.18,0.18$, and $0.16 \mathrm{mmol} \mathrm{g}^{-1}$ of $\mathrm{Kr}$ uptake, respectively. The $\mathrm{Xe} / \mathrm{Kr}$ selectivity was much higher for the $\mathrm{MoS}_{x}$ chalcogels than for all of the SbS chalcogels (see Figure 3-4).

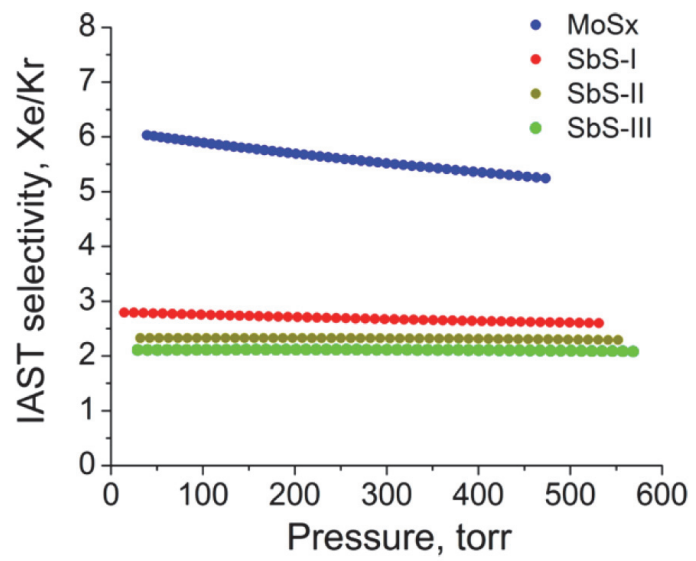

Figure 3-4. Ideal Adsorbed Solution Theory (IAST) Xe/Kr selectivity of MoS $x$, SbS-I, SbS-II, and SbS-III chalcogels at $273 \mathrm{~K}$ calculated from pure adsorption isotherms. This plot was taken from Subrahmanyam et al. (2017).

Management of ${ }^{85} \mathrm{Kr}$, which in its captured form would be a compressed gas that decays to a corrosive metal $(\mathrm{Rb})$, is challenging. Immobilization of $\mathrm{Kr}$ may be needed to meet storage safety requirements. The disposal form durability is not important compared with the risk of storing it as compressed gas, adding another waste form to be produced. $\mathrm{Kr}$ solidification has been demonstrated in the form of zeolite type 5A, Cu metal, and SiC (Bruffey and Jubin, 2017; Jubin and Bruffey, 2016). These processes tend to be expensive, but they represent low technical risk. 


\subsection{Caustic Scrubbing}

For cleaning the salt, it would be highly desirable to combine the filtering action of a gravitational scrubber with a chemical scrubber that will remove most of the volatile species and corrosive or reactive gases. A mixture of molten alkaline hydroxides can do just that displaying the typical characteristics of standard alkaline wet scrubbers but with a higher scrubbing capacity. $\mathrm{NaOH}, \mathrm{KOH}$, and $\mathrm{LiOH}$ mixtures have relatively low melting points (e.g., $\mathrm{Na} / \mathrm{K} / \mathrm{Li} 2 / 2 / 1$ melts at $147-150^{\circ} \mathrm{C}$ ) (Hues et al., 1984). The boiling point based on the individual components should be around $1300^{\circ} \mathrm{C}$. The benefit of having a molten $\mathrm{NaOH}$ scrubbing solution is that it will capture particulates and aerosols as well as neutralize reactive and potentially corrosive (acidic) gases (e.g., $\mathrm{HF}, \mathrm{HCl}, \mathrm{HI}, \mathrm{F}_{2}, \mathrm{Cl}_{2}$, and $\mathrm{I}_{2}$ ) that could be present within the system. The molten hydroxide scrubber would be an inexpensive option to pre-scrub all of these constituents.

The viscosities and densities of pure molten $\mathrm{NaOH}, \mathrm{KOH}$, and $\mathrm{NaOH}-\mathrm{KOH}$ mixtures are very low and similar to those of aqueous solutions $\left(\eta<2.5 \mathrm{cP}\right.$ and density, $\rho<1.8 \mathrm{~g} / \mathrm{cm}^{3}$ at temperatures near the melting point and decrease with temperature) (Janz, 1988).

Nickel 201, a readily available commercial alloy consisting of $99 \%$ nickel with low carbon content, is reported to be fully compatible for use in molten $\mathrm{NaOH}$ at $T \leq 560^{\circ} \mathrm{C}$. The expected operating range for a molten hydroxide trapping system is expected to be well below that temperature limit (e.g., $150-300^{\circ} \mathrm{C}$ ) (Craig and Anderson, 1997).

The combined gravitational/alkaline scrubbing system should remove mist, aerosol, particles, and reactive species including long-lived ${ }^{36} \mathrm{Cl}\left(t_{1 / 2}=3 \times 10^{5} \mathrm{y}\right),{ }^{79} \mathrm{Se}\left(t_{1 / 2}=6.5 \times 10^{4} \mathrm{y}\right)$, and ${ }^{129} \mathrm{I}\left(t_{1 / 2}=1.6 \times 10^{7} \mathrm{y}\right)$. Any tritium present as $\mathrm{HF}$ in molten fluoride reactors (Compere et al., 1975), and probably as ${ }^{3} \mathrm{HCl}$ in chloride systems, will be transformed into $\mathrm{H}_{2} \mathrm{O}$ by the hydroxide scrubber ${ }^{\mathrm{a}}$ and released into the flowing $\mathrm{He}$ along with unreactive gaseous species such as $\mathrm{N}_{2}, \mathrm{O}_{2}, \mathrm{Ar}, \mathrm{Kr}$, and $\mathrm{Xe}$. The removal of these species will require additional systems. The schematic provided in Figure 3-5 shows a combined system that will treat and remove all of the contaminants from the He cover, allowing for its recycle back to the reactor vessel.

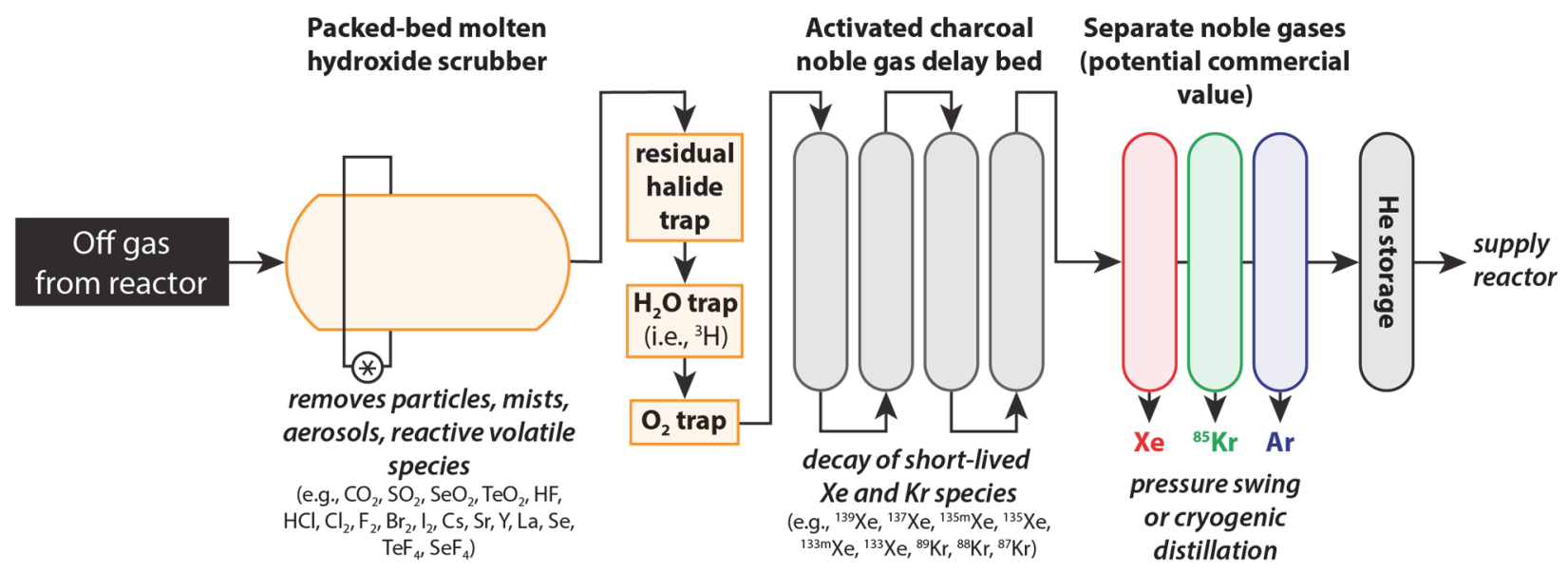

Figure 3-5. Schematic of the overall off-gas system for a commercial MSR based on the MSRE experience. All of the components shown, except the molten hydroxide packed-bed scrubber, are commercially available.

${ }^{\text {a Some }}{ }^{3} \mathrm{H}$ will remain in the hydroxide as ${ }^{3} \mathrm{HO}^{-}$. 
The components of the system proposed in Figure 3-5 are as follows:

1) Hydroxide scrubber. Upfront is the molten hydroxide scrubber envisioned as a slow flowing waterfall of a molten hydroxide mixture with low $T_{\mathrm{m}}$ over a stationary high-surface-area substrate (e.g., a packed bed of nickel spheres). It should be able to remove particles and salt residue from the gas stream acting as a "non-pluggable" filter. At the same time it should dissolve and trap alkaline species (e.g., Cs, Ba, Rb, Sr, La), noble metals (e.g., Ru, Tc, Se, Te), halogens (i.e., $\mathrm{F}_{2}$, $\mathrm{Cl}_{2}, \mathrm{Br}_{2}, \mathrm{I}_{2}$ ), and acidic species (e.g., $\mathrm{CO}_{2}, \mathrm{SO}_{2}, \mathrm{SeO}_{2}, \mathrm{TeO}_{2}, \mathrm{HF}, \mathrm{HCl}$ ). Some water may be partially retained as molten hydrates but eventually will escape from the hydroxide scrubber. Permanent gases such $\mathrm{O}_{2}, \mathrm{Ar}, \mathrm{He}, \mathrm{Kr}$, and $\mathrm{Xe}$ will bypass the trap.

2) Trap for long-lived halides. Highly efficient removal of key long-lived isotopes such as ${ }^{36} \mathrm{Cl}$ and ${ }^{129}$ I may require a secondary trap made of $\mathrm{AgZ}$ or silver-impregnated aerogels.

3) Tritium trapping. Tritium is expected to be released from the hydroxide scrubber as water that can be trapped using molecular sieves or other suitable material(s), and the remaining ${ }^{3} \mathrm{H}$ will stay in the hydroxide solution as ${ }^{3} \mathrm{HO}^{-}$.

4) $\boldsymbol{O}_{2}$ Trap. Oxygen gas (i.e., $\mathrm{O}_{2}$ ), which should be present at ppm levels, may be removed using a titanium sponge, as was done for the MSRE off-gas, or other suitable material.

5) Noble gases. The short-lived isotopes of $\mathrm{Kr}$ and $\mathrm{Xe}$ can be allowed to decay using commercially available activated charcoal delay bed systems similar to the ones used in commercial nuclear power plants; ${ }^{85} \mathrm{Kr}$ and stable species of $\mathrm{Xe}, \mathrm{Kr}$, and Ar will eventually emerge from these delaybeds along with the He carrier (NUCON Technical Bulletin 11B10, 2012; Stockinger, 2012). The ${ }^{85} \mathrm{Kr}$, Xe, and Ar can be separated from the helium carrier using standard industrial techniques (e.g., pressure swing adsorption, cryogenic distillation) (IAEA, 1980). Depending on the applicable regulations, ${ }^{85} \mathrm{Kr}$ may be releasable or it may need to be contained for long-term decay-storage. A concentrated stream of ${ }^{85} \mathrm{Kr}$ and the Xe may have commercial application; otherwise, they can be released to the ambient air (NRC, 2012).

6) Recycle. The purified helium stream can be reinjected into the reactor system.

A drier would need to be applied to remove any water vapor from these processes (e.g., aqueous-based processes, reactants potentially containing water) to maintain the downstream performance of the salt product for recycling.

\subsection{Volatile Uranium and Transuranics}

This section serves as a brief review of the chemistry of volatile fluorides and chlorides. Application of volatility in production of stable waste forms is discussed further in Section 4.4.

\subsubsection{Volatile Fluorides}

Table 3-4 shows a list of the volatile actinide and fission product fluorides, their boiling points $\left(T_{\mathrm{b}}\right)$, and a typical concentration (mass\%) in LWR used nuclear fuel (UNF), to provide a prospective. The concentrations expected for MSRs will depend on the particular fuel cycle involved. Of the actinides, $U$, $\mathrm{Np}$, and $\mathrm{Pu}$ can form volatile hexafluorides. While $\mathrm{UF}_{6}$ and $\mathrm{NpF}_{6}$ are stable, $\mathrm{PuF}_{6}$ is thermally and radiolytically unstable. Thorium and the transuranics form nonvolatile fluorides (e.g., $\mathrm{ThF}_{4}, \mathrm{PuF}_{4}, \mathrm{AmF}_{3}$, $\mathrm{AmF}_{4}, \mathrm{CmF}_{3}$ ). Of the fission products, the rare earths, alkalis, and alkaline earths (e.g., Cs, Sr) all form nonvolatile fluorides. The so-called noble-metal fission products (i.e., Mo, Tc, Ru, Rh) and some of the other fission products (i.e., $\mathrm{Sb}, \mathrm{I}, \mathrm{Br}, \mathrm{Cl}, \mathrm{S}, \mathrm{Nb}, \mathrm{Se}$, and $\mathrm{Te}$ ) form volatile fluorides and oxyfluorides, along with $\mathrm{Kr}$ and $\mathrm{Xe}$, which are permanent gases. Relevant to structural materials is the fact that chromium forms two volatile oxyfluorides, $\mathrm{CrO}_{2} \mathrm{~F}_{2}$ and $\mathrm{CrOF}_{4}$ (Johnson, 1981). The former compound, chromyl fluoride, is fairly stable and well known, unlike chromium oxide tetrafluoride. Other fluorides 
include: $\mathrm{FeF}_{3}$, which becomes volatile at $T>450^{\circ} \mathrm{C}, \mathrm{ZrF}_{4}$ at $T>600^{\circ} \mathrm{C}$, and $\mathrm{CrF}_{3}$ at $T>650^{\circ} \mathrm{C}$ ( $\mathrm{HSC}$ Chemistry).

Table 3-4. Summary of volatile fluorides that can be found in LWR used nuclear fuel (UNF), along with boiling temperature $\left(T_{b}\right)$ and the typical amount found in LWR UNF. (In the references, HSC Chemistry refers to the chemistry software package.)

\begin{tabular}{|c|c|c|c|}
\hline $\begin{array}{l}\text { Volatile } \\
\text { fluorides }\end{array}$ & $T_{\mathrm{b}}\left({ }^{\circ} \mathrm{C}\right)$ & $\begin{array}{l}\text { Typical elemental amount } \\
\text { in LWR UNF (mass\%) }\end{array}$ & Reference(s) \\
\hline $\mathrm{UF}_{6}$ & 56.5 & 94.7 & HSC Chemistry \\
\hline $\mathrm{NpF}_{6}$ & 76.8 & 0.06 & HSC Chemistry \\
\hline $\mathrm{PuF}_{6}$ & 61.8 & 0.94 & HSC Chemistry \\
\hline $\mathrm{Xe}$ & -108.4 & 0.68 & HSC Chemistry \\
\hline $\mathrm{MoF}_{6}$ & 33.8 & \multirow[b]{2}{*}{0.40} & HSC Chemistry \\
\hline $\mathrm{MoOF}_{4}$ & 185.8 & & $\begin{array}{l}\text { HSC Chemistry, Ngai and Stafford } \\
\text { (1971) }\end{array}$ \\
\hline $\mathrm{RuF}_{6}$ & $\begin{array}{l}100.0 \\
\text { (unstable) }\end{array}$ & \multirow{3}{*}{0.28} & Rak and Lisý (1979) \\
\hline $\mathrm{RuF}_{5}$ & 226.8 & & HSC Chemistry, Rak and Lisý (1979) \\
\hline $\mathrm{RuOF}_{4}$ & 186 & & HSC, Ngai and Stafford (1971) \\
\hline $\mathrm{TcF}_{6}$ & 55.3 & \multirow{3}{*}{0.09} & \multirow{3}{*}{ Simmons (1996) } \\
\hline $\mathrm{TcO}_{3} \mathrm{~F}$ & 100 & & \\
\hline $\mathrm{TcOF}_{4}$ & 165 & & \\
\hline $\mathrm{RhF}_{6}$ & 73.5 & 0.06 & Chernick et al. (1961) \\
\hline $\mathrm{TeF}_{6}$ & -46.5 & 0.06 & HSC Chemistry \\
\hline $\mathrm{Kr}$ & -153.2 & 0.04 & HSC Chemistry \\
\hline $\mathrm{IF}_{7}$ & 4.8 & \multirow{2}{*}{0.03} & \multirow{2}{*}{ HSC Chemistry } \\
\hline $\mathrm{IF}_{5}$ & 100.5 & & \\
\hline $\mathrm{SeF}_{6}$ & -46.5 & 0.006 & HSC Chemistry \\
\hline $\mathrm{BrF}_{5}$ & 40.8 & \multirow{2}{*}{0.002} & \multirow{2}{*}{ HSC Chemistry } \\
\hline $\mathrm{BrF}_{3}$ & 125.8 & & \\
\hline $\mathrm{SbF}_{5}$ & 143 & 0.001 & HSC Chemistry \\
\hline
\end{tabular}

\subsubsection{Fluorinating Agents}

The process of fluorination requires moderate to high temperatures. Low-temperature fluorination (e.g., $300-350^{\circ} \mathrm{C}$ ) can produce $\mathrm{UF}_{6}$ with very little $\mathrm{PuF}_{6}$; increasing the temperature above $600^{\circ} \mathrm{C}$ highly increases the yield of $\mathrm{PuF}_{6}$ (Schmets, 1967; Shatalov et al.Shatalov2001, 2001). Several fluorinating agents can be used for fluoride volatility processes. The most common are $\mathrm{F}_{2}$, interhalogens (e.g., $\mathrm{ClF}_{3}$, $\mathrm{BrF}_{3}, \mathrm{BrF}_{5}, \mathrm{ClF}$ ), and $\mathrm{NF}_{3}$. For reference, $\mathrm{F}_{2}$ and $\mathrm{ClF}_{3}$ can produce $\mathrm{PuF}_{6}$ (Schmets, 1967), whereas bromine fluorides, $\mathrm{ClF}$, and $\mathrm{NF}_{3}$ will not (Scheele et al., 2012). The interhalogens can be used for lowtemperature fluorination processes, even at room temperature (Schmets, 1967). $\mathrm{NF}_{3}$ requires higher temperatures $\left(>550^{\circ} \mathrm{C}\right)$ to produce $\mathrm{UF}_{6}$ but will not produce $\mathrm{PuF}_{6}$. Another good feature of this reagent is that it is relatively innocuous at room temperature (Scheele et al., 2012).

\subsubsection{Separations Methods}

Depending on the particular type of MSR and its associated fuel cycle, it would be necessary to separate the volatile fissile and/or fertile species from the rest and/or concentrate them. The two main options for separating individual components are fractional distillation (Uhlır and Marecek, 2009) and selective 
trapping (Trowbridge et al., 2004). Purification of $\mathrm{UF}_{6}$ from uranium ores by distillation is an industrial practice.

Early reprocessing was centered on the recovery of Pu for military purposes. The technology was later adapted to the processing of used LWR commercial fuel, but it still focused on the fissile value of the residual $\mathrm{Pu}(\sim 1 \%$ of the mass). A very high recovery of purified $\mathrm{Pu}$ is a difficult proposition using fluoride volatility, and the difficulty precluded the commercial adoption of fluoride volatility processes despite significant research and development efforts mostly during the 1960s and 1970s. However, the present project philosophy precludes the separation of pure $\mathrm{Pu}$ because of proliferation concerns, with a maximum $\mathrm{Pu}$ concentration $<30$ mass\% (Lumetta et al., 2017).

\subsubsection{Co-separation of $\mathrm{Pu}, \mathrm{Np}$, and $\mathrm{U}$ from the Bulk of $U F_{6}$}

Plutonium hexafluoride and $\mathrm{NpF}_{6}$ are very strong fluorinating agents and they will fluorinate uranyl fluorides (e.g., $\mathrm{UO}_{2} \mathrm{~F}_{2}, \mathrm{UOF}_{4}$ ) and lower uranium fluorides (e.g., $\mathrm{UF}_{4}, \mathrm{UF}_{5}$ ) through the following reactions:

$$
\begin{gathered}
2 \mathrm{PuF}_{6(\mathrm{~g})}+2 \mathrm{UO}_{2} \mathrm{~F}_{2}=2 \mathrm{PuF}_{4}+2 \mathrm{UOF}_{4}+\mathrm{O}_{2(\mathrm{~g})} \\
2 \mathrm{UOF}_{4}+2 \mathrm{PuF}_{6(\mathrm{~g})}=2 \mathrm{UF}_{6(\mathrm{~g})}+2 \mathrm{PuF}_{4}+\mathrm{O}_{2(\mathrm{~g})} \\
\mathrm{UF}_{4}+\mathrm{PuF}_{6(\mathrm{~g})}=\mathrm{PuF}_{4}+\mathrm{UF}_{6(\mathrm{~g})} \\
2 \mathrm{UF}_{5}+\mathrm{PuF}_{6(\mathrm{~g})}=\mathrm{PuF}_{4}+2 \mathrm{UF}_{6(\mathrm{~g})}
\end{gathered}
$$

Plutonium hexafluoride is thermally and radiolytically unstable, and efficient Pu recovery requires rapid cooling and trapping. An upfront trap made of uranyl (or lower) fluorides would allow the fast recovery of the Pu produced during the volatilization process. Since it will always be comingled with $U$ and $\mathrm{Np}$, this trapping methodology will provide a degree of proliferation protection by never producing a pure stream of $\mathrm{Pu}$. This trapping technology has been demonstrated at laboratory scale using $\mathrm{UO}_{2} \mathrm{~F}_{2}$ (Amamoto and Sato, 2007; Sasahira et al., 2005).

Such a trap will not retain any net amount of $\mathrm{UF}_{6}$; however, there will be exchange between the $\mathrm{UF}_{6}$ in the gas phase and uranium compounds in the solids (Yato, 1996). The trap will need to be regenerated using the recovered U stream. For a 30 mass $\%$ Pu loading, it would require the recycling of about $3 \%$ of the $U$ stream to make up the trapping media. The rest of the volatile fluorides, except for ruthenium and niobium fluorides, will not react and should bypass the trap. Ruthenium and $\mathrm{Nb}$ fluorides can be condensed as solids at temperatures $<200^{\circ} \mathrm{C}$ and can be recovered before the Pu trap (Sasahira et al., 2005).

\subsubsection{Selective Trapping using Metallic Fluorides}

Volatile fluorides and oxyfluorides physisorb and chemisorb on other fluorides or oxyfluorides with bonding strengths ranging from weak adsorption to forming double salts, with a degree of interaction varying significantly with temperature. Choosing the appropriate sorbent at a given temperature range can be a means for selective trapping. A large number of reagents were tried and tested at lab scale (e.g., $\mathrm{BiF}_{3}, \mathrm{CoF}_{2}, \mathrm{CoF}_{3}, \mathrm{PbF}_{2}, \mathrm{MnF}_{2}, \mathrm{SnF}_{4}, \mathrm{KF}, \mathrm{BiOF}, \mathrm{K}_{3} \mathrm{NiF}_{6}, \mathrm{Na}_{3} \mathrm{AlF}_{6}$ ), a few were used at pilot scale (e.g., $\mathrm{LiF}$ ), and two were used at industrial scale (i.e., $\mathrm{NaF}$ and $\mathrm{MgF}_{2}$ ) (Capps, 1951). Of these, BiOF shows promise for selectively trapping HF comingled with $\mathrm{UF}_{6}$ (Capps, 1951).

Magnesium fluoride (i.e., $\mathrm{MgF}_{2}$ ) has been used at large scale for the selective trapping of volatile technetium fluorides and oxyfluorides of technetium comingled with $\mathrm{UF}_{6}$ (Golliher et al., 1963; Katz, 1964a; Simmons, 1996). Magnesium fluoride is fairly insoluble in water (i.e., $0.0076 \mathrm{~g} / 100 \mathrm{~mL}$ at $18^{\circ} \mathrm{C}$ ) (Kohlrausch, 1905). It can be agglomerated with water, pressed into green pellets, dehydrated, and sintered at high temperatures to produce porous pellets that can be used to selectively trap technetium. Trapped Tc cannot be easily desorbed from the $\mathrm{MgF}_{2}$, requiring temperatures $>1000^{\circ} \mathrm{C}$. However, 
trapped Tc can be easily removed by washing with water or dilute $\mathrm{HNO}_{3}$. The $\mathrm{MgF}_{2}$ can be reused after a drying step (Golliher et al., 1963).

The first references to interactions between $\mathrm{UF}_{6}$ on $\mathrm{KF}$ and $\mathrm{NaF}$ date back to the early 1900 s, but a violent interaction was erroneously reported (Ruff et al., 1909). The trapping of $\mathrm{UF}_{6}$ by $\mathrm{NaF}$ was revisited by Grosse in 1941 (Grosse, 1941). Since then, numerous studies have reported the reversible sorptiondesorption of $\mathrm{UF}_{6}$ in NaF (Cathers et al., 1958; Katz, 1963) including large-scale industrial use (Schultz et al., 1981). Sodium fluoride pellets can be made by mixing the powder with water to form agglomerates that are pelletized, the pellets are then dehydrated and sintered (Richardson and McNeese, 1968) as described previously for $\mathrm{MgF}_{2}$.

Sodium fluoride will also sorb other species such as $\mathrm{HF}$ and $\mathrm{MoF}_{6}$. Figure 3-6 shows the respective vapor pressures for $\mathrm{UF}_{6}, \mathrm{MoF}_{6}$, and $\mathrm{HF}$ at temperatures between 100 and $400^{\circ} \mathrm{C}$. Operating somewhat below $200^{\circ} \mathrm{C}$ will allow the selective trapping of $\mathrm{UF}_{6}$ while $\mathrm{MoF}_{6}$ and $\mathrm{HF}$ will bypass the trap. Uranium hexafluoride can later be desorbed at higher temperatures (Afzal et al., 2010; Katz, 1964b).

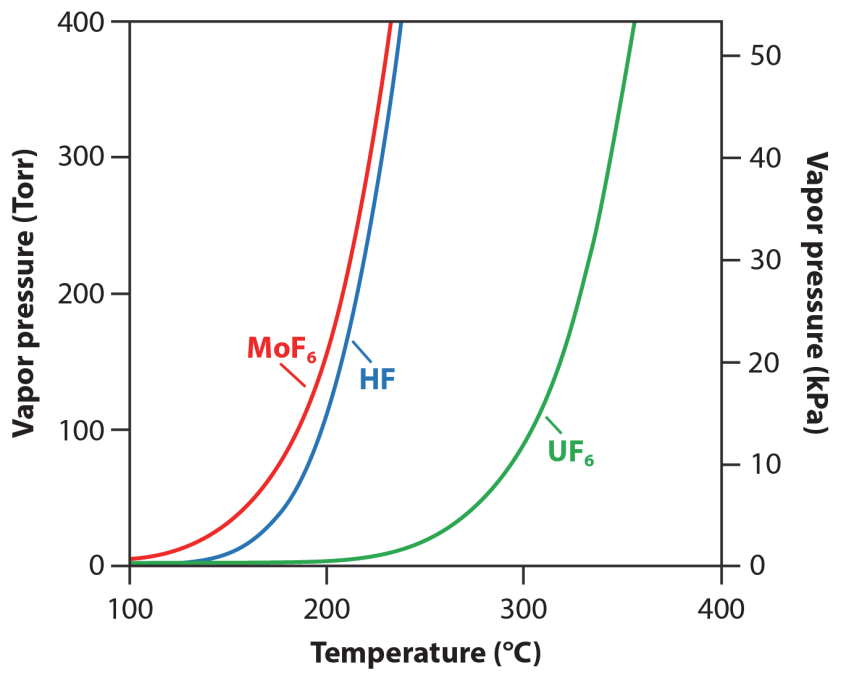

Figure 3-6. Vapor pressures as a function of temperature for $\mathrm{MoF}_{6}, \mathrm{HF}$, and $\mathrm{UF}_{6}$ (HSC Chemistry).

\subsubsection{Volatile Chlorides}

Chloride volatility processes are more complicated than, and not as effective as, fluoride-based processes. Thorium-uranium fuels appear more amenable to chloride volatility processes. Recent developments in voloxidation using $\mathrm{NO}_{2}$ (DelCul et al., 2013) can produce a $\mathrm{UO}_{3}$ powder at a lower temperature. $\mathrm{UO}_{3}$ can be chlorinated at a lower temperature and a faster rate using $\mathrm{Cl}_{2}$ or $\mathrm{Cl}_{2}-\mathrm{CCl}_{4}$ mixtures allowing for the distillation of a pure uranium stream. Other chlorinating agents can also be used including liquid $\mathrm{CCl}_{4}$ (Kraus, 1943), $\mathrm{SOCl}_{2}$ (McBee et al., 1946), $\mathrm{Al}_{2} \mathrm{Cl}_{6}$ (Calkins, 1958; Fried, 1945; Gruen and McBeth, 1968, 1969; Rudel and Kraus, 2017), and hexachloropropane (McBee and Evans, 1945; Patel et al., 2015). The effective trapping of volatile uranium chlorides in $\mathrm{NaCl}$ suggests a strong complexation; suggesting a more difficult volatilization of uranium chlorides out of alkaline molten chloride salt.

As shown in Table 3-5, $\mathrm{Pa}$ and $\mathrm{U}$ form chlorides (e.g., $\mathrm{PaCl}_{5}, \mathrm{UCl}_{5}, \mathrm{UCl}_{6}$ ) that are volatile at relatively low temperature. Increasing the temperature will volatilize $\mathrm{ThCl}_{4}$, followed by $\mathrm{NpCl}_{4}$, and at even higher temperatures, $\mathrm{AmCl}_{3}$. The volatility of $\mathrm{PuCl}_{3}$ by itself is very low, but it is increased by the formation of $\mathrm{PuCl}_{4}$ in the gas phase according to the reaction (Hariharan et al., 1969a):

$$
2 \mathrm{PuCl}_{3}+\mathrm{Cl}_{2(\mathrm{~g})} \rightleftharpoons \mathrm{PuCl}_{4(\mathrm{~g})}
$$


Of the fission products, the rare earths and alkaline earths form nonvolatile chlorides. The fission products $\mathrm{Mo}, \mathrm{Zr}, \mathrm{Nb}, \mathrm{In}, \mathrm{I}, \mathrm{Br}, \mathrm{Cl}, \mathrm{Se}$, and Te form volatile chlorides along with $\mathrm{Kr}$ and $\mathrm{Xe}$ that are permanent gases. Technetium forms volatile oxychlorides and $\mathrm{TcCl}_{4}$ that are volatile but not well characterized (Johnstone et al., 2012; Schwochau, 2000). Cesium and ruthenium require higher volatilization temperatures.

Table 3-5. Summary of vapor pressures and boiling temperatures $\left(T_{\mathrm{b}}\right)$ for various chloride species.

\begin{tabular}{|l|c|c|c|c|l|}
\hline \multirow{2}{*}{ Species } & \multicolumn{3}{|c|}{ Vapor pressure (Torr) } & \multirow{2}{*}{$\boldsymbol{T}_{\mathbf{b}}$} & \multirow{2}{*}{ Reference } \\
\cline { 2 - 4 } & $\boldsymbol{T = 3 0 0}{ }^{\circ} \mathbf{C}$ & $\boldsymbol{T}=\mathbf{5 0 0}{ }^{\circ} \mathbf{C}$ & $\boldsymbol{T}=\mathbf{7 0 0}^{\circ} \mathbf{C}$ & $\left({ }^{\circ} \mathbf{C}\right)$ & \\
\hline $\mathrm{ThCl}_{4}$ & $5.9 \mathrm{E}-9$ & $4.0 \mathrm{E}-3$ & 10.8 & 922 & Hariharan et al. (1969a) \\
\hline $\mathrm{PaCl}_{5}$ & 4.6 & 520 & $>760$ & 420 & Hariharan et al. (1969a) \\
\hline $\mathrm{UCl}_{5}$ & 2.4 & 370 & $>760$ & 527 & Hariharan et al. (1969a) \\
\hline $\mathrm{UCl}_{6}$ & $>760$ & $>760$ & $>760$ & 277 & Hariharan et al. (1969a) \\
\hline $\mathrm{NpCl}_{4}$ & $3.3 \mathrm{E}-7$ & $9.3 \mathrm{E}-3$ & 0.60 & 847 & HSC Chemistry \\
\hline $\mathrm{PuCl}_{3}$ & $7.9 \mathrm{E}-5$ & $2.0 \mathrm{E}-8$ & $1.1 \mathrm{E}-3$ & 1790 & Hariharan et al. (1969a) \\
\hline $\mathrm{AmCl}_{3}$ & $9.6 \mathrm{E}-12$ & $8.4 \mathrm{E}-6$ & $2.63 \mathrm{E}-2$ & 1180 & Wiegel and Schuster (1984) \\
\hline $\mathrm{ZrCl}_{4}$ & 225 & $>760$ & $>760$ & 331 & Hariharan et al. (1969a) \\
\hline $\mathrm{NbCl}$ & $>760$ & $>760$ & $>760$ & 267 & Hariharan et al. (1969a) \\
\hline $\mathrm{MoCl}_{5}$ & $>760$ & $>760$ & $>760$ & 260 & Hariharan et al. (1969a) \\
\hline $\mathrm{MoOCl}_{4}$ & $>760$ & $>760$ & $>760$ & - & HSC Chemistry \\
\hline $\mathrm{TcCl}_{5}$ & $>760$ & $>760$ & $>760$ & 232 & HSC Chemistry \\
\hline $\mathrm{InCl}_{3}$ & $2.26 \mathrm{E}-2$ & 82 & $>760$ & 582 & HSC Chemistry \\
\hline $\mathrm{TeCl}_{4}$ & 266 & $>760$ & $>760$ & 387 & HSC Chemistry \\
\hline $\mathrm{CsCl}$ & $6.5 \mathrm{E}-8$ & $2.0 \mathrm{E}-3$ & 0.7 & 1300 & Hariharan et al. (1969a) \\
\hline $\mathrm{RuCl}_{3}$ & $3.4 \mathrm{E}-12$ & $3.1 \mathrm{E}-5$ & 0.3 & dec & Hariharan et al. (1969a) \\
\hline $\mathrm{RhCl}_{3}$ & $2.5 \mathrm{E}-17$ & $3.7 \mathrm{E}-9$ & $2.0 \mathrm{E}-4$ & dec $^{a}$ & Hariharan et al. (1969a) \\
\hline $\mathrm{SrCl}_{2}$ & $2.3 \mathrm{E}-18$ & $2.5 \mathrm{E}-11$ & $3.5 \mathrm{E}-7$ & 2027 & Hariharan et al. (1969a) \\
\hline $\mathrm{BaCl}_{2}$ & $1.8 \mathrm{E}-16$ & $1.6 \mathrm{E}-9$ & $1.5 \mathrm{E}-5$ & 2100 & Hariharan et al. (1969a) \\
\hline $\mathrm{CeCl}_{3}$ & $1.0 \mathrm{E}-16$ & $6.8 \mathrm{E}-9$ & $1.7 \mathrm{E}-4$ & 1730 & Hariharan et al. (1969a) \\
\hline $\mathrm{GdCl}_{3}$ & $8.3 \mathrm{E}-15$ & $3.5 \mathrm{E}-7$ & $1.7 \mathrm{E}-3$ & 1580 & Hariharan et al. (1969a) \\
\hline
\end{tabular}

${ }^{a}$ The term "dec" denotes that the compound decomposes rather than boils.

\subsubsection{Processing of Fuels}

Early attempts to develop chloride volatility processing schemes for nuclear fuels were not very successful. Warren and Ferris (1966) studied the possibility of using a chloride volatility process on mixed-oxide (MOX) fuel and concluded it was unpractical. To speed up the chlorination process, they pre-treated the fuel by air/oxygen oxidation at temperatures of $400-600^{\circ} \mathrm{C}$ to form a very fine $\mathrm{U}_{3} \mathrm{O}_{8}$ powder. This pretreatment process was successful for concentration of $\mathrm{PuO}_{2}$ up to 20 mass\%. As a chlorination reagent, they used a mixture of $85 \% \mathrm{Cl}_{2}$ and $15 \% \mathrm{CCl}_{4}$. The chlorination process required 3$5 \mathrm{~h}$. However, they could not devise a method to separate the uranium chlorides from other components, and the removal of $\mathrm{Pu}$ in operation at $550^{\circ} \mathrm{C}$ required an excessive amount of chlorine gas (i.e., 10,000 moles of chlorine per mole of $\mathrm{Pu}$ ). Operating at higher temperatures was impractical because of corrosion and the formation of liquid oxychloride phases.

The laboratory investigations by Hariharan et al. appear somewhat more promising (Hariharan et al., 1969a; Hariharan et al., 1969b). They used a 4:1:1 $\mathrm{Cl}_{2}-\mathrm{CCl}_{2}-\mathrm{N}_{2}$ (assumed to be molar basis, but not specified) mixture as the chlorinating reagent on powdered $\mathrm{Th} / \mathrm{U}$ and $\mathrm{U}-\mathrm{Pu}$ oxide fuels. As trapping materials, they used two alumina filter beds followed by a $\mathrm{NaCl}$ bed. For the Th-U fuels, they used a 
chlorination temperature of $750^{\circ} \mathrm{C}$ and collected $>99$ mass $\%$ of the Th on the first alumina filter; $>90 \%$ of the uranium was collected in the $\mathrm{NaCl}$ trap with decontaminations factors of the order of 100 . They observed that both $\mathrm{UCl}_{5}$ and $\mathrm{UCl}_{6}$ were retained in the $\mathrm{NaCl}$ bed, forming a sharp orange-red band; they possibly formed the binary compound $\mathrm{NaUCl}_{6}$, which can be transformed into a green compound (i.e., $\mathrm{Na}_{2} \mathrm{UCl}_{6}$ ) by reduction with hydrogen. Based on these results, they generated a flow sheet that adds a second-stage purification for $U$ and Th products, achieving an overall decontamination factor of 10,000.

For the U-Pu fuel, they chlorinated the powdered fuel at $450^{\circ} \mathrm{C}$. The uranium was trapped in the $\mathrm{NaCl}$ along with $\mathrm{Mo}, \mathrm{Nb}$, and $\mathrm{Zr}$. The rest of the fission products remain with the plutonium in the chlorination chamber. They did not attempt to recover and purify Pu because they concluded that a fluoride volatility step would be more efficient.

\subsubsection{Chloride Volatility in Molten Salts}

Very limited information is available on the topic of chloride volatility in molten salts. The article by Olander and Camahort (1966) describes the chlorination of $\mathrm{UCl}_{4}$ dissolved in a $\mathrm{KCl}-\mathrm{LiCl}$ eutectic salt. Using $\mathrm{Cl}_{2(\mathrm{~g})}$ at $400^{\circ} \mathrm{C}$, about 30 mass $\%$ of the uranium volatilized in $1 \mathrm{~h}$. Operating at $600^{\circ} \mathrm{C}$, about 50 mass $\%$ of the uranium volatilized in $1 \mathrm{~h}$. In addition to pure $\mathrm{Cl}_{2(\mathrm{~g})}$, they used $\mathrm{Cl}_{2(\mathrm{~g})} / \mathrm{Ar}$ mixtures $(50 / 50$ and $25 / 75)$ and $50 / 50 \mathrm{Cl}_{2(\mathrm{~g})} / \mathrm{He}$ mixtures (assumed to be molar basis, but not specified).

\subsubsection{The U-O-CI System}

Uranium forms four chlorides (i.e., $\mathrm{UCl}_{6}, \mathrm{UCl}_{5}, \mathrm{UCl}_{4}, \mathrm{UCl}_{3}$ ) and numerous oxychlorides (e.g., $\mathrm{UOCl}$, $\mathrm{UOCl}_{2}, \mathrm{UOCl}_{3}, \mathrm{UO}_{2} \mathrm{Cl}_{2}$ ). During chlorination, the products can be $\mathrm{UCl}_{4}$ and/or $\mathrm{UCl}_{5}$, and, in some instances, $\mathrm{UCl}_{6}$. The three chlorides $\mathrm{UCl}_{4}, \mathrm{UCl}_{5}$, and $\mathrm{UCl}_{6}$ are interrelated by the following reactions:

$$
\begin{gathered}
2 \mathrm{UCl}_{5} \leftrightarrow \mathrm{UCl}_{6}+\mathrm{UCl}_{4} \\
2 \mathrm{UCl}_{5}+\mathrm{Cl}_{2(\mathrm{~g})} \leftrightarrow 2 \mathrm{UCl}_{6} \\
2 \mathrm{UCl}_{5} \leftrightarrow 2 \mathrm{UCl}_{4}+\mathrm{Cl}_{2(\mathrm{~g})}
\end{gathered}
$$

The presence of oxygen as an impurity, or from activation of the salt, can also cause the formation of oxychlorides. Typically, chlorination is done in open systems. However, to exemplify the different equilibria, Figure 3-7 and Figure 3-8 show the preponderate phases as a function of temperature and $\mathrm{Cl}_{2(\mathrm{~g})}$ partial pressure $\left[\mathrm{pCl}_{2(\mathrm{~g})}\right]$ at two fixed oxygen levels of $1 \times 10^{-20}$ bar and $1 \times 10^{-10}$ bar, respectively. The oxygen partial pressure measured in MSRE fuel before irradiation was $1 \times 10^{-5}$ to $5 \times 10^{-4}$ bar (Briggs, 1966), suggesting the possibility of oxychlorides in the reactor salt. 


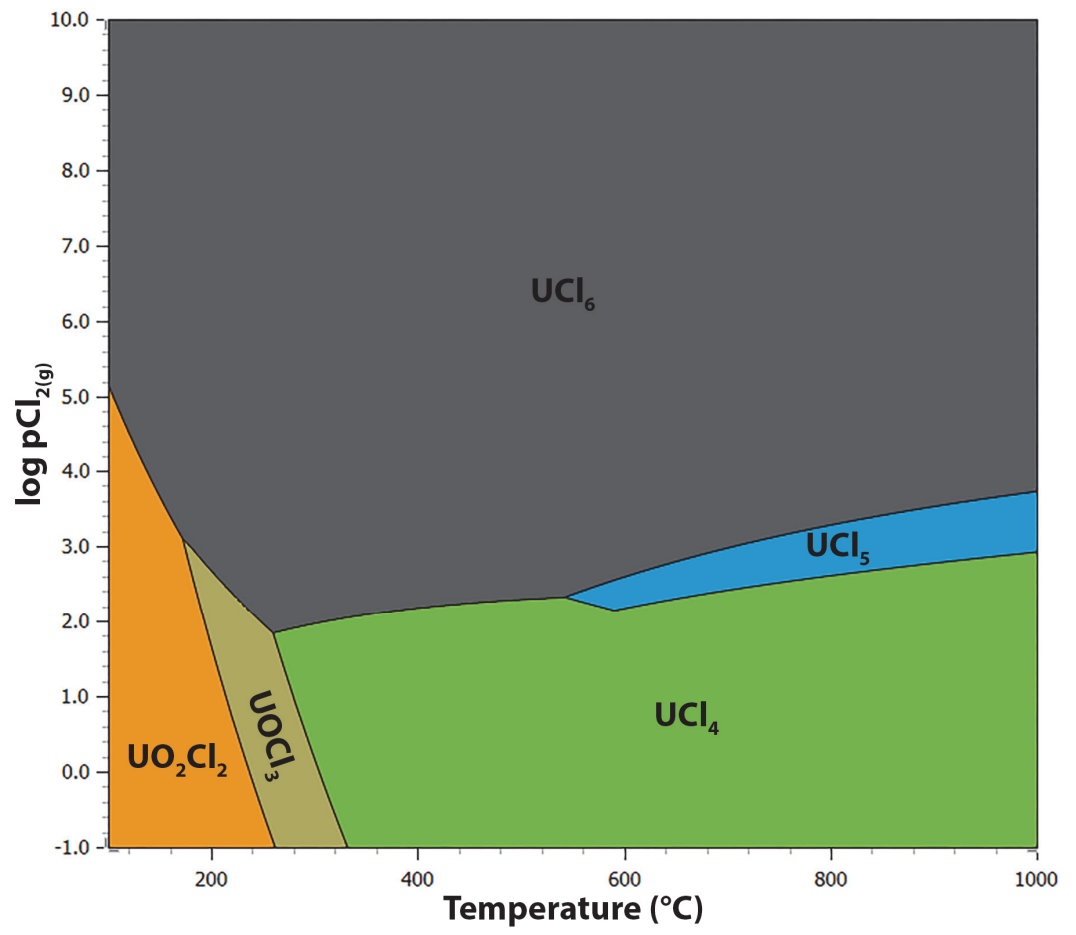

Figure 3-7. Predominance diagram for U-Cl-O system at $\mathrm{pO}_{2(\mathrm{~g})}=1 \times 10^{-20}$ bar (HSC Chemistry).

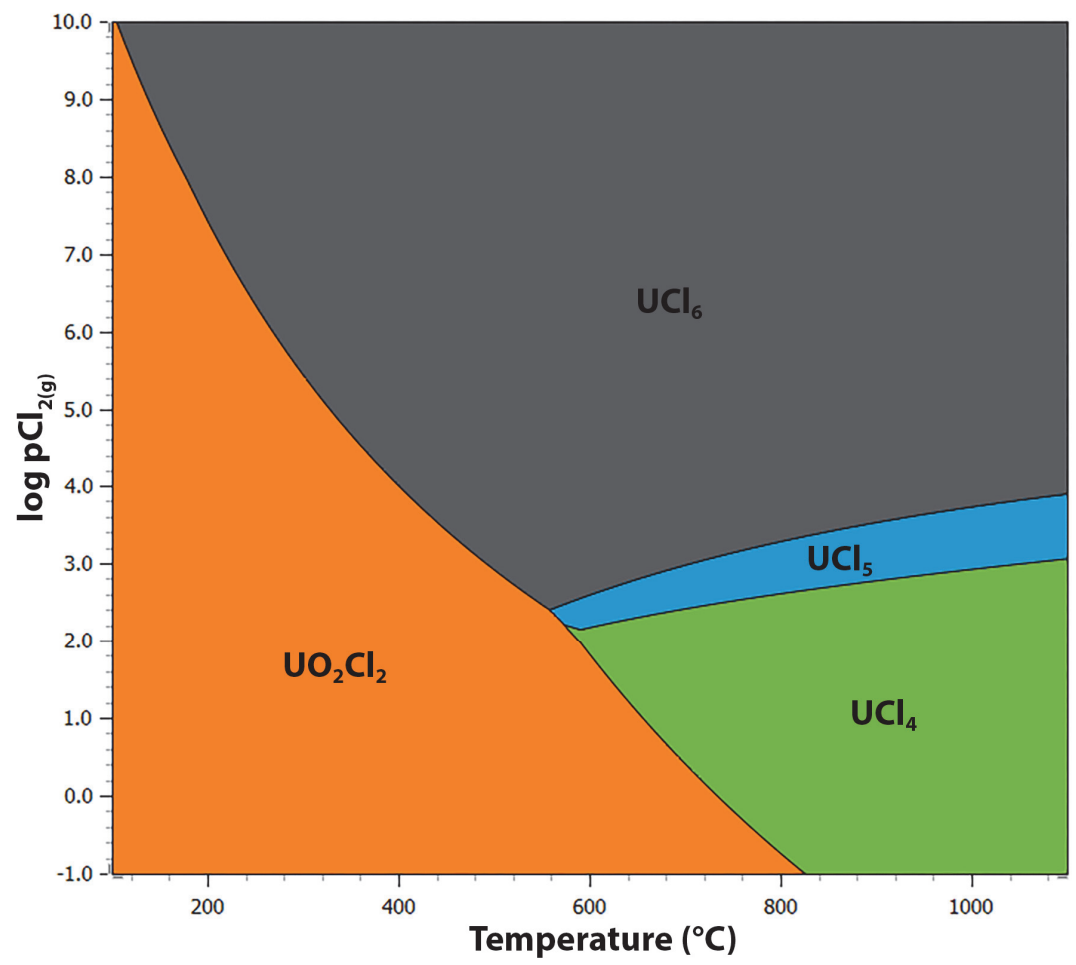

Figure 3-8. Predominance diagram for U-Cl-O system at $\mathrm{pO}_{2(\mathrm{~g})}=1 \times 10^{-10} \mathrm{bar}(\mathrm{HSC}$ Chemistry). 


\subsubsection{Interconversion of Chlorides and Fluorides}

It is possible that conversion of fluorides to chlorides will assist in online processing of MSR salts or in the preparation of an optimal waste form. Thus, this topic is discussed briefly within this section.

Fluorides (e.g., $\mathrm{UF}_{4}$ or $\mathrm{UF}_{6}$ ) can be transformed into $\mathrm{UCl}_{4}$ using reagents such $\mathrm{BCl}_{3}$ or $\mathrm{AlCl}_{3}$ through the following reactions:

$$
\begin{aligned}
3 \mathrm{UF}_{4}+\mathrm{BlCl}_{3} & \rightleftharpoons \mathrm{UCl}_{4}+4 \mathrm{BF}_{3} \\
3 \mathrm{UF}_{4}+\mathrm{AlCl}_{3} & \rightleftharpoons \mathrm{UCl}_{4}+4 \mathrm{AlF}_{3}
\end{aligned}
$$

Additionally, chlorides can be transformed into fluorides using anhydrous HF. These reactions take place at moderate temperatures of $250-500^{\circ} \mathrm{C}$ (Fried, 1945). Similarly, Calkins (1958) mentions that $\mathrm{UF}_{6}$ can be directly converted to $\mathrm{UCl}_{4}$ using $\mathrm{AlCl}_{3}, \mathrm{BCl}_{3}$, or $\mathrm{NaAlCl}_{4}$ through the following reactions:

$$
\begin{gathered}
\mathrm{UF}_{6}+\mathrm{Al}_{2} \mathrm{Cl}_{6} \rightleftharpoons 2 \mathrm{AlF}_{3}+\mathrm{UCl}_{4}+\mathrm{Cl}_{2} \\
\mathrm{UF}_{6}+2 \mathrm{BCl}_{3} \rightleftharpoons 2 \mathrm{BF} 3+\mathrm{UCl}_{4}+\mathrm{Cl}_{2} \\
2 \mathrm{UF}_{6}+3 \mathrm{NaAlCl}_{4} \rightleftharpoons 3 \mathrm{NaF}+3 \mathrm{AlF}_{3}+2 \mathrm{UCl}_{4}+2 \mathrm{Cl}_{2}
\end{gathered}
$$

Inversely, chlorides can be transformed into fluorides using fluorinating agents such as $\mathrm{F}_{2}, \mathrm{NF}_{3}, \mathrm{ClF}_{3}$, and anhydrous HF and then treated using fluoride volatility processes (Matsuda et al., 2015). 


\section{OPTIONS FOR UNSEPARATED AND SEPARATED SALTS}

This section elaborates on Subsection 2.2, Unseparated Salt Waste Streams and Subsection 2.3, Salt Separations Streams. The actual waste that will require subsequent treatment following MSR operation could vary significantly, depending on the composition of the salt(s), the fission products present, and the fission product concentrations. The waste streams that have been identified at this stage include (1) volatile off-gas waste components, (2) salt-based waste components, (3) separated salt streams, (4) metals streams (i.e., metal components and corroded metals), (5) carbon streams (e.g., graphite, SiC), and (6) decommission and decontamination wastes. Each of these is discussed in more detail within this section. In addition, flowsheets for unseparated salts and separated are presented in Figure 2-2 and Figure 2-3, respectively.

\subsection{Mineral Waste Forms}

A variety of mineral forms have been demonstrated in the literature as possible hosts for portions of, or the full range of, species that will be present in the fluoride and/or chloride salt wastes, including halides, alkalis, alkaline earths, and rare earths. A summary of the mineral options is presented in Table 4-1. In most cases, for consolidation into a final waste form, the mineral form could either be hot-pressed or mixed with a glass binder and then hot-pressed.

\subsection{Waste Form Options Based on Salt Type}

Depending on whether chloride or fluoride salts are used, some options might exist for immobilizing the entire salt. In other cases, these salts can be treated to better prepare the waste for immobilization in a more effective waste form option. These options are separated in the following discussion by the salt halide.

\subsubsection{Options for Fluoride-Based Waste Components}

\subsubsection{Fluoride-Based Glasses}

Fluoride glasses containing $\mathrm{BeF}_{2}$ have been around for nearly a century, and $\mathrm{BeF}_{2}$ is the only singlecomponent fluoride that can be made into a glass (Tran et al., 1984). Heavy metal fluoride (HMF) glasses (Poulain et al., 1977; Poulain and Lucas, 1978) have been studied as well. The HMF glass systems include $\mathrm{ZBLAN}\left(\mathrm{ZrF}_{4}-\mathrm{BaF}_{2}-\mathrm{LaF}_{3}-\mathrm{AlF}_{3}-\mathrm{NaF}\right)$ glass (Ohsawa et al., 1981), one of the more common types of HMF glasses reported in the literature and the most stable (Zhu and Peyghambarian, 2010) (see Figure 4-1). The HFM glasses have been synthesized with actinide fluorides (e.g., $\left.\mathrm{UF}_{3}, \mathrm{UF}_{4}, \mathrm{ThF}_{3}, \mathrm{ThF}_{4}\right)(\mathrm{Maze}$ et al., 1984; Poignant et al., 1982; Poulain et al., 1992) as well as rare earth fluorides (e.g., $\mathrm{LaF}_{3}, \mathrm{CeF}_{3}$, $\mathrm{CeF}_{4}, \mathrm{GdF}_{3}, \mathrm{TbF}_{3}, \mathrm{ErF}_{3}, \mathrm{YbF}_{3}, \mathrm{YF}_{3}$ ) (Jianfeng and Ji-Jian, 1989; Mivshsita and Manabe, 1983; Poignant et al., 1982; Poulain et al., 1987), most of which could be expected in an MSR waste stream, depending on whether it is a burner-type or breeder-type fuel mixture. Also, a variety of alkali fluorides have been incorporated into fluoride glasses, including LiF, NaF, KF, RbF, and CsF (Kawamoto et al., 1991; Poulain et al., 1987; Vogel and Gerth, 1958). Finally, work by Iqbal et al. (1991) as well as Kulkarni and Gupta (1996) demonstrated that including $\mathrm{AlF}_{3}$ in a fluoride glass matrix results in drastically improved chemical durability over ZBLAN; these glasses had water solubilities more than 3 orders of magnitude lower than those of ZBLAN glasses. 



\begin{tabular}{|c|c|c|c|c|c|c|c|c|c|c|c|c|c|c|c|c|c|c|c|}
\hline 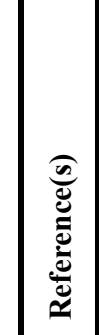 & 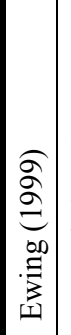 & 定 & 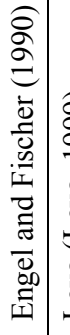 & 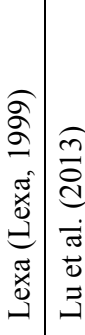 & 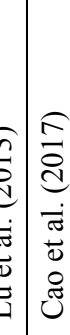 & 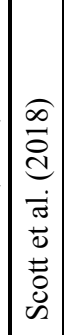 & 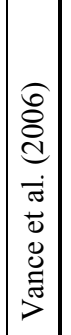 & 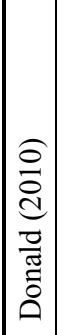 & 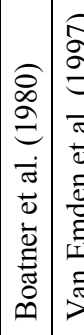 & 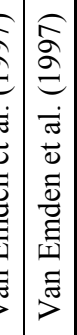 & 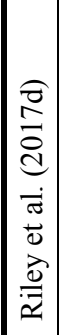 & 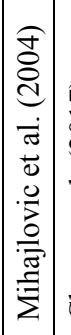 & 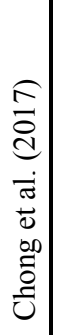 & 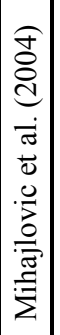 & 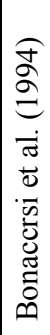 & 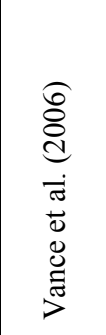 & 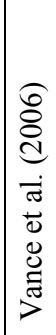 & 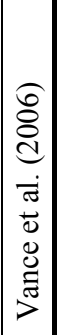 & 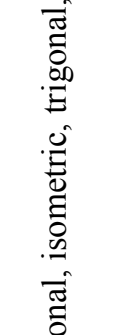 \\
\hline$\xi$ & 1 & 1 & 1 & 1 & \begin{tabular}{l|l}
1 & 1
\end{tabular} & $\frac{Z}{4}$ & $\stackrel{0}{0}$ & I & 18 & 记 & 1 & 1 & 1 & 1 & 1 & $\overbrace{}^{\infty}$ & $\stackrel{\infty}{0}$ & $\stackrel{0}{2}$ & 志 \\
\hline 児 & 된 & 1 & 1 & 1 & \begin{tabular}{l|l}
1 & 1
\end{tabular} & $\frac{1}{2}$ & $\stackrel{0}{0}$ & I & $|c|$ & | II & 1 & 1 & 1 & 1 & 1 & $e^{\infty}$ & $\infty^{\infty}$ & $\stackrel{0}{0}$ & $\frac{\Xi}{0}$ \\
\hline 究 & 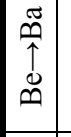 & $\pi$ & $\ddot{\infty}$ & \begin{tabular}{l|l}
$\tilde{U}$ & $\tilde{0}$ \\
$\tilde{\infty}$ & $\tilde{n}$
\end{tabular} & $\begin{array}{l}* \\
0\end{array}$ & 1 & $\stackrel{\infty}{\infty}$ & $\tilde{U}$ & 1 & 11 & ' & $\tilde{U}$ & ' & $\begin{array}{l}\sum^{\infty} \\
\tilde{U}^{\infty}\end{array}$ & $\tilde{J}$ & $\overbrace{}^{\infty}$ & $\sum_{\nu}^{\infty}$ & $\stackrel{0}{\infty}$ & है \\
\hline$\simeq$ & 1 & 10 & $\tilde{z}$ & \begin{tabular}{l|l} 
& 1
\end{tabular} & 1 & U & 1 & 1 & I & $\begin{array}{ll}1 & 1\end{array}$ & $\begin{array}{l}\frac{4}{\uparrow} \\
: \frac{1}{9}\end{array}$ & 1 & $\ddot{z}$ & I & $\begin{array}{l}\qquad y \\
z \\
z\end{array}$ & 1 & 1 & $\underset{\nu}{0}$ & 胥 \\
\hline$x$ & $\omega$ & \begin{tabular}{|l|l}
1 & 6
\end{tabular} & 工 & 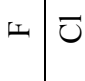 & 5 & $\bar{U}$ & 1 & $\begin{array}{l}L \\
\overrightarrow{0}\end{array}$ & 1 & $\begin{array}{ll}1 & 1\end{array}$ & $\bar{\tau}$ & $\bar{v}$ & -1 & $\bar{\sigma}$ & $\bar{v}$ & 1 & 1 & 1 & $\overline{0}$ \\
\hline 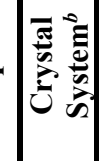 & 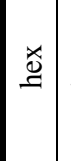 & 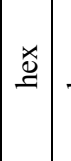 & $\stackrel{x}{0}$ & 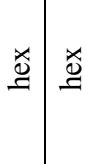 & 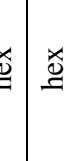 & है & 롱 & 吾 & $\mid \begin{array}{ll}0 \\
\Xi \\
\Xi \\
\Xi\end{array}$ & $\begin{array}{l}2 \\
\Xi\end{array}$ & $\vec{z}$ & $\overrightarrow{\bar{z}}$ & $\overrightarrow{0}$ &. & $\stackrel{x}{0}$ & 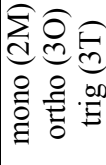 & F & $\begin{array}{l}\stackrel{0}{0} \\
\stackrel{\Xi}{\Xi} \\
\text { a }\end{array}$ & 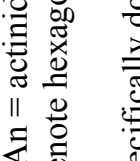 \\
\hline D & $\begin{array}{l}\equiv \\
\vdots \\
2\end{array}$ & \begin{tabular}{ll}
$\Sigma$ & \\
\hdashline & 0 \\
2 &
\end{tabular} & $\begin{array}{l}\approx \\
\varrho\end{array}$ & 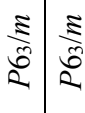 & 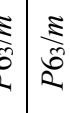 & 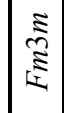 & $\underset{2}{\Xi}$ & 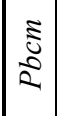 & 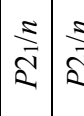 & 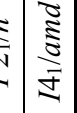 & 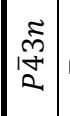 & 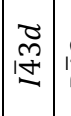 & $\begin{array}{c}\tilde{\tilde{m}} \\
\stackrel{2}{\Sigma} \\
\Sigma\end{array}$ & 8 & $\begin{array}{l}\equiv \\
\vdots \\
2\end{array}$ & 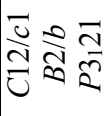 & 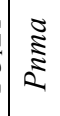 & 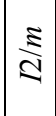 & 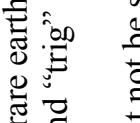 \\
\hline 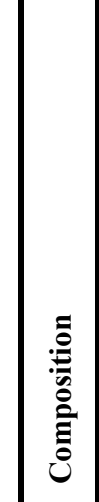 & 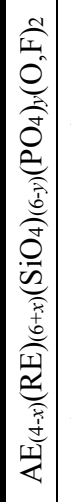 & 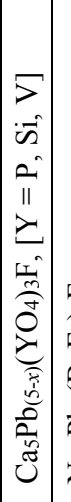 & 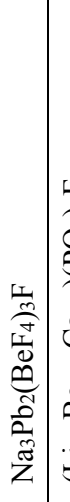 & 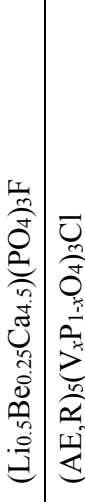 & 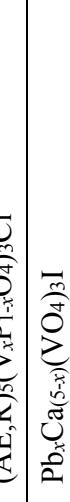 & $\begin{array}{l}0 \\
0 \\
\tilde{n} \\
\tilde{v}\end{array}$ & 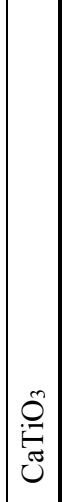 & 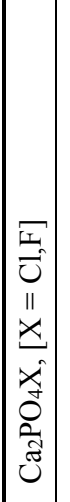 & 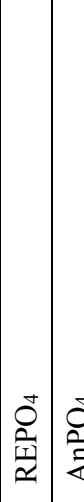 & : & 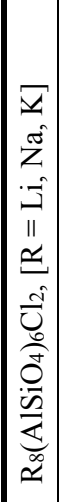 & 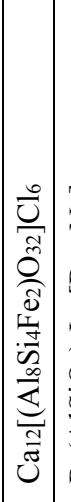 & 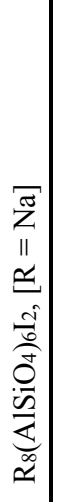 & 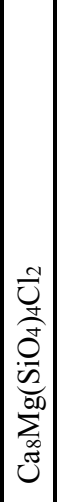 & 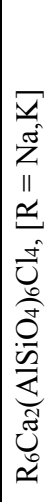 & 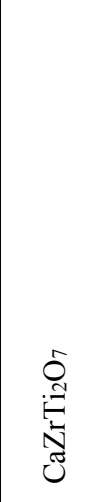 & $\begin{array}{l}\mathscr{O} \\
\stackrel{E}{E} \\
\tilde{U}\end{array}$ & 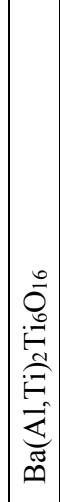 & 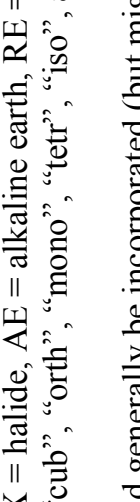 \\
\hline 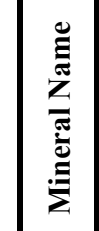 & 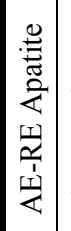 & 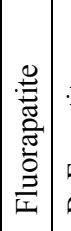 & 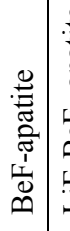 & 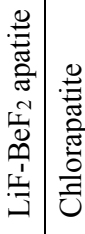 & 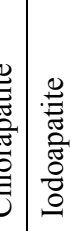 & 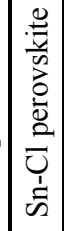 & 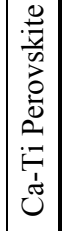 & 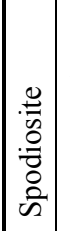 & 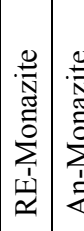 & 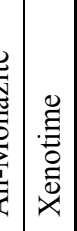 & 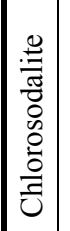 & 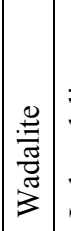 & 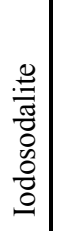 & 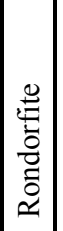 & 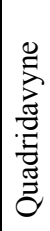 & 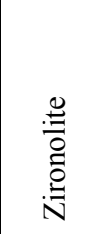 & $\mid \begin{array}{c}\frac{0}{0} \\
\frac{.}{0} \\
0 \\
0 \\
0 \\
0 \\
2\end{array}$ & 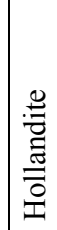 & 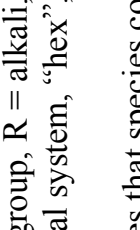 \\
\hline 焉 & & & $\begin{array}{l}\stackrel{9}{0} \\
\text { 娄 }\end{array}$ & & & 这 & 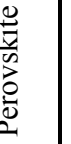 & & $\begin{array}{l}\frac{0}{\pi} \\
\frac{\pi}{20} \\
\frac{0}{2} \\
\frac{0}{2}\end{array}$ & & & 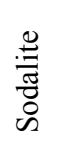 & & 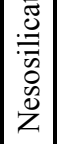 & $\exists$ & & & & $\begin{array}{ll} & = \\
0 \\
0 \\
0\end{array}$ \\
\hline
\end{tabular}



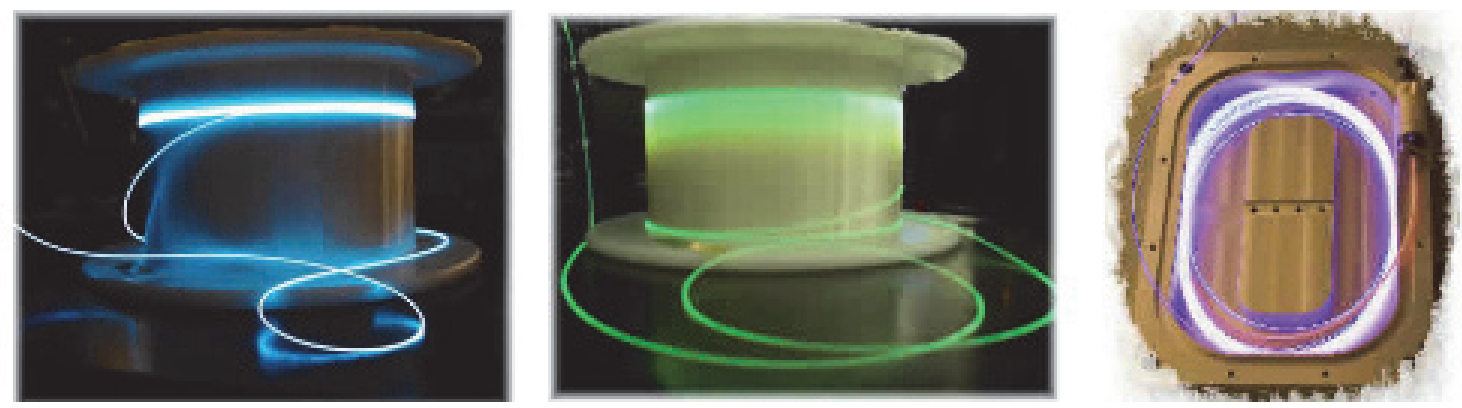

Figure 4-1. Pictures of ZBLAN glass fibers showing visible fluorescence from rare-earth-doped ZBLAN fibers, including (from left to right): Tm-doped, Er-doped, and Nd-doped (courtesy of FiberLabs Inc.).

It is not known if these types of glasses have been used as a waste form material so the properties pertaining to waste forms are likely unknown. These types of properties include

- Chemical stability, or whether forming a glass with these fluorides will yield a more stable form than direct disposal of the salt from the reactor in a salt repository (e.g., WIPP)

- The thermal stability of complex mixture of fluorides in a glass (e.g., crystallization kinetics, glass transition temperature, thermal conductivity, thermal diffusivities) as a function of composition

- The glass-formation regions for the target fission product fluorides and fuel-type fluorides (e.g., $\mathrm{UF}_{4}, \mathrm{ThF}_{4}, \mathrm{LaF}_{3}, \mathrm{NdF}_{3}, \mathrm{YF}_{3}$ ) when combined with different mixtures of salt fluxes (e.g., $\mathrm{BeF}_{2}-$ $\mathrm{LiF}$ )

Some data exist for the incorporation of LiF into tellurite glasses. For instance, in a paper by Yoko et al. (1989), up to $\sim 9 \mathrm{~mol} \%$ of $\mathrm{LiF}$ can be dissolved into a $\mathrm{TeO}_{2}$ glass without initializing crystallization. The authors synthesized glasses by melting the components in $\mathrm{Au}$-coated Pt crucibles at $650-800^{\circ} \mathrm{C}$ for $15-30$ min followed by rapid quenching between two cold iron plates. Thus, it is possible (and likely) that the glassy phases formed near the glass-formation regions shown in Figure 4-2 would be crystallized if slower cooling rates were used during quenching. Although tellurite glasses are capable of incorporating a variety of halides salts (Riley et al., 2017c), the chemical stabilities of these glasses are not ideal because some salts tend to separate into water-soluble immiscible phases. Additionally, the high cost of $\mathrm{TeO}_{2}$ would make these glasses an expensive waste form to produce. 

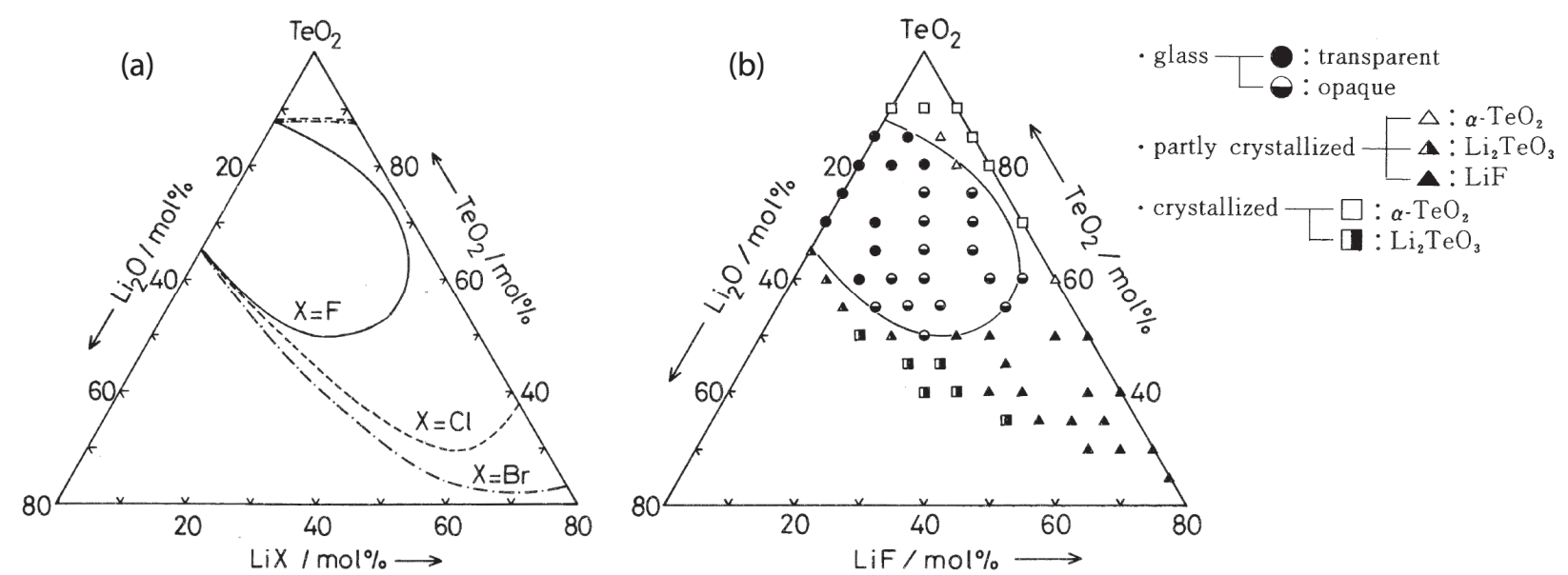

Figure 4-2. Glass formation region phase diagrams for (a) $\mathrm{TeO}_{2}-\mathrm{Li}_{2} \mathrm{O}-\mathrm{LiX}(\mathrm{X}=\mathrm{F}, \mathrm{Cl}, \mathrm{Br})$ and (b) $\mathrm{TeO}_{2}-\mathrm{Li}_{2} \mathrm{O}-$ LiF. This figure was taken from Yoko et al. (1989).

\subsubsection{Fluoride-Based ceramics}

Several fluoride-based ceramics are described in the mineralogical databases, where the cations are either those expected in the salts (i.e., $\mathrm{Li}^{+}, \mathrm{Be}^{2+}, \mathrm{RE}^{3+/ 4+}, \mathrm{An}^{3+/ 4+}$ ) or elements of similar chemistries and oxidation states (i.e., $1+\rightarrow 4+$ cations). It is unclear whether a ceramic waste form made with those salts would be more stable than an unprocessed salt. Nonetheless, a review is provided of potential mineralogical chemistries and structures for immobilizing the MSR salt components.

The fluoride salts expected for MSRs primarily consist of ${ }^{7} \mathrm{LiF}$ and $\mathrm{BeF}_{2}$ or ${ }^{7} \mathrm{LiF}-\mathrm{NaF}-\mathrm{KF}$. One of the more commonly studied mineralogical waste form options that contains both alkali and halides is sodalite. The formula for sodalite is nominally $M_{8}^{+}\left(\mathrm{AlSiO}_{4}\right)_{6} X_{2}^{-}$, where $M^{+}$can be an alkali, i.e., $\mathrm{Li}^{+}, \mathrm{Na}^{+}, \mathrm{K}^{+}$, and $\mathrm{Rb}^{+}$and $X^{-}$can be a halide, i.e., $\mathrm{Cl}^{-}, \mathrm{Br}^{-}$, and $\mathrm{I}^{-}$(Beagley et al., 1982; Henderson and Taylor, 1978;

Nielsen et al., 1991; Weller and Wong, 1989). However, while fluoride-based sodalites are not prevalent in the literature, the formation of LiF-based sodalite is a possibility under the optimal experimental conditions (Féron et al., 1994; Sangthong et al., 2009b).

One of the more commonly studied fluoride-based minerals for waste form applications is apatite. The general formula for apatite is nominally $\mathrm{AE}_{(4-x)}(\mathrm{RE})_{(6+x)}\left(\mathrm{SiO}_{4}\right)_{(6-y)}\left(\mathrm{PO}_{4}\right)_{y}(\mathrm{O}, \mathrm{F})_{2}$, where $\mathrm{AE}$ and $\mathrm{RE}$ denote alkaline earths and rare-earths, respectively (Ewing, 1999). A model of the crystal structure for the $\mathrm{Ca}_{5}\left(\mathrm{PO}_{4}\right)_{3} \mathrm{~F}$ compound is shown in Figure 4-3. 


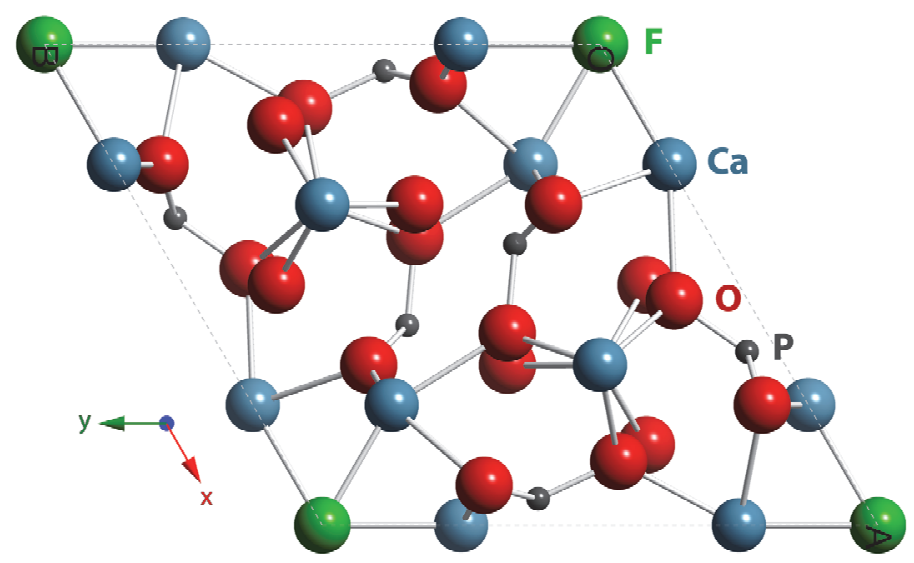

Figure 4-3. Crystal structure for $\mathrm{Ca}_{5}\left(\mathrm{PO}_{4}\right)_{3} \mathrm{~F}$ fluorapatite. This image was created by viewing Inorganic Crystal Structure Database file 302261 with CrystalMaker (v9.2.9f1).

One of the potential options for $\mathrm{BeF}_{2}$ is the apatite mineral structure, but $\mathrm{BeF}_{2}$-based compounds with this structural motif are very rare in the literature (Engel and Fischer, 1990; Luxa, 1999). Additionally, Lexa (1999) describes a process by which a compound of $\mathrm{Li}_{0.50} \mathrm{Be}_{0.25} \mathrm{Ca}_{4.5}\left(\mathrm{PO}_{4}\right)_{3} \mathrm{~F}$ was synthesized by reacting $\mathrm{Li}_{2} \mathrm{BeF}_{4}$ with $\mathrm{Ca}_{3}\left(\mathrm{PO}_{4}\right)_{2}$ through Equation (4-1). In this particular reaction, the ratio of total cations $(\mathrm{Li}+$ $\mathrm{Be}+\mathrm{Ca}$ ) to $\mathrm{F}$ is $5.25: 1$, whereas a ratio of $5: 1$ is normally found in the apatite structure.

$$
\mathrm{Li}_{2} \mathrm{BeF}_{4}+6 \mathrm{Ca}_{3}\left(\mathrm{PO}_{4}\right)_{2} \rightarrow 4 \mathrm{Li}_{0.5} \mathrm{Be}_{0.25} \mathrm{Ca}_{4.5}\left(\mathrm{PO}_{4}\right)_{3} \mathrm{~F}
$$

\subsubsection{Options for Chloride-Based Waste Components}

\subsubsection{Chloride-Based Glasses}

One potential glass option is immobilizing the salt in a tellurite glass, as was discussed previously in the context of fluoride salt disposal (see Section 4.2.1.1). These glasses have been demonstrated to host a high loading of mixed chloride salts. However, their chemical durability is not ideal and so they were abandoned for this application (Riley et al., 2017c; Riley et al., 2018b).

(a)<smiles>[SiH3]</smiles>

$5 \% \quad 10 \% \quad 15 \% \quad 17.5 \% \quad 25 \% \quad 30 \%$ $\mathrm{SrCl}_{2}$

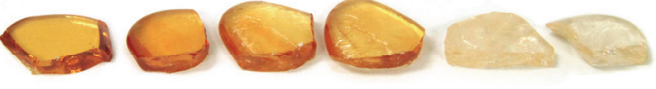

OR

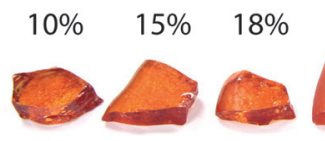

ER(SF)

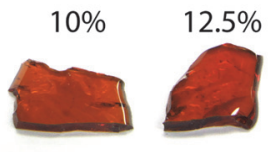

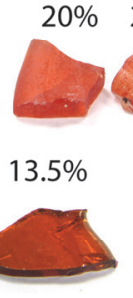
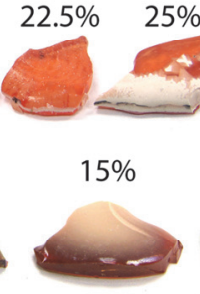

(b)

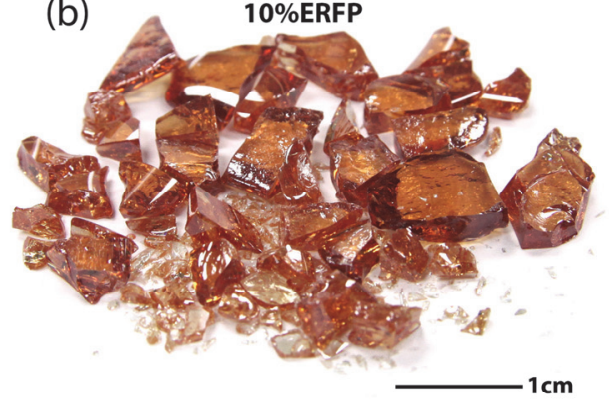

Figure 4-4. Summary of $\mathrm{TeO}_{2}-\mathrm{PbO}$ glasses fabricated with different chloride salt simulants from electrochemical reprocessing of $\mathrm{UNF}$, including (a) $\mathrm{SrCl}_{2}$, OR salt simulant (LiCl-rich), ER(SF) salt simulant (LiCl-KCl-rich) (Riley et al., 2017c), and (b) the rare-earth chloride fission products simulant (Riley et al., 2018b). The percentages listed in the figure denote mass \% loadings of each salt. 


\subsubsection{Chloride-Based Ceramics}

One of the most well-studied waste form options for immobilizing the Cl-rich salt stream is the glassbonded sodalite ceramic waste form option developed by Argonne National Laboratory (Bateman et al., 2007; Ebert, 2005; Riley et al., 2017d). For this process, mixed salt is occluded into zeolite 4A in a $\mathrm{V}$-blender at $500^{\circ} \mathrm{C}$, a glass binder is added to the mixture and homogenized, and then the mixture is heated at $\sim 925^{\circ} \mathrm{C}$. The salt-occluded zeolite forms sodalite, the fission products that cannot enter into the sodalite structure incorporate into the glass phase, and the glass phase encapsulates the sodalite crystals. Sodalite is a mineral from the $P \overline{4} 3 n$ (218) or $I \overline{4} 3 m$ (217) space groups with the nominal formula of $M_{8}^{+}\left(\mathrm{AlSiO}_{4}\right)_{6} X_{2}^{-}$, where $M^{+}$is an alkali (i.e., $\mathrm{Li}^{+}, \mathrm{Na}^{+}, \mathrm{K}^{+}$, and/or $\mathrm{Rb}^{+}$) and $X^{-}$are typically halides (i.e., $\mathrm{Cl}^{-}, \mathrm{Br}^{-}$, and $\mathrm{I}^{-}$). While it is possible to make NaF-based sodalite (Féron et al., 1994), as far as the authors of the current work are aware, LiF-based sodalite is not currently documented in the literature on more than just a theoretical basis (Sangthong et al., 2009a).
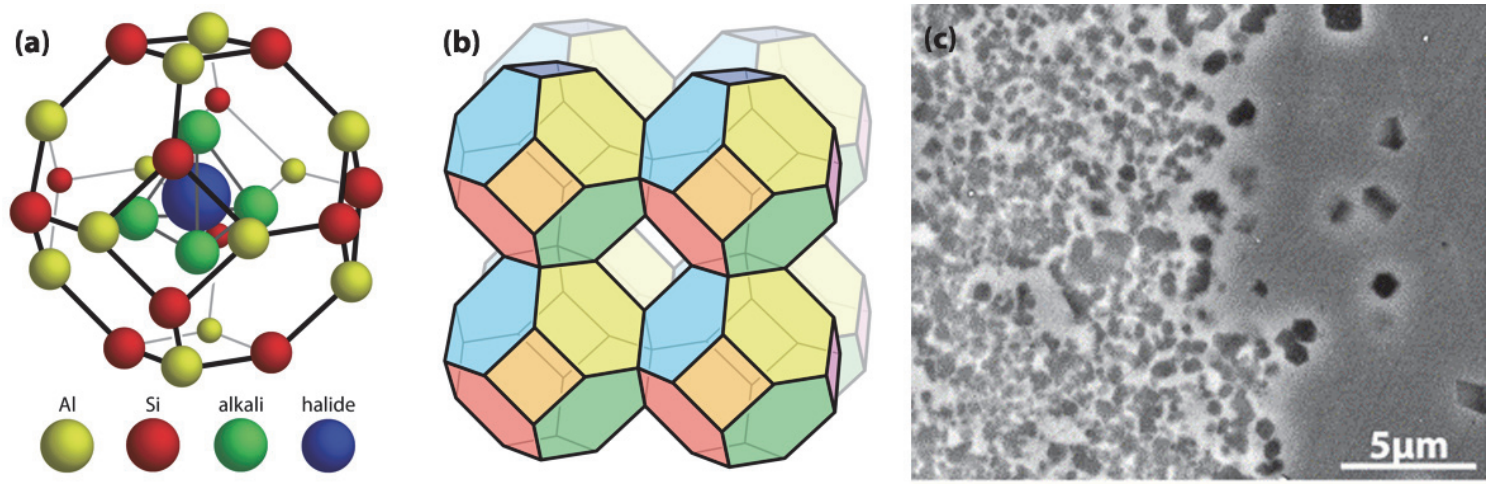

Figure 4-5. Summary of (a) generic alkali-halide sodalite unit cell and (b) sodalite $\beta$-cage arrangement. (c) Scanning electron micrograph of a glass-bonded sodalite waste form (Riley et al., 2018a; Riley et al., 2017d).

\subsection{Nonspecific Waste Form Options}

\subsubsection{Glasses}

Radionuclide-bearing waste forms are required for the long-term storage and disposal of high-level waste (HLW). For HLW originating from aqueous reprocessing of LWR fuels, the most accepted international waste form is glass. The vitrification process uses nuclear waste that has been calcined into an oxide powder mixed with glass forming "frit" and then melted at temperatures in the range of 1100 to $1200^{\circ} \mathrm{C}$. The waste loading is typically $<10 \mathrm{vol} \%$, so the waste volume expands by a factor of $\geq 10$ when it is converted into a glass log. The loading limitations are due to a combination of acceptable heat loading and chemical interactions.

Actinide-bearing fluoride/chloride salts are proposed for used as coolants or fuels for numerous MSR designs; after irradiation, these salts will contain fission products and transuranic elements in addition to the fuel component (often U or Th). Typical glasses cannot accommodate large amounts of chlorides or fluorides. Chloride-based HLW resulting from pyrochemical processing is typically reacted with a zeolite-based material that is then incorporated into glass (Ebert, 2005) (see Section 4.2.2.2). This process is complicated, and the waste volume expands significantly compared with traditional glass. A durable waste form for this material has not yet been identified for fluoride-based wastes.

For glasses in which halide incorporation is possible, it is uncertain what the chemical durability would be. For instance, in a study by Beall and Reade (1979), a variety of borate and aluminoborate glasses were made with additions of $\mathrm{LiCl}, \mathrm{LiF}$, and $\mathrm{LiCl}+\mathrm{LiF}$ by melting in covered $\mathrm{Pt}$ crucibles at $1000-1150^{\circ} \mathrm{C}$ 
for 2-4 h. Some of these glasses were subjected to a rudimentary chemical durability test with mass loss determinations after a room-temperature soak in water for $16 \mathrm{~h}$. Some of these glasses showed release rates of $<0.1 \%$ mass loss.

\subsubsection{Ceramic-Metal (Cermet) Composites}

Some of the most common alternatives to glass include immobilization of radioactive waste within mineral, metal, or grout matrices. In the so called "cermet" waste form, the individual waste particles are homogeneously dispersed and fully encapsulated by a metal matrix material except at the surface. The metal matrix provides containment while maintaining a very high thermal and electrical conductivity typical of metals (Tucker and Jacobson, 2011).

Patents by Aaron et al. describe the production of cermet waste pucks to immobilize a waste stream containing uranium oxide as the primary constituent (Aaron et al., 2012; Aaron et al., 1983). Cermet waste forms display several advantages over glass, including improved thermal conductivity (such that the centerline temperature of the waste form is decreased), increased waste form density, and higher overall waste loadings typically $40-60 \mathrm{vol} \%$. Additionally, cermets can be produced at lower temperatures than glass, which decreases the loss of volatile radioactive species during waste form production (Ortega et al., 2011).

To date, the use of cermet waste forms has not been considered for the immobilization of waste streams containing large amounts of fluoride or chloride salts. It is postulated here that a copper-based cermet waste form is well suited for this application. The selection of copper as the metal matrix has distinct advantages for this particular application. Copper is an excellent material for long-term storage or geologic disposition, as it is highly durable under reducing conditions (Diomidis et al., 2017). Internationally, copper has been used in radioactive waste storage as an exterior canister liner due to its corrosion resistance and chemical stability (see Figure 4-6), e.g., at the Onkalo geological repository in Finland (Bohner, 2018) and for coating steel containers encasing CANDU fuel in the Canadian Precambrian Shield (Boyle and Meguid, 2015).

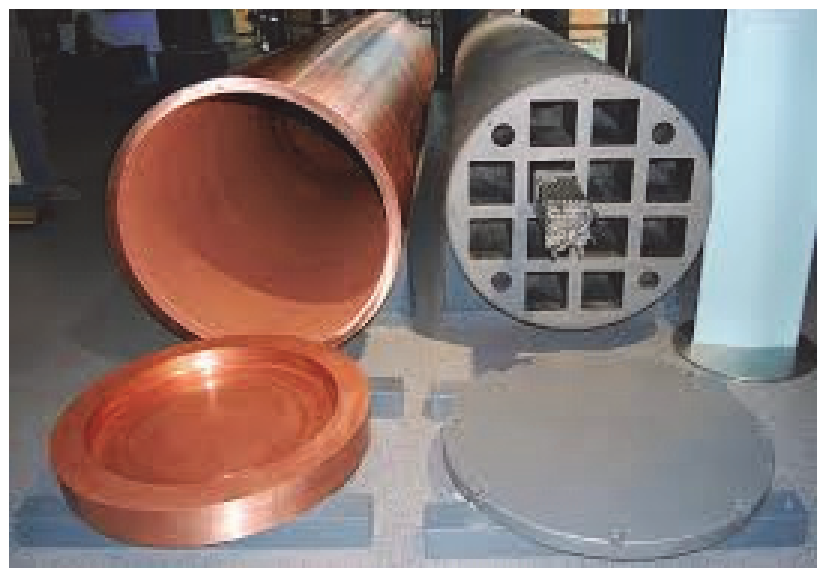

Figure 4-6. Picture of copper exterior canister liner (left) and canister (right) for the Onkalo geological repository in Finland (Bohner, 2018).

In the storage of fluoride or chloride salt wastes, copper is chemically compatible. As a result of the intense radiolysis of the halide waste constituents, chlorine and/or fluorine atoms or radicals will be generated. However, they will not be able to escape the copper matrix, as they will react to form a surface copper-halide (e.g., $\mathrm{CuF}, \mathrm{CuF}_{2}, \mathrm{CuCl}, \mathrm{CuCl}_{2}$ ).

The extent of the reaction will remain minimal in the long term, as the system will re-equilibrate as radiolysis decreases to form more stable halides with salt components, such as $\mathrm{LiF}, \mathrm{ZrF}_{4}$, and $\mathrm{ZrCl}_{4}$ 
shown in Equations (4-2) through (4-4) below. This indicates that, through encapsulation, individual waste particles become less likely to degrade over time.

$$
\begin{aligned}
\mathrm{LiF}+\mathrm{Cu} & \leftrightarrow \mathrm{CuF}+\mathrm{Li} ; K=2.2 \times 10^{-59} \text { at } 20^{\circ} \mathrm{C} \text { and } 8.7 \times 10^{-13} \text { at } 1000^{\circ} \mathrm{C} \\
\mathrm{ZrF}_{4}+\mathrm{Cu} & \leftrightarrow \mathrm{ZrF}_{3}+\mathrm{CuF} ; K=1.1 \times 10^{-40} \text { at } 20^{\circ} \mathrm{C} \text { and } 1.1 \times 10^{-8} \text { at } 1000^{\circ} \mathrm{C} \\
\mathrm{ZrCl}_{4}+\mathrm{Cu} & \leftrightarrow \mathrm{ZrCl}_{3}+\mathrm{CuCl} ; K=1.0 \times 10^{-22} \text { at } 20^{\circ} \mathrm{C} \text { and } 7.1 \times 10^{-4} \text { at } 1000^{\circ} \mathrm{C}
\end{aligned}
$$

A combination of favorable chemical, mechanical, and thermal properties means copper is well suited for generating durable and economical waste forms. Copper is highly ductile and malleable, allowing for very easy and homogeneous compression, as well as sintering into a solid form of near-theoretical density at temperatures in the range of $600-900^{\circ} \mathrm{C}$, well below its melting point $\left(T_{\mathrm{m}}=1085^{\circ} \mathrm{C}\right)$ and well below the temperatures $\left(1100-1150^{\circ} \mathrm{C}\right)$ required for glass making. Waste-forms can be made using hotprocessing techniques such as hot isostatic pressing (HIP). Alternatively, a copper liner can be added to a canister of a different material to create a fully encapsulated and contamination-free waste form. The liner can be made from an electrodeposited or electro-sprayed copper coating, or produced as an additional assembly during the HIP process.

Production of a copper-based cermet would involve the following steps:

(1) Mixing of calcined fluoride or chloride salt waste (i.e., containing fission products and transuranic elements) with copper powder

(2) Initial compaction into a preformed porous solid (i.e., cold-pressing)

(3) Encasement of the pellet into a copper liner

(4) Sintering, forging, or HIP of the pellet to produce a densified waste form

Figure 4-7 shows a 41-mm Cu pellet (no liner) made with surrogate calcined HLW at a 40 vol\% loading and the microstructure with waste particles surrounded by a continuous copper matrix (DelCul et al., 2018).
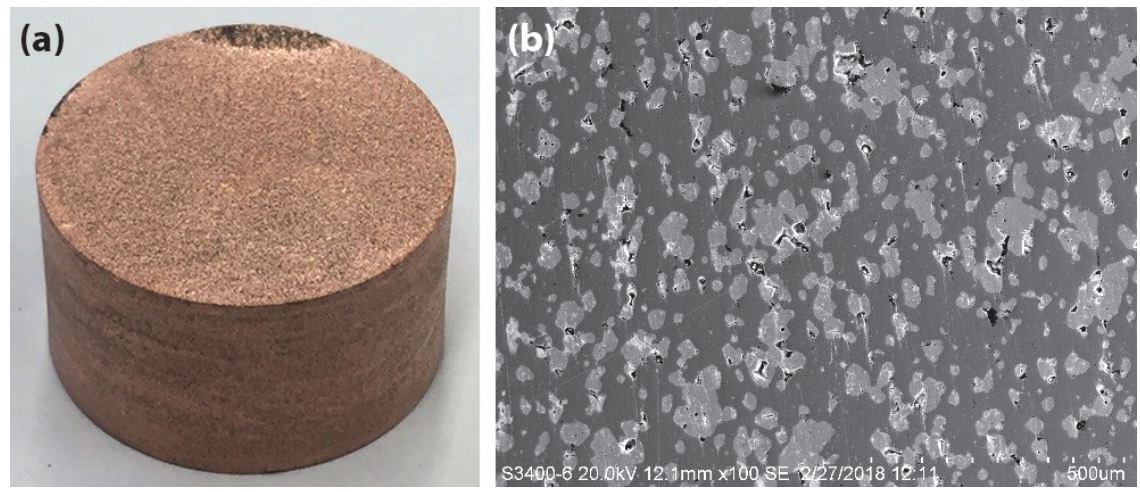

Figure 4-7. Copper cermet made with HLW at a 40 vol\% loading. (a) Picture of the product (diameter is 41 $\mathrm{mm}$ ) and (b) scanning electron micrograph of the material at $100 \times$ magnification (DelCul et al., 2018).

\subsubsection{Dehalogenation of Salts Using Phosphate Precursors}

\subsubsection{Dehalogenation Reactions}

It is possible to dehalogenate chloride-based salts through reactions with phosphate precursors, e.g., $\mathrm{H}_{3} \mathrm{PO}_{4}, \mathrm{NH}_{4} \mathrm{H}_{2} \mathrm{PO}_{4}$, and $\left(\mathrm{NH}_{4}\right)_{2} \mathrm{HPO}_{4}$. The goal of this process is to remove the halides from the salt so 
that the salt cations left can be incorporated into a waste form, typically at higher waste loadings that can be achieved when the halides are not removed.

This concept is based on previous work in which the reaction between the chloride salts and $\mathrm{H}_{3} \mathrm{PO}_{4}$ (Siemer, 2012b) or $\mathrm{NH}_{4} \mathrm{H}_{2} \mathrm{PO}_{4}$ (Donze et al., 2000) generated $\mathrm{NH}_{4} \mathrm{Cl}$ as a byproduct that can be easily collected and possibly recycled. The cations from the salt incorporate into a phosphate glass through the general reactions shown in Reactions (4-5) - (4-10) for different salt cation valences (i.e., $\mathrm{Me}^{+}, \mathrm{Me}^{2+}$, $\left.\mathrm{Me}^{3+}\right)$. Other byproducts include $\mathrm{H}_{2} \mathrm{O}$ and possibly $\mathrm{HCl}$, depending on the ratio of the phosphate precursor to the salt and the operation temperatures during the dechlorination process.

$\left(\mathrm{Me}^{1+}\right)$

$$
\begin{gathered}
2 \mathrm{H}_{3} \mathrm{PO}_{4}+2 \mathrm{MeCl} \rightarrow \mathrm{Me}_{2} \mathrm{O} \cdot \mathrm{P}_{2} \mathrm{O}_{5} \text { (glass) }+2 \mathrm{HCl}_{(\mathrm{g})}+2 \mathrm{H}_{2} \mathrm{O}_{(\mathrm{g})} \\
2 \mathrm{H}_{3} \mathrm{PO}_{4}+\mathrm{MeCl}_{2} \rightarrow \mathrm{MeO} \cdot \mathrm{P}_{2} \mathrm{O}_{5} \text { (glass) }+2 \mathrm{HCl}_{(\mathrm{g})}+2 \mathrm{H}_{2} \mathrm{O}_{(\mathrm{g})} \\
6 \mathrm{H}_{3} \mathrm{PO}_{4}+2 \mathrm{MeCl}_{3} \rightarrow \mathrm{Me}_{2} \mathrm{O}_{3} \cdot 3 \mathrm{P}_{2} \mathrm{O}_{5} \text { (glass) }+6 \mathrm{HCl}_{(\mathrm{g})}+6 \mathrm{H}_{2} \mathrm{O}_{(\mathrm{g})} \\
2 \mathrm{NH}_{4} \mathrm{H}_{2} \mathrm{PO}_{4}+2 \mathrm{MeCl} \rightarrow \mathrm{Me}_{2} \mathrm{O} \cdot \mathrm{P}_{2} \mathrm{O}_{5} \text { (glass) }+2 \mathrm{NH}_{4} \mathrm{Cl}_{(\mathrm{g})}+2 \mathrm{H}_{2} \mathrm{O}_{(\mathrm{g})} \\
2 \mathrm{NH}_{4} \mathrm{H}_{2} \mathrm{PO}_{4}+\mathrm{MeCl}_{2} \rightarrow \mathrm{MeO} \cdot \mathrm{P}_{2} \mathrm{O}_{5} \text { (glass) }+2 \mathrm{NH}_{4} \mathrm{Cl}_{(\mathrm{g})}+2 \mathrm{H}_{2} \mathrm{O}_{(\mathrm{g})} \\
6 \mathrm{NH}_{4} \mathrm{H}_{2} \mathrm{PO}_{4}+2 \mathrm{MeCl}_{3} \rightarrow \mathrm{Me}_{2} \mathrm{O}_{3} \cdot 3 \mathrm{P}_{2} \mathrm{O}_{5} \text { (glass) }+6 \mathrm{NH}_{4} \mathrm{Cl}_{(\mathrm{g})}+6 \mathrm{H}_{2} \mathrm{O}_{(\mathrm{g})}
\end{gathered}
$$$$
\left(\mathrm{Me}^{3+}\right)
$$$$
\left(\mathrm{Me}^{1+}\right)
$$$$
\left(\mathrm{Me}^{2+}\right)
$$$$
\left(\mathrm{Me}^{3+}\right)
$$

In a study by Siemer (2012a), $\mathrm{H}_{3} \mathrm{PO}_{4}, \mathrm{Fe}_{2} \mathrm{O}_{3}$, and different chloride salts (i.e., $\mathrm{NaCl}$ only, $\mathrm{LiCl}+\mathrm{KCl}$, and $\mathrm{LiCl}+\mathrm{NaCl}+\mathrm{KCl}$ ) were added to porcelain crucibles and then gradually heated to remove water and $\mathrm{HCl}$. Following this, the mixture was heated to $\sim 1050^{\circ} \mathrm{C}$ for $30 \mathrm{~min}$ and quenched into a steel mortar. During the study, the effect of the Fe:P molar ratio was 0.4 or 0.8 ; and it was found that it was more difficult to dissolve the increasing loadings of $\mathrm{KCl}$ into the glass when the $0.4(\mathrm{Fe}: \mathrm{P})$ ratio was used.

In a study by Donze et al. (2000), $\mathrm{Pb}$-, $\mathrm{Cd}$-, $\mathrm{Na}$-, and $\mathrm{K}$-metal chlorides were mixed with $\mathrm{NH}_{4} \mathrm{H}_{2} \mathrm{PO}_{4}$ heated at $10^{\circ} \mathrm{C} \mathrm{min}^{-1}$ with intermediate 1 -h holds at 200,300 , and $400^{\circ} \mathrm{C}$ (to recover $\mathrm{NH}_{4} \mathrm{Cl}$ ) followed by melting at either $700^{\circ} \mathrm{C}$ for $30 \mathrm{~min}$ or $900^{\circ} \mathrm{C}$ for $2 \mathrm{~h}$. They noted that when the molar ratio of $\mathrm{Cl}: \mathrm{NH}_{4} \mathrm{H}_{2} \mathrm{PO}_{4}$ was too high (i.e., $\left.>1\right), \mathrm{HCl}_{(\mathrm{g})}$ was released. For full dechlorination, they stated that the ideal $\mathrm{P}_{2} \mathrm{O}_{5}$ concentrations in the final glass were $>45 \mathrm{~mol} \%$. The compositions of the batches were measured as a function of salt loading and heat-treatment temperature. It was apparent from these measurements that, while the chloride content in the products decreased, the other species remained largely unchanged from targeted values (Figure 4-8). Also, achieving full dechlorination was more effective at the $900^{\circ} \mathrm{C}$ heat-treatment temperature as opposed to heating at $700^{\circ} \mathrm{C}$ (Figure 4-8).
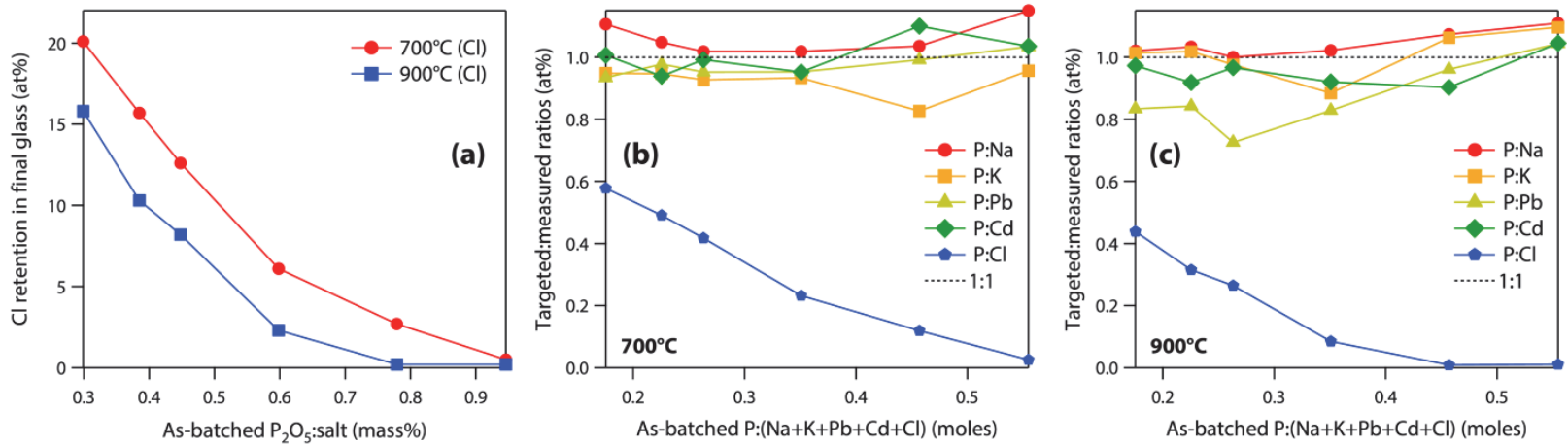

Figure 4-8. Data plotted from Donze et al. (2000) including (a) Cl retention as a function of salt $\left(\mathrm{PbCl}_{2}+\mathrm{CdCl}_{2}+\mathrm{NaCl}+\mathrm{KCl}\right)$ loading, (b) ratio of targeted:measured values (by element) in glasses heated at $700 \mathrm{C}$ for $30 \mathrm{~min}$, and (c) ratio of targeted:measured values (by element) in glasses heated at $900^{\circ} \mathrm{C}$ for $2 \mathrm{~h}$.

To optimize this process for a given salt, the following parameters should be considered:

- Preferential reactivity between salts and the phosphate precursor 
- $\mathrm{NH}_{4} \mathrm{H}_{2} \mathrm{PO}_{4}$ :salt molar ratio

- $\quad$ Phosphate precursor, e.g., $\mathrm{P}_{2} \mathrm{O}_{5}, \mathrm{H}_{3} \mathrm{PO}_{4}, \mathrm{NH}_{4} \mathrm{H}_{2} \mathrm{PO}_{4}$, and $\left(\mathrm{NH}_{4}\right)_{2} \mathrm{HPO}_{4}$ (potentially)

- Heat-treatment temperature

- Soak time

Several of these variable can be selected to reduce, or even eliminate, unwanted byproducts such as acids (e.g., HF, HCl, HI). Some critical temperatures and processing conditions for Cl-salts are presented in Table 1-1. To the authors' knowledge, this dehalogenation process has not yet been demonstrated for pure fluoride or iodide salts, but a similar approach could potentially be applied. It is likely that HF would be generated with any moisture present during the process, so this issue would have to be considered and properly mitigated. Note that the decomposition temperature of $\mathrm{NH}_{4} \mathrm{~F}$ is $238^{\circ} \mathrm{C}$, versus $338^{\circ} \mathrm{C}$ where $\mathrm{NH}_{4} \mathrm{Cl}$ sublimes (Table 1-1); therefore, the fluoride system would require an entirely different set of conditions for operation than the chloride system. If HF is a potential byproduct, it is likely that finding structural equipment for the apparatus would prove difficult, considering that $\mathrm{HF}$ readily attacks glassware.

Table 4-2. Important data and parameters for mixing $\mathrm{NH}_{4} \mathrm{H}_{2} \mathrm{PO}_{4}$ with Cl-salts based on work by Donze et al. (2000) as well as melting temperatures $\left(T_{\mathrm{m}}\right)$ and boiling temperatures $\left(T_{\mathrm{b}}\right)$ for applicable compounds ("Physical Constants of Inorganic Compounds", 2007-2008).

\begin{tabular}{|c|c|c|c|}
\hline Parameter & Value & $T_{\mathrm{m}}\left({ }^{\circ} \mathrm{C}\right)$ & $T_{\mathrm{b}}\left({ }^{\circ} \mathrm{C}\right)$ \\
\hline Optimal P:(salt cations) & $>45 \mathrm{~mol} \%$ & - & - \\
\hline Optimal $\mathrm{NH}_{4} \mathrm{H}_{2} \mathrm{PO}_{4}$ :salt ratio & $\geq 1.26$ (by mass) & - & - \\
\hline $\mathrm{NH}_{4} \mathrm{H}_{2} \mathrm{PO}_{4}$ & - & 190 & - \\
\hline$\left(\mathrm{NH}_{4}\right)_{2} \mathrm{HPO}_{4}$ & - & $155^{a}$ & - \\
\hline $\mathrm{NH}_{4} \mathrm{~F}$ & - & $238^{a}$ & - \\
\hline $\mathrm{NH}_{4} \mathrm{Cl}$ & - & 520 & $338^{b}$ \\
\hline $\mathrm{NH}_{4} \mathrm{I}$ & - & $551^{(\mathrm{a})}$ & $405^{b}$ \\
\hline
\end{tabular}

${ }^{a}$ Decomposes

${ }^{b}$ Sublimes

As is shown in Figure 4-9, the thermodynamic favorability of the formation of $\mathrm{NH}_{4}$-halides decreases in the order $\mathrm{F}>\mathrm{Cl}>\mathrm{Br}>\mathrm{I}$ at a given temperature. These data provide thermodynamic evidence for the favorability of $\mathrm{NH}_{4} \mathrm{~F}$ formation, and this reaction could possibly occur at temperatures even lower than the reactions demonstrated for $\mathrm{NH}_{4} \mathrm{Cl}$ formation (see Figure 4-10, Table 4-2, and Equations 4-5 - 4-10). 


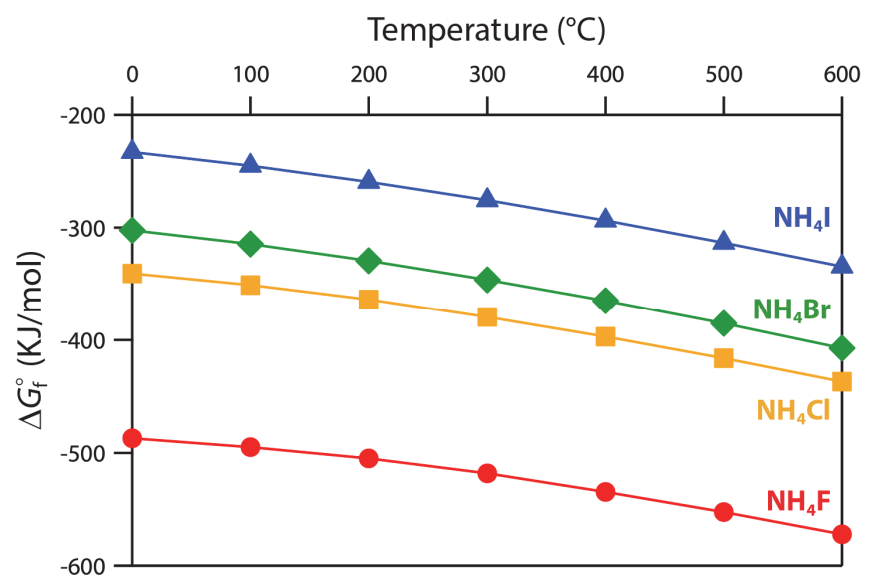

Figure 4-9. Gibbs free energy of formation of ammonium halide salts (halide $=\mathrm{F}, \mathrm{Cl}, \mathrm{Br}, \mathrm{I}$ ) as a function of temperature. These data were collected with HSC.

Some literature exists demonstrating dehalogenation of $\mathrm{CsCl}$ salt through the synthesis of an iron phosphate glass (Mesko et al., 2000). In Mesko et al., different amounts of $\mathrm{CsCl}$ and/or $\mathrm{SrF}_{2}$ were added to a binary mixture of $\mathrm{Fe}_{2} \mathrm{O}_{3}-\mathrm{P}_{2} \mathrm{O}_{5}$ (with varying $\mathrm{Fe}_{2} \mathrm{O}_{3}: \mathrm{P}_{2} \mathrm{O}_{5}$ molar ratios). The data from this study show that the chloride was almost completed removed during the melting process while the remaining species were almost completely retained (see Figure 4-10). This was the case whether just $\mathrm{CsCl}$ was added (Figure 4-10a) or $\mathrm{CsCl}$ and $\mathrm{SrF}_{2}$ were added (Figure 4-10b). For the glasses with $\mathrm{CsCl}$ and $\mathrm{SrF}_{2}$, the Cs, $\mathrm{Cl}$, and $\mathrm{Sr}$ were tracked for each glass, but the $\mathrm{F}$ was not; so it is unclear how much was retained within the glass.

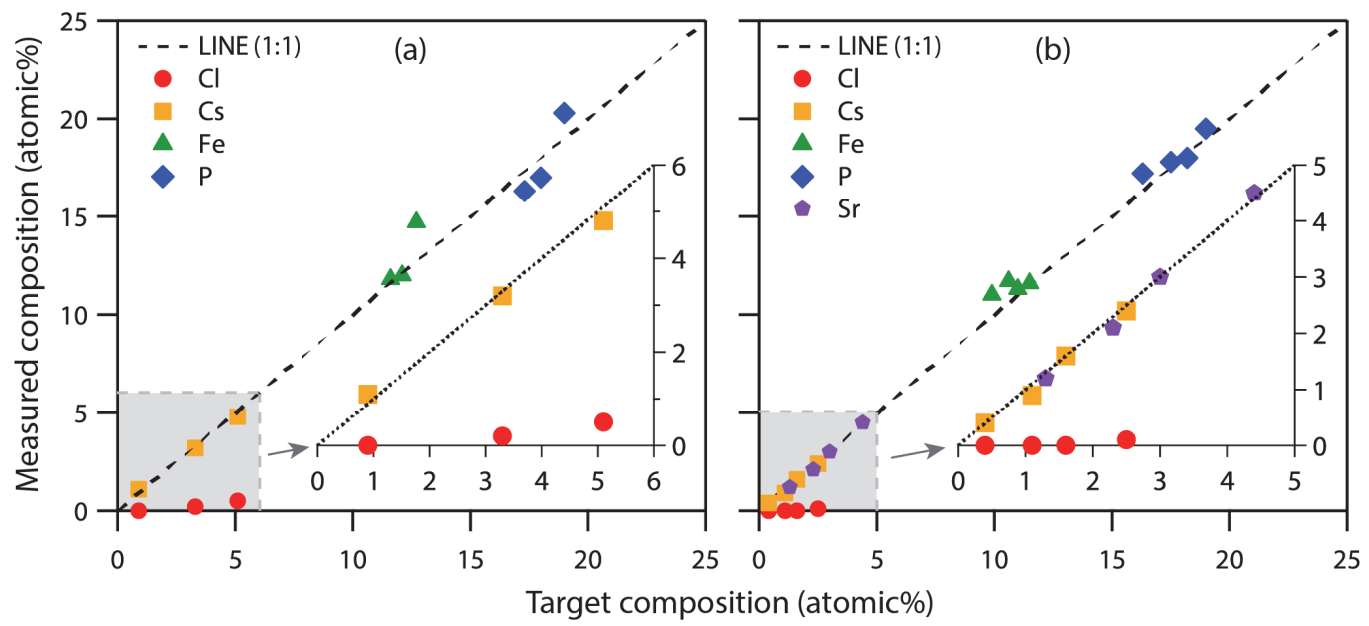

Figure 4-10. Summary of measured compositions as a function of target composition for iron phosphate glasses batched with (a) $\mathrm{CsCl}$ or (b) $\mathrm{CsCl}+\mathrm{SrF}_{2}$ (Mesko et al., 2000). The gray boxes in the bottom left corner of each plot show the encompassing regions for which magnified insets are provided in the bottom right corners of each plot. Note that fluoride retention was not measured and is not included here.

In a study by Kim and Day (2003), an iron phosphate glass was used to immobilize a Hanford lowactivity waste containing both $\mathrm{Cl}$ and $\mathrm{F}$. These glasses were synthesized by reacting $\mathrm{Fe}_{2} \mathrm{O}_{3}, \mathrm{P}_{2} \mathrm{O}_{5}$, and the waste simulants in air at $1000-1050^{\circ} \mathrm{C}$ for $2-3 \mathrm{~h}$ in high-purity alumina crucibles. The melts were stirred 3 or 4 times with a fused silica rod to improve the homogeneity of the melt. The melts were cast into bars and annealed at $430-450^{\circ} \mathrm{C}$ for $5 \mathrm{~h}$. The results shown in Table 4-3 reveal that $\mathrm{Cl}$ and $\mathrm{F}$ concentrations in 
the final glasses were below the detection limits of the instruments and were likely released as gases (i.e., $\mathrm{Cl}_{2}$ and $\mathrm{F}_{2}$ ) during the melting process.

Table 4-3. Batch and analyzed inductively-coupled plasma emission spectroscopy (ICP-ES) compositions (mass\%) of iron phosphate glasses containing 30 mass\% simulated LAW waste (i.e., IP30LAW, IP30- LAWA and IP30LAW-C) according to Kim and Day (2003) ( NM = not measured).

\begin{tabular}{|l|c|c|c|c|c|c|}
\hline \multirow{2}{*}{ Additive } & \multicolumn{2}{|c|}{ IP30LAW } & \multicolumn{2}{c|}{ IP30LAW-A } & \multicolumn{2}{c|}{ IP30LAW-C } \\
\cline { 2 - 7 } & Batch & ICP-ES & Batch & ICP-ES & Batch & ICP-ES \\
\hline $\mathrm{Al}_{2} \mathrm{O}_{3}$ & 1.3 & 3.4 & 11.3 & 13.6 & 1.3 & 3.0 \\
\hline $\mathrm{Cl}$ & 0.2 & $N M$ & 0.2 & NM & 0.2 & NM \\
\hline $\mathrm{Cr}_{2} \mathrm{O}_{3}$ & 0.1 & 0.1 & 0.1 & 0.1 & 3.1 & 2.8 \\
\hline $\mathrm{F}$ & 0.5 & $N M$ & 0.5 & NM & 0.5 & NM \\
\hline $\mathrm{Fe}_{2} \mathrm{O}_{3}$ & 20.0 & 17.2 & 10.0 & 9.4 & 17.0 & 15.3 \\
\hline $\mathrm{Na}_{2} \mathrm{O}$ & 22.6 & 23.1 & 22.6 & 22.4 & 22.6 & 22.5 \\
\hline $\mathrm{P}_{2} \mathrm{O}_{5}$ & 52.2 & 53.9 & 52.2 & 52.6 & 52.2 & 54.0 \\
\hline $\mathrm{SiO}_{2}$ & 0.2 & 0.1 & 0.2 & 0.1 & 0.2 & 0.1 \\
\hline $\mathrm{SO}_{3}$ & 2.9 & $1.3 \mathrm{a}$ & 2.9 & $1.5 \mathrm{a}$ & 2.9 & 1.5 \\
\hline $\mathrm{Total}^{2}$ & 100.0 & 99.1 & 100.0 & 99.7 & 100.0 & 99.2 \\
\hline
\end{tabular}

\subsubsection{Immobilization of Dehalogenated Products in Phosphate Glass}

Dechlorinated phosphate glass is not chemically durable, but it can be subsequently mixed with other glass-forming components to optimize the chemical durability (e.g., $\mathrm{Fe}_{2} \mathrm{O}_{3}$ ) and maximize the waste loading capacity (Bingham and Hand, 2006; Day and Ray, 2013; Leerssen, 2002; Marasinghe et al., 2000a; Marasinghe et al., 2000b; Mesko et al., 2000). For phosphate glasses, one of the key parameters for maximizing chemical durability is the O:P molar ratio, where values of $\sim 3.4$ to 3.6 showed the highest durabilities (see red arrow in Figure 4-11a). When this range is expanded to accommodate more compositionally flexible wastes, it is suggested that a range of 3.25 to 4.0 be targeted with an (Fe+ $\mathrm{Al}): \mathrm{P}$ molar ratio target of 0.45-0.70 to achieve the highest possible chemical stabilities (Day and Ray, 2013).

Additional options that are currently under investigation include the optimal P:Fe molar ratio as well as additional components that can help improve the final properties of the final waste form. More information about this approach, other work with phosphate glasses for these types of wastes, and how to improve the chemical durability of such glasses is provided by Frank et al. (2017). 

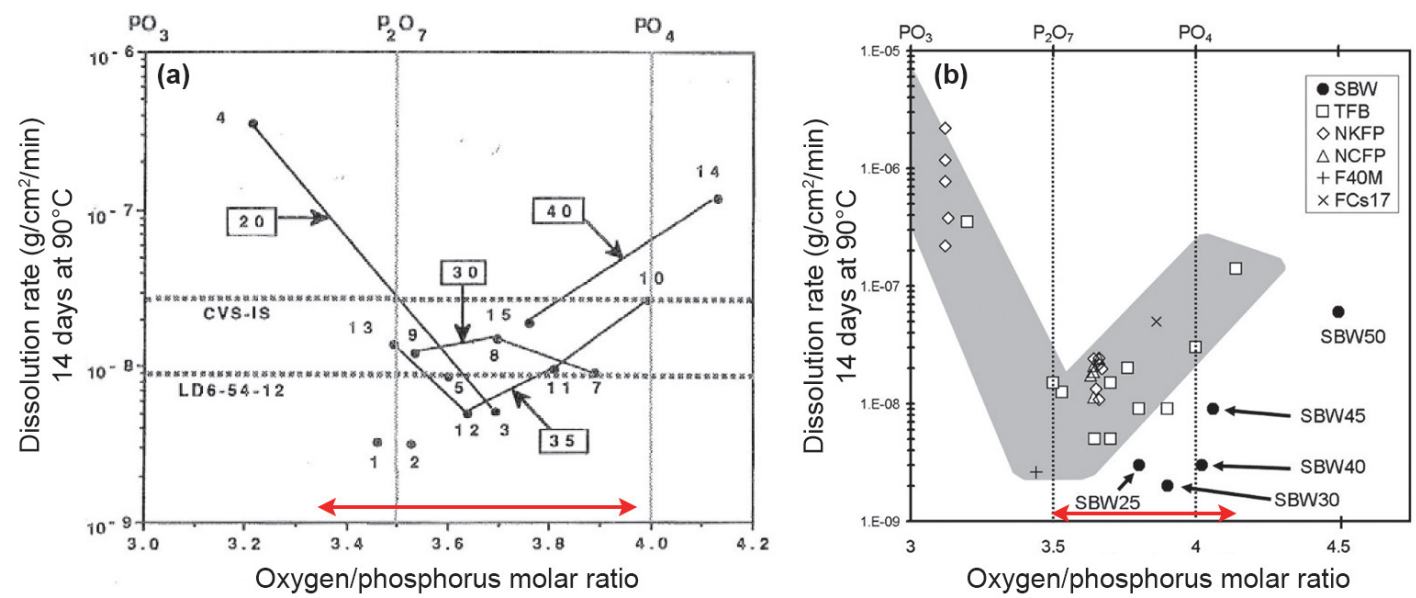

Figure 4-11. Variation in the iron phosphate glass dissolution rate as a function of the $\mathrm{O} / \mathrm{P}$ molar ratio for (a) Hanford Tank Farm B waste (Day et al., 1998) and (b) Idaho National Laboratory Na-bearing waste compared with other waste forms (Day and Ray, 2013).

\subsubsection{Dehalogenation of Salt through Reaction with Ultrastable H-Y Zeolite}

Work is currently being done by Simpson et al. (Bagri and Simpson, 2015) at the University of Utah to use ultrastable $\mathrm{H}-\mathrm{Y}$ (USH-Y) zeolite to remove $\mathrm{Cl}$ from a chloride salt simulant representative of used pyroprocessing salts. This process is shown schematically in Figure 4-12, which shows a dehydrated USH-Y zeolite reacted with a $\mathrm{LiCl}-\mathrm{KCl}$ eutectic salt containing fission products in a high-temperature blender. The halides from the salt react with the $\mathrm{H}^{+}$from the zeolite to create volatile acids (i.e., $\mathrm{HCl}$, $\mathrm{HI}$ ), which are captured in a condenser. This results in a salt-occluded zeolite (SOZ) containing the other salt cations, which decomposes at around $650^{\circ} \mathrm{C}$. The SOZ product can be (1) encapsulated in a lowmelting glass such as a bismuth silicate glass (Gardner et al., 2018), or (2) destroyed through incorporation into a glass binder that melts at $T>650^{\circ} \mathrm{C}$ [e.g., a high-SiO ${ }_{2}$ binder like NBS-1, NBS-4, or P57 (Riley et al., 2017d; Vienna et al., 1998)]. Alternatively, it is also possible that this approach could be a viable option for defluorinating fluoride-based salts, although it has not yet been tested for that application.

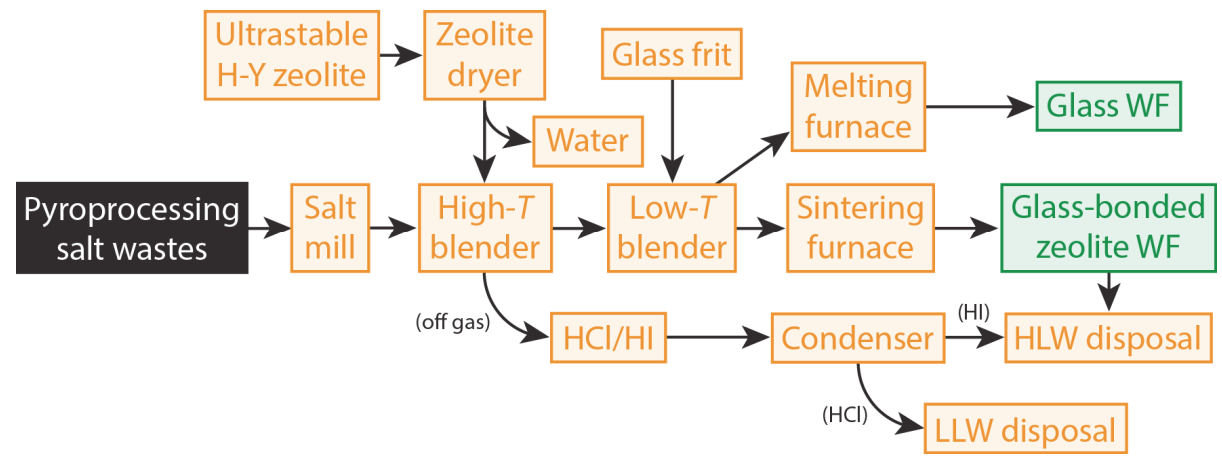

Figure 4-12. Process flow diagram for using ultrastable $\mathrm{H}-\mathrm{Y}$ zeolite to dechlorinate used pyroprocessing salt wastes before immobilization (Bagri and Simpson, 2015). "GBZ" denotes glass-bonded zeolite. 


\subsection{Separations and Products of Separations}

Products of separations are dependent up on the types of processes used and the goals of the specific separation process. These objectives could include any (or all) of the following:

- Removal of the actinide fuel and highly radiative fission and activation products for waste disposal at the end of the reactor lifetime

- Online removal of volatile fission products and activation products and neutron poisons

- Collection of solids from the operating reactor

- Salt recycling to reuse isotopically pure components

A few different options have been proposed for partitioning chloride- and fluoride-based salts. They are discussed below in the following sections in more detail, along with how separated streams can be prepared for disposal as waste.

\subsubsection{Oxidative Precipitation}

For oxidative precipitation, rare-earth chloride $\left(\mathrm{RECl}_{3}\right)$ fission products in a molten LiCl-KCl eutectic salt can be converted to a mixture of REOCl (i.e., La, $\mathrm{Pr}, \mathrm{Nd}, \mathrm{Sm}, \mathrm{Eu}$, and $\mathrm{Gd}$ ) and $\mathrm{REO}_{x}$ (i.e., $\mathrm{Ce}, \mathrm{Pr}$, and Y), which settle to the bottom of the vessel because they have higher densities than the eutectic salt (Cho et al., 2009). The reactions that occur between the $\mathrm{RECl}_{3}$ precursors and $\mathrm{O}_{2(\mathrm{~g})}$ to create the $\mathrm{REOCl}, \mathrm{RE}_{2} \mathrm{O}_{3}$, or $\mathrm{REO}_{2}$ products are presented in Reactions (4-11) - (4-13). It was determined from this study that $>99 \%$ conversion efficiency was achieved at heat-treatment temperatures of $750^{\circ} \mathrm{C}$, a 12 -h sparging time, and an $\mathrm{O}_{2(\mathrm{~g})}$ flow rate of $5 \mathrm{~L} \mathrm{~min}^{-1}$. The same efficiency was achieved at this $\mathrm{O}_{2(\mathrm{~g})}$ flow rate in only $6 \mathrm{~h}$ when a heat-treatment temperature of $800^{\circ} \mathrm{C}$ was used instead.

$$
\begin{aligned}
& 2 \mathrm{RECl}_{3}+\mathrm{O}_{2(\mathrm{~g})} \stackrel{\Delta}{\rightarrow} 2 \mathrm{REOCl}+2 \mathrm{Cl}_{2(\mathrm{~g})} \\
& 4 \mathrm{RECl}_{3}+3 \mathrm{O}_{2(\mathrm{~g})} \stackrel{\Delta}{\rightarrow} 2 \mathrm{RE}_{2} \mathrm{O}_{3}+6 \mathrm{Cl}_{2(\mathrm{~g})} \\
& 2 \mathrm{RECl}_{3}+2 \mathrm{O}_{2(\mathrm{~g})} \stackrel{\Delta}{\rightarrow} 2 \mathrm{REO}_{2}+3 \mathrm{Cl}_{2(\mathrm{~g})}
\end{aligned}
$$

Once these components are removed, they could be immobilized in a lanthanide borosilicate (LaBS) glass. This family of glasses has been documented to incorporate $>60$ mass $\%$ of lanthanide oxides (Riley et al., 1999; Youchak-Billings et al., 2008). If the oxychlorides do not incorporate, it is possible that they could be immobilized in a tellurite glass (Riley et al., 2018b), albeit at lower loadings and a substantially increased cost.

A similar process for fluorides salts seems unlikely. As an example, Reactions (4-14) - (4-19) were considered, and their equilibrium constants are presented in Table 4-4. An equilibrium calculation using the entire set of species containing $\mathrm{Li}, \mathrm{Be}, \mathrm{Zr}, \mathrm{U}, \mathrm{Pu}, \mathrm{Sm}, \mathrm{F}$, and $\mathrm{O}$ seems to indicate only the fluorides species are predominant, with no formation of oxyfluorides or oxides. While the direct removal of fluorine by oxygen is in general an unlikely proposition, the formation of oxyfluorides and fluorides can be promoted using oxide species with very high affinity for fluoride, such as $\mathrm{B}_{2} \mathrm{O}_{3}, \mathrm{SiO}_{2}, \mathrm{P}_{2} \mathrm{O}_{3}, \mathrm{P}_{2} \mathrm{O}_{5}$, and/or $\mathrm{Al}_{2} \mathrm{O}_{3}$. All of these species produce volatile fluorides except $\mathrm{AlF}_{3}$, which is a solid.

$$
\begin{gathered}
\mathrm{ZrF}_{4}+\mathrm{O}_{2(\mathrm{~g})} \rightleftharpoons \mathrm{ZrO}_{2}+2 \mathrm{~F}_{2(\mathrm{~g})} \\
2 \mathrm{UF}_{4}+\mathrm{O}_{2(\mathrm{~g})} \rightleftharpoons 2 \mathrm{UOF}_{2}+2 \mathrm{~F}_{2(\mathrm{~g})} \\
\mathrm{UF}_{4}+\mathrm{O}_{2(\mathrm{~g})} \rightleftharpoons \mathrm{UO}_{2}+2 \mathrm{~F}_{2(\mathrm{~g})}
\end{gathered}
$$




$$
\begin{aligned}
2 \mathrm{BeF}_{2}+\mathrm{O}_{2(\mathrm{~g})} & \rightleftharpoons 2 \mathrm{BeO}+2 \mathrm{~F}_{2(\mathrm{~g})} \\
2 \mathrm{PuF}_{3}+\mathrm{O}_{2(\mathrm{~g})} & \rightleftharpoons 2 \mathrm{PuOF}+2 \mathrm{~F}_{2(\mathrm{~g})} \\
2 \mathrm{SmF}_{3}+\mathrm{O}_{2(\mathrm{~g})} & \rightleftharpoons 2 \mathrm{SmOF}+2 \mathrm{~F}_{2(\mathrm{~g})}
\end{aligned}
$$

Table 4-4. Equilibrium constants calculated using HSC for Reactions (4-14) - (4-19). Values are in $\mathbf{~ k m o l} / \mathbf{k m o l}$ (unitless).

\begin{tabular}{|l|c|c|c|c|c|c|}
\hline $\begin{array}{l}\text { Temperature } \\
\left({ }^{\circ} \mathbf{C}\right)\end{array}$ & $\begin{array}{c}\mathbf{Z r F}_{4} / \\
\mathbf{Z r O}_{2}\end{array}$ & $\begin{array}{c}\mathbf{U F}_{4} / \\
\mathbf{U O F}_{2}\end{array}$ & $\begin{array}{c}\mathbf{U F}_{4} / \\
\mathbf{U O}_{2}\end{array}$ & $\begin{array}{c}\mathbf{B e F}_{2} / \\
\mathbf{B e O}\end{array}$ & $\begin{array}{c}\mathbf{P u F}_{3} / \\
\mathbf{P u O F}\end{array}$ & $\begin{array}{c}\mathbf{S m F}_{3} / \\
\mathbf{S m O F}\end{array}$ \\
\hline 400 & $3.46 \mathrm{E}-56$ & $1.36 \mathrm{E}-57$ & $1.11 \mathrm{E}-58$ & $1.72 \mathrm{E}-59$ & $6.30 \mathrm{E}-63$ & $1.28 \mathrm{E}-73$ \\
\hline 500 & $4.19 \mathrm{E}-48$ & $1.78 \mathrm{E}-49$ & $2.11 \mathrm{E}-50$ & $3.48 \mathrm{E}-51$ & $4.96 \mathrm{E}-54$ & $2.82 \mathrm{E}-63$ \\
\hline 600 & $6.89 \mathrm{E}-42$ & $3.09 \mathrm{E}-43$ & $4.99 \mathrm{E}-44$ & $7.90 \mathrm{E}-45$ & $3.43 \mathrm{E}-47$ & $2.69 \mathrm{E}-55$ \\
\hline 700 & $5.78 \mathrm{E}-37$ & $2.72 \mathrm{E}-38$ & $5.71 \mathrm{E}-39$ & $7.95 \mathrm{E}-40$ & $8.98 \mathrm{E}-42$ & $5.85 \mathrm{E}-49$ \\
\hline 800 & $5.68 \mathrm{E}-33$ & $2.79 \mathrm{E}-34$ & $7.36 \mathrm{E}-35$ & $9.00 \mathrm{E}-36$ & $2.22 \mathrm{E}-37$ & $8.20 \mathrm{E}-44$ \\
\hline 900 & $1.13 \mathrm{E}-29$ & $5.80 \mathrm{E}-31$ & $1.87 \mathrm{E}-31$ & $2.00 \mathrm{E}-32$ & $9.48 \mathrm{E}-34$ & $1.49 \mathrm{E}-39$ \\
\hline 1000 & $4.31 \mathrm{E}-27$ & $3.55 \mathrm{E}-28$ & $1.36 \mathrm{E}-28$ & $1.29 \mathrm{E}-29$ & $1.06 \mathrm{E}-30$ & $5.68 \mathrm{E}-36$ \\
\hline
\end{tabular}

As an example, we can consider the Reactions (4-20) - (4-27) that would apply to MSRE fluoride salt treated with $\mathrm{B}_{2} \mathrm{O}_{3}$. Table 4-5 shows the equilibrium constants for Reactions (4-20) - (4-27). In a molten salt, we would have to correct by using the activity coefficients and complexation constants. However, the table is in general agreement with observed behavior. Zirconium oxide is one of the first oxides to form and precipitate, closely followed by the formation and segregation of $\mathrm{UOF}_{2}, \mathrm{UO}_{2}$, and $\mathrm{BeO}$. According to the multi-equilibria calculations using $\mathrm{HSC}, \mathrm{LiF}$ and $\mathrm{SmCl}_{3}$ (as a representative of the rare earth family) will remain unreacted. The $\mathrm{Pu}$ will precipitate as $\mathrm{PuOF}$ at the later stages after all of the $\mathrm{Zr}$ and $\mathrm{U}$ precipitate, along with a large fraction of Be. Lithium fluoride is highly soluble in anhydrous hydrogen fluoride, while higher-charge species are not; accordingly, such an extraction could be used to recover the $\mathrm{LiF}$ (Campbell and Cathers, 1960).

$$
\begin{gathered}
1.5 \mathrm{ZrF}_{4}+\mathrm{B}_{2} \mathrm{O}_{3} \rightleftharpoons 2 \mathrm{BF}_{3(\mathrm{~g})}+1.5 \mathrm{ZrO}_{2} \\
3 \mathrm{UF}_{4}+\mathrm{B}_{2} \mathrm{O}_{3} \rightleftharpoons 3 \mathrm{UOF}_{2}+2 \mathrm{BF}_{3(\mathrm{~g})} \\
1.5 \mathrm{UF}_{4}+\mathrm{B}_{2} \mathrm{O}_{3} \rightleftharpoons 1.5 \mathrm{UO}_{2}+2 \mathrm{BF}_{3(\mathrm{~g})} \\
\mathrm{PuF}_{4}+\mathrm{UF}_{3} \rightleftharpoons \mathrm{PuF}_{3}+\mathrm{UF}_{4} \\
3 \mathrm{PuF}_{3}+\mathrm{B}_{2} \mathrm{O}_{3} \rightleftharpoons 3 \mathrm{PuOF}+2 \mathrm{BF}_{3(\mathrm{~g})} \\
3 \mathrm{Li}_{2} \mathrm{BeF}_{4}+\mathrm{B}_{2} \mathrm{O}_{3} \rightleftharpoons 3 \mathrm{BeO}+2 \mathrm{BF}_{3(\mathrm{~g})}+6 \mathrm{LiF} \\
3 \mathrm{BeF}_{2}+\mathrm{B}_{2} \mathrm{O}_{3} \rightleftharpoons 3 \mathrm{BeO}+2 \mathrm{BF}_{3(\mathrm{~g})} \\
3 \mathrm{SmF}_{3}+\mathrm{B}_{2} \mathrm{O}_{3} \rightleftharpoons 2 \mathrm{BF}_{3(\mathrm{~g})}+3 \mathrm{SmOF}
\end{gathered}
$$


Table 4-5. Equilibrium constants calculated using HSC for Reactions (4-20) - (4-27). Values are in $\mathbf{k m o l} / \mathbf{k m o l}$ (unitless).

\begin{tabular}{|l|c|c|c|c|c|c|c|c|}
\hline $\begin{array}{l}\text { Temperature } \\
\left({ }^{\circ} \mathbf{C}\right)\end{array}$ & $\begin{array}{c}\mathbf{Z r F}_{4} / \\
\mathbf{Z r O}\end{array}$ & $\begin{array}{c}\mathbf{U F}_{4} / \\
\mathbf{U O F}\end{array}$ & $\begin{array}{c}\mathbf{U F}_{4} / \\
\mathbf{U O}_{2}\end{array}$ & $\begin{array}{c}\mathbf{P u F}_{4} / \\
\mathbf{P u F}_{3}\end{array}$ & $\begin{array}{c}\mathbf{P u F}_{3} / \\
\mathbf{P u O F}\end{array}$ & $\begin{array}{c}\mathbf{L i}_{2} \mathbf{B e F}_{4} / \\
\mathbf{B e O}\end{array}$ & $\begin{array}{c}\mathbf{B e F}_{2} / \\
\mathbf{B e O}\end{array}$ & $\begin{array}{c}\mathbf{S m F}_{3} / \\
\mathbf{S m O F}\end{array}$ \\
\hline 400 & $1.31 \mathrm{E}+02$ & $1.02 \mathrm{E}+00$ & $2.39 \mathrm{E}-02$ & $8.83 \mathrm{E}+11$ & $1.02 \mathrm{E}-08$ & $2.49 \mathrm{E}-07$ & $1.46 \mathrm{E}-03$ & $9.36 \mathrm{E}-25$ \\
\hline 500 & $1.05 \mathrm{E}+04$ & $9.17 \mathrm{E}+01$ & $3.75 \mathrm{E}+00$ & $2.76 \mathrm{E}+10$ & $1.35 \mathrm{E}-05$ & $2.97 \mathrm{E}-05$ & $2.51 \mathrm{E}-01$ & $1.84 \mathrm{E}-19$ \\
\hline 600 & $2.14 \mathrm{E}+05$ & $2.03 \mathrm{E}+03$ & $1.32 \mathrm{E}+02$ & $1.92 \mathrm{E}+09$ & $2.38 \mathrm{E}-03$ & $1.54 \mathrm{E}-04$ & $8.33 \mathrm{E}+00$ & $1.65 \mathrm{E}-15$ \\
\hline 700 & $2.11 \mathrm{E}+06$ & $2.15 \mathrm{E}+04$ & $2.07 \mathrm{E}+03$ & $2.34 \mathrm{E}+08$ & $1.29 \mathrm{E}-01$ & $4.32 \mathrm{E}-04$ & $1.08 \mathrm{E}+02$ & $2.14 \mathrm{E}-12$ \\
\hline 800 & $1.24 \mathrm{E}+07$ & $1.35 \mathrm{E}+05$ & $1.82 \mathrm{E}+04$ & $4.26 \mathrm{E}+07$ & $3.02 \mathrm{E}+00$ & $8.16 \mathrm{E}-04$ & $7.80 \mathrm{E}+02$ & $6.78 \mathrm{E}-10$ \\
\hline 900 & $4.98 \mathrm{E}+07$ & $5.76 \mathrm{E}+05$ & $1.05 \mathrm{E}+05$ & $1.05 \mathrm{E}+07$ & $3.81 \mathrm{E}+01$ & $2.57 \mathrm{E}-03$ & $3.70 \mathrm{E}+03$ & $7.53 \mathrm{E}-08$ \\
\hline 1000 & $7.81 \mathrm{E}+07$ & $1.85 \mathrm{E}+06$ & $4.40 \mathrm{E}+05$ & $3.28 \mathrm{E}+06$ & $3.01 \mathrm{E}+02$ & $1.17 \mathrm{E}-02$ & $1.27 \mathrm{E}+04$ & $3.74 \mathrm{E}-06$ \\
\hline
\end{tabular}

\subsubsection{Reactive Distillation}

Reactive distillation can be used to convert rare-earth chlorides (i.e., $\mathrm{RECl}_{3}$ ) to rare-earth phosphates (i.e., $\mathrm{REPO}_{4}$ ) through the introduction of phosphates, e.g., $\mathrm{Li}_{3} \mathrm{PO}_{4}, \mathrm{~K}_{3} \mathrm{PO}_{4}, \mathrm{NH}_{4} \mathrm{H}_{2} \mathrm{PO}_{4},\left(\mathrm{NH}_{4}\right)_{2} \mathrm{HPO}_{4}$. In a demonstration by Eun et al. (2016), $2.5 \mathrm{~kg}$ of LiCl-KCl (0.59:0.41, by mole) was mixed with $0.125 \mathrm{~kg}$ of $\mathrm{RECl}_{3}$, and melted in a reactor at $450^{\circ} \mathrm{C}$ under constant stirring. To this mixture was added $(\mathrm{Li}, \mathrm{K})_{3} \mathrm{PO}_{4}$ ( $\mathrm{Li}: \mathrm{K}=0.59: 0.41$, by mole) while stirring and Reaction (4-28) took place. Following this process, the $(\mathrm{Li}, \mathrm{K}) \mathrm{Cl}$ product was recovered through a distillation process. The $\mathrm{REPO}_{4}$ product is a durable mineral (i.e., typically monazite) that can be hot-pressed into a waste form or mixed with a glass binder to create a glass-composite material (Boatner et al., 1980; McCarthy et al., 1978).

$$
\mathrm{RECl}_{3}+(\mathrm{Li}, \mathrm{K})_{3} \mathrm{PO}_{4} \stackrel{\Delta}{\rightarrow} \mathrm{REPO}_{4}+3(\mathrm{Li}, \mathrm{K}) \mathrm{Cl}
$$

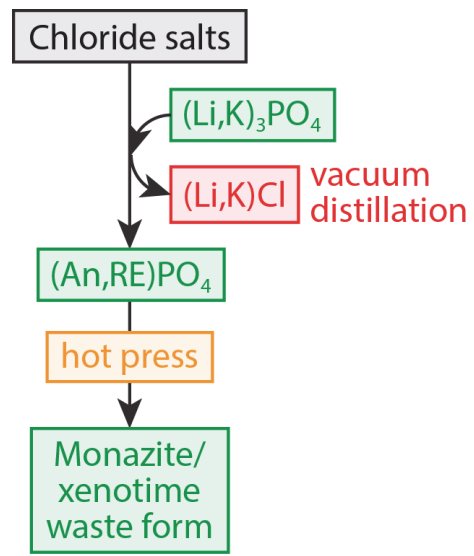

Figure 4-13. Reactive distillation process demonstrated by demonstrated by Eun et al. (2016).

This process was also demonstrated through the reaction of $\mathrm{LaCl}_{3}$ with $\mathrm{NH}_{4} \mathrm{H}_{2} \mathrm{PO}_{4}$ within a molten salt flux (i.e., $\mathrm{LiCl}, \mathrm{LiCl}-\mathrm{KCl}$, or $\mathrm{KCl}$ ) to produce monazite-like $\mathrm{LaPO}_{4}$ through Reaction (4-29) (Hudry et al., 2009). For this study, nuclear magnetic resonance (NMR) was used to track the evolution of ${ }^{35} \mathrm{Cl}$ and ${ }^{139} \mathrm{La}$ chemical shifts during the reactions using in situ analysis techniques, and after reactions using ex situ analyses. One of the key findings in this study is that $\mathrm{LaOCl}$ does form as a byproduct if the partial pressure of $\mathrm{O}_{2}$ is too high during the reaction. Once this compound forms, it is stable and cannot be further converted to $\mathrm{LaPO}_{4}$, but its formation can be eliminated if the reaction is performed in an environment with low enough $\mathrm{O}_{2}$ or in an $\mathrm{O}_{2}$-free atmosphere. 


$$
\mathrm{LaCl}_{3}+\mathrm{NH}_{4} \mathrm{H}_{2} \mathrm{PO}_{4} \stackrel{\text { (flux) } @ 500^{\circ} \mathrm{C}}{\longrightarrow} \mathrm{LaPO}_{4}+\mathrm{NH}_{4} \mathrm{Cl}+2 \mathrm{HCl}
$$

Lucas et al. (2004a; 2004b) precipitated $\mathrm{REPO}_{4}(\mathrm{RE}=\mathrm{La}, \mathrm{Ce}, \mathrm{Y})$ crystallites from aqueous solutions through reactions of $\mathrm{RECl}_{3}$ with phosphate precursors [i.e., $\mathrm{H}_{3} \mathrm{PO}_{4}$ or $\left(\mathrm{NH}_{4}\right)_{2} \mathrm{HPO}_{4}$ ]. Several variables were altered during the experiments, including solution temperature, $\mathrm{pH}$, ripening time, and the initial RE:P molar ratio of the mixture. For $\mathrm{LaCl}_{3}$ and $\mathrm{CeCl}_{3}$, the precipitation of $\mathrm{LaPO}_{4}$ and $\mathrm{CePO}_{4}$, respectively, required temperatures of $80^{\circ} \mathrm{C}$ or ripening times of $\geq 20 \mathrm{~h} ; \sim 1$ week of ripening at $90^{\circ} \mathrm{C}$ was required for well-crystallized hexagonal rhabdophane-type $\mathrm{REPO}_{4} \cdot 0.5 \mathrm{H}_{2} \mathrm{O}$ compounds. For the $\mathrm{YCl}_{3}$, the crystalline product was monoclinic churchite-type $\mathrm{YPO}_{4} \cdot 2 \mathrm{H}_{2} \mathrm{O}$ and could be easily synthesized at temperatures of just $30^{\circ} \mathrm{C}$ after $1-\mathrm{h}$ ripening times. These products could be filtered, dried, and heated to make waste forms.

Defluorination of $\mathrm{LiF}$ through a reaction with $\mathrm{NH}_{4} \mathrm{H}_{2} \mathrm{PO}_{4}$ was demonstrated in a study performed by Wang et al. (2004). In this study, $\mathrm{FeC}_{2} \mathrm{O}_{4} \cdot 2 \mathrm{H}_{2} \mathrm{O}, \mathrm{NH}_{4} \mathrm{H}_{2} \mathrm{PO}_{4}$, and $\mathrm{LiF}$ were calcined in a tube furnace under $\mathrm{Ar} / \mathrm{H}_{2}\left(92: 8\right.$, by volume) at $400^{\circ} \mathrm{C}$ for $8 \mathrm{~h}$. This sample was reground and fired at $400,500,600$, 700 , or $800^{\circ} \mathrm{C}$ for $24 \mathrm{~h}$ under the same atmosphere as before. The sample prepared at $600^{\circ} \mathrm{C}$ was analyzed with inductively-coupled plasma (ICP) spectroscopy, and no fluoride was found to be within the sample. Fluorine was found within the distilled water scrubbing solution coming off the exit of the tube furnace. In addition, $\mathrm{NH}_{4} \mathrm{~F}$ was detected from species on the inner walls of the low-temperature side of the tube furnace. It was noted that HF was generated as a byproduct through Reactions (4-30) - (4-32) in which the intermediate contains $\mathrm{Fe}, \mathrm{H}$, and $\mathrm{P}$ in a molar ratio of $1: 1: 1$ and could be $\mathrm{FeHPO}_{4}$. This approach could potentially be used to defluorinate other salts such as $\mathrm{BeF}_{2}, \mathrm{UF}_{3}, \mathrm{UF}_{4}$, and $\mathrm{ThF}_{4}$.

$$
\begin{gathered}
\mathrm{NH}_{4} \mathrm{H}_{2} \mathrm{PO}_{4}+\mathrm{FeC}_{2} \mathrm{O}_{4} \cdot 2 \mathrm{H}_{2} \mathrm{O} \stackrel{\mathrm{H}_{2} / \mathrm{Ar}}{\longrightarrow} \text { (intermediate) }+\mathrm{NH}_{3(\mathrm{~g})}+\mathrm{H}_{2} \mathrm{O}_{(\mathrm{g})}+\mathrm{CO}_{2(\mathrm{~g})}+\mathrm{CO}_{(\mathrm{g})}\left(\boldsymbol{T}<\mathbf{4 0 0}^{\circ} \mathbf{C}\right) \\
\text { (intermediate) }+\mathrm{LiF} \stackrel{\mathrm{H}_{2} / \mathrm{Ar}}{\longrightarrow} \mathrm{LiFePO}_{4(\mathrm{~s})}+\mathrm{HF}_{(\mathrm{g})}\left(\boldsymbol{T}>\mathbf{4 0 0}^{\circ} \mathbf{C}\right) \\
\mathrm{HF}+\mathrm{NH}_{3} \rightarrow \mathrm{NH}_{4} \mathrm{~F}
\end{gathered}
$$

\subsubsection{Vacuum Distillation}

McNeese et al. (1972) performed vacuum distillation experiments at $1000^{\circ} \mathrm{C}$ and $\sim 13 \mathrm{~Pa}(0.1$ Torr) in Hastelloy-N to recover ${ }^{7} \mathrm{LiF}$ and $\mathrm{BeF}_{2}$ from molten salt streams pertaining to the MSRE. A picture of the distillation apparatus is shown in Figure 4-14. Here, ${ }^{7} \mathrm{LiF}, \mathrm{BeF}_{2}$, and $\mathrm{ZrF}_{4}$ could be volatilized and recovered and the $\mathrm{REF}_{3}$ components left behind. If $\mathrm{ThF}_{4}$ is present in the initial salt, it will be left behind as well, which is not ideal. One of the conclusions of this study by McNeese et al. (1972) was that, "...even if the effective relative volatilities of the lanthanides are [higher than desired], adequate recovery of ${ }^{7} \mathrm{LiF}$ from waste salt streams by distillation would be possible." The vacuum distillation rate as a function of temperature for these experiments is shown in Figure 4-15. 


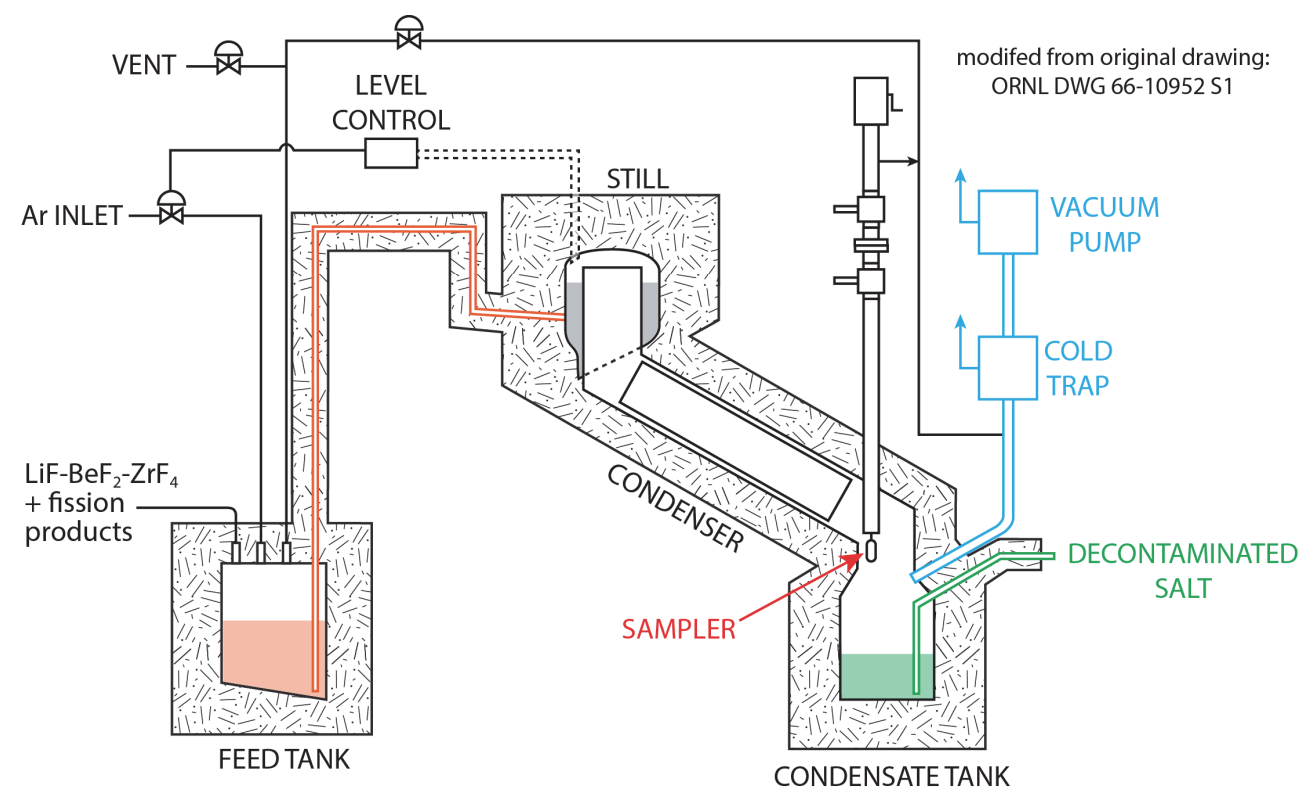

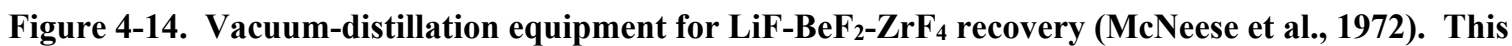
drawing was modified from the original version to call attention to specific portions of the apparatus.

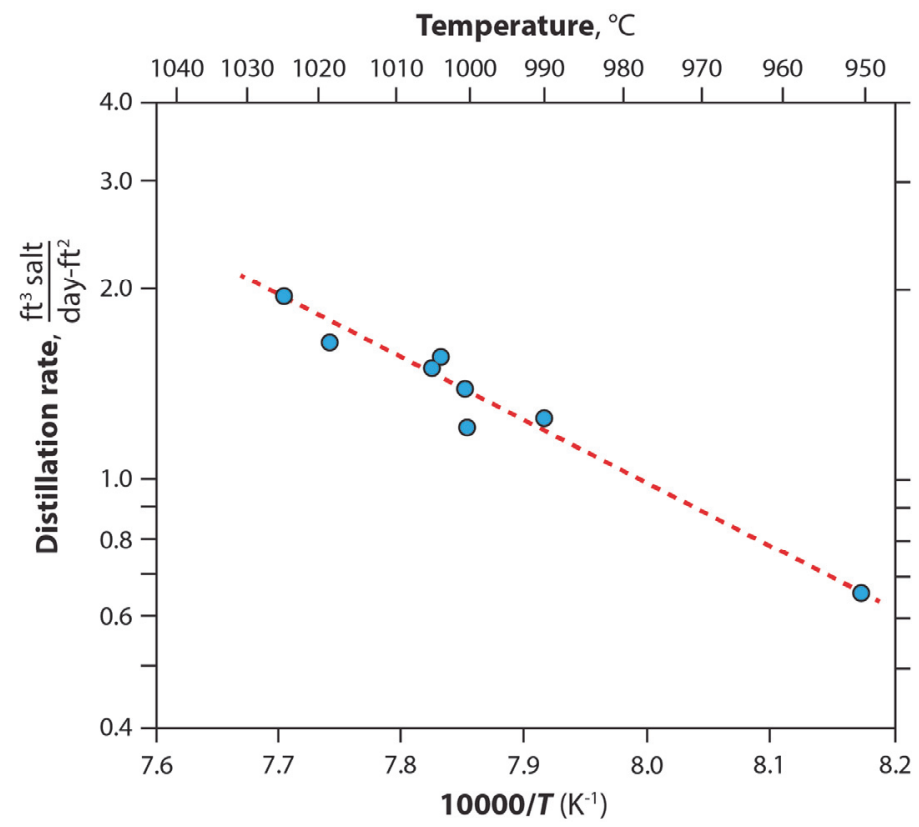

Figure 4-15. Vacuum distillation rate (i.e., $\mathrm{ft}^{3}$ of salt distilled per day per $\mathrm{ft}^{2}$ of vaporization surface area) as a function of temperature when the condenser pressure was $<13.3 \mathrm{~Pa}(<0.1$ Torr) (McNeese et al., 1972). This figure was modified from the original.

\subsubsection{Melt Crystallization}

The melt crystallization process is a technique whereby a molten solution can be partitioned through the selective crystallization of a pure salt. For example, cooled plates (or a cold finger) were immersed in a molten salt mixture containing $\mathrm{LiCl}$ along with simulated fission products, and pure $\mathrm{LiCl}$ was selectively crystallized out on the plates and the simulated fission product impurities remained in the melt (Cho et al., 
2011). This process can be optimized for a given salt and depends on the levels of impurities in the starting salt mixture and the crystal growth rate, which was dictated by the flow rate of cooling air running through the plates (Cho et al., 2011). This worked well for the high-LiCl oxide reduction salt, but it is unclear how it would fare for MSR-type chloride-salt or fluoride-salt mixtures.

In a study by Trowbridge et al. (2003), a molten hydroxide scrubber was tested to remove radioiodine species from off-gas streams. In this approach, the gas streams were reacted directly with molten hydroxides (e.g., $\mathrm{NaOH}, \mathrm{KOH}$ ), the iodine dissolved in the hydroxide was converted to an iodide, and, once the iodine concentration of the iodide was high enough $(\sim 70-80 \mathrm{~mol} \%)$ within the mixture, the mixture was cooled. During the cooling period, the iodide phase grew and could be separated from the hydroxide phase through melt crystallization. Through this system, an iodine trapping efficiency of $96 \%$ was reported, which was dependent upon temperature and glass-melt contact. One unintended issue reported during the study was that some hydroxide was noted in the iodide crystals.

Melt crystallization has been conducted on fluoride systems as well. In a study by Kuznetsov and Fedorov (2008), 55 different fluorite solid solutions of the general formula $M_{1-x} R_{x} \mathrm{~F}_{2+x}$ [where $M=\mathrm{Ca}, \mathrm{Sr}$, $\mathrm{Ba}, \mathrm{Cd}$ and $R$ is a rare earth element; i.e., hexoctahedral $m \overline{3} m$ space group] were investigated and experimental data on phase equilibria were analyzed; phase diagrams were provided. They noted that alterations in chemistry can have a wide range of effects, including mechanical changes (e.g., drastically increased microhardness) and electrical changes (drastically increased ionic conductivity). To prevent dendritic growth during melt crystallization processes, high temperature gradients and low growth rates are ideal for these materials. It is likely that alkali fluorides could be grown using melt crystallization as well, but that will depend on the melting temperatures of the salt impurities (fission products) compared with those of the eutectic salt fluorides.

\subsubsection{Metal Transfer Process}

\subsubsection{Liquid Bismuth Reductive Extraction}

The liquid bismuth reductive extraction process was discussed throughout the literature as a potential method of cleaning MSR salts (LeBlanc, 2010; McNeese, 1971; Robertson, 1971). For instance, this particular process can be used to extract $\mathrm{Pa}$ from the reactor as well as rare earths and actinides. Here is an overview of the process provided by Rosenthal et al. (1972) and Robertson (1971):

- Before the liquid Bi reductive extraction process for removing the $\mathrm{Pa}$, all $\mathrm{U}$ must be removed from the fuel salt.

- The salt flows to an extractor, where it is contacted with liquid Bi containing some dissolved Li; using a reductive-extraction process, the Li enters the fuel salt in exchange for $\mathrm{Pa}$, which enters the Bi.

- The $\mathrm{Pa}$ is transferred into a separate salt, where it is held until it decays to $\mathrm{U}$ and is returned to the reactor.

- The fuel salt (now free of $\mathrm{U}$ and $\mathrm{Pa}$ ) goes to the metal-transfer process where it is contacted with a captive volume of $\mathrm{Bi}$ into which the rare earths and some other fission products pass; from the $\mathrm{Bi}$, the fission products are transferred into $\mathrm{LiCl}$.

- In the metal-transfer process, the Bi acts somewhat as a selective membrane that permits the passage of the fission products between the fuel salt and the $\mathrm{LiCl}$ without the passage of $\mathrm{Th}$.

- The process is far more efficient if Th is removed from the salt (it acts similarly to the rare earths). 
- In the older $\mathrm{Pa}$ isolation method, the salt stream from the reactor was fed directly into a $\mathrm{Bi}$ contactor, and sufficient reductant was fed counter-current to the fuel salt to not only isolate the $\mathrm{Pa}$ but also reduce all of the $\mathrm{UF}_{4}$ in the fuel salt.

- In the preferred $\mathrm{Pa}$ isolation system, fluorination is used for removing most of the $\mathrm{U}$ from the fuel salt before $\mathrm{Pa}$ isolation. Here, the quantity of reductant required is such that it can be purchased economically, and an electrolytic cell is not required.

- Removal of rare earth fission products is more difficult because the rare-earth fluorides act similarly to the $\mathrm{ThF}_{4}$ (major fuel salt component in the breeder concept, i.e., the MSBR). Two rare earth removal systems based on reductive extraction have been considered.

- In the older system, the fuel carrier salt containing rare-earth fluorides was counter-currently contacted with Bi to exploit the small differences in the extent to which Th and the rare earths distribute between the fuel carrier salt and Bi containing a reductant. Since the distribution behavior of the rare earths and Th are quite similar, it was necessary to use a large number of stages in the extraction columns and high metal-to-salt flow ratios. The system used a large amount of reductant, which was provided by electrolytic reduction of $\mathrm{LiF}$.

- The preferred method (called the metal-transfer process) exploits the relatively large differences in the extent to which rare earths and Th distribute between Bi containing a reductant and $\mathrm{LiCl}$. This process does not require and electrolytic cell, an important advance over the aforementioned process.

- Removal of rare earth and alkaline earth fission products from the fuel salt can be effectively accomplished by the metal-transfer process. Here, Bi containing $\mathrm{Th}$ and $\mathrm{Li}$ is used to transport the rare earths from the reactor fuel salt to an acceptor salt; while $\mathrm{LiCl}$ is the preferred acceptor salt, LiBr or LiCl-LiBr mixtures are also options (see Figure 4-16).

- The Th transfers to the Bi with the rare earths, but, due to favorable distribution coefficients for rare earths, only a small fraction of the Th transfers with the rare earths from the $\mathrm{Bi}$ to the $\mathrm{LiCl}$. Then, the rare earths are removed from $\mathrm{LiCl}$ by extraction, with Bi containing $0.05 \rightarrow 0.50 \mathrm{~mol}$ fraction Li. 


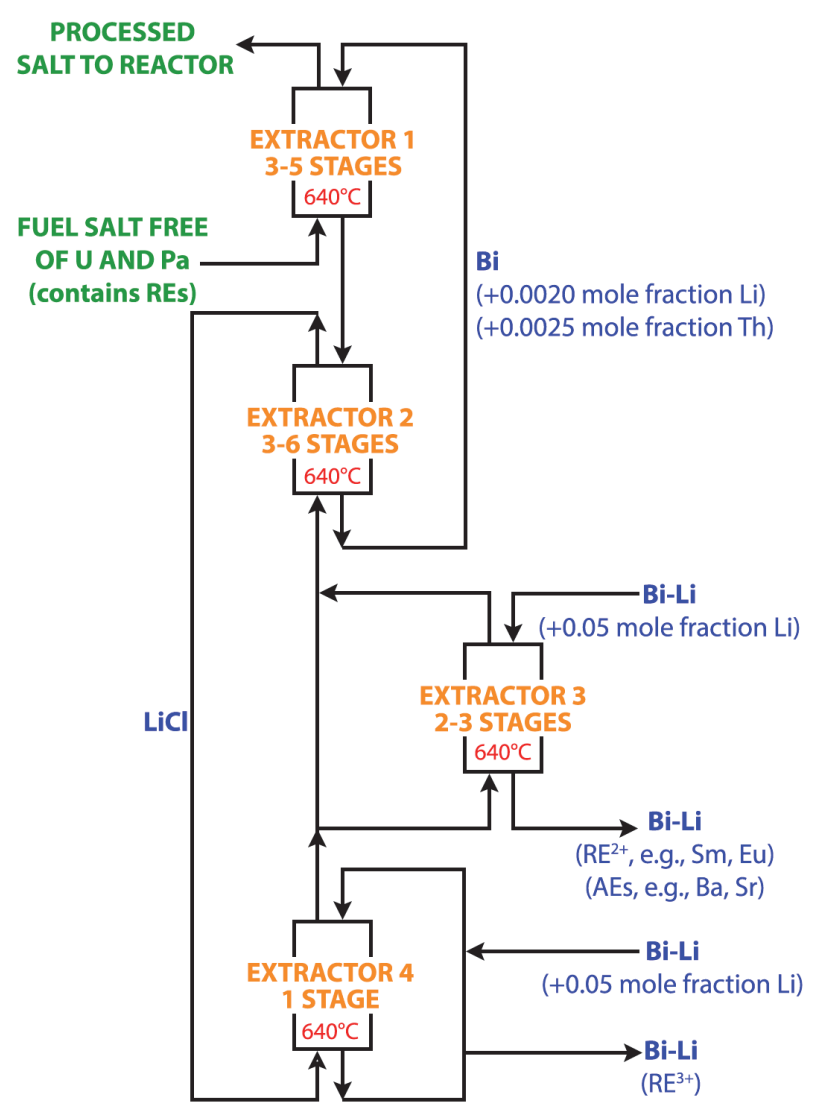

Figure 4-16. Mass transfer process for removal of rare earths from a single-fluid MSBR (Robertson, 1971).

\subsubsection{Glass Material Oxidation and Dissolution System}

In the 1990s, a process named the Glass Material Oxidation and Dissolution System (GMODS) was developed by Forsberg et al. (1994; 1997). This process was developed to directly vitrify radioactive, mixed, and chemical wastes in a single-step process involving a two-liquid melt of glass and molten lead in a furnace. The feedstock can be a wide range of materials including metals, ceramics, amorphous solids, organics, and mixtures; the organics are destroyed, and the heavy metals and radionuclides are oxidized and immobilized in the glass. A drawing and a flow diagram of the GMODS process are shown in Figure 4-17 and Figure 4-18, respectively. The primary byproduct of this process is a cleaned sodium halide stream. The process was designed to be run as either a continuous or batch process, depending on the specific needs. The reaction of $\mathrm{PbO}$ with the metals (i.e., Me) present in the waste stream result in metal oxides (i.e., $\mathrm{Me}_{y}^{n} \mathrm{O}_{z}$ ) and the corresponding reduction of $\mathrm{PbO}$ to $\mathrm{Pb}^{0}$ through the following reactions:

$$
\begin{gathered}
y \mathrm{Me}+z \mathrm{PbO} \rightarrow \mathrm{Me}_{y}^{n} \mathrm{O}_{z}+z \mathrm{~Pb}^{0} \downarrow \\
\mathrm{Me} \rightarrow \mathrm{Me}^{n+}+(n) e^{-} \\
\mathrm{Pb}^{2+}+2 e^{-} \rightarrow \mathrm{Pb}
\end{gathered}
$$

where $y$ and $z$ correspond to moles of reactants or products and $n$ is the charge on the oxidized metal (Me). Small-scale experiments were demonstrated using this process, and the results show promise that it could be used on a larger scale to treat salt-based wastes from MSRs. 


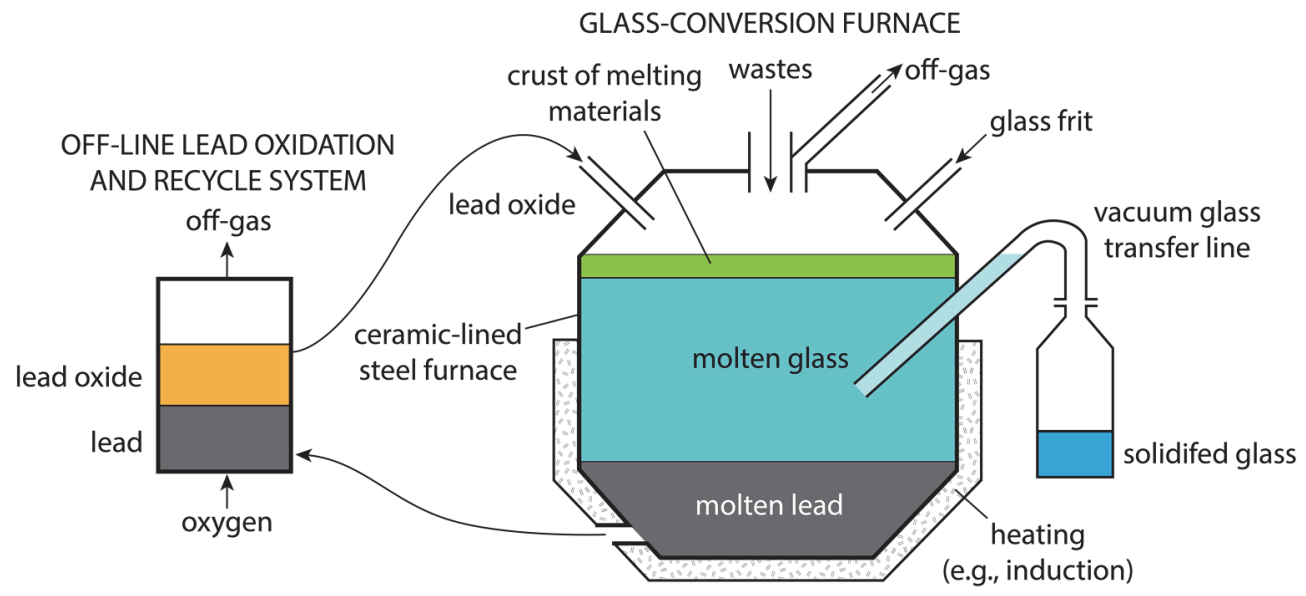

Figure 4-17. Drawing of Glass Material Oxidation and Dissolution System (GMODS; modified from original) (Forsberg et al., 1994).

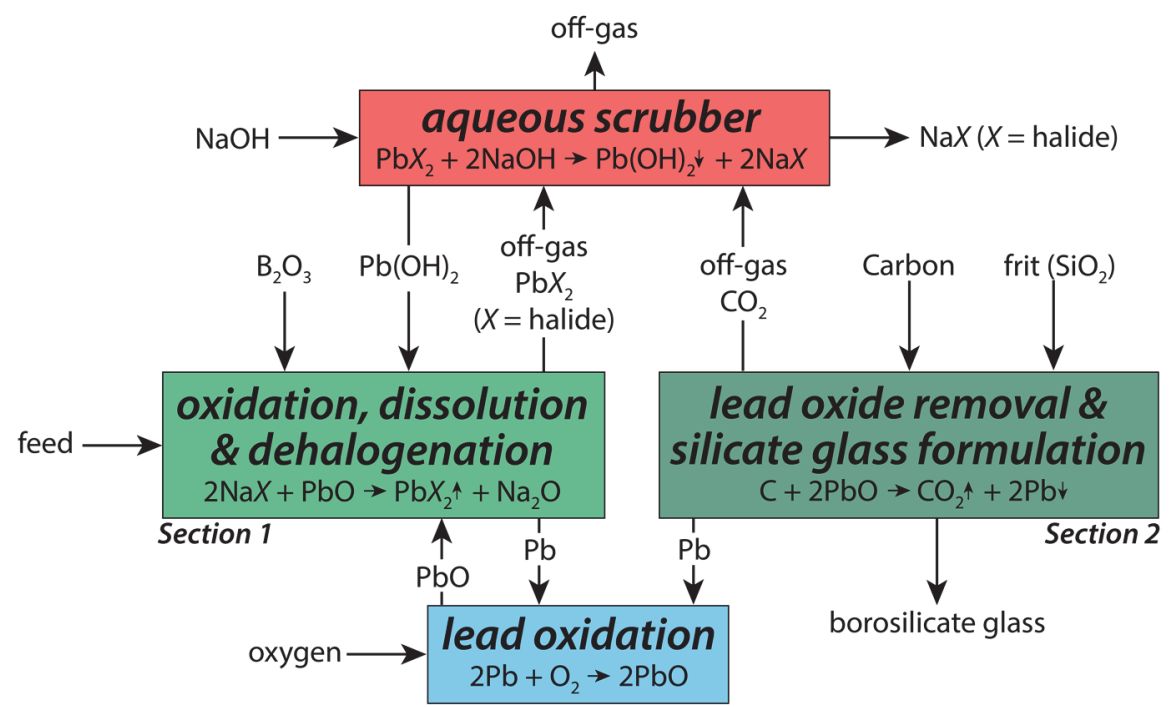

Figure 4-18. Flow diagram of the Glass Material Oxidation and Dissolution System (GMODS; modified from original) (Forsberg et al., 1997).

\subsection{Lithium-7 (' $\left.{ }^{7} \mathrm{Li}\right)$ Recovery Options for Fluoride Salt Systems}

A concern with Li-based salts for MSR applications is that ${ }^{6} \mathrm{Li}$ will activate to form ${ }^{3} \mathrm{H}$, as discussed in Section 3.2. Although ${ }^{3} \mathrm{H}$ can be produced through other activation pathways, enrichment of ${ }^{7} \mathrm{Li}$ over ${ }^{6} \mathrm{Li}$ is necessary for tritium management in an MSR. The natural abundance ratio of ${ }^{6} \mathrm{Li}$ to ${ }^{7} \mathrm{Li}$ is about 7.59:92.41 (atomic\%) (WebElements, 2018b), but for an MSR, a ratio 0.001:99.999 (atomic\%) is desirable (Stempien, 2015). Hence, once Li has been prepared for an MSR, recycling of ${ }^{7} \mathrm{Li}$ will drastically improve the economic feasibility MSR technologies using Li-based salts. One potential option for recovering ${ }^{7} \mathrm{LiF}$ is vacuum distillation. In a process described earlier (see Section 4.4.3), McNeese et al. (1972) demonstrated ${ }^{7} \mathrm{LiF}_{-} \mathrm{BeF}_{2}$ salt recovery using vacuum distillation at elevated temperatures (e.g., $\sim 950-1025^{\circ} \mathrm{C}$ ). Lithium separation has been extensively studied in the context of nuclear fusion (Übeyli, 2009) and so will not be discussed further in this report. 


\subsection{Chlorine-37 $\left({ }^{37} \mathrm{Cl}\right)$ Recovery Options for Chloride Salt Systems}

A concern regarding chloride-based salts for MSR applications is that the ${ }^{35} \mathrm{Cl}$ will activate to ${ }^{36} \mathrm{Cl}$, a longlived chlorine isotope with $t_{1 / 2}=3.01 \times 10^{5} \mathrm{y}$ (Holcomb et al., 2011). Chlorine has two stable isotopes, ${ }^{35} \mathrm{Cl}$ and ${ }^{37} \mathrm{Cl}$, and the natural abundance ratio of ${ }^{35} \mathrm{Cl}$ to ${ }^{37} \mathrm{Cl}$ is 75.78:24.22 (atomic\%) (WebElements, 2018a). As was discussed earlier with regard to ${ }^{7} \mathrm{Li}$ (see Section 4.5) for Li-containing MSR salts, recycling ${ }^{37} \mathrm{Cl}$ will drastically improve the economic feasibility of MSR technologies using chloride-based salts. Two options that could be used to recover the ${ }^{37} \mathrm{Cl}$ from chloride-based salts are the following:

- The reaction of used salts with ammonium phosphate [e.g., $\mathrm{NH}_{4} \mathrm{H}_{2} \mathrm{PO}_{4},\left(\mathrm{NH}_{4}\right)_{2} \mathrm{HPO}_{4}$ ] precursors to decompose the salts and produce a $\mathrm{NH}_{4} \mathrm{Cl}$ byproduct that could be used to synthesize fresh chloride salts (see Section 4.3.3)

- The reaction of used salts with $\mathrm{H}_{3} \mathrm{PO}_{4}$ to decompose the salts and generate $\mathrm{HCl}$ that could be reacted with metals of the desired chloride salts to generate fresh salt to refill the MSR (see Section 4.3.3).

- The reaction of used salts with USH-Y zeolite to decompose the salts and generate $\mathrm{HCl}$ that could be reacted with metals of the desired chloride salts to generate fresh salt to refill the MSR (see Section 4.3.4). 


\section{OPTIONS FOR CARBON-BASED WASTES}

The purpose of this section is to elaborate on Subsection 2.4, Carbon Streams. The carbon-based wastes will be one of the largest waste streams on a volume basis because of the large volume of the full-sized reactor core.

Graphite used in MSRs will be exposed to interaction with the salt and fission products. Salt penetration into pores will probably be reduced by using a graphite with narrow pore openings (i.e., $<0.4 \mu \mathrm{m}$ ) and avoiding overpressurization of the reactor core (i.e., $<0.2 \mathrm{MPa}$ ). At higher pressures (e.g., $1 \mathrm{MPa}$ ), the salt would penetrate into graphite, but that condition would probably not be encountered in MSRs. Salts may also be retained in cracks or fissures that might be present on graphite components. Based on MSRE experience at ORNL, other chemical impurities that will be found in graphite will be fission products embedded from recoil (e.g., $\mathrm{Sr}, \mathrm{Te}, \mathrm{Ba}, \mathrm{Mo}, \mathrm{Ru}$ ), and decay products of $\mathrm{Xe}$ and $\mathrm{Kr}$ (e.g., $\mathrm{Rb}, \mathrm{Cs}, \mathrm{Sr}, \mathrm{Ba}$, Ln, Zr), along with small amounts of $U$ (Haubenreich and Engel, 1970). Corrosion of metallic parts enhanced by galvanic effects with graphite will probably lead to plating of chromium carbides on graphite (Zheng et al., 2015). Chemically-bonded fluorine may also be found after exposure in FLiBe (Wu et al., 2018).

Tritium retention by graphite is a major concern for graphite recovered from MSRs (Forsberg et al., 2017). Tritium is generated by neutron irradiation of $\mathrm{Li}$ (and Be, if present) in molten salts. It will be present either as acid (i.e., ${ }^{3} \mathrm{HF}$ ) or in molecular form (i.e., ${ }^{3} \mathrm{H}_{2}$ ). Both forms can be retained by carbon materials, either in chemisorbed form (e.g., as $\geq \mathrm{C}-{ }^{3} \mathrm{H}$ ) or physisorbed (e.g., ${ }^{3} \mathrm{HF}$ ) or simply trapped in the graphite structure (e.g., ${ }^{3} \mathrm{H}_{2}$ ). There are at least four different states for hydrogen isotope retention in nuclear graphite, from strong chemisorption, to molecular forms weakly trapped at crystallite boundaries. Thermal desorption from these states needs temperatures between 400 and $1300^{\circ} \mathrm{C}$ (Atsumi et al., 2009). Tritium retention by carbon components will increase with the time of exposure in the reactor and will vary with redox conditions in the salt. Based on multiple sources, it was estimated that the maximum retention capacity of tritium in carbon components used in FHRs/MSRs is roughly of the order of a few tens of $\mu \mathrm{g} / \mathrm{g}$, depending strongly on carbon porosity and ambient conditions (e.g., tritium partial pressure in the source, temperature) (Young et al., 2015).

The management of spent nuclear fuel and graphite moderator from FHRs was analyzed by Forsberg and Paterson (Forsberg and Peterson, 2015). They found many similarities with the corresponding materials management in HTGR systems, and a few differences. The graphite moderator from an FHR will be similar in nature to the HTGR moderator, except that it may still contain traces of salt coolant and will have higher tritium content (e.g., chemisorbed on graphite). The graphite moderator from an MSR (with fuel dissolved in the salt) will contain an addition residual amount of fuel. Several additional steps, not needed for disposal of HTGR carbon and graphite, will be needed in the cases of MSRs and FHRs. First, the graphite moderator materials will have to be evaluated for tritium content. Tritium chemisorbed in carbon can be removed by thermal treatment at elevated temperatures (up to $1400^{\circ} \mathrm{C}$ ). Then, the irradiated graphite will need to be treated for removal of traces of coolant salt. The impact of residual salt traces on the long-term operation of disposal and storage facilities should be evaluated.

The options for characterization, handling, conditioning, and disposal of radioactive graphite waste (from HTGR reactors) have been analyzed in International Atomic Energy Agency (IAEA) documents as part of the operating and decommissioning life cycle (IAEA-TECDOC-1521, 2006). There are over 250,000 tons of irradiated graphite worldwide. Most irradiated graphite is damaged by irradiation, cracked, oxidized, difficult to extract, and/or contaminated, and may still contain Wigner stored energy. There is no generally accepted agreement on the best solution for management of radioactive graphite waste. Different solutions may be appropriate for different cases. The most preferred option is long-term storage, following one of three possible scenarios: 
- Direct disposal after suitable packaging in either near-surface repositories or geological formations

- Disposal after incineration with consequent ash conditioning

- Disposal after chemical treatment (liquid or gaseous extraction) and conditioning (impregnation, encapsulation) and proper packaging.

The IAEA does not prescribe policy on management of irradiated waste. Its objective is to advise Member States of the various options that are being investigated and thus to enable them to make informed decisions. A new project was started under the auspices of IAEA as a result of discussions and studies through the International Decommissioning Network (Wickham et al., 2017) and International Pre-Disposal Network (IAEA-IPN, 2018), documented in the 2016 IAEA-TECDOC-1790 (IAEATECDOC-1790, 2016). The Project GRAPA (Irradiated GRAphite Processing Approaches), a follow-up of the IAEA research program on treatment options, reunites international specialists active in the area of decommissioning irradiated graphite (Wickham et al., 2017). There are still numerous issues not solved regarding decommissioning of irradiated graphite. Better understanding is needed of the mobility and stability of various isotopes, and their chemical forms in irradiated graphite, to evaluate the effects of long-term storage. Also, research is needed to evaluate the advantages of recovering useful isotopes during processing methods like heat treatment and incineration.

\subsection{EU CARBOWASTE Program}

A joint venture between 10 European countries and South Africa was initiated in 2008 under the 7th EURATOM Framework Programme to address the treatment and disposal of irradiated graphite and other carbonaceous wastes. This program is called CARBOWASTE (Banford et al., 2008; von Lensa et al., 2011). Under the auspices of this program, researchers are evaluating the best path(s) forward for retrieval, treatment, and ultimate disposal of existing and future irradiated graphite and other carbonaceous wastes such as non-graphitized carbon bricks and fuel coatings (i.e., pyrocarbon, $\mathrm{SiC}$ ). Many of the fission products of concern that are present within reactor graphite $\left(\right.$ e.g., ${ }^{3} \mathrm{H},{ }^{14} \mathrm{C},{ }^{36} \mathrm{Cl},{ }^{60} \mathrm{Co}$ ) can be removed using thermal, chemical, electrochemical, and/or microbiological treatments. For example, oxidation of reactor graphite at temperatures of $1000^{\circ} \mathrm{C}$ in a $2 \% \mathrm{O}_{2} / \mathrm{Ar}$ stream showed significant removal of ${ }^{14} \mathrm{C}$ present within the graphite. Tritium can be removed through heat treatment under an inert atmosphere (e.g., $\mathrm{N}_{2(\mathrm{~g})}>\mathrm{Ar}_{(\mathrm{g})}$ ) at temperatures of $\sim 1300^{\circ} \mathrm{C}$ through the pyrolysis of ${ }^{3} \mathrm{H}-\mathrm{C}$ bonds. The remaining isotopes can be removed using acidic leachants. The option of recycling irradiated graphite waste was investigated by two major graphite manufacturers under the CARBOWASTE program, and the results were reported as a reasonable success.

\subsection{Graphite Recycle}

One processing option for recycling reactor graphite is to pulverize the material and etch it in acid to release most of the fission products from the material into the acid (DelCul, 2018). The graphite powder product resulting from this process could be hot-pressed into a monolithic waste form or even hot-pressed into new components for future reactor cores and recycled.

In a report by Burchell and Pappano (2010), the approach outlined in Figure 5-1 was presented for producing nuclear-grade graphite, and ground recycled graphite could be used in the feed stock. Results obtained while evaluating this proposed process on a small scale showed that increasing the recycled fraction of graphite had no deleterious effects on the overall properties of the graphite (Burchell and Pappano, 2010). 


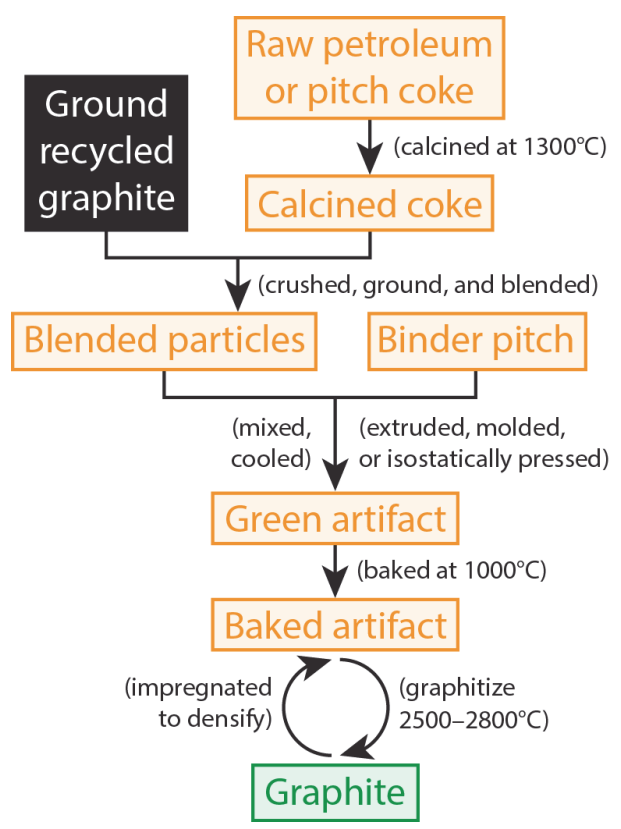

Figure 5-1. Proposed process for producing nuclear-grade graphite using ground recycled graphite as a feed stock. The impregnation step is carried out by adding new pitch to improve strength and density; this process is typically performed three times for nuclear graphite. This image was modified from the original by Burchell and Pappano (2010).

\subsection{Spent Nuclear Fuel from FHRs}

The spent nuclear fuel of FHR, which is TRISO fuel in fuel matrix pebbles (see Figure 5-2), would be like the spent fuel resulting from HTGRs; the difference is the additional presence of coolant salt traces and higher tritium content. Comparing the volumes per unit of energy produced, the volume of spent fuel from an FHR is less than half of that of HTGR spent fuel, but it is about four times higher than that of an LWR system. However, the spent fuel from an FHR can be stored at higher temperatures than LWR spent fuel, which makes it easier to find practical disposal solutions. In addition, and most importantly, spent fuel from MSRs is superior to other forms of spent fuel waste in terms of better nonproliferation and security characteristics. More specific information can be found in Forsberg and Peterson (2015). 


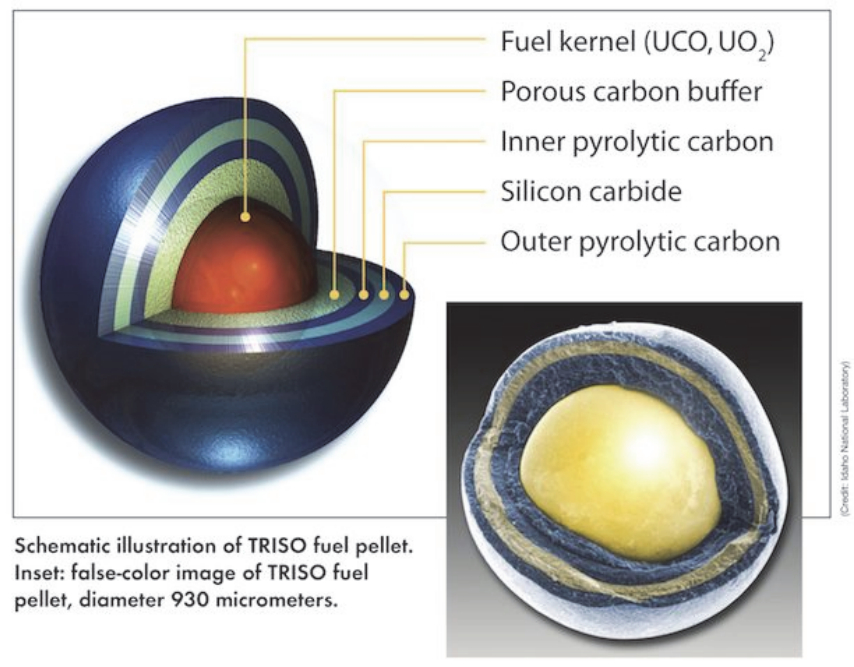

Figure 5-2. Schematic (left) and pseudocolored micrograph (right) of TRISO fuel Courtesy of Idaho National Laboratory (De Guire, 2013) (Copyright American Ceramic Society).

Ground spent salt will be coated with an organic bituminous binder, mixed with ground graphite waste (e.g., moderator blocks) and fed to a screw extrusion system to create solid HLW logs. Then, the HLW logs would be baked to pyrolyze/decompose the organic binder producing amorphous carbon and graphite. This process is similar to standard processes used to produce a variety of carbon products. The organics must be destroyed to avoid hydrogen generation in the repository from radiation, and to avoid organics that can complex radionuclides and enhance migration from the waste form to the environment. The carbonization process is designed to reduce the long-term permeability of the waste form to air and groundwater. Firing to higher temperatures produces a more graphitic product; as the temperature increases, volatile species may evolve that require capture by the off-gas system and recycling back to the solidification system. Thus, an optimal temperature must be selected to reduce the permeability and enhance the structural strength while maintaining a low volatility. Experimental work is required to confirm the viability of manufacturing carbon HLW forms. If the initial work indicates that the waste form is significantly better than alternative waste forms and relatively easy to manufacture, then the waste form should be considered for MSR HLW streams. A fraction of the salt components will intercalate within the layered graphite structure, and some will remain as interstitial particles. The actual overall waste performance (i.e., leachability, structural integrity, durability) will have to be determined. 


\section{OPTIONS FOR METAL WASTES}

The purpose of this section is to elaborate on Subsection 2.5, Metal-Based Waste Streams. Because molten salts are highly corrosive to most materials, MSRs would be constructed of materials mostly inert to corrosion. One such material is Hastelloy-N. Others include various types of stainless steels (SS), Inconel alloys, and international alloys such as MONICR (see Table 2-1 in Section 2.5 for compositions). The most common approach for managing metal waste streams is to reduce the sizes of the components and then either melt or compact them into a monolithic form for storage and disposal.

A few key differences exist between the metal waste stream from LWRs and those anticipated from MSRs:

- Metal waste streams from LWR operations include the fuel cladding, plenums, other hardware, and the 5-metal $\varepsilon$-phase within the fuel, consisting of Mo, Pd, Rh, Ru, and Tc (Crum et al., 2013) (see Figure 6-1). While MSRs do not have metal fuel cladding, most of the other waste streams are consistent between the two reactor types. Possibilities for discussing immobilization options for Tc-containing metal wastes were discussed by Westsik Jr. et al. (2014) and these can be applied to MSR-type wastes.

- The fates of the noble metal fission products (e.g., Mo, $\mathrm{Pd}, \mathrm{Rh}, \mathrm{Ru}, \mathrm{Tc}, \mathrm{Nb}, \mathrm{Sb}, \mathrm{Ag}$ ) are unknown. It is anticipated that they will form fine particles within the salt and can plate out on the inner metal surfaces of the reactor core along with secondary components within the reactor such as secondary loops, heat exchangers, and pumps (Forsberg, 2006).

- MSRs could have salt-impregnated metal components that might limit immobilization options. For example, high-temperature melting might be prohibitive due to volatile losses of entrained fission products in the structural metals from the reactor.

As was mentioned previously for recycling graphite components (see Section 5.2), it is possible that some metallic reactor components could be recycled into future MSRs following full or partial decontamination, or even without decontamination if the components were deemed structurally and chemically sound for this purpose. 

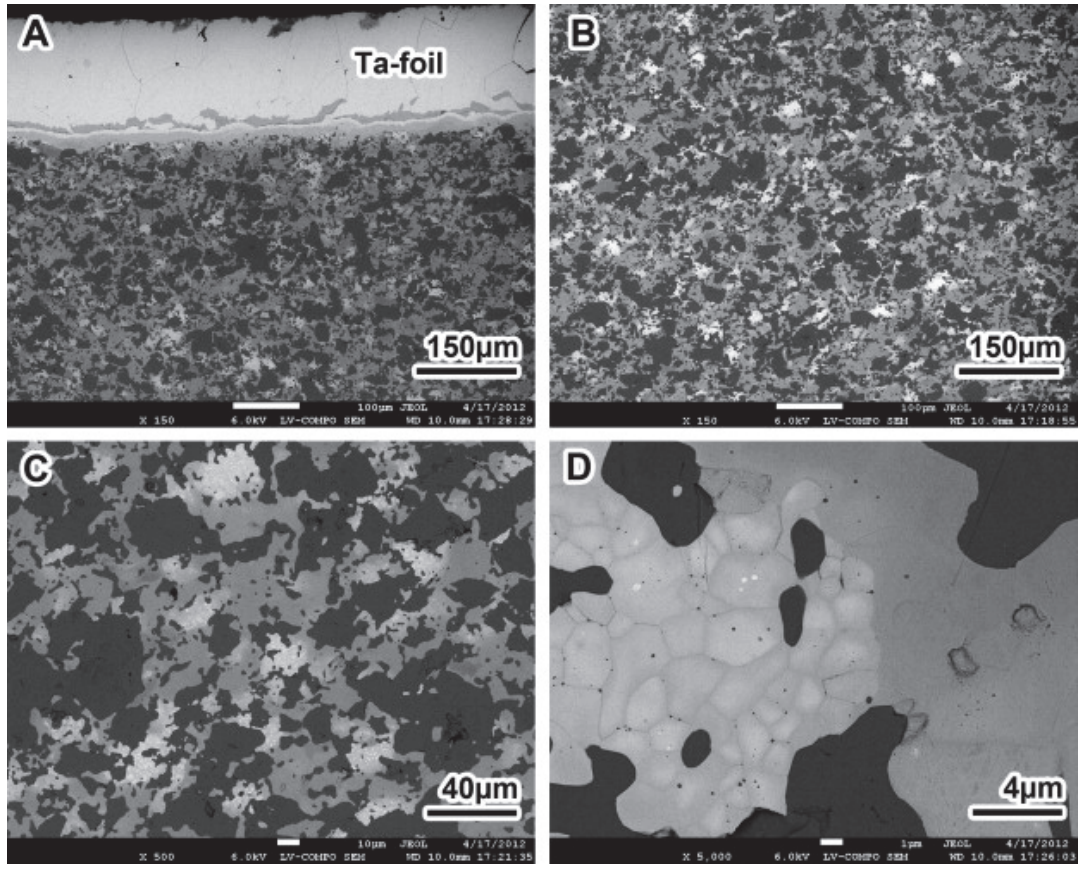

Figure 6-1. Backscattered scanning electron micrographs of Mo-Ru-Rh-Pd-Re $\varepsilon$-metal sample $(35 \% \mathrm{ZrO}-$ HIP-1-Ta-2012) consolidated with hot isostatic pressing at $1500^{\circ} \mathrm{C}$ for $1 \mathrm{~h}$ at $207 \mathrm{MPa}$ in a tantalum-foil package from Crum et al. (2013). The dark phase within the sample is $\mathrm{ZrO}_{2}$. The \&-metal yield in this sample after heat-treatment was 54.8 mass \% (49.7 mass\% hexagonal and 5.1 mass\% cubic). 


\section{OPTIONS FOR DECOMMISSIONING AND DECONTAMINATION WASTES}

The purpose of this section is to elaborate on Subsection 2.6, Streams from Decommissioning and Decontaminating. The D\&D wastes include metal, cement, and carbon-based waste streams that can be reduced in size, packaged, and processed as LLW or GTCC waste. To minimize costs and reduce wastes, it is possible that some of these streams can be recycled, such as the metal (see Section 6) and graphite (see Section 5.2) reactor components. One option for extending the life of an MSR is to recycle the metallic shell of the core and swap out the graphite moderator. In which case, some purification of the components would be required to remove activation products and contaminants. However, it is likely that activity levels will preclude shell recycling. 


\section{OPTIONS FOR OPERATING WASTES}

The purpose of this section is to elaborate on Subsection 2.7, Streams for Operating Wastes. The operating wastes can be reduced in size, potentially decontaminated, packaged, and processed as LLW or GTCC waste. 


\section{STORAGE, TRANSPORATION, AND DISPOSAL REQUIREMENTS 9.1 Package Content}

The exact content of disposal packages has not been characterized at this time. More definitive enveloping information would need to be provided to better characterize the package contents and provide specific packaging options. The following is preliminary information that was provided regarding the package content that may be taken into consideration in evaluating the transportation, storage, and disposal options (some of this information is discussed in previous sections of this report).

- Chemical/physical form of the waste material. The reactor salts are expected to be mainly in solid form. If the salts from the reactor are not treated after being pulled, the product will be solid salts. If they are post-processed, the form could be any of a number of possibilities (but all in solid form), e.g., glass, glass-ceramic, ceramic. At the current time, there are no plans for any water to be included in the waste material. Radiolysis, particularly of unprocessed salts, will produce headspace gases that could be highly corrosive (e.g., $\mathrm{F}_{2(\mathrm{~g})}, \mathrm{Cl}_{2(\mathrm{~g})}$, derivatives of $\mathrm{F}_{2(\mathrm{~g})}$ or $\mathrm{Cl}_{2(\mathrm{~g})}$ ), depending on the redox conditions in the salt.

- Size. The size of the package is unknown. One scenario would be to transfer the salts from the reactor into cooling tanks, which could be removed and shipped directly to a repository. One issue for the case in which the salts are not post-processed is that there is some concern regarding reactions occurring within the holding tanks and the generation of pressure (Forsberg, 2018b). Thus, the decay of the salt and the chemical reactions that could occur must be modeled as part of the design of the containment vessel.

- Mass. For the MSBR concept, the anticipated starting fissile load was $1500 \mathrm{~kg}{ }^{233} \mathrm{U} / \mathrm{GW}(\mathrm{e})$ (LeBlanc, 2010; Weinberg, 1970). It is unknown how large the full salt load is (total salt mass or volume). It is not known if this is the planned design for a potential breeder reactor. Masses are also unknown for the chloride salts at this time.

- Isotopics. The isotopic abundances have been investigated by collaborators at ORNL (Betzler et al., 2017a; Betzler et al., 2017b; Betzler et al., 2018).

- Impurities. For the MSRE, the salt impurities at the start included $\mathrm{Cr}$ (16 ppm), Ni (39 ppm), Fe (123 ppm), S (<5 ppm), and oxides (<100 ppm) (Thoma, 1972). Impurities from burnup, in addition to those produced by fission and activation, will include corrosion products (additional Cr) and degradation of structural materials (graphite fines) (Baes Jr., 1974). Starting levels of impurities for chloride salts are not known, but they are likely to be comparable to fluoride salt specifications.

\subsection{Transportation}

Transportation of a packaging requires compliance with:

- Department of Transportation regulations in Title 49 CFR (Transportation), Subtitle B, Chapter I, Subchapter C ("Hazardous Materials Regulations")

○ Specifically, 49 CFR 171 through 180 (49 CFR 171-180, Subtitle B, Chapter I, Subchapter C)

- Nuclear Regulatory Commission (NRC) regulations in Title 10 CFR, Part 71 ("Packaging and Transportation of Radioactive Material") (10 CFR 71)

- In particular, evaluation criteria for normal conditions of transport (NCT) and hypothetical accident conditions (HAC) 
The following is a summary of the critical supporting safety analyses required to establish the transportation safety basis. Note that more specificity can be provided once additional information is available regarding the package content.

\subsubsection{Structural Safety Analysis}

Regulations in 10 CFR 71 require specific package performance for NCT and HAC; the package must survive without loss of its shielding, criticality, and containment safety functions (10 CFR 71).

\section{NCT conditions and tests include:}

- Heat. An ambient temperature of $100^{\circ} \mathrm{F}\left(\sim 38^{\circ} \mathrm{C}\right)$ in still air and solar insolation.

- Cold. An ambient temperature of $-40^{\circ} \mathrm{F}\left(-40^{\circ} \mathrm{C}\right)$ in still air and shade.

- Reduced external pressure. An external pressure of $3.5 \mathrm{lbf} / \mathrm{in}^{2}$ (pounds of force per square inch; $\sim 24 \mathrm{kPa}$ ) absolute.

- Increased external pressure. An external pressure of $20 \mathrm{lbf} / \mathrm{in}^{2}(\sim 138 \mathrm{kPa})$ absolute.

- Vibration. Vibration normally incident to transport.

- Water spray. A water spray that simulates exposure to rainfall of approximately 2 in $(\sim 5.1 \mathrm{~cm})$ per hour for at least $1 \mathrm{~h}$.

- Free drop. Between 1.5 and $2.5 \mathrm{~h}$ after the conclusion of the water spray test, a free drop onto a flat, essentially unyielding, horizontal surface, striking the surface in a position for which maximum damage is expected. Note that the distance of the drop is a function of weight.

- Corner drop. A free drop onto each corner of the package in succession from a height of $1 \mathrm{ft}$ $(\sim 30 \mathrm{~cm})$ onto a flat, essentially unyielding, horizontal surface. Note that for a cylindrical package, the free drop would be onto each quarter of each rim.

○ This test applies only to fiberboard, wood, or fissile material rectangular packages not exceeding $110 \mathrm{lb}(\sim 49.9 \mathrm{~kg})$ and fiberboard, wood, or fissile material cylindrical packages not exceeding $220 \mathrm{lb}(\sim 99.8 \mathrm{~kg})$.

- Compression. The package is subjected for a period of $24 \mathrm{~h}$ to a compressive load applied uniformly to the top and bottom of the package in the position where the package would normally be transported. The compressive load is the greater of 5 times the weight of the package or the equivalent of $2 \mathrm{lbf} / \mathrm{in}^{2}(\sim 13.8 \mathrm{kPa})$ multiplied by the vertically projected area of the package.

- This test is applicable for packages weighting up to $11,000 \mathrm{lb}(4,990 \mathrm{~kg})$.

- Penetration. Impact of the hemispherical end of a vertical steel cylinder of 1.25 in $(3.18 \mathrm{~cm})$ diameter and 13- $\mathrm{lb}(5.9 \mathrm{~kg})$ mass dropped from a height of $40 \mathrm{in}(102 \mathrm{~cm})$ onto the surface of the package that is expected to be the most vulnerable to puncture.

\section{$\underline{H A C \text { tests include: }}$}

- Free drop. A free drop of a package through a distance of $30 \mathrm{ft}(\sim 9.1 \mathrm{~m})$ onto a flat, essentially unyielding, horizontal surface, striking the surface in a position for which maximum damage is expected. 
- Crush. A crush test on a flat, essentially unyielding, horizontal surface so as to impose maximum damage by the drop of a 1100-lb ( 499 kg) mass from $30 \mathrm{ft}(\sim 9.1 \mathrm{~m})$ onto the package. The mass must consist of a solid mild steel plate $40 \times 40$ in $(\sim 102 \times 102 \mathrm{~cm})$ and must fall in a horizontal attitude.

- The crush test is required only when the package has a mass not greater than $1100 \mathrm{lb}(\sim 499$ $\mathrm{kg})$, an overall density not greater than $62.4 \mathrm{lb} / \mathrm{ft}^{3}\left(\sim 1 \mathrm{~g} / \mathrm{cm}^{3}\right)$ based on external dimensions, and radioactive contents greater than $1000 \mathrm{~A}_{2}{ }^{(\dagger)}$ not as special form radioactive material.

- Note: for packages containing fissile material, the radioactive contents greater than $1000 \mathrm{~A}_{2}{ }^{(\dagger)}$ criterion does not apply.

- Puncture. A free drop of the package through a distance of 40 in $(\sim 102 \mathrm{~cm})$ in the position for which maximum damage is expected onto the upper end of a solid, vertical, cylindrical, mild steel bar mounted onto an essentially unyielding, horizontal surface. The bar must be 6 in $(\sim 15 \mathrm{~cm})$ in diameter and have a length as to cause maximum damage to the package, but not less than 8 in $(\sim 20 \mathrm{~cm})$ long.

- Thermal. Exposure of the package fully engulfed in a hydrocarbon fuel/air fire with an average flame temperature of at least $1475^{\circ} \mathrm{F}\left(\sim 802^{\circ} \mathrm{C}\right)$ for a period of 30 minutes.

- Immersion (fissile material). For fissile material subject to 10 CFR 71.55, in cases where water inleakage has not been assumed for criticality analyses, immersion under a head of water of at least $3 \mathrm{ft}(\sim 91 \mathrm{~cm})$ in the attitude for which maximum leakage is expected (10 CFR 71).

- Immersion (all packages). A separate, undamaged package subjected to water pressure equivalent to immersion under a head of water of at least $50 \mathrm{ft}(\sim 15.2 \mathrm{~m})$.

\subsubsection{Thermal Safety Analysis}

The thermal safety analysis is performed to demonstrate/determine that package materials and contents remain at temperatures below specified limits, and to ensure structural and other functional properties are maintained at design specifications for postulated conditions.

- Modeling of NCT, for extreme environmental conditions:

- Hot normal. Still air at $100^{\circ} \mathrm{F}\left(\sim 38^{\circ} \mathrm{C}\right)$ with solar heat load on external surfaces.

- Hot off-normal. Still air at $125^{\circ} \mathrm{F}\left(\sim 52^{\circ} \mathrm{C}\right)$ with solar heat load on external surfaces.

- Cold normal. Still air at $20^{\circ} \mathrm{F}\left(-6.7^{\circ} \mathrm{C}\right)$ without solar heat load on external surfaces.

- Cold off-normal. Still air at $-40^{\circ} \mathrm{F}\left(-40^{\circ} \mathrm{C}\right)$ without solar heat load on external surfaces.

\footnotetext{
${ }^{\dagger}$ The $\mathrm{A}_{2}$ values are in units of $\mathrm{Ci}$ or TBq. They represent the activity allowed in a Type-A package when the radioactive material is in "normal" form (i.e., not in a special form engineered capsule). To put it simply, the term $\mathrm{A}_{2}$, or more correctly the number of $\mathrm{A}_{2} \mathrm{~S}$ in a package, is defined as the sum of the fractions of the activity you intend to ship for each isotope divided by the allowable $A_{2}$ value in Table A-1 of 10 CFR 71 Appendix A (10 CFR 71). Thus, if you intend to ship $1 \mathrm{Ci}$ of ${ }^{60} \mathrm{Co}$ in normal form, the number of $\mathrm{A}_{2} \mathrm{~S}=1 \mathrm{Ci} / 42 \mathrm{Ci}=0.024$ because the $\mathrm{A}_{2}$ value for ${ }^{60} \mathrm{Co}$ is $42 \mathrm{Ci}$. For a mixture of isotopes, you sum the fraction of the "have" (in $\mathrm{Ci}$ or TBq) over the "allowed" (in $\mathrm{Ci}$ or TBq) for each isotope to determine the total number of $\mathrm{A}_{2} \mathrm{~s}$ intended for shipment. The $1000 \mathrm{~A}_{2}$ here refers to a sum of fractions of 1000 , or $1000 \mathrm{~A}_{2} \mathrm{~s}$.
} 
- Modeling of HAC of a fully engulfing fire with average flame temperature of at least $1475^{\circ} \mathrm{F}$

$\left(\sim 802^{\circ} \mathrm{C}\right)$ for 30 minutes (HAC fire),

- Pre-fire initial steady state consisting of hot normal NCT (i.e., still air at $100^{\circ} \mathrm{F}$, or $\sim 38^{\circ} \mathrm{C}$, with solar heat load on external surfaces).

- After 30 minute fire exposure, post-fire cooldown transient in still air at $100^{\circ} \mathrm{F}$, or $\sim 38^{\circ} \mathrm{C}$, with solar heat load on external surfaces, with no forced cooling from external source.

\subsubsection{Shielding Safety Analysis}

Shielding safety analysis is required to ensure that the packaging, together with its maximum allowable radioactive contents, meets regulatory dose rate limits during NCT and postulated HAC. It is also necessary to ensure that radiation from the contents does not adversely impact the performance of the materials that are important for package safety.

- Modeling of the package while taking into account changes in the package geometry and materials as a result of the NCT tests to

- Ensure that the dose rates on the package surface and at various distances from the package meet the 10 CFR 71.47 dose rate limits (10 CFR 71).

- Ensure that the neutron and gamma radiation from the radioactive contents does not adversely impact the properties of the materials important for package safety (e.g., containment seals).

- Ensure that the shielding design features of the package are adequate during normal package operations.

- Modeling of the package while taking into account changes in the package geometry and materials as a result of the HAC tests to:

- Ensure that the dose rates on the package surface and at various distances from the package meet the 10 CFR 71.51 dose rate limits at $1 \mathrm{~m}$ from the damaged package surface (10 CFR $71)$.

- Ensure that the design basis shielding features of the package are adequate and that no additional shielding design features are necessary.

\subsubsection{Criticality Safety Analysis}

If fissile content is below a specific level, criticality safety analysis may not be needed. Most of the waste streams with $\mathrm{Pu}$ and $\mathrm{U}$ recycled would meet that requirement for shipping. However, processing systems would have to be evaluated for possible hold-up of fissile material.

If the actinides are not removed, criticality safety analysis is required to ensure that the packaging, together with its maximum allowable fissile contents, remains subcritical during NCT and postulated HAC. It is also required that the Criticality Safety Index (CSI) be established, which is used by shippers to control the number of fissile packages allowed on a conveyance.

- Modeling of the package to ensure that the package remains subcritical if water were to leak into the containment system or liquid contents were to leak out of the containment system, assuming that the fissile material is 
- In the most reactive credible configuration consistent with the chemical and physical form of the material.

- With moderation by water to the most reactive credible extent.

- With close full reflection of the containment system by water on all sides, or such greater reflection of the containment system as may additionally be provided by the surrounding material of the packaging.

- Modeling of the package while taking into account changes in the package geometry and materials as a result of the 10 CFR 71.71 NCT tests to ensure that (10 CFR 71)

○ The package remains subcritical.

- The geometric form of the package contents would not be substantially altered.

- There would be no substantial reduction in the effectiveness of the packaging, including

- A no more than 5\% reduction in the total effective volume of the packaging on which nuclear safety is assessed.

- A no more than 5\% reduction in the effective spacing between the fissile contents and the outer surface of the packaging.

- No occurrence of an aperture in the outer surface of the packaging large enough to permit the entry of a 10-cm (4-in) cube.

- Modeling of the package while taking into account changes in the package geometry and materials as a result of the 10 CFR 71.73 HAC tests to ensure that the package remains subcritical assuming that (10 CFR 71)

- The fissile material is in the most reactive credible configuration consistent with the damaged condition of the package and the chemical and physical form of the contents;

- Water moderation occurs to the most reactive credible extent consistent with the damaged condition of the package and the chemical and physical form of the contents; and

- There is full reflection by water on all sides, as close as is consistent with the damaged condition of the package.

- Modeling of the package to determine the maximum allowable packages in an array that will remain subcritical to establish a CSI. To enable control of the number of packages, calculations must be performed to derive a number " $\mathrm{N}$," assuming that

- Five times "N" undamaged packages with nothing between the packages would be subcritical with optimum interspersed hydrogenous moderation.

- Two times "N" damaged packages, if each package were subjected to the tests specified in 10 CFR 71.73, would be subcritical with optimum interspersed hydrogenous moderation (10 CFR 71).

- There is full reflection by water on all sides, as close as is consistent with the damaged condition of the package.

○ The CSI must be determined by dividing the number 50 by the value of "N": i.e., CSI $=50 / \mathrm{N}$.

\subsection{Storage}

Once the salt is transported to its storage location, regulations will be dependent on the content and where the storage facility is located. Applicable documents could include federal and state laws and regulations, 
DOE requirements, and design criteria defined by national codes and standards. At a minimum, standards and requirements for a given storage system or site are likely to include the following:

- 10 CFR Part 72 ("Licensing Requirements for the Independent Storage of Spent Nuclear Fuel, High-Level Radioactive Waste, and Reactor-Related Greater than Class C Waste") (10 CFR 72)

- 10 CFR 830, Subpart B, Safety Basis Requirements (10 CFR 830, Subpart B)

- $\quad$ DOE O 420.1C, Chg 1 (Facility Safety) (DOE Order 420.1C Chg 1) and DOE Guide 420.1-1A (DOE Guide 420.1-1A)

- DOE O 435.1, Chg 1 (Radioactive Waste Management) (DOE Order 435.1 Chg 1)

- DOE O 458.1 Chg 3 (Radiation Protection of the Public and the Environment) (DOE Order 458.1 Chg 3)

Critical supporting safety analyses required to establish the storage safety basis are very similar in nature to those for transport (see Transportation Section 9.2) but will also include considerations for seismic capacity, gas flammability, etc.

A lesson that was learned from the storage of fuel salt from the MSRE is that storage of fuel salt needs to be undertaken with an understanding of the effect of radiolysis on the system, and that continuous monitoring of the storage facilities is required. From reactor shutdown in 1969 until 1989, pressure in the MSRE drain tanks had been relieved yearly to release $\mathrm{F}_{2(\mathrm{~g})}$ generated by radiolysis. The program was stopped in 1990 because of activity transport. Volatile ${ }^{233} U$ and ${ }^{232} U$ isotopes, along with $F_{2(g)}$, migrated from the salt drain tanks through the off-gas system over the course of several years. Uranium was found to be collecting at the entrance to the activated carbon bed. The vapor phase in contact with the bed included $\mathrm{F}_{2(\mathrm{~g})}$ saturated with $\mathrm{UF}_{6(\mathrm{~g})}$ at pressures close to atmospheric. Because of water inleakage, the activated carbon bed was also saturated with water, and there was a concern about criticality (Hollenbach and Hopper, 1996). Additionally, $\mathrm{UF}_{6}$ had been plating out as uranium oxyfluorides in the piping between the drain tanks and the carbon filter. Uranium oxyfluorides are formed from the reaction of $\mathrm{UF}_{6}$ and inleaking moisture. Treatment of the issue required an understanding of the complex chemistry of uranium fluorides and reengineering of existing contaminated structures to remove and sequester the $\mathrm{UF}_{6}$ (Trowbridge, 1997).

Additional information on the radiolysis and gaseous product evolution from solidified fluoride salts is presented in Appendix B.

\subsubsection{Structural Safety Analysis}

Regulations in 10 CFR 72 contain similar performance requirements for packages, casks, and canisters in long-term storage at a specific site to the requirements contained in 10 CFR 71 (see Section 9.2.1, Structural Safety Analysis under Transportation) (10 CFR 71; 10 CFR 72).

\subsubsection{Thermal Safety Analysis}

The tests for NCT and HAC (see Section 9.2.2, Thermal Safety Analysis under Transportation) are from 10 CFR 71 (for transportation packages), but 10 CFR 72 (for storage systems) has very similar definitions and requirements. Where they differ, the 10 CFR 72 requirements are generally less severe than those in 10 CFR 71 (10 CFR 71; 10 CFR 72).

\subsubsection{Radiological Protection}

Storage-related requirements for radiological protection are highly similar in terms of required performance. However, the specifics of a given design may be somewhat less limiting for the stored 
container, depending on shielding features designed into the storage facility definition and facility safety analysis report. General requirements for storage related to radiological protection include the following:

- Exposure control. Radiation protection systems must be provided for all areas and operations where onsite personnel may be exposed to radiation or airborne radioactive materials. Structures, systems, and components for which operation, maintenance, and required inspections may involve occupational exposure must be designed, fabricated, located, shielded, controlled, and tested so as to control external and internal radiation exposures to personnel. The design must include means to

- Prevent the accumulation of radioactive material in those systems requiring access.

- Decontaminate those systems to which access is required.

- Control access to areas of potential contamination or high radiation.

- Measure and control contamination of areas requiring access.

- Minimize the time required to perform work in the vicinity of radioactive components; for example, by providing sufficient space for ease of operation and designing equipment for ease of repair and replacement.

- Shield personnel from radiation exposure.

- Radiological alarm systems. Radiological alarm systems must be provided in accessible work areas as appropriate to warn operating personnel of radiation and airborne radioactive material concentrations above a given set point and of concentrations of radioactive material in effluents above control limits. Radiation alarm systems must be designed with provisions for calibrating and testing their operability.

- Areas containing radioactive materials must be provided with systems for measuring the direct radiation levels in and around these areas.

- Effluent control. The storage area must be designed to provide means to limit the release of radioactive materials in effluents to levels as low as is reasonably achievable during normal operations, and to control the release of radioactive materials under accident conditions. Analyses must be performed to show that releases to the general environment during normal operations and anticipated occurrences will be within the following exposure limits:

- The annual dose equivalent to a maximally exposed individual who is located beyond the controlled area must not exceed $0.25 \mathrm{mSv}(25 \mathrm{mrem})$ to the whole body, $0.75 \mathrm{mSv}(75 \mathrm{mrem})$ to the thyroid and $0.25 \mathrm{mSv}$ ( $25 \mathrm{mrem}$ ) to any other critical organ.

Analyses of design-basis accidents must be performed to show that releases to the general environment will be within the following exposure limits:

- Any individual located on or beyond the nearest boundary of the controlled area may not receive from any design-basis accident the more limiting of a total effective dose equivalent of $0.05 \mathrm{~Sv}$ (5 rem), or the sum of the deep-dose equivalent and the committed dose equivalent to any individual organ or tissue (other than the lens of the eye) of $0.5 \mathrm{~Sv}$ (50 rem). The lens dose equivalent may not exceed $0.15 \mathrm{~Sv}(15 \mathrm{rem})$ and the shallow dose equivalent to skin or any extremity may not exceed $0.5 \mathrm{~Sv}(50 \mathrm{rem})$. The minimum distance from the spent fuel or high-level radioactive waste handling and storage facilities to the nearest boundary of the controlled area must be at least $100 \mathrm{~m}$. 


\subsubsection{Criticality Safety Analysis}

Storage-related requirements for critical safety are highly similar in terms of required performance. However, specifics of a given design may be somewhat less limiting for the stored container, depending on criticality safety features designed into the storage facility definition. Some general requirements for storage related to criticality include the following:

- Design for criticality safety. Spent fuel handling, packaging, transfer, and storage systems must be designed to be maintained in a subcritical state and to ensure that, before a nuclear criticality accident is possible, at least two unlikely, independent, and concurrent or sequential changes have occurred in the conditions essential to nuclear criticality safety. The design of handling, packaging, transfer, and storage systems must include margins of safety for the nuclear criticality parameters that are commensurate with the uncertainties in the data and methods used in calculations and demonstrate safety for the handling, packaging, transfer, and storage conditions and in the nature of the immediate environment under accident conditions.

- Methods of criticality control. When practicable, the design of the storage facility must be based on favorable geometry, permanently fixed neutron absorbing materials (poisons), or both. Where solid neutron absorbing materials are used, the design must provide for positive means of verifying their continued efficacy. For dry spent fuel storage systems, the continued efficacy may be confirmed by a demonstration or analysis before use, showing that significant degradation of the neutron absorbing materials cannot occur over the life of the facility.

- Criticality monitoring. A criticality monitoring system shall be maintained in each area where special nuclear material is handled, used, or stored, which will energize clearly audible alarm signals if accidental criticality occurs. Underwater monitoring is not required when special nuclear material is handled or stored beneath water shielding. Monitoring of dry storage areas where special nuclear material is packaged in its stored configuration under a license issued under this subpart is not required.

\subsection{Disposal}

Disposal options will be highly dependent on the waste form and the contents of the waste form. Therefore, existing regulations concerning waste disposal will have to be reviewed for MSR wastes. Issues related to disposal of MSR wastes include hazardous wastes, high halogen concentrations, high heat density, and waste form performance. These issues are touched upon in the following subsections.

\subsubsection{Hazardous Waste}

The proposed Yucca Mountain repository application for construction authorization (DOE/RW-0573, Update No. 1, NRC Docket No. 63-001, 2008) restricted waste to nonhazardous waste, according to the Resource Conservation and Recovery Act (RCRA). Untreated salt waste and salt-contaminated wastes from MSRs are likely to be characteristically hazardous under toxicity (e.g., Be) and/or reactivity (e.g., Li-containing salts) regulations (40 CFR 261, 1983). MSRE fuel salts have been declared hazardous mixed waste under RCRA (DOE/OR/02-1671\&D2, 1998). For a future geologic repository to directly dispose of untreated MSR salts and salt-contaminated wastes, the repository should be licensed to manage mixed (i.e., hazardous and radioactive) wastes. This may require dual regulation under the NRC to regulate for the radioactive hazards and the Environmental Protection Agency to regulate the toxicity and reactivity hazards.

Salt and salt-contaminated wastes may be treated to remove the toxicity and reactivity hazards associated with the salt to render the waste nonhazardous and/or allow for delisting of the waste if it is listed. To demonstrate that the toxicity hazard is removed, the treated waste form performance with respect to the Toxicity Characteristic Leaching Procedure (TCLP) (SW 846 Method 1311, 1992) or similar tests 
(methods 1313 or 1315). Most waste forms designed to meet long-term durability requirements for disposal will also meet standards for delisting or universal treatment standards. Although there is no official test for reactivity, nuclear waste forms will, in general, also be nonreactive.

\subsubsection{Halogen Content}

The corrosivity of high-concentration sources of halide salts (fluoride- and chloride-based) is an issue that needs to be resolved for the disposal of salt and salt-contaminated wastes from an MSR. Point sources of significant quantities of chlorine and/or fluorine may increase the corrosion rate of engineered systems in the repository (including waste packages and waste forms), adding another safety issue to be evaluated. The disposal of Hanford Site $\mathrm{CsCl}$ and $\mathrm{SrF}_{2}$ capsules at the proposed repository at Yucca Mountain was evaluated and found to be unacceptable, with solubility and corrosivity impacts cited as the reason: "The radioactive cesium and strontium, in the form of crystalline salts, are unacceptable in their present form because of their solubility and corrosivity" (Foust, 1994). However it is believed that more thorough analyses combined with design enhancements (e.g., over-packages and/or spatial segregation) would allow acceptance of such wastes in most or all repository concepts (SAND2014-0187P, SAND20140189P, 2014). For example, $\mathrm{SrF}_{2}$ capsules have been disposed of in intermediate-depth (40 $\mathrm{m}$ deep) greater confinement disposal boreholes at Nevada Test Site Area 5. In this respect, borehole and salt repository environments are particularly well suited for MSR salt wastes.

\subsubsection{Heat Density}

Typical MSR salt streams are tolerant of relatively high decay heats, and may experience high decay heats because of their greater overall power density compared with LWR ceramic fuels. A cooling requirement of $100 \mathrm{~kW}$ was used in a recent assessment of an operating $10 \mathrm{MW}$ MSRE-type reactor (Zhao et al., 2015). Thus, at the time of waste treatment, decay heats can still be high. High decay heat creates two challenges: (1) waste form tolerance of elevated temperature and (2) disposal package thermal limits. Depending on the waste form selected for the heat-generating components of the waste (primarily alkali and alkaline earth fission products and actinides), there will be temperature limits for safe waste form storage. For example, glass waste forms typically must be maintained at temperatures below the glass transition temperature $\left(T_{\mathrm{g}}\right)$ in the container centerline throughout storage. The storage temperature is dependent on both container diameter and method of cooling. For active cooling, safety-significant cooling systems are required if necessary to maintain centerline temperatures below $T_{\mathrm{g}}$. Passive cooling systems tend to require either relatively small, high-surface-area, containers or low heat loading per container. A detailed analysis of heat management for electrochemical separation salt waste forms was performed by Vienna et al. (2015b). They found that for salt wastes decayed for $5 \mathrm{y}$ before waste form fabrication, optimal container diameters ranged from 8.5 to $20.5 \mathrm{in}$. Depending on the temperature tolerance of the waste form. A similar relationship would be expected for the high-heat portions of MSR wastes. However, an additional trade-off between cooling time out of reactor, interim storage, and waste form fabrication would need to be considered for the case of MSR wastes; that factor was not considered in the electrochemical salt waste treatment study.

Heat tolerance at time of disposal adds another constraint. Different disposal concepts have different heat tolerances. Hardin et al. (2012) analyzed three generic repository environments - clay, granite, and saltand found thermal limits from waste packages at time of emplacement of roughly 1.2, 1.27, and $7.2 \mathrm{~kW}$, respectively. Brady et al. (2009) evaluated heat limits for deep boreholes and found no practical limit, because no credit is taken for near-field rock stability, and seals are placed far beyond the thermal nearfield. As waste management costs (storage, transportation, and disposal) generally scale with the number of packages, the salt and deep borehole disposal approaches are favored for high-specific-heat waste forms.

A more detailed analysis of heat impacts on waste management for high-heat portions of MSR wastes would be needed to obtain more definitive guidelines. 


\subsubsection{Waste-Form Performance}

The waste form is one of multiple engineered barriers to the release of radionuclides and hazardous components of nuclear waste to the environment. The impact of the waste form durability on repository performance depends strongly on the repository design, waste form durability, and immobilization of isotopes/hazardous components. For example, the proposed Yucca Mountain repository (DOE/RW-0573, Update No. 1, NRC Docket No. 63-001, 2008) and the Belgian deep geological repository concepts (Haverkamp et al., 2012) rely heavily on the waste packages and natural barriers, with little reliance on waste form performance. Alternatively, the Hanford Site Integrated Disposal Facility (Lee, 2018) and the French deep geologic disposal facility (ANDRA, 2005) rely heavily on the waste form performance. Also, the reliance on waste form performance often depends on the scenario analyzed. For example, human intrusion scenarios and scenarios that disrupt either engineered or natural barriers tend to rely more heavily on the waste form.

For long-term dose to the public, the waste form half-life should be on the order of the half-life of the radionuclide being immobilized. This is particularly challenging for ${ }^{129} \mathrm{I}\left(t_{1 / 2}=1.6 \times 10^{7} \mathrm{y}\right)$ and ${ }^{36} \mathrm{Cl}\left(t_{1 / 2}=\right.$ $3 \times 10^{5} \mathrm{y}$ ), which significantly contribute to dose calculations of nearly every HLW repository analysis worldwide. Waste forms that immobilize the halide fission products and activation products are thus required to have lifetimes on the order of $10^{7} \mathrm{y}$. Other long-lived isotopes, such as actinides and ${ }^{99} \mathrm{Tc}$, will also require durable waste forms with lifetimes in the $10^{5}$ to $10^{7}$ y range. Currently, contaminated graphite and Hastelloy $\mathrm{N}$ are not anticipated to have lifetimes of that order of magnitude. Typical borosilicate glass waste forms are projected to have lifetimes in the $10^{6} \mathrm{y}$ range under most repositoryrelevant environments. 


\section{EVALUATION OF WHAT WE KNOW HOW TO MANAGE AND WHAT WE DO NOT: RECOMMENDATIONS ON WHAT TO DO NEXT}

\subsection{What We Know How to Manage}

Several moderately to highly mature processes and technologies exist that could be implemented to manage the off-gas streams, including those for noble gases (e.g., $\mathrm{Xe}, \mathrm{Kr}$ ), reactive gases (e.g., halides), hydrogen (e.g., ${ }^{3} \mathrm{H}_{2(\mathrm{~g})},{ }^{3} \mathrm{HF}$ ), particulates, and aerosols (see Section 3). Since off-gas capture and immobilization has been the focus of study for decades, a wealth of knowledge exists in the literature. Advanced sorbents with high technical maturity exist including metal-exchanged zeolites (e.g., AgZ, $\mathrm{AgX}), \mathrm{Ag}^{0}$-functionalized silica aerogels, activated carbon, and MOFs. Molten hydroxide or aqueous hydroxide scrubbers could be used to clean these streams.

For the salt-based streams (see Section 4), a lot of recent work has been done to develop and test waste forms for chloride-based pyrochemical processing salt wastes, and it is likely that many of the chloridebased MSR options could benefit from this research. Some of these could also be applied to fluoridebased MSR salt wastes. Several waste forms have been identified, including glass-bonded ceramics (e.g., sodalite, apatite) and glasses (e.g., lead tellurite). Additional, less mature technologies are currently under investigation that show promise for dehalogenation (i.e., I and $\mathrm{Cl}$ removal) of halide salt wastes that could be used for ${ }^{37} \mathrm{Cl}$ recycling as well as improving waste loading in the final waste forms. These options include reactions between the salts and phosphate precursors (i.e., phosphate glass waste form) or USH-Y zeolite (i.e., glass-bonded zeolite or glassy waste forms).

For graphite streams (Section 5), it is highly likely that this will be one of the largest waste fraction (if not the largest) coming from an MSR concept where liquid fuel is used (not TRISO). Thus, to limit the volume of this waste fraction, recycling the graphite is an attractive path forward and has been demonstrated (albeit on simulants and on a small scale) using different techniques outlined in Section 5.2.

Processing the metal into a waste form is likely as simple as reducing the sizes of the components and then either melting or compacting them into a monolithic form for storage and disposal (see Section 6). However, some potential complications of this approach could arise, considering the potential volatility of fission products entrained in the metallic reactor components during the process of immobilization (e.g., high-temperature melting). While this issue does not eliminate the possibility of high-temperature melting as an immobilization approach, it does introduce added requirements, such as methods to capture potential volatiles evolving during the melting process.

The D\&D wastes, as well as operating wastes, can likely be dealt with through size reduction, packaging, and processing as LLW or GTCC wastes (see Sections 7 and 8, respectively).

\subsection{Proposed Path Forward}

The following are the primary areas in which more work is needed for the effective treatment and storage of effluents and wastes generated during the operation and processing of a generic MSR concept:

- Specific waste compositions, isotope concentrations, and mass estimates. Develop a reference mass balance for MSR effluents for each of the four baseline cases shown in Table 1-2 (Section 1). This analysis must include the waste streams from anticipated processing of reactor materials, online or during decommissioning. Perform a systems analysis study of the optimal treatment and disposal options for those wastes, as was done for electrochemical salt wastes by Vienna et al. (2015b).

- Functional requirements for disposal of MSR wastes. Develop initial functional and operational requirements for the disposal of salt, carbon, products of separations, and other MSR 
wastes. Compare these functional and operational requirements with current NE- 8 generic repository design concepts (Hardin et al., 2011).

- Initiate off-gas treatment technology testing. Evaluate and test getters and scrub systems for noble gases (e.g., Xe, Kr), reactive gases (e.g., halides), hydrogen (e.g., $\left.{ }^{3} \mathrm{H}_{2(\mathrm{~g})},{ }^{3} \mathrm{HF}\right)$, particulates, and aerosols for reactor operation.

- Investigate waste form options for salt streams and separated salt streams. Begin scoping tests (e.g., waste loading, performance testing, storage affects such as radiation/heat) for highhalide salt containing HLW streams, starting with the most promising options (e.g., glass-bonded sodalite, glass-bonded apatite, cermets, phosphate glass).

- Treat and/or recycle contaminated carbon-based materials (i.e., graphite). Develop simulants for contaminated graphite and perform scoping tests for treatment/recycling options (these may require simulated irradiation). Evaluate treatment options and select options to evaluate (e.g., CARBOWASTE Program).

- Investigate the radiolysis and chemical kinetics of interactions between waste isotopes and structural materials. The kinetics are likely not to be homogeneous, and so the microstructures and grain boundaries of materials will have to be considered. The salt itself is likely to phasesegregate when cooled, which will add complexity to the model. Liberation of gases, some of them corrosive, must be considered in choosing options for storage and disposal.

- Investigate methods for ${ }^{7} \mathrm{Li}$ and/or ${ }^{37} \mathrm{Cl}$ recovery. In an attempt to moderate the financial liabilities of MSR concepts, it will likely be necessary to recover ${ }^{7} \mathrm{Li}$ for Li-containing salts and ${ }^{37} \mathrm{Cl}$ for $\mathrm{Cl}$-containing salts. To support this effort, recovery/recycling concepts should be evaluated. 


\section{REFERENCES}

10 CFR 71. Packaging and Transportation of Radioactive Material. United States Nuclear Regulatory Commission, Code of Federal Regulations.

10 CFR 72. Licensing Requirements for the Independent Storage of Spent Nuclear Fuel, High-Level Radioactive Waste, and Reactor-Related Greater than Class C Waste. United States Nuclear Regulatory Commission, Code of Federal Regulations.

10 CFR 830, Subpart B. Safety Basis Requirements. United States Nuclear Regulatory Commission, Code of Federal Regulations.

316L SS. Accessed 2018 at https://www.upmet.com/products/stainless-steel/3163161\#ChemicalProperties.

40 CFR 261. 1983. Identification and Listing of Hazardous Waste. U.S. Environmental Protection Agency, Washington, D.C.

49 CFR 171-180, Subtitle B, Chapter I, Subchapter C. Hazardous Materials Regulations. United States Nuclear Regulatory Commission, Code of Federal Regulations.

Aaron, W. S., E. D. Collins, G. D. DelCul, R. T. Jubin, and R. J. Vedder. 2012. "Cermet high level waste forms." Patent No. US2012/02136558 A1.

Aaron, W. S., D. L. Kinser, and T. C. Quinby. 1983. "Cermets and method for making same." Patent No. 4383855.

Afzal, S., A. Rahimi, M. R. Ehsani, and H. Tavakoli. 2010. "Experimental study of hydrogen fluoride adsorption on sodium fluoride." Journal of Industrial and Engineering Chemistry 16(1):147-51.

Alloy $800 \mathrm{H} / \mathrm{HT}^{\circledR}$. Accessed 2018 at https://www.corrosionmaterials.com/documents/dataSheet/alloy800DataSheet.pdf.

Amamoto, I. and K. Sato. 2007. "Reprocessing method by fluoride volatility process using solid-gas separation." Patent No. US7208129B2.

ANDRA. 2005. Dossier 2005 Argile Tome, Phenomenalogical Evolution of a Geologic Repository. Agence Nationale pour la Destion des Déchets Radioactifs, Châtenay-Malabry, France.

Atsumi, H. 2002. "Hydrogen bulk retention in graphite and kinetics of diffusion." Journal of Nuclear Materials 307-311:1466-70.

Atsumi, H., A. Muhaimin, T. Tanabe, and T. Shikama. 2009. "Hydrogen trapping in neutron-irradiated graphite." Journal of Nuclear Materials 386-388:379-82.

Baes Jr., C. F. 1974. "The chemistry and thermodynamics of molten salt reactor fuels." Journal of Nuclear Materials 51:149-62.

Baetsle, L. H. and J. Broothaerts. 1977. "Reprocessing Off-Gas Treatment Research in Belgium." In Seminar on Radioactive Effluents from Nuclear Fuel Reprocessing Plants, Schule für Kerntechnik Kernforschungszentrum, Karlsruhe, Germany. 
Bagri, P. and M. F. Simpson. 2015. "Occlusion and ion exchange of eutectic LiCl-KCl in H-Y zeolite." Journal of Nuclear Fuel Cycle and Waste Technology 13(Special):45-53.

Baker, F. S., C. I. Contescu, C. Tsouris, and J. McFarlane. 2007. Activated carbon composites for air separation. ORNL/TM-2007/329, Oak Ridge National Laboratory, Oak Ridge, TN.

Banerjee, D., C. M. Simon, A. M. Plonka, R. K. Motkuri, J. Liu, X. Chen, B. Smit, J. B. Parise, M. Haranczyk, and P. K. Thallapally. 2016. "Metal-organic framework with optimally selective xenon adsorption and separation." Nature Communications 7:11831-1-7.

Banford, A. W., H. Eccles, M. J. Graves, W. von Lensa, and S. Norris. 2008. "CARBOWASTE - An Integrated Approach to Irradiated Graphite." Nuclear Future 4(5):1-5.

Bari, K., S. Z. Khan, T. Lowe, and J. K. Farooqi. 2013. "Measurement of thermal diffusivity for alumina borosilicate glass bearing TRISO fuel particles: experiment and modelling correlation." Journal of Material Science 48:4866-75.

Bateman, K. J., C. J. Knight, and C. W. Solbrig. 2007. Current Status of Ceramic Waste Form Development. INL/INT-06-11736, Rev. 1, Idaho National Laboratory, Idaho Falls, ID.

Bazan, R. E., M. Bastos-Neto, A. Moeller, F. Dreisbach, and R. Staudt. 2011. "Adsorption equilibria of $\mathrm{O}_{2}, \mathrm{Ar}, \mathrm{Kr}$ and $\mathrm{Xe}$ on activated carbon and zeolites: single component and mixture data." Adsorption 17(2):371-83.

Beagley, B., C. M. B. Henderson, and D. Taylor. 1982. "The crystal structures of aluminosilicatesodalites: X-ray diffraction studies and computer modelling." Mineralogical magazine 46(341):459-64.

Beall, G. H. and R. F. Reade. 1979. "Glasses exhibiting high lithium ion mobility." USA Patent No. 4164610.

Bettis, E. S. and R. C. Robertson. 1970. "The Design and Performance Features of a Single-Fluid Molten-Salt Breeder Reactor." Nuclear Applications and Technology 8(2):190-207.

Betzendahl, R. 2014. "The 2014 rare gases market report." CryoGas International.

Betzler, B. R., J. J. Powers, J. L. Peterson-Droogh, and A. Worrall. 2017a. Fuel cycle analysis of fast and thermal molten salt reactors. In Proceedings of GLOBAL International Fuel Cycle Conference.

Betzler, B. R., J. J. Powers, and A. Worrall. 2017b. "Molten salt reactor and fuel cycle modeling and simulation with SCALE." Annals of Nuclear Energy 101:489-503.

Betzler, B. R., S. Robertson, E. Davidson, J. Powers, A. Worrall, L. Dewan, and M. Massie. 2018. "Fuel cycle and neutronic performance of a spectral shift molten salt reactor design." Annals of Nuclear Energy 119:396-410.

Bingham, P. and R. J. Hand. 2006. "Structure and properties of iron borophosphate glasses." European Journal of Glass Science and Technology 47B(4):313-17. 
Boatner, L. A., G. W. Beall, M. M. Abraham, C. B. Finch, P. G. Huray, and M. Rappaz. 1980. "Monazite and other lanthanide orthophosphates as alternate actinide waste forms." In Advances in Nuclear Science \& Technology, ed. CJM Northrup Jr., pp. 289-96.

Bohner, E. Design and Performance of Engineered Barrier Systems for the Finnish Deep Geological Repository. 2018. Accessed at https://www.dmtgroup.com/fileadmin/redaktion/documents/DMT_Events/FG-Endlager/01_Bohner.pdf.

Bonaccrsi, E., S. Merlino, P. Orlandi, M. Pasero, and G. Vezzalini. 1994. "Quadridavyne, $\left[(\mathrm{Na}, \mathrm{K})_{6} \mathrm{Cl}_{2}\right]\left[\mathrm{Ca}_{2} \mathrm{Cl}_{2}\right]\left[\mathrm{Si}_{6} \mathrm{Al}_{6} \mathrm{O}_{24}\right]$, a new feldspathoid mineral from Vesuvius area." European Journal of Mineralogy 6(4):481-88.

Boyle, C. H. and S. A. Meguid. 2015. "Mechanical performance of integrally bonded copper coating for the long term disposal of used nuclear fuel." Nuclear Engineering and Design 293:403-12.

Brady, P. V., B. W. Arnold, G. A. Freeze, P. N. Swift, S. J. Bauer, J. L. Kanney, R. P. Rechard, and J. S. Stein. 2009. Deep Borehole Disposal of High-Level Radioactive Waste. SAND2009-4401, Sandia National Laboratories, Albuquerque, NM.

Briggs, R. B. 1966. Molten-Salt Reactor Program Semiannual Progress Report. ORNL-3936, Oak Ridge National Laboratory, Oak Ridge, TN.

Brown, N. R., B. R. Betzler, J. J. Carbajo, A. J. Wysocki, A. S. Greenwood, C. Gentry, and A. L. Qualls. 2017. "Preconceptual design of a fluoride high-tempreature salt-cooled engineering demonstration reactor: Core design and safety analysis." Annals of Nuclear Energy 103:49-59.

Bruffey, S. H. and R. T. Jubin. 2017. "Analysis of Krypton-85 Legacy Waste Forms: Part I." Nuclear Technology 200(2):159-69.

Bruffey, S. H., R. T. Jubin, and J. A. Jordan. 2016. "Capture of Elemental and Organic Iodine from Dilute Gas Streams by Silver-exchanged Mordenite." Procedia Chemistry 21:293-99.

Burchell, T. and P. Pappano. 2010. The Characterization of Grade PCEA Recycle Graphite Pilot Scale Billets. ORNL/TM-2010/00169, Oak Ridge National Laboratory, Oak Ridge, TN.

Calderoni, P., X. Sun, P. Sabharwall, X. Wu, and S. Shi. 2008. "Measurement of tritium permeation in FLiBe (2LiF-BeF 2$)$." Fusion Engineering and Design 83:1331-34.

Calkins, V. P. 1958. "Production of uranium tetrachloride." Patent No. US2864666A.

Campbell, D. and G. I. Cathers. 1960. "Processing of molten salt power reactor fuels." Industrial and Engineering Chemistry 52(1):41-44.

Cao, C., S. Chong, L. Thirion, J. C. Mauro, J. S. McCloy, and A. Goel. 2017. "Wet chemical synthesis of apatite-based waste forms - A novel room temperature method for the immobilization of radioactive iodine." Journal of Materials Chemistry A 5(27):14331-42.

Capps, R. H. 1951. Reaction of Gaseous Uranium Hexafluoride and Hydrogen Fluoride with Metallic Fluorides. K-770, Oak Ridge Gaseous Diffusion Plant, Oak Ridge, TN. 
Cathers, G. I., M. R. Bennett, and R. L. Jolley. 1958. "UF $6-3 \mathrm{NaF}$ complex formation and decomposition." Industrial \& Engineering Chemistry 50(11):1709-10.

Chandler, W. T. and R. J. Walter. 1968. Hydrogen Effects in Refractory Metals. In Proceedings of Refractory Metal Alloys Metallurgy and Technology. eds. I Machlin, RT Begley and ED Weisert, pp. 197-249, Metallurgical Society of AIME and the National Aeronautics and Space Administration.

Chernick, C. L., H. H. Claassen, and B. Weinstock. 1961. "Rhodium hexafluoride." Journal of the American Chemical Society 83(14):3165-66.

Chesne, A., P. Miquel, J. P. Goumondy, and A. Leseur. 1977. "Progress Report on French Research and Development in the Treatment of Off-Gases from Reprocessing Plants." In Seminar on Radioactive Effluents from Nuclear Fuel Reprocessing Plants, Schule für Kerntechnik Kernforschungszentrum, Karlsruhe, Germany.

Cho, Y.-Z., B.-G. Ahn, H.-C. Eun, J.-S. Jung, and H.-S. Lee. 2011. "Melt crystallization process treatment of $\mathrm{LiCl}$ salt waste generated from electrolytic reduction process of spent oxide fuel." Energy Procedia 7:525-28.

Cho, Y.-Z., G.-H. Park, H.-C. Yang, D.-S. Han, H.-S. Lee, and I.-T. Kim. 2009. "Minimization of eutectic salt waste from pyroprocessing by oxidative precipitation of lanthanides." Journal of Nuclear Science and Technology 46(10):1004-11.

Chong, S., J. Peterson, J. Nam, B. Riley, and J. McCloy. 2017. "Synthesis and characterization of iodosodalite." Journal of the American Ceramic Society 100(5):2273-84.

Christensen, R., X. Sun, P. Sabharwall, X. Wu, and S. Shi. 2016. Tritium Mitigation/Control for Advanced Reactor System. Ohio State University, Columbus, $\mathrm{OH}$.

Compere, E. L., S. S. Kirslis, E. G. Bohlmann, F. F. Blankenship, and W. R. Grimes. 1975. Fission product behavior in the molten salt reactor experiment. ORNL-4865, Oak Ridge National Laboratory, Oak Ridge, TN.

Craig, B. D. and D. B. Anderson, eds. 1997. Sodium Hydroxide. in "Handbook of Corrosion Data," ASM International, Materials Park, $\mathrm{OH}$.

Crum, J. V., D. Strachan, A. Rohatgi, and M. Zumhoff. 2013. "Epsilon metal waste form for immobilization of noble metals from used nuclear fuel." Journal of Nuclear Materials 441(1):103-12.

Daniel, C., A. Elbaraoui, S. Aguado, M.-A. Springuel-Huet, A. Nossov, J.-P. Fontaine, S. Topin, T. Taffary, L. Deliere, Y. Schuurman, and D. Farrusseng. 2013. "Xenon capture on silver-loaded zeolites: characterization of very strong adsorption sites." The Journal of Physical Chemistry C 117(29):15122-29.

Day, D., Z. Wu, C. Ray, and P. Hrma. 1998. "Chemically durable iron phosphate glass waste forms." Journal of Non-Crystalline Solids 241:1-12.

Day, D. E. and C. S. Ray. 2013. A Review of Iron Phosphate Glasses and Recommendations for Vitrifying Hanford Waste. INL/EXT-13-30389, Idaho National Laboratory, Idaho Falls, ID. 
De Guire, E. From new fuels to waste disposal, next-gen nuclear reactors depend on advanced ceramics. 2013. Accessed at http://ceramics.org/ceramic-tech-today/nuclear-2/from-new-fuels-to-waste-disposalnext-gen-nuclear-reactors-depend-on-advanced-ceramics.

DelCul, G. D. Personal communication. 2018. "Recycling graphite through pulverization and acid leaching."

DelCul, G. D., R. D. Hunt, and W. S. Aaron. 2018. Complete tests to produce cermet and grout waste forms using surrogate oxide and nitrate powders. NTRD-MRWFD-2018-000143, ORNL/SPR-2018/877, Oak Ridge National Laboratory, Oak Ridge, TN.

DelCul, G. D., J. A. Johnson, B. B. Spencer, and E. D. Collins. 2013. Roadmap for development of an advanced head-end. In Proceedings of GLOBAL 2013. pp. 879-81.

Deliere, L., B. Coasne, S. Topin, C. Gréau, C. Moulin, and D. Farrusseng. 2016. "Breakthrough in xenon capture and purification using adsorbent-supported silver nanoparticles." Chemistry: A European Journal 22:9660-66.

Diomidis, N., L. H. Johnson, P. Bastid, and C. Allen. 2017. "Design development of a copper-coated canister for the disposal of spent fuel in a deep geological repository in Opalinus Clay." Corrosion Engineering Science and Technology 52:31-39.

DOE Guide 420.1-1A. Nonreactor Nuclear Safety Design Guide for use with DOE O 420.1C, Facility Safety. U.S. Department of Energy, Washington, D.C.

DOE Order 420.1C Chg 1. Facility Safety. U.S. Department of Energy, Washington, D.C.

DOE Order 435.1 Chg 1. Radioactive Waste Management. U.S. Department of Energy, Washington, D.C.

DOE Order 458.1 Chg 3. Radiation Protection of the Public and the Environment. U.S. Department of Energy, Washington, D.C.

DOE/OR/02-1671\&D2. 1998. Record of Decision for Interim Action to Remove Fuel and Flush Salts from the Molten Salt Reactor Experiment Facility at the Oak Ridge National Laboratory. U.S. Department of Energy, Oak Ridge, TN.

DOE/RW-0573, Update No. 1, NRC Docket No. 63-001. 2008. Yucca Mountain Repository License Application. U.S. Department of Energy, Office of Civilian Radioactive Waste Management.

Donald, I. W. 2010. Waste Immobilization in Glass and Ceramic Based Hosts: Radioactive, Toxic and Hazardous Wastes, John Wiley \& Sons, Ltd., United Kingdom. 
Donze, S., L. Montagne, and G. Palavit. 2000. "Thermal conversion of heavy metal chlorides $\left(\mathrm{PbCl}_{2}\right.$, $\left.\mathrm{CdCl}_{2}\right)$ and alkaline chlorides $(\mathrm{NaCl}, \mathrm{KCl})$ into phosphate glasses." Chemistry of Materials 12(7):192125.

Ebert, W. L. 2005. Testing to Evaluate the Suitability of Waste Forms Developed for Electrometallurgically-Treated Spend Sodium-Bonded Nuclear Fuel for Disposal in the Yucca Mountain Repository. ANL-05/43, Argonne National Laboratory-East, Argonne, IL.

Ebisuzaki, Y., W. J. Kass, and M. O'Keeffe. 1968. "Solubility and diffusion of hydrogen and deuterium in platinum." The Journal of Chemical Physics 49(8):3329-32.

Engel, G. and U. Fischer. 1990. "Die kristallstruktur von $\mathrm{Na}_{3} \mathrm{~Pb}_{2}\left(\mathrm{BeF}_{4}\right)_{3} \mathrm{~F}$, einem fluoroberyllat mit apatitstruktur." Journal of the Less Common Metals 158(1):123-30.

Eun, H. C., J. H. Choi, I. H. Cho, T. K. Lee, T. J. Kim, J. S. Shin, H. S. Park, and D. H. Ahn. 2016. "Purification of $\mathrm{LiCl}-\mathrm{KCl}$ eutectic waste salt containing rare earth chlorides delivered from the pyrochemical process of used nuclear fuel using a reactive distillation process." J. Radioanal. Nucl. Chem. 307:1419-27.

Ewing, R. C. 1999. Nuclear waste forms for actinides. In Proceedings of National Academy of Sciences. vol. 96, pp. 3432-39.

Féron, B., J. L. Guth, and N. Mimouni-Erddalane. 1994. "Influence of the presence of NaF on the crystallization of zeolite A (LTA): First evidence for the existence of fluorosodalite, the missing endmember of the halosodalite series." Zeolites 14(3):177-81.

Forsberg, C. 2018a. In Proceedings of ICAPP 2018 - International Congress on Advances in Nuclear Power Plants pp. 23923.

Forsberg, C. Personal communication. 2018b. "Discussion of potential MSR hold tank pressurization."

Forsberg, C. W. 2006. Molten-Salt-Reactor Technology Gaps. In Proceedings of International Congress on Advances in Nuclear Power Plants (ICAPP'06).

Forsberg, C. W., E. C. Beahm, and G. W. Parker. 1994. Direct converstion of radioactive and chemical waste containing metals, ceramics, amorphous solids, and organics to glass. In Proceedings of Spectrum '94.

Forsberg, C. W., E. C. Beahm, and J. C. Rudolph. 1997. Direct conversion of halogen-containing wastes to borosilicate glass. In Proceedings of MRS Scientific Basis for Nuclear Waste Management XX. vol. 465, pp. 131-37.

Forsberg, C. W., S. Lam, D. M. Carpenter, D. G. Whyte, R. Scarlat, C. Contescu, L. Wei, J. Stempien, and E. Blandford. 2017. "Tritium control and capture in salt-cooled fission and fusion reactors: status, challenges, and path forward." Nuclear Technology 197(2):119-39.

Forsberg, C. W. and P. F. Peterson. 2015. "Spent nuclear fuel and graphite management for salt-cooled reactors: Storage, safeguards, and repository disposal." Nuclear Technology 191(2):113-21. 
Foust, L. D. 1994. Decision Regarding the Acceptance of Strontium Fluoride and Cesium Chloride as a Waste Form for the Repository. LY.SER.WFV.2/94-046, Civilian Radioactive Waste Management System, Vienna, VA.

Frank, S. M., B. J. Riley, W. L. Ebert, and J. A. Peterson. 2017. Literature Review of Dehalogenation Processes for Salt Wastes and Suitable Waste Forms. NTRD-MRWFD-2017-000193, Idaho National Laboratory, Idaho Falls, ID.

Fried, S. 1945. The Reaction of Uranium Compounds with Aluminum Chloride. USAEC N-2188, MUCFWHZ-152, Chicago University Metallurgical Laboratory, Oak Ridge, TN.

Fukada, S. 2007. "Reaction rate of beryllium with fluorine ion for FLiBe redox control." Journal of Nuclear Materials 367-370:1190-96.

Fukada, S. and A. Morisaki. 2006. "Hydrogen permeability through a mixed molten salt of LiF, NaF and KF (FLiNaK) as a heat-transfer fluid." Journal of Nuclear Materials 358:235-42.

Gardner, L. D., B. J. Riley, C. Elliott, M. F. Simpson, and K. Carlson. 2018. "Viscosities and working region predictions for bismuth aluminoborosilicate glasses." submitted to Journal of Non-Crystalline Solids.

Golliher, W. R., R. A. LeDoux, S. Bernstein, and V. A. Smith. 1963. Separation of Technetium-99 from Uranium Hexafluoride. TID-18290, Union Carbide Nuclear Company, Paducah Plant, KY.

Gonzalez, O. D. 1967. Permeation of hydrogen and deuterium in alpha iron. In Proceedings of Transactions of the Metallurgical Society of AIME. vol. 239, pp. 929-30.

Greenwood, M. S., B. Betzler, G. Flanagan, D. Holcomb, A. L. Qualls, and A. Worrall. 2018. Thermalfluoride and fast-chloride molten salt-fueld reactor dynamic models for licensing, safeguards, $m$ and separations investigations. ORNL/TM-2018/XXX, Oak Ridge National Laboratory, Oak Ridge, TN.

Grimes, W. R. 1970. "Molten-Salt Reactor Chemistry." Nuclear Applications and Technology 8(2):13755.

Grosse, A. V. 1941. Chemical Properties of Uranium Hexafluoride, UF 6 . A-83, Columbia University, New York, NY.

Gruen, D. M. and R. L. McBeth. 1968. "Uranium tetrachloride - aluminum trichloride vapor complex." Inorganic and Nuclear Chemistry Letters 4(5):299-303.

Gruen, D. M. and R. L. McBeth. 1969. "Vapor complexes of uranium pentachloride and uranium tetrachloride with aluminum chloride. The nature of gaseous uranium pentachloride." Inorganic Chemistry 8(12):2625-33.

Hardin, E., J. Blink, H. Greenberg, M. Sutton, M. Fratoni, J. Carter, M. Dupont, and R. Howard. 2011. Generic Repository Design Concepts and Thermal Analysis (FY11). SAND2011-6202, Sandia National Laboratories, Albuquerque, NM.

Hardin, E., T. Hadgu, H. Greenberg, and M. Dupont. 2012. Parameter Uncertainty for Repository Thermal Analysis. FCRD-UFD-2012-000097, Sandia National Laboratories, Albuquerque, NM. 
Hariharan, A. V., D. D. Sood, S. P. Sood, R. Prasad, and R. Sampathkumar. 1969a. Laboratory investigations in non-aqueous process chemistry. In Proceedings of Department of Atomic Energy, Chemistry and Metallurgy Committee. vol. 1, pp. 283-89.

Hariharan, A. V., S. P. Sood, R. Prasad, D. D. Sood, K. Rengan, P. V. Balakrishnan, and M. V. Ramaniah. 1969b. Direct chlorination volatility processing of nuclear fuels: Laboratory studies - CONF690801. In Proceedings of Nuclear Metallurgy - Symposium on Reprocessing of Nuclear Fuels. eds. P Chiotti, vol. 15, pp. 261-77.

Harrison, T. J., D. K. Felde, R. J. Logsdon, J. McFarlane, and A. L. Qualls. 2016. Preliminary Tritium Management Design Activities at ORNL. ORNL/TM-2016/526, Oak Ridge National Laboratory, Oad Ridge, TN.

Haubenreich, P. N. and J. R. Engel. 1970. "Experience with the molten-salt reactor experiment." Nuclear Applications \& Technology 8(2):118-36.

Haverkamp, B., E. Biurrun, G. H. Nieder-Westermann, H. Van Humbeeck, and A. Van Cotthem. 2012. Engineering for operation of a future Belgian deep geological repository for ILW and HLW. In Proceedings of Waste Management. pp. 12379.

Heath, P. G., C. L. Corkhill, M. C. Stennett, R. J. Hand, W. C. H. M. Meyer, and N. C. Hyatt. 2013. "Encapsulation of TRISO particle fuel in durable soda-lime-silicate glass." Journal of Nuclear Materials 436:139-49.

Henderson, C. M. B. and D. Taylor. 1978. "The thermal expansion of synthetic aluminosilicatesodalites, $\mathrm{M}_{8}\left(\mathrm{Al}_{6} \mathrm{Si}_{6} \mathrm{O}_{24}\right) \mathrm{X}_{2}$." Phys. Chem. Mater. 2:337-47.

Henrich, E. and R. von Ammon. 1985. "Das Konzept Der Abgasreingung in Wiederaufarbeitungsanlgen." Atomkernenergie, Kerntechnik 46(2):81-88.

Heuer, D., E. Merle-Lucotte, M. Allibert, M. Brovchenko, V. Ghetta, and P. Rubiolo. 2014. "Towards the thorium fuel cycle with molten salt fast reactors." Annals of Nuclear Energy 64(Supplement C):42129.

Holcomb, D. E., G. F. Flanagan, B. W. Patton, J. C. Gehin, R. L. Howard, and T. J. Harrison. 2011. Fast Spectrum Molten Salt Reactor Options. ORNL/TM-2011/105, Oak Ridge National Laboratory, Oak Ridge, TN.

Hollenbach, D. F. and C. M. Hopper. 1996. Criticality Safety Study of the MSRE Auxiliary Charcoal Bed. ORNL/M-5450, Oak Ridge National Laboratory, Oak Ridge, TN.

HSC Chemistry, version 9.06, Outotec.

Hudry, D., A. Rakhmatullin, C. Bessada, I. Bardez, F. Bart, S. Jobic, and P. Deniard. 2009. "Reactivity of $\mathrm{NH}_{4} \mathrm{H}_{2} \mathrm{PO}_{4}$ toward $\mathrm{LaCl}_{3}$ in LiCl-KCl Melt Flux. Step by Step Formation of Monazite-Like $\mathrm{LaPO}_{4}$." Inorganic Chemistry 48(15):7141-50.

Hues, A. D., C. K. Rofer-DePoorter, and R. N. Rogers. 1984. Processing of oil shale in molten hydroxides. In Proceedings of Symposium on Characterization and Chemistry of Oil Shales. pp. 154-58. 
IAEA. 1980. Separation Storage and Disposal of Krypton-85: Report of the Technical Committee on Separation, Storage, and Disposal of Krypton-85 Organized by the International Atomic Energy Agency. IAEA-Technical Reports.

IAEA. 1987. Design of off-gas and air cleaning systems at nuclear power plants. IAEA-Technical Reports.

IAEA. 2009. Advanced Reactor Technology Options for Utilization and Transmutation of Actinides in Spent Nuclear Fuel. IAEA-TECDOC-1626, International Atomic Energy Agency, Vienna, Austria.

IAEA-IPN. International Predisposal Network. 2018. Accessed on 05/02/2018, at https://nucleus.iaea.org/sites/connect/IPNpublic/Pages/default.aspx.

IAEA-TECDOC-1521. 2006. Characterization, treatment and conditioning of radioactive graphite from decommissioning of nuclear reactors.

IAEA-TECDOC-1790. 2016. Processing of irradiated graphite to meet acceptance criteria for waste disposal.

Ihle, H., U. Kurz, and G. Stöcklin. 1976. The permeation of tritium through aluminum in the temperature range of 25 to $250^{\circ} \mathrm{C}$. In Proceedings of International Conferences on Radiation Effects and Tritium Technology for Fusion Reactors. vol. CONF-750989, pp. IV-414 - IV-22, National Technical Information Service, U.S. Department of Commerce.

Inconel ${ }^{\circledR}$ 600. Accessed 2018 at http://www.hightempmetals.com/techdata/hitempInconel600data.php.

Iqbal, T., M. R. Shahriari, G. Merberg, and G. H. Sigel. 1991. "Synthesis, characterization, and potential application of highly chemically durable glasses based on $\mathrm{AlF}_{3} . "$ Journal of Materials Research 6(2):401-06.

Janz, G. J. 1988. Thermodynamic and Transport Properties of Molten Salts: Correlation Equations for Critically Evaluated Density, Surface Tension, Electrical Conductance, and Viscosity Data, 17, American Chemical Society and the American Institute of Physics.

Janz, G. J., R. P. T. Tomkins, C. B. Allen, J. R. Downey Jr., G. L. Garner, U. Krebs, and S. K. Singer. 1975. "Molten salts: chlorides and mixtures-electrical conductance, density, viscosity, and surface tension data." Journal of Physical and Chemical Reference Data 4(2):871-1175.

Jianfeng, $\mathrm{H}$. and C. Ji-Jian. 1989. "New heavy-metal fluoride glasses in $\mathrm{ZrF}_{4}-\mathrm{FeF}_{3}-\mathrm{PbF}_{2}-\mathrm{YF}_{3}$ systems." Journal of Non-Crystalline Solids 109(1):64-68.

Johnson, B. M. 1981. "Chemistry of chromium oxyfluorides and group VIB perfluoroglutarates." Portland State University, M.S. Chemistry thesis.

Johnstone, E. V., F. Poineau, P. M. Forster, L. Ma, T. Hartmann, A. Cornelius, D. Antonio, A. P. Sattelberger, and K. R. Czerwinski. 2012. "Technetium tetrachloride revisited: A precursor to lowervalent binary technetium chlorides." Inorganic Chemistry 51(15):8462-67.

Jubin, R. T. 1981. Organic Iodine Removal from Simulated Dissolver off-Gas Systems Utilizing SilverExchanged Mordenite. Oak Ridge National Laboratory, Oak Ridge, TN. 
Jubin, R. T. 1988. Airborne Waste Management Technology Applicable for Use in Reprocessing Plants for Control of Iodine and Other Off-Gas Constituents. ORNL/TM-10477, Oak Ridge National Laboratory, Oak Ridge, TN.

Jubin, R. T. and S. H. Bruffey. 2016. Analysis of Selected Legacy ${ }^{85} \mathrm{Kr}$ Samples. FCRD-MRWFD-2016000047, FCRD-MRWFD-2016-000299, ORNL/TM-2016/350, Oak Ridge National Laboratory, Oak Ridge, TN.

Katz, S. 1963. Apparatus for the gasometric study of solid-gas reactions: Sodium fluoride with hydrogen fluoride and uranium hexafluoride. ORNL-3497, Oak Ridge National Laboratory, Oak Ridge, TN.

Katz, S. 1964a. Reduction of Uranium Hexafluoride Retention on Beds of Magnesium Fluoride used for Removal of Technetium Hexafluoride. ORNL-3544, Oak Ridge National Laboratory, Oak Ridge, TN.

Katz, S. 1964b. "Use of high-surface-area sodium fluoride to prepare $\mathrm{MF}_{6}-2 \mathrm{NaF}$ complexes with uranium, tungsten, and molybdenum hexafluorides." Inorganic Chemistry 3(11):1598-600.

Kawamoto, Y., R. Kanno, Y. Umetani, K. Tohji, and H. Morikawa. 1991. "Zr-EXAFS study of fluoride ion-conducting $\mathrm{ZrF}_{4}-\mathrm{BaF}_{2}-\mathrm{CsF}$ glasses." Solid State Ionics 44:181-86.

Kim, C.-W. and D. E. Day. 2003. "Immobilization of Hanford LAW in iron phosphate glasses." Journal of Non-Crystalline Solids 331(1):20-31.

Kim, H. T., C. H. Jung, S. N. Oh, and K. W. Lee. 2001. "Particle efficiency of gravitational wet scrubber considering diffusion, interception, and impaction." Environmental Engineering Science 18(2):125-36.

Koffler, S. A., J. B. Hudson, and G. S. Ansell. 1969. Hydrogen permeation through alpha-palladium. In Proceedings of Transactions of the Metallurgical Society of AIME. vol. 245, pp. 1735-40.

Kohlrausch, F. 1905. "Die Löslichkeit einiger schwerlöslicher Salze im Wasser bei $18^{\circ}$ (The solubility of some sparingly soluble salts in water at 18²)." Zeitschrift für Physikalische Chemie 50(1):355-56.

Kraus, C. A. 1943. Summarizing Report of Investigations Relating to Uranium Covering the Period September 1, 1942 to April 15, 1943. A-726, Brown University, Providence, RI.

Krishna, R. 2017. "Screening metal-organic frameworks for mixture separations in fixed-bed adsorbers using a combined selectivity/capacity metric." RSC Advances 7(57):35724-37.

Kulkarni, A. R. and P. K. Gupta. 1996. "Chemical durability and infrared transmission in the $\mathrm{YF}_{3}-\mathrm{PbF}_{2}-$ $\mathrm{CdF}_{2}-\mathrm{AlF}_{3}$ glasses." Transactions of the Indian Ceramic Society 55(6):143-46.

Kuznetsov, S. V. and P. P. Fedorov. 2008. "Morphological stability of solid-liquid interface during melt crystallization of $M_{1-x} R_{x} \mathrm{~F}_{2+x}$ solid solutions." Inorganic Materials 44(13):1434-58.

Laser, M., H. Beaujean, J. Bohnenstingl, P. Filss, M. Heidendael, S. Mastera, E. Merz, and H. Vygen. 1973. Off-Gas Treatment and Krypton Disposal in HTGR-Fuel Element Reprocessing. In Proceedings of Symposium on the Management of Radioactive Wastes from Fuel Reprocessing. Organisation for Economic Co-operation and Development. 
LeBlanc, D. 2010. "Molten salt reactors: A new beginning for an old idea." Nuclear Engineering and Design 240:1644-56.

Lee, K. P. 2018. Overview of the 2017 IDF Performance Assessment for LAW. TOC-PRES-18-0441, AREVA Federal Services, Richland, WA.

Leerssen, R. 2002. "Iron phosphate glass for the vitrification of INEEL sodium bearing waste and Hanford low activity waste." Missouri University of Science and Technology, MS Thesis.

Lexa, D. 1999. "Preparation and physical characteristics of a lithium-beryllium-substituted fluorapatite." Metallurgical and Materials Transactions A 30A:147-53.

Liu, J., C. A. Fernandez, P. F. Martin, P. K. Thallapally, and D. M. Strachan. 2014a. "A Two-Column Method for the Separation of $\mathrm{Kr}$ and Xe from Process Off-Gases." Industrial \& Engineering Chemistry Research 53(32):12893-99.

Liu, J., C. A. Fernandez, P. F. Martin, P. K. Thallapally, and D. M. Strachan. 2014b. "A two-column method for the separation of $\mathrm{Kr}$ and Xe from process off-gases." Industrial \& Engineering Chemistry Research 53(32):12893-99.

Louthan, M. R., J. A. Donovan, and G. R. Caskey. 1975. "Hydrogen diffusion and trapping in nickel." Acta Metallurgica 23(6):745-49.

Lu, F., Z. Dong, J. Zhang, T. White, R. C. Ewing, and J. Lian. 2013. "Tailoring the radiation tolerance of vanadate-phosphate fluorapatites by chemical composition control." RSC Advances 3(35):15178-84.

Lu, W., Z. Wei, Z.-Y. Gu, T.-F. Liu, J. Park, J. Park, J. Tian, M. Zhang, Q. Zhang, T. Gentle Iii, M. Bosch, and H.-C. Zhou. 2014. "Tuning the structure and function of metal-organic frameworks via linker design." Chemical Society Reviews 43(16):5561-93.

Lucas, S., E. Champion, D. Bernache-Assollant, and G. Leroy. 2004a. "Rare earth phosphate powders $\mathrm{RePO}_{4} \cdot n \mathrm{H}_{2} \mathrm{O}$ (Re=La, Ce or Y) II. Thermal behavior." Journal of Solid State Chemistry 177(4):1312-20.

Lucas, S., E. Champion, D. Bregiroux, D. Bernache-Assollant, and F. Audubert. 2004b. "Rare earth phosphate powders $\mathrm{RePO}_{4} \cdot n \mathrm{H}_{2} \mathrm{O}(\mathrm{Re}=\mathrm{La}, \mathrm{Ce}$ or $\mathrm{Y})$-Part I. Synthesis and characterization." Journal of Solid State Chemistry 177(4):1302-11.

Lumetta, G., J. C. Bresee, P. Paviet, M. Miller, and T. Todd. 2017. The Alliance of Advanced Process Control and Accountability - A Future Safeguards-By-Design Tool. In Proceedings of 58th INMM Annual Meeting. vol. 3, pp. 1645-54.

Luxa, D. 1999. "Preparation and physical characteristics of a lithium-beryllium-substituted fluorapatite." Metallurgical and Materials Transactions A 30A:147-53.

Marasinghe, G., M. Karabulut, X. Fang, C. Ray, D. Day, D. Caulder, J. Bucher, N. Edelstein, D. Shuh, and P. Allen. 2000a. Vitrified Iron Phosphate Nuclear Waste forms Containing Multiple Waste Components. In Proceedings of Ceramic Transactions. vol. 107, pp. 115-22, American Ceramic Society. 
Marasinghe, G., M. Karabulut, C. Ray, D. Day, D. Shuh, P. Allen, M. Saboungi, M. Grimsditch, and D. Haeffner. 2000b. "Properties and Structure of Vitrified Iron Phosphate Nuclear Waste forms." Journal of Non-Crystalline Solids 263\&264:146-54.

Matsuda, H., H. Habuka, Y. Ishida, and T. Ohno. 2015. "Metal fluorides produced using chlorine trifluoride gas." Journal of Surface Engineered Materials and Advanced Technology 5:228-36.

Matyáš, J., G. E. Fryxell, B. J. Busche, K. Wallace, and L. S. Fifield. 2011. Functionalized silica aerogels: advanced materials to capture and immobilize radioactive iodine. In Proceedings of Ceramic Materials for Energy Applications: Ceramic Engineering and Science. eds. H-T Lin, et al., vol. 32, pp. 23-33, Wiley-The American Ceramic Society.

Maze, G., V. Cardin, and M. Poulain. 1984. Fluoride glass infrared fibers for light transmission up to 5 $\mu \mathrm{m}$. In Proceedings of SPIE Technical Symposium East '84 pp. 484-16.

McBee, E. T. and L. R. Evans. 1945. The Identification of the By-Products from the Reaction of Tuballoy Trioxide with Hexachloropropene. A-2704, Purdue University, Lafayette, IN.

McBee, E. T., D. W. Pearce, and R. Mezey. 1946. Chlorination of tuballoy U oxides with thionyl chloride. A-2706, Purdue University, Lafayette, IN.

McCarthy, G. J., W. B. White, and D. E. Pfoertsch. 1978. "Synthesis of nuclear waste monazites, ideal actinide hosts for geologic disposal." Materials Research Bulletin 13(11):1239-45.

McNeese, L. E. 1971. Engineering Development Studies for Molten Salt Breeder Reactor Processing, No. 2. ORNL-TM-3137, Oak Ridge National Laboratory, Oak Ridge, TN.

McNeese, L. E., E. L. Youngblood Jr., J. R. Hightower Jr., and H. O. Weeren. 1972. Removal of rare earths from molten fluoride mixtures. CONF-720522-4, Oak Ridge National Laboratory, Oak Ridge, TN.

Mesko, M. G., D. E. Day, and B. C. Bunker. 2000. "Immobilization of $\mathrm{CsCl}$ and $\mathrm{SrF}_{2}$ in iron phosphate glass." Waste Management 20:271-78.

Mihajlovic, T., C. L. Lengauer, T. Ntaflos, U. Kolitsch, and E. Tillmanns. 2004. "Two new minerals, rondorfite, $\mathrm{Ca}_{8} \mathrm{Mg}\left[\mathrm{SiO}_{4}\right]_{4} \mathrm{Cl}_{2}$, and almarudite, $\mathrm{K}(\square, \mathrm{Na})_{2}(\mathrm{Mn}, \mathrm{Fe}, \mathrm{Mg})_{2}(\mathrm{Be}, \mathrm{Al})_{3}\left[\mathrm{Si}_{12} \mathrm{O}_{30}\right]$, and a study of iron-rich wadalite, $\mathrm{Ca}_{12}\left[\left(\mathrm{Al}_{8} \mathrm{Si}_{4} \mathrm{Fe}_{2}\right) \mathrm{O}_{32}\right] \mathrm{Cl}_{6}$, from the Bellerberg (Bellberg) volcano, Eifel, Germany." Neues Jahrbuch für Mineralogie - Abhandlungen: Journal of Mineralogy and Geochemistry 179(3):26594.

Mineo, H., M. Gotoh, M. Iizuka, S. Fujisaki, H. Hagiya, and G. Uchiyama. 2003. "Applicability of a model predicting iodine-129 profile in a silver nitrate silica-gel column for dissolver off-gas treatment of fuel reprocessing." Separation Science and Technology 38(9):1981-2001.

Mineo, H., M. Gotoh, M. Iizuka, S. Fujisaki, and G. Uchiyama. 2002. "A Simple Model Predicting Iodine Profile in a Packed Bed of Silica-Gel Impregnated with Silver Nitrate." Journal of Nuclear Science and Technology 39(3):241-47.

Mivshsita, T. and T. Manabe. 1983. Progress in fluoride glass fiber research and development in Japan. In Proceedings of Second International Symposium on Halide Glasses pp. 33. 
Molten Salt Reactors. World Nuclear Association. 2017. Accessed on May 8, 2018, at http://www.worldnuclear.org/information-library/current-and-future-generation/molten-salt-reactors.aspx.

Ngai, L. H. and F. E. Stafford. 1971. "Gaseous Oxohalides, Hydroxides, and Complex Oxides of Group III and Transition Elements." In Advances in High Temperature Chemistry, ed. L Eyring, Vol 3, pp. 21370. Elsevier.

Nielsen, N. C., H. Bildsøe, H. J. Jakobsen, and P. Norby. 1991. ${ }^{17} \mathrm{Li},{ }^{23} \mathrm{Na}$, and ${ }^{27} \mathrm{Al}$ quadrupolar interactions in some aluminosilicate sodalites from MAS NMR spectra of satellite transitions." Zeolites 11(6):622-32.

Nouar, F., J. F. Eubank, T. Bousquet, L. Wojtas, M. J. Zaworotko, and M. Eddaoudi. 2008. "Supermolecular building blocks (SBBs) for the design and synthesis of highly porous metal-organic frameworks." Journal of the American Chemical Society 130(6):1833-35.

NRC. 2012. "Chapter 7: Gaseous Radioactive Wastes." In Radioactive Waste Management Technology, USNRC Technical Training Center 7-1 Rev. 0311.

NUCON Technical Bulletin 11B10. 2012. Noble Gas Delay Carbons. NUCON International Inc.

Ohsawa, K., T. Shibata, K. Nakamura, and S. Yoshida. 1981. Fluorozirconate glasses for infrared transmitting optical fibers. In Proceedings of $7^{\text {th }}$ European Conference on Optical Communication (ECOC). pp. 1.1-1-1.1-4.

Olander, D. R. and J. L. Camahort. 1966. "Reaction of chlorine and uranium tetrachloride in the fused lithium chloride-potassium chloride eutectic." AIChE Journal 12(4):693-99.

Ortega, L., Z. Zeng, M. Kaminski, J. Cunnane, and K. Natesan. 2011. Cermet waste forms for waste streams from advanced aqueous processing of spent nuclear fuels - 11348. In Proceedings of Waste Management.

Patel, D., A. J. Wooles, E. Hashem, H. Omorodion, R. J. Baker, and S. T. Liddle. 2015. "Comments on reactions of oxide derivatives of uranium with hexachloropropene to give $\mathrm{UCl}_{4}$." New Journal of Chemistry 39(10):7559-62.

Peachey, N. M., R. C. Snow, and R. C. Dye. 1996. "Composite Pd/Ta metal membranes for hydrogen separation." Journal of Membrane Science 111:123-33.

"Physical Constants of Inorganic Compounds." 2007-2008. In CRC Handbook of Chemistry and Physics, $88^{\text {th }}$ Edition, ed. DR Lide, CRC Press, New York.

Pitner, A. L. 1971. "Irradiation behavior of POCO graphites." Carbon 9(5):637-44.

Poignant, H., J. F. LeMellot, and Y. Bossis. 1982. Infrared fluorozirconate and fluorohafnate glass optical fibers. In Proceedings of Technical Digest, European Conference on Optical Communication '82.

Poulain, M., M. Chanthanasinh, and J. Lucas. 1977. "New fluoride glasses." Materials Research Bulletin 12:151-56. 
Poulain, M. and J. Lucas. 1978. "A new class of materials: Fluoride glasses made with $\mathrm{ZrF}_{4}$." Verres et réfractaires 32:505-13.

Poulain, M., A. Soufiane, Y. Messaddeq, and M. Aegerter. 1992. "Fluoride glasses: synthesis and properties." Brazilian Journal of Physics 22(3):205-17.

Poulain, M. J., M. A. Poulain, and G. A. Maze. 1987. "Fluoride glasses." United States Patent No. 4666879.

Rak, V. and F. Lisý. 1979. Physical and Chemical Properties of Volatile Ruthenium Fluorides. UJV 4502 - CH, Ústav Jaderného Výzkumu Řež, Řež, Czechoslovakia.

Richardson, E. W. and L. E. McNeese. 1968. "Process for making porous sodium fluoride pellets." Patent No. US3372004A.

Riley, B. J., J. Chun, J. V. Ryan, J. Matyáš, X. S. Li, D. W. Matson, S. K. Sundaram, D. M. Strachan, and J. D. Vienna. 2011. "Chalcogen-based aerogels as a multifunctional platform for remediation of radioactive iodine." RSC Advances 1:1704-15.

Riley, B. J., J. Chun, W. Um, W. C. Lepry, J. Matyáš, M. J. Olszta, X. Li, K. Polychronopoulou, and M. G. Kanatzidis. 2013a. "Chalcogen-Based Aerogels As Sorbents for Radionuclide Remediation." Environmental Science \& Technology 47(13):7540-47.

Riley, B. J., J. O. Kroll, J. A. Peterson, J. Matyáš, M. J. Olszta, X. Li, and J. D. Vienna. 2017a. "SilverLoaded Aluminosilicate Aerogels As Iodine Sorbents." ACS Applied Materials \& Interfaces 9(38):32907-19.

Riley, B. J., J. O. Kroll, J. A. Peterson, J. Matyáš, M. J. Olszta, X. Li, and J. D. Vienna. 2017b. "Silverloaded aluminosilicate aerogels as iodine sorbents." ACS Applied Materials \& Interfaces 9(38):32907-19.

Riley, B. J., J. O. Kroll, J. A. Peterson, D. A. Pierce, W. L. Ebert, B. D. Williams, M. M. V. Snyder, S. M. Frank, J. L. George, and K. Kruska. 2017c. "Assessment of lead tellurite glass for immobilizing electrochemical salt wastes from used nuclear fuel reprocessing." Journal of Nuclear Materials 495:40520 .

Riley, B. J., J. A. Peterson, J. O. Kroll, and S. M. Frank. 2018a. "Immobilization of LiCl- $\mathrm{Li}_{2} \mathrm{O}$ pyroprocessing salt wastes in chlorosodalite using glass-bonded hydrothermal and salt-occlusion methods." Journal of Nuclear Materials 502:236-46.

Riley, B. J., D. Pierce, A, and J. Chun. 2013b. Efforts to Consolidate Chalcogels with Adsorbed Iodine. FCRD-SWF-2013-000249, PNNL-22678, Pacific Northwest National Laboratory, Richland, WA.

Riley, B. J., D. Pierce, A, J. Chun, J. Matyáš, W. C. Lepry, T. Garn, J. Law, and M. G. Kanatzidis. 2014. "Polyacrylonitrile-chalcogel hybrid sorbents for radioiodine capture." Environmental Science \& Technology 48(10):5832-39.

Riley, B. J., D. A. Pierce, J. V. Crum, B. D. Williams, M. M. V. Snyder, and J. A. Peterson. 2018 b. "Waste form evaluation for $\mathrm{RECl}_{3}$ and $\mathrm{REO}_{x}$ fission products separated from used electrochemical salt." Progress in Nuclear Energy 104:102-08. 
Riley, B. J., D. A. Pierce, W. C. Lepry, J. O. Kroll, J. Chun, K. S. Subrahmanyam, M. G. Kanatzidis, F. K. Alblouwy, A. Bulbule, and E. M. Sabolsky. 2015. "Consolidation of Tin Sulfide Chalcogels and Xerogels with and without Adsorbed Iodine." Industrial \& Engineering Chemistry Research 54(45):11259-67.

Riley, B. J., J. D. Vienna, S. M. Frank, J. O. Kroll, Z. Zhu, N. L. Canfield, K. Kruska, D. K. Schreiber, J. A. Peterson, and J. V. Crum. 2017d. "Glass Binder Development for a Glass-Bonded Sodalite Ceramic Waste Form." J. Nucl. Mater. 489:42-63.

Riley, B. J., J. D. Vienna, M. J. Schweiger, D. K. Peeler, and I. A. Reamer. 1999. Liquidus temperature of rare earth-aluminoborosilicate glasses for treatment of americium and curium. In Proceedings of Proceedings of the Scientific Basis for Nuclear Waste Management XXIII. eds. RW Smith and DW Shoesmith, vol. 608, pp. 677-82, Materials Research Society.

Riley, B. J., J. D. Vienna, D. M. Strachan, J. S. McCloy, and J. L. Jerden. 2016. "Materials and processes for the effective capture and immobilization of radioiodine: A review." Journal of Nuclear Materials 470:307-26.

Ringel, H. D. 1990. Development of a process for adsorptive separation of $\mathrm{Kr}-85$ from off-gas of nuclear facilities. In Proceedings of $21^{\text {st }}$ DOE/NRC Nuclear Air Cleaning Conference. eds. DC Washington, vol. 1, pp. CONF-900813, US Department of Energy.

Robertson, R. C. 1965. MSRE Design and operations Report. ORNL-TM-728. Oak Ridge National Laboratory, Oak Ridge, TN.

Robertson, R. C., ed. 1971. Conceptual Design Study of a Single-Fluid Molten-Salt Breeder Reactor. ORNL-4511. Oak Ridge National Laboratory, Oak Ridge, TN.

Rosenthal, M. W., P. N. Haubenreich, and R. B. Briggs. 1972. The Development Status of Molten-Salt Breeder Reactors. ORNL-4812, Oak Ridge National Laboratory, Oak Ridge, TN.

Rudel, S. S. and F. Kraus. 2017. "Facile syntheses of pure uranium halides: $\mathrm{UCl}_{4}, \mathrm{UBr}_{4}$ and $\mathrm{UI}_{4} . "$ Dalton Transactions 46(18):5835-42.

Ruff, O., E. Schiller, and A. Heinzelmann. 1909. "Über einige neue Fluoride (About some new fluorides)." Berichte 42(1):492-97.

Ryan, P., O. K. Farha, L. J. Broadbelt, and R. Q. Snurr. 2011. "Computational screening of metalorganic frameworks for xenon/krypton separation." AIChE Journal 57(7):1759-66.

SAND2014-0187P, SAND2014-0189P. 2014. Evaluation of Options for Permanent Geologic Disposal of Spent Nuclear Fuel and High-Level Radioactive Waste in Support of a Comprehensive National Nuclear Fuel Cycle Strategy. Sandia National Laboratories, Albuquerque, NM.

Sangthong, W., S. T. Bromley, F. Illas, and J. Limtrakul. 2009a. Comparing the stabilities of nanoclusters and cluster-based materials: Alkali halides and the first row element compounds. Presented at NSTI-Nanotech 2009, Vol. 3, pp. 304-07. 
Sangthong, W., S. T. Bromley, F. Illas, and J. Limtrakul. 2009b. Comparing the stabilities of nanoclusters and cluster-based materials: Alkali halides and the first row element compounds. Presented at NSTI-Nanotech 2009, Vol. 3.

Sasahira, A., Y. Kani, F. Kawamura, K. Hoshino, V. N. Prusakov, and O. Amano. 2005. Adsorption of plutonium fluoride with uranyl fluoride trap. In Proceedings of Global 2005. pp. 395.

Sava, D. F., K. W. Chapman, M. A. Rodriguez, J. A. Greathouse, P. S. Crozier, H. Zhao, P. J. Chupas, and T. M. Nenoff. 2013. "Competitive $\mathrm{I}_{2}$ Sorption by Cu-BTC from Humid Gas Streams." Chemistry of Materials 25(13):2591-96.

Sava, D. F., T. J. Garino, and T. M. Nenoff. 2012. "Iodine confinement into metal-organic frameworks (MOFs): low-temperature sintering glasses to form novel glass composite material (GCM) alternative waste forms." Industrial \& Engineering Chemistry Research 51(2):614-20.

Sava, D. F., M. A. Rodriguez, K. W. Chapman, P. J. Chupas, J. A. Greathouse, P. S. Crozier, and T. M. Nenoff. 2011. "Capture of volatile iodine, a gaseous fission product, by zeolitic imidazolate framework8." Journal of the American Chemical Society 133(32):12398-401.

Scheele, R., B. McNamara, A. M. Casella, and A. Kozelisky. 2012. "On the use of thermal $\mathrm{NF}_{3}$ as the fluorination and oxidation agent in treatment of used nuclear fuels." Journal of Nuclear Materials 424(1):224-36.

Schmets, J. J. 1967. Review of Halide Volatility Processes. in "Reprocessing of fuel from present and future power reactors." KR-126, Centre d'Etude de l'Energie Nucléaire, Mol, Belgium.

Schultz, R. M., W. E. Hobbs, J. L. Norton, and M. J. Stephenson. 1981. Sorbent Selection and Design Considerations for Uranium Trapping. K/ET-5025, Union Carbide Corporation, Oak Ridge, TN.

Schwochau, K. 2000. Technetium: Chemistry and radiopharmaceutical applications, Wiley-VCH Verlag GmbH, Weinheim, Germany.

Scott, S. M., T. Hu, T. Yao, G. Xin, and J. Lian. 2015. "Graphene-based sorbents for iodine-129 capture and sequestration." Carbon 90:1-8.

Scott, S. M., W. Zhu, T. Yao, J. D. Vienna, R. C. Ewing, and J. Lian. 2018. "The thermal stability and consolidation of perovskite variant $\mathrm{Cs}_{2} \mathrm{SnCl}_{6}$ using spark plasma sintering." Journal of the American Ceramic Society 101(5):2060-65.

Serp, J., M. Allibert, O. Beneš, S. Delpech, O. Feynberg, V. Ghetta, D. Heuer, D. Holcomb, V. Ignatiev, J. L. Kloosterman, L. Luzzi, E. Merle-Lucotte, J. Uhlír, R. Yoshioka, and D. Zhimin. 2014. "The molten salt reactor (MSR) in generation IV: Overview and perspectives." Progress in Nuclear Energy 77(Supplement C):308-19.

Shatalov, V. V., M. B. Seregin, V. F. Kharin, and L. A. Ponomarev. 2001. "Gas-fluoride technology for processing spent oxide fuel." Atomic Energy 90(3):224-34.

Siemer, D. D. 2012a. "Improving the integral fast reactor's proposed salt waste management system." Nuclear Technology 178(3):341-52. 
Siemer, D. D. 2012b. "Improving the integral fast reactor's proposed salt waste management system." Nuclear Technology 178:341-52.

Simmons, D. 1996. An Introduction to Technetium in the Gaseous Diffusion Cascades. KTSO-39, Lockheed Martin Energy Systems, Inc., Oak Ridge, TN.

Simpson, M. F., G. R. Smolik, J. P. Sharpe, R. A. Anderl, D. A. Petti, Y. Hatano, M. Hara, Y. Oya, S. Fukada, S. Tanaka, T. Terai, and D.-K. Sze. 2006. "Quantiative measurement of beryllium-controlled redox of hydrogen fluoride in FLiBe." Fusion Engineering and Design 81:541-47.

Slama, P. and M. Marecek. 2015. "Corrosion testing of nickel alloy for molten salt reactors." Journal of Achievements in Materials and Manufacturing Engineering 70(2):78-85.

Smith, G. P. 1956. Corrosion of Materials in Fused Hydroxides. ORNL-2048, Oak Ridge National Laboratory, Oak Ridge, TN.

Snelling, W. O. 1916. "Apparatus for Separating Gases." United States Patent No. US1174631A.

Stempien, J. D. 2015. "Tritium transport, corrosion, and fuel performance modeling in the fluoride saltcooled high temperature reactor (FHR)." Massachusetts Institute of Technology, Ph.D.

Stempien, J. D., R. G. Ballinger, and C. W. Forsberg. 2015. A model of tritium transport and corrosion in salt-cooled reactors - 15081. In Proceedings of American Nuclear Society Winter Meeting.

Stempien, J. D., R. G. Ballinger, and C. W. Forsberg. 2016. "An integrated model of tritium transport and corrosion in fluoride salt-cooled high-temperature reactors (FHRs) - Part I: Theory and benchmarking." Nuclear Engineering and Design 310:258-72.

Steward, S. A. 1983. Review of Hydrogen Isotope Permeability Through Materials. UCRL-53441, Lawrence Livermore National Laboratory, Livermore, CA.

Stockinger, S. L. 2012. Nuclear Power Plant Gaseous Waste Treatment System Design Prepared for the American Society of Mechanical Engineers American Society of Mechanical Engineers - Radioactive Waste Systems Committee.

Subrahmanyam, K. S., I. Spanopoulos, J. Chun, B. J. Riley, P. K. Thallapally, P. N. Trikalitis, and M. G. Kanatzidis. 2017. "Chalcogenide aerogels as sorbents for noble gases (Xe, Kr)." ACS Applied Materials \& Interfaces 9(39):33389-94.

SW 846 Method 1311. 1992. Toxicity Characteristic Leaching Procedure. U.S. Environmental Protection Agency, Washington, D.C.

Tanabe, H., T. Sakuragi, K. Yamaguchi, T. Sato, and H. Owada. 2010. "Development of new waste forms to immobilize iodine-129 released from a spent fuel reprocessing plant." Adv. Sci. Technol. (StafaZuerich, Switz.) 73(B):158-70.

Thoma, R. E. 1971. Molten-salt reactor program. ORNL-4658, Oak Ridge National Laboratory, Oak Ridge, TN. 
Thoma, R. E. 1972. Chemical Aspects of MSRE Operations. ORNL-4658, Oak Ridge National Laboratory, Oak Ridge, TN.

Thomas, T. R., B. A. Staples, and L. P. Murphy. 1978. The Development of $\mathrm{Ag}^{\circ} \mathrm{Z}$ for Bulk ${ }^{129}$ I Removal from Nuclear Fuel Reprocessing Plants and $\mathrm{PbX}$ for ${ }^{129}$ I Storage. In Proceedings of $15^{\text {th }} \mathrm{DOE} / \mathrm{NRC} \mathrm{Nucl}$. Air Cleaning Treat. Conf., CONF-780819. eds. MW First, vol. 1, pp. 394-415, The Harvard Air Cleaning Laboratory, Cambridge, MA.

Tran, D. C., G. H. Sigel Jr., and B. Bendow. 1984. "Heavy metal fluoride glasses and fibers: A review." Journal of Lightwave Technology LT-2(5):566-86.

Trevorrow, L. E., V. N. Kolba, G. F. Vandergrift, and M. J. Steindler. 1983. Compatibility of Technologies with Regulations in the Waste Management of H-3, I-129, C-14, and Kr-85. Part II. Analysis. ANL-83-57-Pt.2, Argonne National Laboratory, Argonne, IL.

Trowbridge, L. D. 1997. Technical Basis for the Use of $\mathrm{ClF}_{3}$ in the MSRE Reactive Gas Removal Project at Oak Ridge National Laboratory, Oak Ridge, Tennessee. ORNL/ER-402, Oak Ridge National Laboratory, Oak Ridge, TN.

Trowbridge, L. D., G. D. DelCul, B. B. Spencer, and E. D. Collins. 2004. Advanced Spent Fuel Processing Based on Fluorination and Volatility of Fluoride Species: The "Trufluor" Concept". In Proceedings of American Nuclear Society. vol. 90, pp. 81.

Trowbridge, L. D., L. M. Toth, and E. D. Collins. 2003. Molten Hydroxide Trapping Process for Radioiodine. ORNL/TM-2002/247, Oak Ridge National Laboratory, Oak Ridge, TN.

Tucker, M. C. and C. P. Jacobson. 2011. "Cu-based cermet for high-temperature fuel cell." Patent No. US2011/0053041 A1.

Übeyli, M. 2009. "Effect of lithium enrichment on the tritium breeding characteristics of various breeders in a fusion driven hybrid reactor." Journal of Fusion Energy 28(3):300-03.

Uhlır, J. and M. Marecek. 2009. "Fluoride volatility method for reprocessing of LWR and FR fuels." Journal of Fluorine Chemistry 130:89-93.

Van Emden, B., M. R. Thornber, J. Graham, and F. J. Lincoln. 1997. "The incorporation of actinides and xenotime from placer deposits in western Australia." The Canadian Mineralogist 35:95-104.

Vance, E. R., B. D. Begg, D. R.A., S. Moricca, D. S. Perera, M. W. A. Stewart, M. L. Carter, P. J. McGlinn, and K. L. Smith. 2006. ANSTO's waste form research and development capabilities. In Proceedings of Ceramic Transactions. eds. J Vienna, C Herman and S Marra, vol. 168, pp. 91-97, John Wiley \& Sons, Inc., Hoboken, NJ.

Veleckis, E. and R. K. Edwards. 1969. "Thermodynamic properties in the systems vanadium-hydrogen, niobium-hydrogen, and tantalum-hydrogen." The Journal of Physical Chemistry 73(3):683-92.

Vienna, J., J. Luey, P. Hrma, H. Li, D. Smith, and R. Scheele. 1998. Glass frit development for encapsulation of rocky flats ash. Presented at Ceram. Trans., Vol. 93, pp. 399-407, American Ceramic Society, Westerville, $\mathrm{OH}$. 
Vienna, J. D., E. D. Collins, J. V. Crum, W. L. Ebert, S. M. Frank, T. G. Garn, D. Gombert, R. Jones, R. T. Jubin, V. C. Maio, J. C. Marra, J. Matyas, T. M. Nenoff, B. J. Riley, G. J. Sevigny, N. R. Soelberg, D. M. Strachan, P. K. Thallapally, and J. H. Westsik. 2015a. Closed Fuel Cycle Waste Treatment Strategy. FCRD-MRWFD-2015-000674, PNNL-24114, Pacific Northwest National Laboratory, Richland, WA.

Vienna, J. D., N. R. Soelberg, W. L. Ebert, J. L. Willit, M. A. Williamson, S. M. Frank, G. Fredrickson, and B. J. Riley. 2015b. Initial Salt Waste Management Trade Study. FCRD-MRWFD-2015-000469, Pacific Northwest National Laboratory, Richland, WA.

Vogel, W. and K. Gerth. 1958. "Über modellsilikatgläser und ihreKonstitution. Die glassysteme LiF-

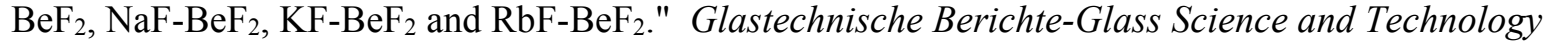
31:15.

von Lensa, W., D. Vulpius, H.-J. Steinmetz, N. Girke, D. Bosbach, B. T. Jülich, A. W. Banford, D. Bradbury, B. Grambow, M. J. Grave, A. N. Jones, L. Petit, and G. Pina. 2011. "Treatment and disposal of irradiated graphite and other carbonaceous waste." ATW - International Journal for Nuclear Power.

Völkl, J. and G. Alefeld. 1975. "Hydrogen Diffusion in Metals." In Diffusion in Solids: Recent Developments, eds. AS Nowick and JJ Burton, pp. 231-302. Academic Press, New York.

Wang, C., D. Liu, and W. Lin. 2013. "Metal-organic frameworks as a tunable platform for designing functional molecular materials." Journal of the American Chemical Society 135(36):13222-34.

Wang, D., H. Li, Z. Wang, X. Wu, Y. Sun, X. Huang, and L. Chen. 2004. "New solid-state synthesis routine and mechanism for $\mathrm{LiFePO}_{4}$ using $\mathrm{LiF}$ as lithium precursor." Journal of Solid State Chemistry 177(12):4582-87.

Wang, H., K. Yao, Z. Zhang, J. Jagiello, Q. Gong, Y. Han, and J. Li. 2014. "The first example of commensurate adsorption of atomic gas in a MOF and effective separation of xenon from other noble gases." Chemical Science 5(2):620-24.

Wareing, A., L. Abrahamsen, A. Banford, M. Metcalfe, and W. von Lensa. 2013. CARBOWASTE: Treatment and Disposal of Irradiated Graphite and Other Carbonaceous Waste. CARBOWASTE-1306D-0.3.12, European Atomic Energy Community.

Warren, K. S. and L. M. Ferris. 1966. Oxidation and Chlorination of $\mathrm{UO}_{2}-\mathrm{PuO}_{2}$. ORNL-3977, Oak Ridge National Laboratory, Oak Ridge, TN.

WebElements. Chlorine: Isotope Data. 2018a. Accessed at https://www.webelements.com/chlorine/isotopes.html.

WebElements. Lithium: Isotope Data. 2018b. Accessed at https://www.webelements.com/lithium/isotopes.html.

Weinberg, A. M. 1970. "Molten-salt reactors." Nuc. App. Tech. 8(2):105.

Weller, M. T. and G. Wong. 1989. "Characterisation of novel sodalites by neutron diffraction and solidstate NMR." Solid State Ionics 32-33(1):430-35. 
Westsik Jr., J. H., K. J. Cantrell, R. J. Serne, and N. P. Qafoku. 2014. Technetium Immobilization Forms Literature Survey. PNNL-23329, EMSP-RPT-023, Pacific Northwest National Laboratory, Richland, WA.

Wickham, A., H.-J. Steinmetz, P. O'Sullivan, and M. I. Ojovan. 2017. "Updating irradiated graphite disposal: Project GRAPA and the international decommissioning network." Journal of Environmental Radioactivity 171:34-40.

Wiegel, F. and W. Schuster. 1984. "The vapor pressure of americium trichloride." Inorganic Chimica Acta 94(1-3):111.

Wigeland, R., T. Taiwo, H. Ludewig, M. Todosow, W. Halsey, J. Gehin, and R. Jubin. 2014. Nuclear Fuel Cycle Evaluation and Screening-Final Report. INL/EXT-14-31465, Idaho National Laboratory, Idaho Falls, ID.

Wilhelm, J. and L. Puppe. 1989. "Process for removal of iodine and iodine compounds from gases and vapours with silver containing zeolite X." Patent No. US5075084A.

Wu, H., F. Carotti, R. Gakhar, N. Patel, and R. Scarlat. 2018. "Fluorination of nuclear graphite IG-110 in molten $2 \mathrm{LiF}-\mathrm{BeF}_{2}$ (FLiBe) salt at $700{ }^{\circ} \mathrm{C} . "$ Journal of Fluorine Chemistry: doi:

10.1016/j.jfluchem.2018.04.001.

Yarbro, O. O., J. C. Mailen, and M. J. Stephenson. 1977. Retention of Gaseous Isotopes, International Atomic Energy Agency, Vienna, Austria.

Yato, Y. 1996. "Uranium isotope exchange between gaseous $\mathrm{UF}_{6}$ and solid $\mathrm{UF}_{5} . "$ Journal of Nuclear Science and Technology 33(10):758-66.

Yoko, T., K. Kamiya, K. Tanaka, H. Yamada, and S. Sakka. 1989. "Glass-forming region and structure of oxyhalide tellurite glasses containing $\mathrm{LiX}(\mathrm{X}=\mathrm{F}$ and $\mathrm{Br})$ and $\mathrm{Li}_{2} \mathrm{O}$." Journal of the Ceramic Society of Japan 97(1123):289-94.

Youchak-Billings, A. L., J. V. Crum, J. C. Marra, B. J. Riley, J. D. Vienna, and A. Edmondson. 2008. Waste/Storage Form Baseline-Fission Products \& Lanthanides. GNEP-WAST-PMO-MI-DV-2008000151, Savannah River National Laboratory, Aiken, SC.

Young, M., H. Wu, and R. Scarlat. 2015. Characterization of tritium transport in the Flibe-graphite system, for in-situ tritium absorption by the fuel elements of the fluoride-salt-cooled high-temperature reactor (FHR). In Proceedings of NURETH-16. pp. 4972-86.

Zagnit'ko, A. V. and Y. D. Chuvilin. 2009. "Nanoaerosols formation during the bubbling of lithium and beryllium fluorides molten salt to produce reactor radioisotopes." Nanotechnologies in Russia 4(1112):851-56.

Zhao, H., C. Yan, L. Sun, K. Zhao, and D. Fa. 2015. "Design of a natural draft air-cooled condenser and its heat transfer characteristics in the passive residual heat removal system for $10 \mathrm{MW}$ molten salt reactor experiment." Applied Thermal Engineering 76:423-34. 
Zheng, G., B. Kelleher, G. Cao, M. Anderson, T. Allen, and K. Stridharan. 2015. "Corrosion of 316 stainless steel in high temperature molten $\mathrm{Li}_{2} \mathrm{BeF}_{4}$ (FLiBe) salt." Journal of Nuclear Materials 461:14350 .

Zhu, X. and N. Peyghambarian. 2010. "High-Power ZBLAN Glass Fiber Lasers: Review and Prospect." Advances in OptoElectronics 2010:1-23. 



\section{Appendix A}

\section{Modified Molten Hydroxide Scrubber}


The expected oxygen levels are in the parts-per-million range and should not affect the charcoal beds. The charcoal beds could serve as secondary halide traps. The amount of water should also be very low. If there is no interest in collecting the tritium upfront (for usage), the off-gas could be rearranged, as shown in the below figure. The main advantage of this approach is that the traps are located after the decay-bed, so the radiation field should be highly diminished; this would facilitate the maintenance and replacement of the trapping media.

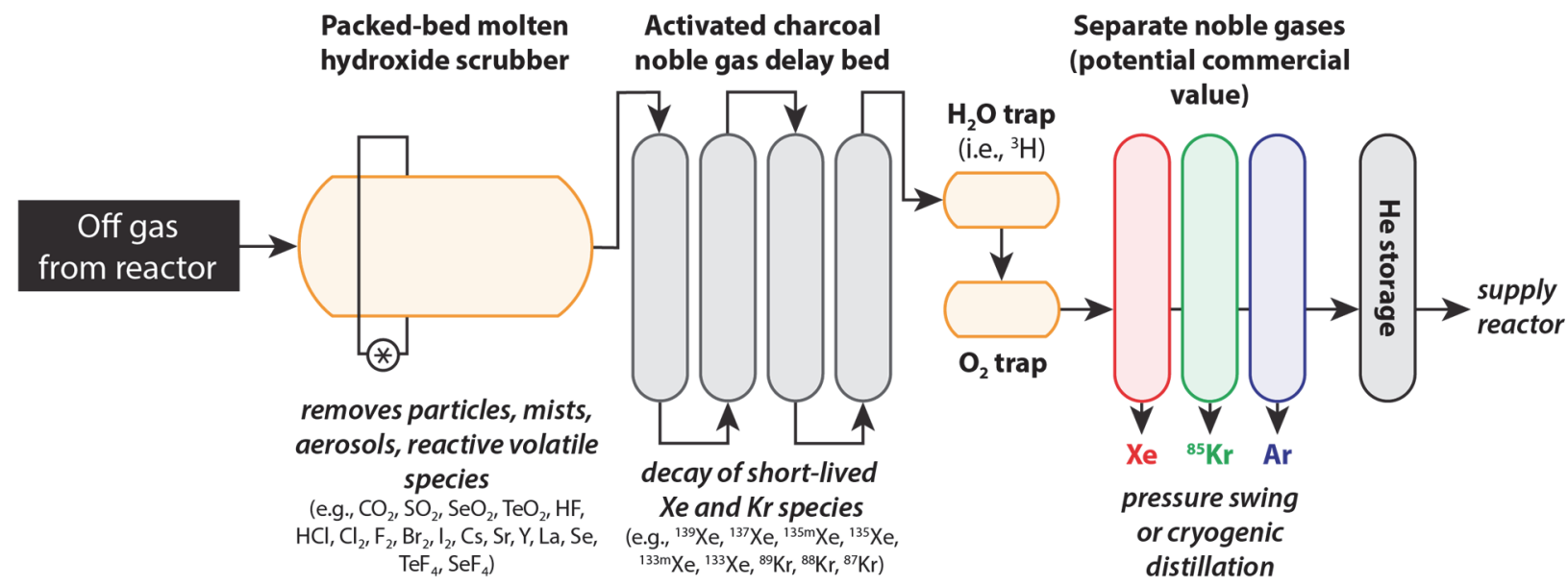

Figure A1. Modified schematic (from Figure 3-5 in Section 3.6) of the overall off-gas system for a commercial MSR based on the MSRE experience. All of the components shown here except the molten hydroxide packed-bed scrubber are commercially available. 


\section{Appendix B}

\section{Radiolysis and Gaseous Product Evolution from Solidified Halide Salts}




\section{B-1. Fluoride Salts}

The evolution of fluorine from solidified fluoride salt was first noticed during irradiation of salt capsules in the Material Testing Reactor in 1962 (ORNL-3708, 1964). During these irradiation experiments, some of the capsules developed $\mathrm{F}_{2(\mathrm{~g})}$ pressures as high as $50 \mathrm{~atm}$. Subsequent experiments that included temperature control and pressure measurements showed that $F_{2(g)}$ would only evolve from solidified salts below a threshold temperature and that no $\mathrm{F}_{2(\mathrm{~g})}$ would evolved from molten specimens. For salts irradiated at temperatures $<80^{\circ} \mathrm{C}$, the $\mathrm{F}_{2(\mathrm{~g})}$ yield was 0.02 molecules $/ 100 \mathrm{eV}$ of $\beta-\gamma$ deposited energy (Haubenreich, 1970).

The experimental results could be explained on the basis of some assumptions:

1) $\mathrm{F}_{2(\mathrm{~g})}$ molecules were produced in the solidified salt at a rate proportional to the adsorbed energy; the proportionality factor was independent of the temperature.

2) $F_{2(g)}$ would evolve into the gas phase only after the average concentration in the salt reached some limiting value known as saturation concentration; the time needed for the concentration to exceed this limiting value is known as the induction period and the saturation concentration is temperature dependent.

3) Evolved $F_{2(g)}$ would recombine with the salt at a rate proportional to the average concentration of fluorine in the salt. The proportionality factor is strongly dependent on the temperature with an activation energy of about $19.4 \mathrm{Kcal} / \mathrm{mol}(\mathrm{Notz}, 1985)$. At temperatures $>85^{\circ} \mathrm{C}$, the recombination reaction exceeded the rate of the $\mathrm{F}_{2(\mathrm{~g})}$ generation effectively quenching the evolution of fluorine.

The evolution of gases was shown to be dependent on the crystallite size. Salts that underwent faster cooling rates would develop smaller crystallites that favored the release of gases, compared to slowlycooled salts with bigger crystallite sizes. All of these findings are consistent with solid-state diffusion mechanisms. Irradiation experiments that included small graphite spheres embedded in the salt show the evolution of $\mathrm{CF}_{4}$ in addition to $\mathrm{F}_{2(\mathrm{~g})}$. The ratio of $\mathrm{CF}_{4}$ to $\mathrm{F}_{2(\mathrm{~g})}$ varied significantly from test to test indicating the presence of some unidentified factors.

The energy released into the solidified salt includes three major components, including:

- $\quad \beta-\gamma$ from the decay of fission products (this component rapidly diminishes over time),

- $\alpha$ radiolysis generated by the decay of the actinide species (depending on the decay chain, it can slowly diminish or grow to an intermediate maximum, followed by a final decay), and

- some intense neutron activity for MSRE-like salts due to $\alpha$-n reactions because of the presence of ${ }^{9} \mathrm{Be},{ }^{19} \mathrm{~F}$, and ${ }^{7} \mathrm{Li} ;<1 \%$ of the $\alpha$ particles are converted to neutrons.

Gamma irradiation of MSRE-like salts at temperatures ranging from $38^{\circ} \mathrm{C}$ to $41^{\circ} \mathrm{C}$ with and without $\mathrm{UF}_{4}$ showed that fluorine was released until the accumulated damage (i.e., moles of fluorine in the gas phase divided by the total moles of fluorine initially available in the fluoride salt) in the crystals reached a concentration of $\sim 2 \mathrm{~mol} \%$, independent of the $\mathrm{F}_{2(\mathrm{~g})}$ pressure above the salt. At this point, the release of $\mathrm{F}_{2(\mathrm{~g})}$ ceased, indicating that, beyond this point, the rate of generation of fluorine equated to the rate recombination of fluorine with the metals sites. In these experiments, the gas generated was assumed to be $\mathrm{F}_{2(\mathrm{~g})}$, but it was not actually analyzed. Similar tests at elevated temperature from 70 to $100^{\circ} \mathrm{C}$ showed no $F_{2(g)}$ release (Toth and Felker, 1990).

The combined knowledge acquired from MSRE salt irradiations suggested that the solidified MSRE salt would produce about $26 \mathrm{~L} / \mathrm{h}$ of $\mathrm{F}_{2(\mathrm{~g})}$ with an induction period of about $5 \mathrm{y}$. To avoid any release of $\mathrm{F}_{2(\mathrm{~g})}$, 
an annual reheat of the stored salt at $\sim 175^{\circ} \mathrm{C}$ was instituted (well above the $85^{\circ} \mathrm{C}$ temperature that would eliminate a net $\mathrm{F}_{2(\mathrm{~g})}$ evolution).

In the 1990s, radiation readings at the MSRE site in piping far away from the fuel drain tanks, but connected to them, suggested that uranium had migrated out of the salt tank. Gas sampling in 1994 showed the presence of a large concentration of $\mathrm{UF}_{6}$ and $\mathrm{F}_{2(\mathrm{~g})}$, along with smaller amounts of $\mathrm{MoF}_{6}, \mathrm{CF}_{4}$, and HF (William et al., 1996).

Additionally, it was discovered that about $3.9 \mathrm{~kg}$ of the $\mathrm{UF}_{6}$ had leaked past a faulty valve and deposited onto the charcoal bed that was part of the MSRE off-gas treatment system. Because $F_{2(g)}$ was also present in the gas, it was estimated that about 1-2 m of fluorinated charcoal extended beyond the uranium front. These discoveries resulted in the initiation of an extensive remediation program to remove and recover the uranium, and to passivate the potentially unstable and reactive fluorinated carbon. As it happened, the annual reheating of the salt intended to recombine $F_{2(g)}$ with the reducedmetal sites was also apparently and unknowingly generating $\mathrm{UF}_{6}$ by reaction of the accumulated $\mathrm{F}_{2(\mathrm{~g})}$ and the uranium fluoride in the salt; this most likely occurred on exposed and connected surfaces due to cracks and crevices, and the process was accelerated by the increased temperature.

In retrospect, the unexplained erratic generation of $\mathrm{F}_{2(\mathrm{~g})}$ and $\mathrm{CF}_{4}$ at very different ratios in some of the MSRE irradiation tests, should have forewarned about the need to better understand the totality of the findings before reaching conclusions for an annealing and surveillance practice of the stored MSRE fuel salt that resulted in a potentially very dangerous situation.

\section{B-2. Chloride Salts}

Alkali halides such as $\mathrm{NaCl}$ are known to be sensitive to ionizing radiation. The primary products of these radiolytic processes are interstitial halogen atoms (e.g., $\mathrm{Cl}$ ) or molecular ions (e.g., $\mathrm{Cl}^{-}$) called Hcenters and anion vacancies, respectively, which have trapped an electron that are termed F-centers. The activation energy is low and they move rapidly through the lattice at all temperatures; as a consequence, most of the $\mathrm{H}$-centers recombine and disappear. A few of the $\mathrm{H}$-centers will escape recombination and aggregate into centers of molecular $\mathrm{Cl}_{2}$. The $\mathrm{F}$-centers are less mobile, but at elevated temperatures, they will aggregate into clusters and, eventually, into metal-colloidal particles (Liliard, 1998; Tandon, 2000).

For $\mathrm{NaCl}$ at temperatures $>115^{\circ} \mathrm{C}$ and at high radiation doses, the salt will acquire an intense blueblack color, due to the presence of colloidal sodium metal particles reaching a plateau at a cumulative dose between 104 and $106 \mathrm{~Gy}$. At temperatures $>250$ to $350^{\circ} \mathrm{C}$, the effect is negligible.

Chlorine odor was reported when irradiated rock salt (i.e., Harshaw, New Mexico, Lyons; typically 90 to $98 \% \mathrm{NaCl}$ ) was broken or cleaved. This was attributed to aggregates of trapped holes on the grain boundaries exposed by the cleaving/crushing process (Jenks and Bopp, 1977). Guadez, et al. (1992) reported the detection of $\mathrm{Cl}_{2}$ after the irradiation of Asse Rocksalt, only when the integrated dose was $>10^{7} \mathrm{~Gy}$. In any case, the amount of gas generated was trivial and reported in $\mu \mathrm{mol} / \mathrm{Kg}$.

Overall, it seems that, unlike fluoride salts, chlorides salts will not release any significant amount of $\mathrm{Cl}_{2(\mathrm{~g}) \text {. }}$ Accordingly, the potential formation of volatile chlorides from stored fuel salt is highly unlikely. The only concern would be corrosion and the potential generation of $\mathrm{H}_{2(\mathrm{~g})}$ due to infiltration of ambient humidity and/or water into the storage tanks or containers, but not from direct radiolysis of a chloride salt.

\section{B-3. References}

Del Cul, G. D., A. S. Icenhour, D. W. Simmons, and L. D. Trowbridge, "Present Status of the Recovery and Processing of ${ }^{233} \mathrm{U}$ from the Oak Ridge Molten Salt Reactor Experiment Remediation Activities," invited presentation at the American Nuclear Society, 5th Topical Meeting on Spent Nuclear Fuel and 
Fissile Materials Management, Francis Marion Hotel, Charleston, South Carolina, September 17-20, 2002.

Del Cul, G. D., A. S. Icenhour, D. W. Simmons, L. D. Trowbridge, D. F. Williams, and L. M. Toth, "Overview of the Recovery and Processing of ${ }^{233} \mathrm{U}$ from the Oak Ridge Molten Salt Experiment (MSRE) Remediation Activities," Invited oral presentation and conference paper at Global 2001 Conference, Paris, France, September 9-13, 2001.

Del Cul, G. D., L. D. Trowbridge, L. M. Toth, J. N. Fiedor. 2000. "Some Investigations of the Reaction of Activated Charcoal with Fluorine and Uranium Hexafluoride," Journal of Fluorine Chemistry 101:137-148.

Gaudez, M. T., N. Akram, P. Toulhoat, N. Toulhoat, J. M. Palut. 1992. "Analysis of radiolytic gases resulting from gamma irradiation of Asse rocksalt performed at Saclay," Proceedings of a Progress Meeting held in Brussels 64:209-255; Haijtink and T. McMenamin, Eds.

Haubenreich, P. N. 1970. Fluorine Production and Recombination in Frozen MSR Salts after Reactor Operation. ORNL-TM-3144, Oak Ridge National Laboratory, Oak Ridge, TN.

Jenks, G. H., C. D. Bopp. 1977. Storage and Release of Radiation Energy in Salt in Radioactive Waste Repositories. ORNL-5058, Oak Ridge National Laboratory, Oak Ridge, TN.

Liliard, A. B. 1998. "The radiolysis of alkali halides - the nucleation and growth of aggregates," Zeitschrift für Physikalische Chemie 206, 219-248, 1998

Notz, K. J. 1985. Extended storage-in-Place of MSRE Fuel Salt and Flush Salt. ORNL/TM-9756, Oak Ridge National Laboratory, Oak Ridge, TN.

ORNL. 1964. Molten Salt Reactor Program Semiannual Program Report. ORNL-3708, Oak Ridge National Laboratory, Oak Ridge, TN.

Tandon, L. 2000. Radiolysis of Salts and Long-Term Storage Issues for both Pure and Impure PuO ${ }_{2}$ Materials in Plutonium Storage Containers. LA-13725-MS, Los Alamos National Laboratory, Los Alamos, NM.

Toth, L. M., L. K. Felker. 1990. "Fluorine generation by gamma radiolysis of fluoride salt mixture." Radiation Effects and Defects in Solids 112:201-210.

Trowbridge, L. D., A. S. Icenhour, G. D. Del Cul, and D. W. Simmons, "Radiolytic Processes During Intermediate Stages of ${ }^{233}$ U Removal from the Oak Ridge Molten Salt Reactor Experiment," invited presentation at the American Nuclear Society, 5th Topical Meeting on Spent Nuclear Fuel and Fissile Materials Management, Francis Marion Hotel, Charleston, South Carolina, September 17-20, 2002.

William, D. F., G. D. DelCul, L. M. Toth. 1996. A Descriptive Model of the Molten Salt Reactor Experiment after Shutdown: Review of 1995 Progress. ORNL-TM-13142, Oak Ridge National Laboratory, Oak Ridge, TN. 